\title{
Prizes, Winning, and Identity: Narrative Vocal Music of the Pulitzer Prize, 2008-2018
}

Julia K. Kuhlman

West Virginia University, j.k.kuhlman12@gmail.com

Follow this and additional works at: https://researchrepository.wvu.edu/etd

Part of the Composition Commons, and the Musicology Commons

\section{Recommended Citation}

Kuhlman, Julia K., "Prizes, Winning, and Identity: Narrative Vocal Music of the Pulitzer Prize, 2008-2018" (2019). Graduate Theses, Dissertations, and Problem Reports. 3769.

https://researchrepository.wvu.edu/etd/3769

This Thesis is protected by copyright and/or related rights. It has been brought to you by the The Research Repository @ WVU with permission from the rights-holder(s). You are free to use this Thesis in any way that is permitted by the copyright and related rights legislation that applies to your use. For other uses you must obtain permission from the rights-holder(s) directly, unless additional rights are indicated by a Creative Commons license in the record and/ or on the work itself. This Thesis has been accepted for inclusion in WVU Graduate Theses, Dissertations, and Problem Reports collection by an authorized administrator of The Research Repository @ WVU. For more information, please contact researchrepository@mail.wvu.edu. 


\title{
PRIZES, WINNING, AND IDENTITY:
}

NARRATIVE VOCAL MUSIC OF THE PULITZER PRIZE, 2008-2018

\author{
Julia K. Kuhlman
}

\author{
Thesis submitted \\ to the College of Creative Arts \\ at West Virginia University
}

in partial fulfillment of the requirements for the degree of

\author{
Master of Arts in \\ Musicology
}

Evan A. MacCarthy, Ph.D., Chair

Travis D. Stimeling, Ph.D.

Matthew Heap, Ph.D.

Morgantown, West Virginia

2019

Keywords: Prizes, Awards, Pulitzer, Prestige, Vocal Music, Cultural Arbitration Copyright 2019 Julia K. Kuhlman 


\begin{abstract}
Prizes, Winning, and Identity: Narrative Vocal Music of the Pulitzer Prize, 2008-2018

Julia K. Kuhlman
\end{abstract}

This thesis considers the ways in which the Pulitzer Prize for Music shapes and is shaped by music of the moment. Since 1943, the Pulitzer Prize has marked 83 pieces as "distinguished" examples of American music. The financial rewarding of winning composers and the initiation of a reciprocal transfer of prestige and political capital, the Pulitzer's expert juries and governing body has contributed to the preservation of a perpetually-shifting status quo. By chronicling the year-to-year shifts of administrative power dynamics in prize selections, the Pulitzer Prize has mirrored the changing American musical landscape.

Drawing on methods of reception history, archival research, and sociological theory, I address recent efforts to reform the Pulitzer's arbitration of taste. Through an examination of Pulitzerwinning pieces for voice and the prize juries who selected them, I argue that over the past decade we witness a broader and more inclusive definition of American music. A new emphasis by the Prize on global identities and themes - and the social conflicts they articulate - constitute an alteration of the Pulitzer Prize's institutional identity and its ongoing construction of an American canon for the twenty-first century. 


\section{TABLE OF CONTENTS}

TABLES AND FIGURES.......................................................................................



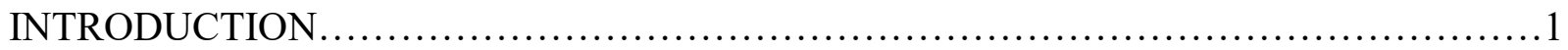

CHAPTER ONE: Prizes \& Price Points: An Economic View of Cultural Prizes..............27

CHAPTER TWO: The History of the Pulitzer Prize \& Music..............................56

CHAPTER THREE: Winners in Waiting: Pulitzer Juries \& Finalists........................78

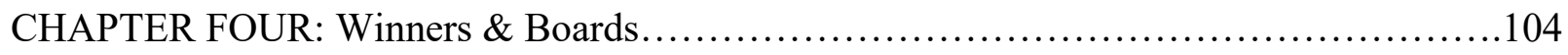

CHAPTER FIVE: The Pulitzer Prize \& the Musical Field................................138

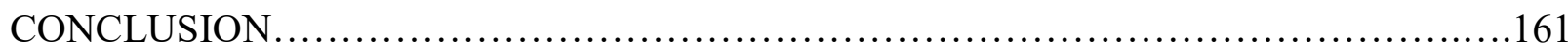



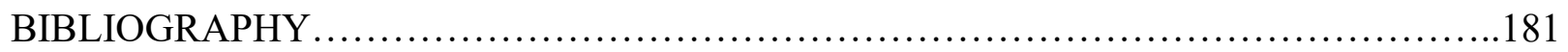




\section{TABLES AND FIGURES}



FIGURE 2, Pulitzer Prizewinners by Performing Forces...................................................93

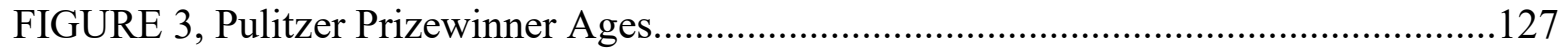

TABLE 1, Narrative Vocal Works of the Pulitzer Prize........................................... 1

TABLE 2, Grawemeyer Award Winners 2008-2018.........................................................52

TABLE 3, Pulitzer Prizewinners and Juries, 1943-1953 _........................................................64

TABLE 4, Vocal Music Winners Before 1960.....................................................................68

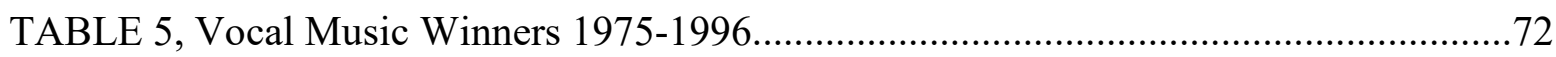

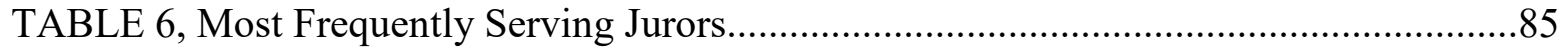

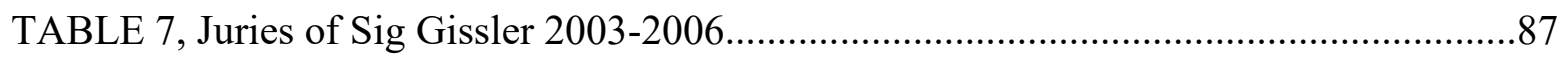

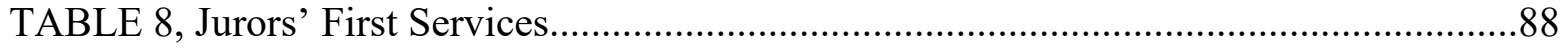

TABLE 9, New Jurors 2008-2018 Serving Multiple Times...................................................89

TABLE 10, Narrative Vocal Finalists 2008-2018.................................................................91

TABLE 11, Pulitzer-Nominated Electroacoustic Works.........................................................99 


\section{Acknowledgements}

I spent a lot of my master's degrees learning and re-learning how to pursue the things that inspire my curiosity. My gratitude for the people who helped me find them (and be tenacious about them) is close to inexpressible, but I'll try:

The words filling these too many pages are only possible because of the Kuhlmen \& Kuhlwomen who put me here-here being happy, healthy, successful, and on this planet. Especially Mom, Grandma, Grandpa, and Joe.

My membership in a dynamic community of musicians always challenges me to think through as many perspectives as I can conceive. Dr. Michael Ibrahim, Dr. Matthew Heap, members of the MMC past and present, the WVU and BGSU saxophone studios (if you could say they're different) have helped me to find my place as a musical "utility man."

Many of the questions that fascinate me the most about music aren't the ones I write about, but the ones that help me to understand how music can help humans be better humans. Dr. Travis Stimeling's modelling of compassionate, empathetic, and ethical scholarship has profoundly shaped these "how and why" questions of my musical practice.

Throughout this thesis, it's not difficult to find examples of the many ways in which I've been influenced by my advisor and mentor, Evan MacCarthy. It isn't simply my frequent use of the word "profound" or Rubiks Cube hand gestures, but the depth and comprehensiveness of thought, work ethic, humor, and worldliness with which he approaches his own work that I strive to capture in mine. The parts of this project of which I'm proudest reflect the lessons he's shared, and I'm thankful to have been supported throughout this process by such an inspiring, generous, and thoughtful scholar. 


\section{Introduction}

The Pulitzer still seems to be the most prestigious prize in most people's mind for music in this country. Certainly there are richer prizes, but the Pulitzer has the most name recognition. People tend to think the Pulitzer prize-winning-composers are some kind of special breed. ${ }^{1}$

Christopher Rouse, Winner of the 1993 Pulitzer Prize for Music

The Pulitzer is... an excuse to conclude that American music sucks. ${ }^{2}$ Kyle Gann, Critic

There is perhaps nothing quite like the annual announcement of the Pulitzer Prize for Music for its ability to inspire skepticism and celebration in equal measure. Awarded annually to an American composer for a musical work premiered during the previous year, the prize has become known to composers as a career-maker. But what does it actually do? How can one organization claim to have an impact upon a compositional landscape as diverse as the United States? This is the question I will explore throughout this thesis through the perspectives of Pulitzer winners, finalists, juries, the prize's governing body, and its audiences.

At its most basic, the Pulitzer's role is to promote outstanding American music by acting as an arbitrator between the musicians who create it and the audiences who consume it. Listeners treat the Pulitzer as a kind of advertisement. A daily confrontation with an overwhelming barrage of pieces, performers, or composers becomes much easier when the Pulitzer Prize presents a single manageable and easy-to-locate selection. The prize transforms a could listen into a should listen. Its legitimization of prizewinners uses two-tiered process: a jury of highly regarded musical specialists narrows an unwieldly list of possibilities for listening to three finalists, and

\footnotetext{
${ }^{1}$ Bruce Duffie, “Composer Christopher Rouse,” Bruce Duffie Interviews, April 29,1994, Accessed April 26, 2019, http://www.bruceduffie.com/rouse.html.

${ }^{2}$ Dean Suzuki, "View from the West: A New Hoper for the Pulitzer," New Music Box, August 1, 2003, https://nmbx.newmusicusa.org/view-from-the-west-new-hope-for-the-pulitzer/.
} 
the Pulitzer's Administrative Board selects one. With the Pulitzer name as a seal of approval, winning pieces and composers can use the award as a sort of credential. Beyond simply rewarding its winners with more listeners, a prize such as the Pulitzer supports its selections with invaluable and necessary resources. The award transfers prestige and money to its winners in massive quantities and its name brand has the ability to unite its winners under one umbrella of renown across years and artistic and intellectual categories. The Pulitzer Prize forges cultural connections by association, from storied works such as Aaron Copland's Appalachian Spring (1945 winner) to newer works, such as Kendrick Lamar's DAMN (2018 winner). The benefit to the recipients of the Pulitzer's legacy and lineage may not always be tangible or obvious, but I will argue throughout this thesis that they are present, and often lucrative.

The Pulitzer also has a second, less recognized role — because the people who bear the brunt of the burden of selection are themselves highly regarded musical specialists who mediate their individual preferences to select common finalists, the prize also reflects the conventions, traditions, and priorities of the time in which they won. The Pulitzer winners and finalists throughout its three-quarters of a century of existence are therefore significant beyond the scope of any one year of competition. Historic winners act as a sort of musical time capsule, allowing contemporary onlookers to view the changes to those conventions, and the emergence of new priorities. Watershed winners, such as Time's Encomium by Charles Wuorinen (1970 winner) or Symphony No. 1 by Ellen Taaffe Zwilich (1983 winner), evince important changes to the compositional and social landscape of music, providing long overdue symbolic legitimation of developments, including electroacoustic composition or recognition of the achievements of women composers. By viewing Pulitzer winners and the jurors who select them as key 
exemplars of their time, we can document the fluctuation of social constructions of “distinguished" music.

As much as the Pulitzer bears witness to some musical changes, it has not captured them all. Implicit in the act of distinction — good from bad, winners from losers - is the idea that some pieces are exemplary or outstanding, and that some pieces are better than others. As an institution, the Pulitzer has navigated through a thick field of competitors to arrive at a pool of winners who represent some (but not all) of the multitudes of styles present in 75 years of American music. Many important styles, idioms, genres, ensembles, composers and pieces have been concertedly left out. Through its winners, the Pulitzer Prize constructs a unique vision of American music, narrowed in scope by its definition of the prize category:

For a distinguished musical composition by any American in any of the larger forms, including chamber, orchestral, choral, opera, song, dance, or other forms of musical theatre, which has had its first performance in the United States during the year.

Pulitzer Prize for Music Composition - Inaugural brief, 1943

For a distinguished musical composition by an American that has had its first performance or recording in the United States during the year, Fifteen thousand dollars $(\$ 15,000)$.

Pulitzer Prize for Music - Current brief, 2019

Despite the resemblance between the Pulitzer Prize for Music's first mission statement and its current form, both the ideology and the people surrounding them have undergone monumental change: everything is different, from its award money to its eligibility requirements, and even its name. The first brief, written by the Pulitzer's 1942 Administrative Board, articulates a hope to recognize composers who embodied the nascent idea of "the American composer." This idea has often shifted to reflect priorities of those who espouse it, creating and recreating a most timely interpretation. What, then, remains at the heart of this prestigious award, and what does winning it mean? 
Every year, the Pulitzer Prize for Music conducts a systematic search for a "distinguished" piece of music by an American composer. This word, "distinguished," is an interesting choice - the Prize does not pretend to recognize the "best" or "greatest" works. In fact, earlier awards in its other categories in Letters and Journalism originally described their winners as "the best," but were eventually reworded to reflect the Music prize's more equivocal language. In spite of the changes, the Pulitzer organization's insistence in labelling their winners as "distinguished" still manages to insinuate something about their quality, their stature, or even their value.

It is no coincidence that some Pulitzer winners have remained an important part of American music even today. Aaron Copland's Appalachian Spring, Elliot Carter's string quartets (No. 2, 1960 winner; No. 3, 1973 winner), and Charles Ives's Symphony No. 3 (1947 winner) circulate as essential parts of performing and teaching repertories, defining implicitly or indirectly the sound of twentieth-century American music. In these pieces' long presence in the repertory and the high regard of their listeners, they are undoubtedly "distinguished." So too, though, are some of the Pulitzer's more marginal works; Samuel Barber's opera Vanessa (1958 winner) or Joseph Schwantner's Aftertones of Infinity (1979 winner) are less often performed, but still emblematic of the time in which they were composed. As a qualifier, "distinguished" has the capacity to describe works well-loved and under-the-surface alike. The notion that the Pulitzer Prize has an ability to choose works of uniformly high quality can bind together a remarkably diverse body of works, and most importantly, it does so using a word that disassociates those efforts to champion that body of works without implying that they dominate other works. From a modern-day perspective, "distinguished" seems a contrivedly demure choice of words. Such a description elevates the winning work, but it does so invisibly, without 
prompting anyone to confront who or what is making that judgement — its denial of superiority is precisely what makes it fraught. On the surface, the Pulitzer's proclamation that a piece is distinguished is no different from an average listener's: both parties have equal recourse to prioritize whatever music they like, and inevitably, they will like some pieces more than others. However, the very idea of a composition competition contradicts the prize's nonchalance.

A Pulitzer Prize is an impactful statement about the pieces which have won one, and all the more influential given its high stature in relation to other composition prizes. Even more so than a Guggenheim Fellowship or a Grammy Award, winning a Pulitzer also begets a composer more opportunities. New commissions, additional performances, and expanded professional networks are all built on the prestige that the prize can endow a composer. In the following section, I will address the mechanics of these exchanges of prestige and contextualize the Pulitzer's maneuvers around composers, pieces, and other cultural prizes.

\section{The Pulitzer Prize and the Field of Prizes}

The Pulitzer Prize for Music is part of a larger set of seventeen annually-presented awards, designed to promote outstanding examples of journalism, fiction, poetry, and drama. To step back even further, the Pulitzer Prizes are but one agent in an expansive network of prizes for cultural fields, what scholars refer to as "culture prizes." 3 They often function as a kind of credential; culture prizes are designed to promote composers, pieces, ensembles, and musical agents with a combination of funding, social or political connections, and brand-name prestige. ${ }^{4}$

\footnotetext{
${ }^{3}$ Culture prizes designate high achievement in cultural fields, and thus serve as an ideal venue through which to observe the circulation of culture. Prizes in music (like the Pulitzer Prize or the Van Cliburn Competition) are a constituent of culture prizes. See James English, The Economy of Prestige: Prizes, Awards, and the Circulation of Cultural Value (Cambridge: Harvard University Press), 2009.

${ }^{4}$ James English, "Winning the Culture Game: Prizes, Awards, and the Rules of Art," New Literary History 33, no 1 (2002): 111.
} 
In music, the Pulitzer is joined by vast constellation of other prizes and grants which aim to accomplish a similar task. The University of Louisville's Grawemeyer Award (in music, since 1985), the MacArthur (since 1981) and Guggenheim (since 1925) Fellowships, the Rome Prize (in music, since 1925, and the Fromm Commissions (since 1952) all provide similar benefits, despite the markedly different trajectories and protocols with which they navigate the field of music composition. In the midst of such a crowded discipline, these prizes serve the muchneeded function of redistributing, and ideally even democratizing, prestige.

To understand present-day perspectives on the role of prestige in art, it is helpful to turn to French sociologist Pierre Bourdieu (1930-2002). He has written extensively using a methodology that blends anthropological observation with quantitative data, addressing the stratification of cultural objects, such as music and art, by studying the way they are consumed rather than how they are produced. Especially relevant to the study of culture prizes are two of his fundamental ideas: the "field" and "cultural capital." The field is the milieu of "social spaces where interactions, transactions, and events" occur, for any given cultural community. ${ }^{5}$ These communities can be construed broadly or narrowly. Any agent that influences the social space of a cultural product can be part of its field, and a larger or smaller frame of similar institutionsthat is, a larger or smaller idea of what constitutes the field — can give insight into the differing kinds of forces that may exert their influence upon that field. A field is structured into a hierarchy using "capital." Bourdieu extends the idea of monetary capital into the social realm, yielding the notion that an agent's social status (in addition to their financial backing) can influence their position in the field. Within the idea of capital, Bourdieu incorporates many

\footnotetext{
${ }^{5}$ Richard Jenkins, Pierre Bourdieu (London: Taylor and Francis, 2014), 129.
} 
varieties of intangible profit, including awareness and exposure, opportunities, and prestige. These ideas reshaped the sociological study of prestige for the following generation of scholars. ${ }^{6}$ Literary scholar James English studies culture prizes using Bourdieusian theory as a springboard. English confirms the interrelatedness of cultural objects, economics, and sociology, but contests "the grand narrative of art's commercialization" and the modernist underpinnings of the work Bourdieu assesses. ${ }^{7}$ Importantly, English achieves this by using as his object of study cultural prizes for fields, such as music, art, and architecture. Culture prizes are uniquely situated to investigate the complexity of cultural exchanges and transactions. For Americans today, prizes such as the Pulitzer or literature prizes such as the Man Booker Prize or the National Book Award are often considered from the outside to be on one of two opposing poles. Culture prizes are either vehicles for the recognition of obscure, high art for elites, or else degraded by their catering to whichever agent has spent the most capital to publicize their art. As such, culture prizes provide English an enlightening vantage point to observe the on-the-ground transfer of prestige among cultural agents.

In order to maintain their place in the hierarchy, composition prizes try to differentiate themselves from one another. For this reason, drawing comparisons between the Pulitzer Prize and other composition prizes can be immensely helpful. Important archival studies by Erika and

\footnotetext{
${ }^{6}$ Scholars almost immediately reacted against Bourdieu's rigidity in matters of social class, especially the lack of agency accorded to individuals to change their social status. For a summary of these arguments, see John Guillory, "Bourdieu's Refusal," Modern Language Quarterly 58, no. 4 (1997): 367-368. The following generation of scholarship, however, took up the task of narrowing their scope and equivocating his rigid stances enough to make it usable. See Malcolm Quinn, et al. eds., The Persistence of Taste: Art Museums, and Everyday Life After Bourdieu (Abingdon: Routledge, 2018).

${ }^{7}$ Because prestige is redistributed and maintained through more structures and organizations than simply academic ones, English asserts that Bourdieu's "modernist underpinning" results in a skewed view of the reality of contemporary cultural fields. Thus, many of English's examples of prestige are taken from popular culture. While a debate over English's commercial and Bourdieu's non-commercial aspirations for art is outside the scope of this thesis, it is impossible to ignore the conflicting visions of prestige and quality that they produces, and which I address throughout this study. See James English, The Economy of Prestige, 8.
} 
Heinz-Dietrich Fischer and former Pulitzer Prize Administrator John Hohenberg shed light onto the procedures behind the Pulitzer selection, as well as otherwise unavailable information about early Pulitzer juries and finalists. ${ }^{8}$ These foundational resources have been used in nearly all major treatments of the Pulitzer Prize, across studies of all categories in arts, letters, and journalism. Similar musical prizes have also received scholarly treatment, especially the French Prix de Rome, the Guggenheim Foundation, and the Grawemeyer Award. ${ }^{9}$

How does the Pulitzer compare in this thick field of composition awards? It is not the biggest composition prize — awards such as the MacArthur Fellowship or the Grawemeyer Award grant their winners more than six times (or, for the MacArthur, 40 times) the reward money. Despite the gap in remuneration, the Pulitzer's presence in the public consciousness makes it just as influential. As a composition prize, the Pulitzer relies on its expert juries (comprised of well-known composers, performers, critics, and scholars of music) to elevate one work by marking it as exceptional: they choose the one work they deem the best. Reliance on subject-area expertise is quite common to composition prizes, fellowships, and commissions. ${ }^{10}$ As with other awards that grant to multiple disciplines, the Pulitzer Prize only makes use of these experts through part of their process: their juries narrow the choices to three finalists, but their winners are selected by their Administrative Board, who are nearly all journalists. Because these two parties have been embroiled in debate over the relevance of their selections, the relationships between juries and Pulitzer Boards have been tense for nearly two decades.

\footnotetext{
${ }^{8}$ See Heinz-Dietrich \& Erika Fischer, Musical Composition Awards, 1943-1999: From Aaron Copland and Samuel Barber to Gian-Carlo Menotti and Melinda Wagner (Munich: De Gruyter Saur, 2011). See also John Hohenberg, The Pulitzer Prizes: The History of the Award in Books, Drama, Music, and Journalism Based on the Private Files Over Six Decades (New York: Columbia University Press, 1974).

${ }^{9}$ See Julia Lu and Alexandre Dratwicki, eds. Le Concours du Prix de Rome de musique (1803-1968) (Lyon: Symmetrie, 2013).

${ }^{10}$ See Michael Uy, "The Big Bang of Music Patronage in the United States: The National Endowment for the Arts, the Rockefeller Foundation, and the Ford Foundation" (Ph.D. diss., Harvard University, 2015). See also Harry Collins \& Robert Evans, Rethinking Expertise (Chicago: University of Chicago Press), 2007.
} 
Critics of the Pulitzer Prize disparage everything from its overt commercialization to the general wrongheadedness of its choices. In performing forces and compositional language alike, many argue that its winners are stale and outdated. Critic Kyle Gann has referred to the Pulitzer as a "reward for conformity, and a compensation prize for ineffectuality." 11 This level of negative attention is something that makes the Pulitzer Prize for Music stand out: elsewhere in the field, awards akin to the MacArthur or Guggenheim Fellowships are rarely treated so vociferously. Although the potential for scandal is key to the public's continued attention to its selections, the Pulitzer's much-debated decisions of the 1980s and 90s led to so sustained a period of criticism that the organization felt a need to react by changing the structure of its juries as well as its eligibility requirements. ${ }^{12}$ During this period, the Pulitzer's prestige-and its value to the field - underwent fierce interrogation. As the organization emerged on the other side of the administrative reform in the early 2000s, it became clear that more than simply infrastructural change was necessary to maintain their high status and ultimately, their relevance. Their selections after the turn of the century represents an acknowledgement of more kinds of composers and pieces, marking a shift into a new institutional identity. In the following section, I will lay the framework for the Pulitzer's attempts to define itself as an institution with particular aesthetic preferences.

\section{American Institutions as American Aesthetics}

Music's inherent collaboration means that networks of composers, performers, and audiences are necessary to producing a field of American music. As an institution, the Pulitzer

\footnotetext{
${ }^{11}$ Kyle Gann, "Pulitzer Hacks: Amateur Composers Versus the Professionals," in Music from Downtown: Writings from the Village Voice (Berkeley: University of California, 2006), 120-123.

12 This will be treated in more detail in Chapters Three, Five, and Six.
} 
binds individuals into just these sorts of groups, under a shared regard for the pieces they choose as winners. Unlike informal groups, however, the Pulitzer Prize can have a legitimizing function, circulating music under the auspices of its brand as a way of marking a piece and its composer as worthy of attention. Because cultural products are so influenced by the systems through which they were created, powerful institutions in the vein of the Pulitzer can affect music from both directions: they play a role in the preservation and distribution of their winners, and they also set a precedent against which future works can be evaluated. ${ }^{13}$ In relation to other awards of the time, however, the Pulitzer's eligibility requirement of American citizenship —as well as the Pulitzer Prizes' historical emphasis on American culture-narrows the scope of music they are able to consider. For this reason, the Pulitzer offers an interesting vantage point to observe the state of American music. Throughout this thesis, I will explore how historically and present-day winners reflect the shifting ideals of what the music of an American composer should sound like.

The idea of "American composition" is elucidated and further complicated by a vast body of scholarship addressing topics from early efforts toward a unique aesthetic identity in the nineteenth century to debates of the present day. ${ }^{14}$ The migration of European musicians and scholars in escape of war-torn Europe in the 1940s had a tremendous impact upon the rising generation of American composers and musicians, and thus in the definition of a new nationalist musical idiom. Georgina Born, Rachel Vandagriff, and Jan Passler place this migration within the context of systems of education. A decades-long process of reorganization occurred as emigrés found safe haven and employment in American universities, imparting to their students a

\footnotetext{
${ }^{13}$ Richard A. Peterson \& N. Anand, "The Production of Cultural Perspective," Annual Review of Sociology 30 (2004): 311.

${ }^{14}$ See Douglas Shadle, Orchestrating the Nation: The Nineteenth-Century American Symphonic Enterprise (New York: Oxford University Press, 2015); Charles Hiroshi Garrett, Struggling to Define a Nation: American Music and the Twentieth Century (Berkeley: University of California Press, 2008).
} 
lineage and a legacy steeped in European tradition. ${ }^{15}$ Aided by the financial stability support of their academic positions, emigrés and their students soon reached out into the prescient system of private foundations, which served as facilitators and gatekeepers in this new music community. Their presence within the prevailing musical institutions in the mid-twentieth century concretized many aesthetic divisions found in musical practice today

A recent turn in musicological scholarship has given rise to publications investigating the practices and biases of comparable private philanthropic foundations. These foundations represented a profound shift in models of patronage. Where composers had previously relied upon state or private support, private foundations had the capacity to redistribute funds to a much wider community of artists. Michael Uy discusses how these foundations relied on the “specialist" opinions of musicians in order to arbitrate over the Ford Foundation's grantmaking decisions. ${ }^{16}$ Eduardo Herrera's dissertation shifts focus outside the United States. Modelled after the Rockefeller Foundation and various newly-founded doctoral programs in music composition, the Centro Latinoamericano de Altos Estudios Musicales in Buenos Aires, Argentina, helped to solidify notions of an elite, avant-garde style in South and Central America. ${ }^{17}$ Rachel Vandagriff's "American Foundations for the Arts" also expands outward, providing a comparative study of several foundations, working toward an effective characterization of the state of the field in the mid-twentieth century. Together, these authors highlight composers' increasing reliance on financial support that these institutions could provide, rather relying solely upon ticket sales and wide public support.

\footnotetext{
${ }^{15}$ See Jann Pasler, "The Political Economy of Composition in the American University, 1965-1985," in Writing Through Music: Essays on Music, Culture, and Politics (Oxford: Oxford University Press, 2008), 318-362.

${ }^{16}$ The contracting of expert musicians such as Aaron Copland, Leonard Bernstein, Henry Cowell and others during the mid-twentieth century helped the non-musicians running private foundations like the Rockefeller Foundation and Ford Foundation to legitimize their selections for music grants. Michael Uy, "The Big Bang in Arts Patronage," 4.

${ }^{17}$ Luis Eduardo Herrera, "The CLAEM and the Construction of Elite Art Worlds: Philanthropy, Latin Americanism, and Avant Garde Music" (Ph.D. diss., University of Illinois at Urbana-Champaign, 2013).
} 
This transition from a necessary reliance on catering to an audience base to pleasing the elite musical specialists became basis for the concept of an "academic" musical language. Composers who found employment in universities and in the government and private programs described above were free to compose in "aesthetics that strongly devalued popular acclaim," using critical praise as an alternative measure of success. ${ }^{18}$ Importantly, not every academic composer subscribed to or defined their music by an antagonistic relationship with public opinion. In fact, academic music might more rightly include several concertedly different idioms: serialism, modernism, and atonality (and finer gradients thereof) but also neoromanticism and spectralism. In reality, music rarely existed squarely within one of these labels; their interactions and interstices are key to understanding the breadth of possibility that a phrase like "academic music" might contain. What academic music does necessitate is a particular relationship with institutional infrastructure. Because opportunities such as academic employment, fellowships, and grants and awards are incredibly limited, elite musical specialists' use of credentials to determine the recipient has become a firmly ingrained form of gatekeeping.

Inside and outside of institutions, many scholars have observed the fragmentation and mixing of aesthetics. Seth Brodsky, Andrea Moore, and Timothy Rutherford-Johnson have recently focused in particular on the state of the music since $1989 .{ }^{19}$ The fall of the Berlin Wall and the collapse of the USSR catalyzed a more globalized approach to composition, especially as it coincided with a new emphasis on technology for faster, farther-reaching communication.

\footnotetext{
${ }^{18}$ Rachel Vandagriff, "An Old Story in a New World: Paul Fromm, the Fromm Music Foundation, and Elliot Carter," Journal of Musicology 35, No. 4 (2018): 535.

${ }^{19}$ The period of globalization following the fall of the Berlin Wall sparked an emphasis on the global in music, especially as mediated by new internet technologies, such as livestreaming and video broadcast. See Seth Brodsky, From 1989, Or European Music and the Modernist Unconscious (Berkeley: University of California Press, 2017); Timothy Rutherford-Johnson, Music After the Fall: Modern Composition and Culture Since 1989 (Berkeley: University of California Press, 2017); Andrea Moore, "Millennial Passions: New Music and the Ends of History 19892011" (Ph.D. diss., University of California at Los Angeles, 2016).
} 
Approaching the new millennium, American composers could be (and were) exposed to music of the world, and proved, as Brodsky put it, that "what modernism is is inconsistency." ${ }^{20}$ The proliferation of modernist-tinged idioms of musical composition means defining academic music today has become all the more difficult. Communities today nonetheless use "academic music" to capture what they see as a restrictive and outdated institutional past.

The Pulitzer's role within the compositional landscape has a complicated history. With a wealth of musical pasts to draw upon and an even greater stockpile of potential frameworks in which to interpret them, composers of the present day represent a staggeringly diverse array of compositional possibilities. Such a diverse landscape thrusts the Pulitzer into a problematic role: as an institution with particular aesthetic biases, the Pulitzer has not supported all aesthetics equally. In particular, the Pulitzer Prize has come to be known as a supporter of purely academic music, with limited connection to their audiences. Academic composers' presumed detachment from the concert-going public has become incredibly problematic in musical culture of the present. ${ }^{21}$ With the long, slow rise of a nonacademic aesthetic within new music, the public's frustration with what was often perceived as a deliberately elitist, obtuse musical language became a problem for the Pulitzer as early as the mid-1980s. Especially as the Pulitzer reinforces the careers of its winners (the performance of their aesthetic biases) with prestige and new opportunities for important commissions, their support of some composers over others is a boon for its winners, and perceived as unfair to its losers. By supporting an outdated academic style, many have observed that the Pulitzer has done damage to nonacademic musical communities.

\footnotetext{
${ }^{20}$ Seth Brodsky, From 1989, 7.

${ }^{21}$ The debate between musicologists Joseph N. Strauss and Anne Shreffler surrounding the influence and dominance of post-serial composition in the United States exemplifies the shift in valued forms of musical capital. Shreffler describes an "anti-serialist rhetoric of the New York press" whose "persistence borders on obsession," documenting the vehemence with which any congratulation of serialism is met. See Joseph N. Straus, "The Myth of Serial Tyranny," Musical Quarterly 83, no. 3 (1999): 301-43; Anne C. Shreffler, "The Myth of Empirical Historiography: A Response to Joseph N. Straus," Musical Quarterly 84, no. 1 (2000): 31.
} 
Outside traditional institutional boundaries, alternative institutions such as festivals and record labels continued to emerge, treating in different forms of capital. ${ }^{22}$ Robert Fink and Julia Wolfe explore the ways in which this community's definition against their academic peers led to the creation of a new set of credentials for success. Instead of composition prizes, their social networks served as the gateway for new opportunities. William Robin highlights the nonacademics' arrival to prominence in the subsequent period in the early $2000 \mathrm{~s} .{ }^{23}$ As the Pulitzer Prize transitioned to the twenty-first century, they began to recognize more and more of these nonacademic composers. In so doing, the Pulitzer was one of the first composition prizes to re-contextualize itself for a rising generation of composers who were then operating largely outside institutions. ${ }^{24}$

Recent scholarship shows how the economic contingency of music on institutional structures can become problematic. Andrea Moore criticizes the "neoliberal rhetoric" with which contemporary music culture is infused, resulting in the valorization of unstable labor conditions. ${ }^{25}$ In projects such as the International Contemporary Ensemble, Moore finds a reliance on grant-based income; due to the limited nature of this funding, however, arts organizations are thrust into competition with one another for financial, and thus artistic support. Another study by William Robin proposes that neoliberal efforts to "brand" ensembles have the capacity to shape the kinds of music written for them by commission. Robin finds the entrepreneurial drive in music best exemplified by the ensemble yMusic: a decidedly market-

\footnotetext{
${ }^{22}$ Robert Fink Repeating Ourselves (Berkeley: University of California Press, 2005); Julia Wolfe "Embracing the Clash" (Ph.D. diss., Princeton University, 2012).

${ }^{23}$ William Robin, "A Scene Without a Name: Indie Classical and American New Music in the Twenty-First Century" (Ph.D. diss., University of North Carolina at Chapel Hill, 2016); William Robin, "Balance Problems: Neoliberalism and New Music in the American University and Ensemble," Journal of the American Musicological Society 71, no. 3 (2018): 749-793.

${ }^{24}$ This will be treated in more detail in Chapter 4-6.

${ }^{25}$ Andrea Moore "Neoliberalism and the Musical Entrepreneur," Journal of the Society of American Music 10, no. 1 (2016): 36 .
} 
leaning LLC, rather than the more typical nonprofit. Their self-promotion has resulted in a "repertory brand" of similarly "groove-typed, hockety" commissioned works, which rarely diverge. ${ }^{26}$ Extending Cold-War oriented studies of musical economies like Vandagriff's to the present day, he highlights the power of neoliberalism over music in comparison to the latecapitalism of decades prior.

Throughout its history, the Pulitzer Prize has concerned itself with all of these aesthetics from multiple angles: they further elevate the results of other institutions' grant-awarded projects, and they also use their own capital (financial and social) to help create new works. The Pulitzer's use as a sort of brand can also function in the same way that yMusic's does, pointing toward a particular successful work by one composer and encouraging commissions in a similar vein. ${ }^{27}$ Notable in this is its tendency to progress through periods where one musical style dominates the others, rather than a genuinely synthesized effort to recognize all kinds of music together, as the institution implies that it does. With a sketch of the major differences between modernist, postminimalist, indie classical, or neoromantic styles, the shifting of in-power groups based on which are dominating is more easily noticeable.

\section{The Pulitzer as Canon}

If canons create and destroy esteem for music, reshaping and reorienting the worldviews of the succeeding generations of musicians, the unique canon represented by Pulitzer Prize is especially important because it is dynamic - its architecture is actively adjusted from year to year. With the addition of each new piece, the shifts in the Pulitzer's canon speak to broader changes in the field. Canons also unify their constituent works, belying the differences within

\footnotetext{
${ }^{26}$ Robin, "Balance Problems," 774.
}

${ }^{27}$ For more on this, see Chapter Four. 
each work to emphasize what makes them worthy of presence in that canon. As such, the Pulitzer can distill a homogenous compositional ideology from what is actually a much more varied body of music. In order to address the Pulitzer as a canon, it will be helpful to explore how the Pulitzer Prizes grew to occupy such a role. Here I will explore the function and structure of musical canons, contextualizing where the Pulitzer fits.

Long before the prize for music emerged, the Pulitzer's prestige had already been wellestablished on the laurels of its winners in other categories; luminaries from James Reston to Willa Cather to Tennessee Williams are among its ranks. Similarly, some of the music prize's winning composers are icons of American music: people such as Samuel Barber, Charles Ives, George Crumb, and John Adams fill out the six decades of its existence. However, contemporary onlookers may observe that some of the Pulitzer's historical awardees are recognized by few, and performed at best, infrequently. Figures such as the inaugural winner William Schuman, composer and educator Mel Powell, and American Music Center Founder Quincy Porter are perhaps better remembered by their affiliations than by their music. Still, Pulitzer winners (no matter who) are endowed with the sense of "distinguished" excellence that the Pulitzer asserts is its legacy. In association with the Pulitzer name and the compositional ideology it implies, the lesser-known composers above might enjoy more visibility than their non-winning contemporaries.

The Pulitzer Prize for Music transmits its own prestige to its winners, and given the prize's superlative status amongst other composition prizes, winners are lauded on the same terms. Works and composers alike are painted in broad strokes as exceptional. Winners stand in for an archetypal vision of American music, despite huge disparities between their specific lineages and stylistic and thematic preferences. Audiences and critics' knee-jerk acceptance of 
the Pulitzer brand as an indicator of quality shows the implicit value they hold for the Pulitzer's prestige; listeners could not hear Appalachian Spring and assume it was a Pulitzer winner, but they could see that it was a Pulitzer winner and have a preconceived notion of what it might sound like or even think without listening that it must be excellent. In fact, the history book canons and the Pulitzer's overlap frequently—in their characterization of major events in twentieth-century music history, Pulitzer winners Aaron Copland or Ellen Taaffe Zwilich (and their winning works) often stand in for the rise of American music and female composers.

Who decides what is and is not "distinguished" or "excellent?" The Pulitzer Prize for Music rose at a time when quality was defined by a small group of "composers at elite institutions, professors from prestigious northeast universities, and leaders of performing arts service organizations." ${ }^{28}$ Through the consolidation of power to a small group of music experts who were involved in some of the most prestigious gatekeeping institutions, the priorities and thus the designation of outstanding work was remarkably homogenous among different arts organizations.

For a fledgling organization, success for the Pulitzer Prize for Music was reflexive and intertwined with the experts they chose as jurors. Pulitzer winners William Schuman, Aaron Copland, and Lukas Foss were key members of the musical elite of the time; they "attached their prestige and influence to the decisions" that institutions such as the Pulitzer, the Ford Foundation, and the National Endowment for the Arts made. ${ }^{29}$ These individuals had the power to dictate the definition of quality for the Pulitzer, and subsequently, their impressions had longstanding impact on choices of jurors, and thus, winners of the future. As Chapter Two will explore, their biases became the benchmark on which future Pulitzer jurors would base their

\footnotetext{
${ }^{28}$ Michael Uy, "The Big Bang of Arts Patronage," 3.
}

${ }^{29}$ Ibid., 80. 
decisions. Legacy conforms exactly to Jan Gorak's definition of canons: inherited instruments of the status quo, promoted by the academy as exemplars of the "intrinsic" quality to which contemporary works should aspire. ${ }^{30}$ Ideological biases concerning quality directly impacted aesthetic and even had the power to define a body of acceptable musical techniques. The conflation between the "Pulitzer" name with specific and prescriptive musical devices (e.g. serialism) thought to indicate "quality," adheres to the same sort of logic. However, the attribution these markers of success only to the winner (when any number of competitors might also have achieved similar success) is problematic.

The method of using exclusivity to recognize achievement is pervasive- any applicationbased credential, from educational programs to grants to employment functions in this way. But as a composition prize designed to reward the best of American music, the Pulitzer's distinction of one work from the rest of its competitors fundamentally contradicts the celebratory spirit its founder intended by redistributing capital under the guise of rational, empirical, and fair judgement. ${ }^{31}$ Literary scholar Joseph Wensink argues that the Pulitzer's claim to disinterested impartiality is impossible due to its basis in bureaucratic machinery; if the Pulitzer's task is to "convert seemingly extra-rational content into rationalizable judgments," that is, to defend musical superiority using empirical judgements, then the particular subjectivities used to judge the pieces submitted must be arbitrary. ${ }^{32}$ From this perspective, the Pulitzer is less an indication of "distinguished" music than it is of its jurors' biases.

\footnotetext{
${ }^{30}$ Jan Gorak, The Making of the Modern Canon: Genesis and Crisis of a Literary Idea (London: Bloomsbury, 2013), 2.

${ }^{31}$ Joseph Wensink, "Literary Philanthropy: The Pulitzer Prize, Oprah's Book Club, and Contemporary U.S. Fiction" (Ph.D. diss., Brandeis University, 2012).

${ }^{32}$ Ibid., 62.
} 
Since the 1980s, musicologists and academics more generally have grown attuned to the havoc canons can wreak on composers in the present day. Among others, Jan Gorak, Joseph Kerman, Philip Bohlman, and Marcia Citron began what has become a decades-long effort to define and historicize canons, questioning how a handful of works came to dominate all others. In music, this drive toward perfectionism has been dated to the early nineteenth century, when old pieces remained in the repertory, rather than being supplanted by newer works. ${ }^{33}$ Joseph Kerman cites the music criticism of E.T.A. Hoffmann as one of the progenitors of a musical canon. He cemented the venerable stature of works by Haydn, Mozart, and Beethoven by couching them in the Romantic rhetoric of the genius. ${ }^{34}$ In elevating the three composers based on their exceptionalism, they came to symbolize an unattainable measure of quality that all future composers would come to be evaluated against, and inevitably fail.

Organizations that redistribute money and prestige, especially ones which promote certain cultural products over others, have the ability to impose their agendas over those of individuals. Cultural theorist Edward Said has proposed that canons are almost always conceived of in this kind of institutional frame. ${ }^{35}$ However, locating the extent of an organization's influence is incredibly difficult. Michael Uy and Georgina Born caution that the drivers of institutional change are individuals; such an observation could complicate a study of the Pulitzer Prize even more. ${ }^{36}$ Given the immense respect the Pulitzer's Administrative Board displayed for the will of their founder Joseph Pulitzer, it is challenging to determine whether the Pulitzer's changes should be attributed to his 1911 guiding mandate (and therefore the organization) or to

\footnotetext{
${ }^{33}$ Joseph Kerman, “A Few Canonic Variations,” Critical Inquiry 10, no. 1 (1983): 111.

${ }^{34}$ Ibid., 112.

${ }^{35}$ Jan Gorak, The Making of the Modern Canon, 187.

${ }^{36}$ Georgina Born, Rationalizing Culture: IRCAM, Boulez, and the Institutionalization of the Musical Avant-Garde, (Berkeley: University of California Press, 1985).
} 
the changes made by radical individuals, including Prize Administrators Sig Gissler or Dana Canady. This conflict between institutional and individual authority is at the heart of many of the Pulitzer's current struggles to remain relevant. Over time, these individual biases can become cemented into the process for awarding the prize, resulting in the consolidation of power to a small group of elite intermediaries. ${ }^{37}$ Early Pulitzer juries were just this insular: the first decade's jurors were both likely to recur in other Pulitzer juries, as well as in other arts organizations, including the Rockefeller Foundation. ${ }^{38}$ Then as now, the music prize's expert juries hold a great deal of power in shaping not only the Pulitzer's institutional profile, but even the field of music composition at large. In addition to a reward which at present totals $\$ 15,000$, Pulitzer winners often receive commissions (guaranteeing future financial profit) as well as important social connections that allow them access to even more opportunities. ${ }^{39}$

The Pulitzer's canonicity follows a similar kind of self-fulfilling prophecy: it purports to represent outstanding American music, but it does so in conformance to its own sets of traditions and biases. During the period of our study here, however, surprising shifts have set the Pulitzer Prize for Music on an altered trajectory. 2008 winner David Lang, 2013 winner Caroline Shaw, and 2018 winner Kendrick Lamar all lay markedly outside what the historical Pulitzer would have considered to be music under its purview in generations past. As Shreffler had written about previous generations, the boundaries of this "European high art tradition" shifted yet again.

Where once vocal music and "music based on repetition or popular styles" had been relegated to the bottom of the new music canon, the Pulitzer's choices of the past decade show its

\footnotetext{
${ }^{37}$ Michael Uy, "The Big Bang in Arts Patronage," 117.

${ }^{38}$ Ibid; See also Heinz-Dietrich \& Erika Fischer, Musical Composition Awards, xvii-1.

${ }^{39}$ For more on this, see Chapter Five.
} 
involvement in the institutionalization of a new emphasis on vocality and postminimalism, especially in combination. ${ }^{40}$

By separating the singular canon into proliferating canons of American music, women composers, or Pulitzer winners, for example, we can achieve a greater degree of granularity in addressing the similarities and differences of music of any historical moment. As the musical landscape today continues to be hospitable to a great variety of aesthetics (inside, far outside, and irrespective of the "academic" and "nonacademic" debate) positioning the Pulitzer Prize as a particular canon situated within a larger frame of American music can provide an understanding to the changing distribution of prestige from the mid-twentieth century to the present.

\section{Prizes, Winning, and Identity}

Today's Pulitzer winners are a different kind of American composer than the institution recognized even in the beginning of the twenty-first century. The past decade in particular has seen a remarkable similarity in thematic content, compositional style, and especially, performing forces. It is a striking change to witness that seven out of the past eleven winners place a special emphasis on the use of the voice. Several are operatic, or at least quasi-operatic, making full use of staging or other dramaturgical elements to help communicate or represent the semantic meaning created by its text. Some of these works, though, are not explicitly theatrical in nature. Nonetheless, the textual content of Julia Wolfe's Anthracite Fields and other works is reliant on narrative devices, moving the listener through a story even if the action is not mirrored onstage. In this thesis, I will evaluate the following pieces as "narrative vocal works," which I define as works that prominently feature voice (either accompanied or solo) whose aim is to communicate

\footnotetext{
${ }^{40}$ Anne Shreffler, "Musical Canonization and Decanonization in the Twentieth Century," In Der Kanon der Musik:
} Theorie und Geschichte, eds. Klaus Pietschmann and Melanie Wald (Munich: edition text + kritik), 2013, at 12. 
a narrative whether it is clear (as in Du Yun's Angel's Bone) or abstract (as in Caroline Shaw's Partita for 8 Voices.)

Table 1. Narrative Vocal Music Winners of the Pulitzer Prize for Music since 2008.

\begin{tabular}{|l|l|l|l|}
\hline Year & Work & Description of Performing Forces & Composer \\
\hline 2018 & DAMN. & Solo hip hop recording & Kendrick Lamar \\
\hline 2017 & Angel's Bone & Opera & Du Yun \\
\hline 2015 & Anthracite Fields & SATB chorus, cl, egtr, perc, pno, vc, & Julia Wolfe \\
$\mathrm{db}$ & SSAATTBB & \\
\hline 2013 & Partita for 8 Voices & Opera & Caroline Shaw \\
\hline 2012 & Silent Night & Opera & Kevin Puts \\
\hline 2011 & Madame White Snake & SATB soloists and hand percussion & David Lang \\
\hline 2008 & the little match girl passion & Zhou Long \\
\hline
\end{tabular}

2008 marked the beginning of a surge of the narrative vocal winners who had long been absent from the Pulitzer Prize. New opera and operetta had featured prominently in the beginning of the Pulitzer, including Gian Carlo Menotti’s The Consul (1950 winner) or Samuel Barber's Vanessa, which address similar commentary on politics at the time. ${ }^{41}$ However, the awards for texted works including voice slowed through the 1970s and dropped off dramatically in the late 1980s and 1990s, replaced largely by orchestral and chamber pieces. ${ }^{42}$ The past decade, between 2008 and 2018, then presents a stark break with that trend. More than their un-

\footnotetext{
41 Stephanie Poxon, "From Sketches to Stage: The Genesis of Samuel Barber's Vanessa" (Ph.D. diss., Catholic University of America, 2005).

42 The exceptions to this observation include 1971 nominee Earl Kim, 1977 winner Richard Wernick, and 1980 winner David del Tredici. For a complete list of winners and nominees, see Appendix.
} 
texted counterparts, these works evince a change in the Pulitzer Prize's artistic agenda: winners of the past decade display a new commitment to a broader and more inclusive definition of American music, with new emphasis on global identities and themes.

I will consider these vocal winners using the embodied methodologies presented by Jelena Novak and Nina Eidsheim. Novak argues for a reinterpretation of contemporary opera with full acknowledgement of the role that the body plays in producing and mediating music. As technologically-enhanced operas explode in popularity (including Pulitzer-nominated works by Tod Machover, Timo Andres, Kendrick Lamar, and Henry Threadgill) the role of extramusical factors grows more and more relevant. Novak writes that technology can play "ventriloquist", expressing on behalf of or in place of the singer, leaving them voiceless and vulnerable.

Nina Eidsheim radically extends the study of embodied musicality, seeking to reorient voice studies away from the "naturalized" properties of music which most listeners take for granted (i.e. pitch and timbre) and move toward a model in which all properties of sound, especially its material qualities, are accounted for. ${ }^{43}$ She recasts music as a "thick event," an understanding that acknowledges the multiple contributing phenomena which make up an experience. A "thick" reading of music includes the acoustic properties of the medium through which sound is conducted, the action of sound production itself, and the "material transmission" of one vibrating apparatus to another. Novak's and Eidsheim's models for approaching contemporary opera are inherently multimodal, pointing audiences toward a new way of interpreting opera: holistically, and in relation to real life.

As narrative vocal music increasingly takes advantage of new modes of presentation (including multimedia) and production (including performance art and extended techniques) the

${ }^{43}$ Nina Eidsheim, Sensing Sound: Singing and Listening as Vibrational Practice (Durham: Duke University Press, 2015), 17. 
techniques of embodied voice studies will yield results that are much closer to the inherently multimodal nature of the genre. In addition to aural understandings of music, Novak and Eidsheim argue that there are also relevant visual and tactile ones. These multimodal considerations contribute to the text of narrative vocal music in meaningful ways. Pulitzer winning vocal works use multisensory influences to create visceral and moving representations of the political issues at work in all Americans' lives, as I will explore more thoroughly in Chapter Four.

The Pulitzer's new priorities — and the problems they engender-constitute an alteration of the Pulitzer's institutional identity, and an attempt at the construction of an American canon for the twenty-first century. This thesis will investigate the Pulitzer's leveraging of prestige and relevance amidst the fluctuating preferences of critics and audiences in the last ten years. In the vocal works of the past decade, I highlight the impact of neoliberalism and cultural competition on the destabilization of vocal genres. Additionally, I document the at-times fraught relationships of the Pulitzer's prize juries and administrators, which shape the perceptible evolution of its aesthetic biases. Pulitzer winning voice works show the Pulitzer's attempts to remain timely by reorienting their ideology, resulting in more awards to the rising generation of composers, for works which include overtly political themes. By considering the 2008-2018 narrative vocal music winners as the enactment of the Pulitzer's new agenda and situating them in relation to a canonic past, I argue that the institution is attempting to forge a new, more democratic artistic identity, but without acknowledging the exclusivity and gatekeeping that composition prizes necessarily uphold. 


\section{Chapter Outline}

Using Bourdieu's ideas of "field" and "capital," Chapter Two explains the rise of culture prizes and their role in structuring the musical landscape. I will show how institutions and individuals capitalize on culture prizes to generate social, cultural, and financial capital. Culture prizes, and more specifically, prizes for music composition are discussed in detail, including a brief typology.

Chapter Three narrows the focus to the Pulitzer Prize, first describing the founding of the Pulitzer Prizes, the founding of the prize in music in 1943, and the processes used to administrate the prize in the present. I will show that the Pulitzer Prize for Music emerged at a time when composers were trying to define and defend a nascent idea of American music, and that the contemporary Pulitzer remains tied to this idea, exemplified by its early operatic winners.

In Chapter Four, the vocal works of the Pulitzer finalists between 2008 and 2018 are compared. I argue that during the span of time between the jury's choice and the administrative board's, all three equal finalists are potential winners. This chapter studies changes to the juries of musical specialists assigned to choose the finalists, as well as the works themselves. Chapter Five builds upon these ideas, extending the discussion from finalists and juries to the winners and the Administrative Board which ultimately chooses them. While the finalists (chosen by musical juries) constitute the priorities of the musical field, Pulitzer winners articulate the priorities of the institution. In this chapter, I argue that recent music winners have fallen into line with the Pulitzer's other categories in letters and journalism. Chapters four and five both combine reception histories of the individual pieces with interviews given by Pulitzer officials, critics, and composers, read through a Bourdieusian lens. 
Chapter Six observes the reflexive influence of the Pulitzer Prize for Music and the musical field. I address the reception of the Pulitzer, especially drawing on studies of the literary prizes for comparison. This chapter finds that cult of celebrity surrounding the Pulitzer has the ability to create substantial positive and negative ramifications for winning composers. The Pulitzer's recent efforts toward "rebranding" for a rising generation of composers, and the subsequent reactions of these changes in the music community are also discussed in detail. 


\section{Prizes \& Price Points: An Economic View of Cultural Prizes}

Whether for art galleries or punk rock concerts, budgets often approach their breaking

point to accommodate the number of unseen personnel needed to see a project to completion.

Imagine, for a moment, just how many contributors may be involved:

For a symphony orchestra to give a concert, instruments must have been invented, manufactured, and maintained, a notation must have been devised and music composed using that notation, people must have learned to play the notated notes on the instruments, times and places for rehearsal must have been provided, ads for the concert must have been placed, publicity must have been arranged and tickets sold, and an audience capable of listening to an in some way understanding and responding to the performance must have been recruited. ${ }^{1}$

Contributors to any cultural event span time and space, and for every one of these roles, there likely exists a set of honors, awards, or prizes to recognize and reward them. Consider, then, the immeasurable quantities of prizes in cultural fields that must exist!

Even as we separate a narrower subset of prizes for music from these culture prizes, the number and variety is still staggering. In music, prizes reallocate resources not only to composers, performers, and conductors, but even producers and critics. ${ }^{2}$ Opera prizes, for example, will occasionally recognize not only the composer, but also the librettist or director. ${ }^{3}$

Conversely, prizes for nonmusical endeavors have selected musical winners. On both sides of the

\footnotetext{
${ }^{1}$ Howard Becker, Art Worlds (Berkeley: University of California Press, 1982), 2.

${ }^{2}$ Other notable studies of musical prizes include Lisa McCormick, Performing Civility: International Competitions in Classical Music (Cambridge: Cambridge University Press, 2015); Kirill Tomoff, Virtuosi Abroad: Soviet Music and Imperial Competition during the Early Cold War, 1945-1958 (Ithaca, NY: Cornell University Press, 2015); Annie Janiero Randall, “Eyes on the Competition Prize," Contemporary Music Review 16, nos. 1-2 (1997): 105-111.

${ }^{3}$ The Charles Ives Opera Award (given by the American Academy of Arts and Letters) recognizes composer and librettist, and the International Opera Awards have categories which recognize both a company and a director.
} 
initiation of the Pulitzer Prize for Music, the Pulitzer Prize for Drama has selected at least nine musical winners, as early as 1931 and as recently as 2016 . Music prizes can be used to inspire the creation of new pieces, to promote and circulate older ones, and to solidify the career and stature of its winners, and at all different levels. Price points are important: prizes that award emerging artists and those with long-established careers have different sets of requirements, toward different goals. This chapter will discuss these divergent functions, from "lifetime achievement" or career capstone prizes such as the MacArthur Fellowship to early-career grants to facilitate a recording, as in those given by Experimental Media and Performing Arts Center $\left(\right.$ EMPAC) ${ }^{4}$

Within this broad category of "culture prizes," composition prizes present an interesting lens through which to study the changing priorities of music over time. Western music's privileging of the composer's authority makes the study of composition prizes particularly telling. While performers and conductors may also be honored for their doing justice to the music, prizes for the authors of music are a compelling medium through which we can observe the changes in field at large. In this chapter, I will explore how culture prizes can shape their disciplines, creating and reifying cultural products under the inescapable influence of the economy. By positioning the Pulitzer among peer awards with similar structures of cultural arbitration, I draw attention to the ways in which its treatment of music as capital is comparable, and how it diverges.

${ }^{4}$ EMPAC is housed within Rensselaer Polytechnic Institute (RPI) in Troy, New York. 


\section{Culture Prizes}

Prizes in cultural fields have a rich history dating back to ancient civilizations. Since antiquity, music has held an important place in culture with competitions in musical performance going at least as far back as the Pythian Games at Delphi in 582 BC. $^{5}$ The renewed interest during the Renaissance in the cultural significance of ancient civilizations fostered a rekindling of artistic rivalry, and a return to competitions of culture. ${ }^{6}$ Commissions by rich and powerful patrons were highly coveted, and entire art collections could be filled with the works born of Michelangelo and Leonardo's constant attempts to best one another. ${ }^{7}$ In France, a new Prix de Rome was initially founded in 1663 for painters and sculptors, and later expanded to include music composition in 1803 . At this early stage, culture prizes were most relevant to a narrow group of people, comprised mostly of those who competed for them and those who awarded them. Renaissance artists, for example, found themselves in a crowded and brutally unforgiving landscape; if the artist could win a prize, however, they could distinguish themselves from the throng by leveraging its prestige in their favor. Prizes provided the artist with a special sort of social currency that allowed them entry into the world of elite: "cultural capital."

In parallel with the term's monetary associations, cultural capital casts the intangible parts of culture, including knowledge, skills, and behaviors, as a resources. Like money, it gives “access to scarce rewards, is subject to monopolization, and, under certain conditions, may be

\footnotetext{
5 Thomas J. Mathiesen, Apollo's Lyre: Greek Music and Music Theory in Antiquity and the Middle Ages (Lincoln: University of Nebraska Press, 1999), 34.

${ }^{6}$ Even the contemporary practice of referring to a winner as a "laureate," refers back to the practice used throughout Antiquity of presenting winners with laurel crowns. Ibid., 87.

${ }^{7}$ Rivalry and competition was central to the artistic practices of Michaelangelo, Raphael, Leonardo, and Titian. See Rona Goffen, Renaissance Rivals: Michelangelo, Raphael, Leonardo, Titian (New Haven: Yale University Press, 2002), 3 .
} 
transmitted from one generation to the next." ${ }^{8}$ Sociologist Pierre Bourdieu coined the term, adding several in a similar vein. Where cultural capital is spent to elevate one's cultural standing or social class, sister terms political and economic capital similarly advance political power and financial wealth.

Always in flux, cultural capital is the result of the push-and-pull between different cultural entities - in fine art or music, this includes universities, museums, archives, libraries, as well as orchestras, dance companies, and most especially, prizes. ${ }^{9}$ These entities are engaged in a perpetual struggle for power, dominance, and relevance to the communities whose patronage supports them. ${ }^{10}$ Bourdieu calls this space the "field." On the first and smallest level, field is the ordering or hierarchy among these cultural entities — people, institutions, communities — at any given moment. ${ }^{11}$ These different cultural agents represent different interests, priorities, and systems of value, and they exist in a constant state of interaction and exchange: they argue and collaborate, merge and dissolve, win and lose. ${ }^{12}$ In Bourdieusian terms, these interactions result in a complex system of power relationships. Bourdieu believed that no two entities can possibly be equal, therefore in every interaction, a hierarchy is either destabilized or reinforced. It may force the gap between two agents to widen or it may reverse entirely, but the hierarchy remains nonetheless. ${ }^{13}$

\footnotetext{
${ }^{8}$ Annette Laureau \& Elliot Weininger, "Cultural Capital in Educational Research: A Critical Assessment," In After Bourdieu: Influence, Critique, Elaboration, ed. David L. Swartz (New York: Kluwer Academic Publishers, 2005), $105-145$, at 105.

${ }^{9}$ Musicological studies of cultural capital include Bonnie Gordon, "The Courtesan's Singing Body as Cultural Capital in Seventeenth-Century Italy," In Courtesan's Arts: Cross-Cultural Perspectives, eds. Martha Feldman \& Bonnie Gordon (New York: Oxford University Press, 2006), 182-208; Nadine Hubbs, Rednecks, Queers, and Country Music (Berkeley: University of California Press, 2014).

${ }^{10}$ Pierre Bourdieu, Distinction: A Social Critique of the Judgement of Taste, trans. Richard Nice (Cambridge: Harvard University Press, 1987).

${ }^{11}$ Richard Jenkins, Pierre Bourdieu (New York: Routledge, 2006), 129-40.

${ }^{12}$ For a detailed description of how cultural entities interact in the field, see Bourdieu, Distinction.

${ }^{13}$ For a competing argument, see Jenkins, Bourdieu, 146-49.
} 
In a hierarchy, one agent's position is contingent upon the ordering of all the other agents. Imagine, for example, that a well-known and well-attended art museum decides to close its doors to the public after years of financial hardship. Rather than abandon their museum-going altogether, its patrons will simply be absorbed by other art museums. The amount of resources within the field remains fixed even while their distribution changes. Prizes too can evince a similar kind of hierarchical change. If a well-established architect such as Frank Lloyd Wright were to have lost a competition to a young upstart, Wright's position of authority as a master architect might have come into question. Both situations are relational — the position of one cultural agent in the field is dependent on the rest.

To further complicate the network of relations among cultural agents, fields can have separate systems of value. ${ }^{14}$ What one field may consider to be indispensable capital, another might consider worthless. Prizes themselves even receive this situationally-dependent treatment. Prizes are not necessarily valuable cultural capital to some people, and not every award-winning work is considered to have the same worth by every community. Take sculptor Rachel Whiteread's 1993 work "House" for example (Fig. 1).

\footnotetext{
${ }^{14}$ See James English, The Economy of Prestige: Prizes, Awards, and the Circulation of Cultural Value (Cambridge:
} Harvard University Press, 2005), 9; Bourdieu, Distinction, 113. 


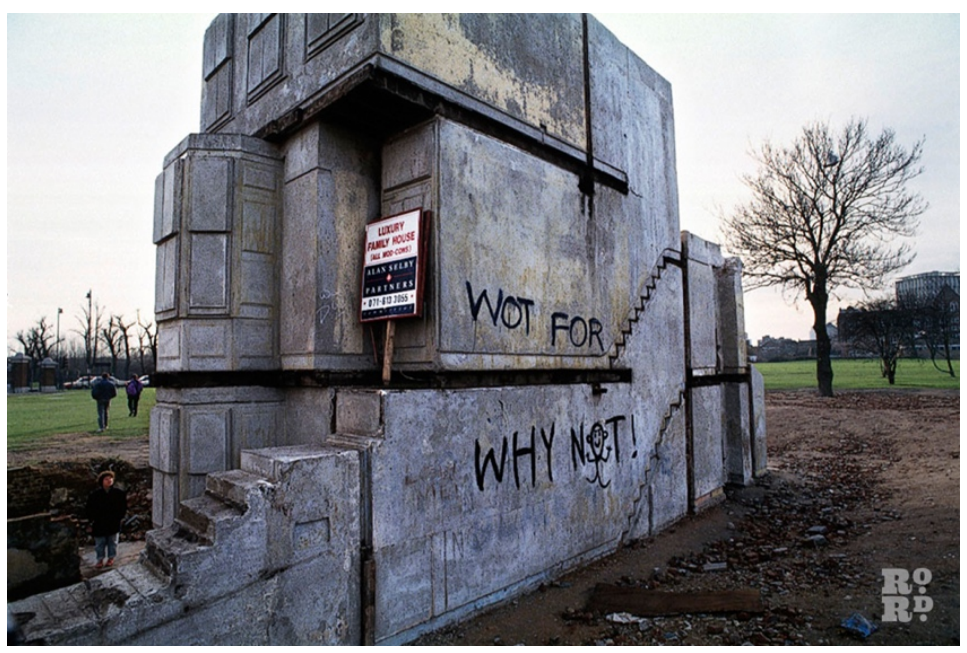

Figure 1. Rachel Whiteread, "House" (1993).

This sculpture was an unattractive and ungainly plaster molding of a house, which Whiteread intended to be a critique of London's cheap and poorly-constructed housing. Built intentionally on public property without permission, the piece was condemned and later torn down, inspiring a flurry of public curiosity and hot debate among the art-world elite. "House" won two important prizes that year: the Turner Prize for England's best work of art and the K. Foundation Award for England's worst piece of art. ${ }^{15}$

Art communities used "House" as a way of defining themselves against one another. The Turner Prize may have seen "House" as an outspoken piece of social commentary, perhaps insignificant in use of form, texture, or color, but notable for its message and social context. Perhaps the K. Foundation saw it only an ugly eyesore, unworthy of all the public attention it had received during and after its display. Although these institutions enacted the opinions of only a few jurors, the conflicting perspectives are representative of the ways in which larger

\footnotetext{
${ }^{15}$ The Turner Prize jury is made of internationally renowned art critics and scholars. The K Foundation Award was an upstart anti-prize begun specifically to castigate the Turner Prize, only active from 1993-95. The members of their jury were the owners of the K Foundation, Bill Drummond and Jimmy Cauty. "BBC Arts Night What Has the Turner Prize Ever Done for Us?" YouTube video, 29:03, posted by "Melvin S. Rodriguez," February 4, 2017, https://www.youtube.com/watch?v=I1tL581WM2c.
} 
communities of artists felt about artistic conventions. ${ }^{16}$ These antithetical interpretations of the same piece are critical to understanding the volatility of the field, a quality which only intensified throughout the twentieth century.

\section{The Culture Prize Renaissance}

An incomparable surge in the number and variety of culture prizes began at the turn of the twentieth century. The year 1901 marked an important moment: the inaugural class of Nobel prizes were awarded in physics, chemistry, medicine, literature, and peace. ${ }^{17}$ Idealistic aspiring benefactors kept all eyes on Alfred Nobel. His fortune had already thrust him into the public eye, and the spectacle of his prizes drew a massive, global following. The following, though, comprised both critics and admirers. Many people, including Nobel himself, vilified his recent invention of dynamite, the use of which augmented weaponry to allow new heights of destruction and mass casualties. His fortune was tainted by this notoriety, and some considered the Nobel Prizes a lackluster attempt to purify his public image. His sincerity notwithstanding, public knowledge of Nobel's moral shortcomings today has been eclipsed by his foundation's recognition of more than a century's worth of influential laureates. Although other prizes existed at this point, the pageantry surrounding the Nobel Prizes brought public awareness and curiosity to the culture prize phenomenon with a then-unprecedented degree of focus.

The Nobel Prizes were a catalyst for the creation of new prizes in literature, art, and music, spreading from Nobel's native Sweden across Europe and the Americas. Within just a decade, new prizes for arts and letters began to appear at a much faster rate. The French literature

\footnotetext{
${ }^{16}$ Deliberate change to the "conventional language of art" can result in ideological conflict. See Becker, Art Worlds, $304-5$.

${ }^{17}$ English, Economy of Prestige, 28-29.
} 
prizes, the Prix Goncourt and Prix Femina were founded only a year apart, in 1903 and 1904 respectively. ${ }^{18}$ The Pulitzer Prizes in journalism and letters followed them closely in 1911 . The American Academy in Rome, already founded prior to the Nobel Prize, added new prizes; they reinstated an award for architecture in 1909, and initiated one for music in 1924. The Nobel Prizes thus heralded the beginning of a period overwhelming proliferation of culture prizes whose effects are still seen today. ${ }^{19}$ For turn-of-the-century prizes, the sense of purpose, legacy, and longevity was of utmost importance. Nobel, Edmond de Goncourt, Joseph Pulitzer, and many other philanthropists had a fervent desire to champion quality art and literature to the masses; an insistence that the public be aware of their prizes was necessary to their explicit goal of educating and elevating their taste. ${ }^{20}$ As former systems of patronage bowed to the power of the free market, prizes' propagation of artistic excellence was more necessary than ever before. ${ }^{21}$ It was at this point that the systematic ranking of artists became so interwoven with the dissemination of their work, and was met with so much public attention.

All this begs the question, why use prizes to do this work? What is the value of a culture prize, and what causes them to exist in such quantities? English treats this topic at length:

On the one hand, cultural prizes are said to reward excellence; to bring publicity to "serious" or "quality" art (thereby encouraging the presumably philistine public to consume higher-grade cultural products); to assist struggling or little-known artists (thus providing a patronage system for the post-patronage era); and to create a forum for displays of pride, solidarity, and celebration on the part of various cultural communities. On the other hand, it is said that they systematically neglect excellence and reward mediocrity; turn a serious artistic calling into a degrading horse race or marketing gimmick; focus unneeded attention on artists

\footnotetext{
${ }^{18}$ Susan Pickford, "The Booker Prize and the Prix Goncourt: A Case Study of Award-Winning Novels in Translation," Book History 14 (2011): 227.

${ }^{19}$ English, The Economy of Prestige, 28-29.

${ }^{20}$ In this situation, the notion of aesthetic quality is best mapped onto the high-art/entertainment binary that plagued artists and critics of the late-nineteenth and twentieth centuries. For a fuller discussion of the debate, see Ibid., 28; Pickford, "The Booker Prize," 227.

${ }^{21}$ Virgil Thomson categorizes prizes as an essential element of composers' income. See Louis K. Epstein, “Toward a Theory of Patronage: Funding for Music Composition in France, 1918-1939” (Ph.D. diss., Harvard University, 2013), 21.
} 
whose reputations and professional livelihoods are already solidly established; and provide a closed, elitist forum where cultural insiders engage in influence peddling and mutual back-scratching. ${ }^{22}$

In the paragraph above, English explains the culture prize's contradictory nature. $\mathrm{He}$

positions them among other indicators of cultural value as a mechanism for recognizing "quality" and "excellence" but acknowledges that such judgements will invariably be met with disagreement. The first perspective operates using a high and low art binary, using prizes as an indication of legitimacy or worthiness. With this binary in mind, culture prizes elevate the works which win them to a variety of ends-education of the "presumably philistine" public, the identification of a rising generation of artists, and as a way to create a sense of community.

Because one prize may not represent every community, it is helpful to consider the ways communities may distinguish themselves from one another. If in English's statement, the second perspective disparages prizes simply for their inability to choose something good, they imply that there are other more worthy choices. They might accuse the juries of "influence peddling and mutual backscratching," awarding only works that are "mediocre." ${ }^{23}$ Consider these perspectives in terms of an insider/outsider binary. As the outsider points out, the closed and hierarchical system of a culture prize is highly exclusionary — the prize tends to favor only the groups that are "in," disregarding the validity of those that are not. The insider disagrees, arguing that the work they are rewarding deserves recognition just the same. Unfortunately for prize scholars, both perspectives ring true, and a deeper examination of the way they influence the field is necessary to reconcile their opposing results.

\footnotetext{
${ }^{22}$ English, The Economy of Prestige, 28.

${ }^{23}$ Lili Boulanger's Prix de Rome win in 1913 drew heated criticism on the grounds that her work was chosen as a political statement in support of feminism rather than on the work's own merits. See Annegret Fauser, "La Guerre en dentelles: Women and the 'Prix de Rome' in French Cultural Politics," Journal of the American Musicological Society 51 no. 1, (1998): 84.
} 


\section{Structuring, Mediating, and Evaluating the Field}

Culture prizes are the field's best currency exchange: they operate by translating one kind of capital into another, converting among social, political, and economic capital. ${ }^{24}$ Bourdieu theorized that through this transfer, called "interconversion," all forms of capital are interchangeable. ${ }^{25}$ Economic capital could fund an education, for example, which grants access to the knowledge and behaviors (a form of cultural capital) necessary to participate in different social circles. In the field of composition, culture prizes are an essential conduit for interconversion. With every new winner, prizes convert their winners' cultural capital into economic and political capital. Consider a lifetime achievement award in the vein of the MacArthur Fellowship, which rewards based upon recognition of accrued cultural capital. As a credential, a MacArthur Fellowship can be used to justify the winner's status as an "expert," leading them to be sought after as a representative of their discipline to non-specialists, perhaps even as a future juror. Following George Lewis's 2002 MacArthur Fellowship, the magnitude of his political capital made him an apt choice for the Pulitzer Prize jury of 2006 and subsequently in 2011, despite never having been affiliated with the Pulitzer organization. ${ }^{26}$ These peripheral benefits of winning (such as an increased amount of attention from critics and audiences and better positioning to receive more accolades) indicate the truth in the popular saying success begets more success. ${ }^{27}$

\footnotetext{
${ }^{24}$ For examples of each of interconversion transactions (cultural to social, cultural to political, and cultural to economic) see Joseph Wensink, "Literary Philanthropy: The Pulitzer Prize, Oprah's Book Club, and Contemporary U.S. Fiction" (Ph.D. diss., Brandeis University, 2012), 4. See also Tobias Pret, Eleanor Shaw, \& Sarah Drakopoulou Dodd, "Painting the Full Picture: The Conversions of Economic, Cultural, Social and Symbolic Capital," International Small Business Journal 34, no. 8 (2016): 1004-1027.

${ }^{25}$ Bourdieu, Distinction, 3.

${ }^{26}$ For a full list of Pulitzer jurors by institutional affiliation, see Appendix.

${ }^{27}$ The first female winners of major composition prizes like the Pulitzer Prize, the Grawemeyer Award, or the Rome Prize have typically ascended through other less prestigious awards. See Randall, "Eyes on the Composition Prize," 106.
} 
Art historian Raymonde Moulin coined a phrase which describes how this works in the art world: "deferred success." The increase or decrease of prices in the art world is determined by intermediaries - not the people who make the art, but people who curate, buy, and sell. As an artist progresses through certain career mileposts, their continued esteem by buyers and sellers proves that their art has staying power beyond sensationalism. ${ }^{28}$ Their success indicates that the art's value will increase as time goes on, making their impending purchase or sale all the more worth it for its promise of an even bigger transaction in the future. The gains of the future are higher because the work's prestige and price accrue value via a "slow and delayed conversion of artistic value into price," as the field's collective acceptance of that artist and their works grows. ${ }^{29}$ In the latter half of the twentieth century, these intermediaries became more specialized. Their skills, education, and the art they oversaw were all powerful forms of cultural capital, accessible to a varied, but elite group of gatekeepers. ${ }^{30}$

As a competition, a culture prize can prompt such consolidation. ${ }^{31}$ Anthropologist Rudi Colloredo-Mansfield identifies competition as both a method and a goal of consolidation, writing that "competition entails not so much individualism as positioning and is thus understood as a structural relationship between competitors. ${ }^{32}$ In more human terms, competition can be framed as "a means of positing an 'us' and an 'our' around which to rally individuals." ${ }^{33}$ Cultural fields are flexible, and they adapt quickly to new groups, unifying and restructuring extant

\footnotetext{
28 Raymonde Moulin "The Museum and the Marketplace: The Constitution of Value in Contemporary Art," International Journal of Political Economy, no. 25 (1995): 47.

${ }^{29}$ Pierre Penét and Kangsan Lee, "Prize \& Price: The Turner Prize as a Valuation Device in the Contemporary Art Market," Poetics 43, no. 1 (2014): 152.

${ }^{30}$ Ibid.

31 In the mid twentieth century, the consolidation of musical networks among three major foundations (the Ford Foundation, the Rockefeller Foundation, and the National Endowment for the Arts) led to a small group of elite composers being trusted with most of the major decisions concerning their grantmaking operations. See Uy, "Public and Private Patronage of Music."

${ }^{32}$ Colloredo-Mansfield, "An Ethnography of Neoliberalism," 113

${ }^{33}$ English, The Economy of Prestige, 50.
} 
communities to reflect changing priorities. Turners, Nobels, and Bookers can restructure communities around their winners because they claim cultural authority, using their decision as a way to claim control over cultural landscape. Their status as cultural arbiters is assumed; no one gives them any power, they simply claim it. Elite bodies, including various national Academies, claim power by an institutionalization of peer judgement, lending the same authority to the prizes they sponsor ${ }^{34}$ Their authority is reinforced in part by the language used by to decide the winners: their awards represent the "best," "greatest," and "most distinguished" in their field. ${ }^{35}$

What makes this a particularly sticky business, however, is that communities are so difficult to define or articulate, and that institutions do not always act on behalf of - or even fairly — towards all of them. Even a person who might meet all the criteria for being a member of a community may not identify themselves as a part of it. Hector Berlioz's win in the 1830 Prix de Rome was criticized perhaps most vehemently by himself. Despite having entered the competition intentionally and the "great practical benefits" Berlioz received, he asserted that he won by writing a cantata which was intentionally mediocre, in an effort to distance himself from the Académie des Beaux Arts. ${ }^{36}$ Although his judgements may have been highly personal, his articulation of shared cultural values and conventions are what bound him to a communities. The disagreements between his own values and those of the Académie established his fracturing from their community, defining its boundaries.

Occasionally, prizes maneuver with their critics in mind; they can stand to gain significant political capital in its choice of a winner. As participants in the cultural field, prizes

\footnotetext{
${ }^{34}$ See Susan Pickford "The Booker Prize," 227 for a description of how this occurs in the Prix Goncourt; See Moulin, "The Museum and the Marketplace," 47, for a description of how curators qualify as cultural arbiters.

35 The Turner Prize states its purpose to be the recognition of the greatest contribution to British art work, see Penét and Lee, "Prize \& price," 151. The Booker prize recognizes the best British book, The Man Booker Prize, "The History of the Man Booker Prize," Accessed April 18, 2019, http://themanbookerprize.com/fiction/history.

${ }^{36}$ Peter Bloom, "Berlioz and the 'Prix de Rome' of 1830," Journal of the American Musicological Society 34, no. 2 (1981): 280.
} 
can forge new alliances with other institutions or communities, claim a moral high ground, and reinforce their own prestige by choosing an already-prestigious winner. Ornette Coleman's 2007 Pulitzer for his album "Sound Grammar" did all three_-it indicated the Pulitzer's renewed commitment to the inclusion of jazz, reconnecting with its community, and drawing critical praise for being among the first "music composition" prizes to acknowledge jazz artists. Even more beneficial for the Pulitzer was its attachment of Ornette Coleman's name and legacy to their own; in 2007, the then 77-year-old Coleman was one of the most important figures in free jazz, and by bringing him into the fold, they further solidified their position as one of the most important prizes for American music.

Despite the ever-present denial that prizes are valuable to the field, the insistence of critical discourse using prizes as a marker of success, quality, and prestige would seem to indicate otherwise. Prizes may not be inherent to cultural fields, nor even necessary, but they continue to proliferate, playing a role in the structure, mediation, and evaluation of cultural fields. Prizes endorse not only the awarding institution's esteem for a piece, composer, or organization, but also indicate to the field a sense of collective acceptance. Yet the theoretical machinations driving the structure of cultural fields are directly impacted by their access to tangible resources, most especially, money. In the following section, I will turn to the economic inequalities underlying the persistence of cultural competition.

\section{Economic Capital}

Financial capital is the most straightforward benefit of a prize, but deeper economic interactions between prizes and winners can quickly become fraught. Because many prizes "conflate economic and cultural capital, a high price point is essential to locating themselves as 
superior in terms of fame, value, and influence." ${ }^{37}$ Nobel Prize winners receive 9,000,000

Swedish Kronin (about $\$ 1,110,000$ US dollars today) and the Breakthrough Prizes for life sciences disciplines receive $\$ 3,000,000$ each. These extreme dollar amounts reflect a societal norm: money and prestige rise in proportion to one another. However, not all prizes come with excessive cash awards - the French Prix Goncourt doles out only about 10 euros. For prizes in elite art forms such as literature, some cultural agents go out of their way to avoid undue association with economics, hoping to escape the impression that their products are tainted by commercial interests. ${ }^{38}$ Despite conflicting dispositions toward prize purses at the time of their receipt, the reward itself is only the beginning of a winner's acquisition of economic capital. ${ }^{39}$

Unlike the above prizes in the sciences, culture prizes seek to promote cultural products; their explicit goal is to increase consumption. Some institutions created prizes for just this purpose: turn-of-the-century philanthropists, such as Alfred Nobel and Joseph Pulitzer, initiated prizes meant to "elevate the public's taste," intending to skew their leisure listening or reading toward products of marked quality. ${ }^{40}$ Indeed, many prizes claim that their seal of approval can result in a marked increase in sales. Each year, the Academy Awards are preceded by $\$ 60$ $80,000,000$ of marketing schemes, intended to sway Academy voters, presumably because a win in the "Best Picture" category would drive in more sales at the box office. ${ }^{41}$ The Pulitzer Prize even acknowledges that "the Pulitzer accolade on the cover of a book or on the marquee of a theater where a prize-winning play is being staged usually does translate into commercial

\footnotetext{
${ }^{37}$ Pickford, "The Booker Prize," 229.

38 James English, "The Economics of Cultural Awards," in Handbook of the Economics of Art and Culture, vol. 2, eds. Victor A. Ginsburgh and David Throsby (Oxford: North Holland, 2014), 119-143.

${ }^{39}$ The Pulitzer Prize has also followed this convention, and its prize purse has risen meteorically in the $21^{\text {st }}$ century. For an analysis of the rise in award amount from 1943 to the present, see Appendix.

${ }^{40}$ This topic will be addressed thoroughly in Chapter Two.

${ }^{41}$ English, "The Economics of Cultural Awards," 2
} 
gain." ${ }^{42}$ As widely as this belief is accepted, current economic studies of the phenomenon disagree. James English reports that the correlation between awards rosters and subsequent bestsellers lists is at best, loose. ${ }^{43}$ To reconcile the unquestioned belief that culture prizes are valuable with this conflicting evidence, we may consider shifting focus from the period immediately following a win to a time weeks, months, or years after.

As a credential, prizes arbitrated by specialists are often key determinants in whether cultural agents receive future subsidy. If a winning artist's increasing prestige is indeed met with correspondingly higher commission prices, a prize is influential in establishing their marketability. This idea of marketability or commodification is important; beyond even the creator's necessary living expenses, their artistic projects require funding to bring into being. The larger the project, the more capital is needed: every performer, collaborator, stagehand, and consultant must be paid. In the field of music (in comparison with a more popular fields such as film) there exists a fundamental disparity between the number of opportunities for payment, and the number of cultural agents competing for those opportunities. ${ }^{44}$ In the United States, the capitalist economy deals with this inequality by distributing the opportunities unevenly throughout the field—some agents have more capital than others. Such a system inherently places agents in competition with one another, and demanding that agents find ways to establish themselves as worthy recipients. For cultural agents inside the United States, government sponsorship of the arts is much less prevalent. ${ }^{45}$ For this reason, the bulk of funding necessary to support larger-scale artistic ventures, including operas, orchestras, as well as smaller ensembles,

\footnotetext{
${ }^{42}$ Seymour Topping, "Administration of the Prizes," Pulitzer Prizes accessed May 25, 2018, http://www.pulitzer.org/page/administration-prizes.

${ }^{43}$ Ibid.

${ }^{44}$ For a discussion of several differing Marxist views of the field of music, see Bryan Parkhurst and Stephan Hammel, “On Theorizing a 'Properly Marxist' Musical Aesthetics," International Review of Aesthetics and Sociology of Music 48, no. 1 (2017): 33-55.

${ }^{45}$ Epstein, "Toward a Theory of Patronage," 29.
} 
must come in the form of private grants and donations. James Allen Smith cites a national average of just $50 \%$ of funding generated by ticket sales, meaning that the remaining revenue must come from elsewhere. ${ }^{46}$

In the period since the $1980 \mathrm{~s}$, the competitive nature of the economy has intensified so much that recent economists have marked it with a new term: "neoliberal." Described by economist Milton Friedman as "competitive capitalism," it prioritizes a free and deregulated market, pitting corporations against one another for the acquisition and maintenance of capital with little to no government interference. Finite as capital is, this concentration of wealth among those who are already wealthy leaves much less available to the middle and lower classes. Thus, the fierce competition of corporations only intensifies as one moves down the economic ladder; the higher the demand, the scarcer the resource.

The situation is dire for musical entrepreneurs, many of whose products are created without the assurance of commercial success. In music, like larger fields such as the auto industry, neoliberalism "gives rise to temporary, unstable labor conditions." ${ }^{47}$ Many funding opportunities exist as individual, one-off grants, such as Guggenheim Fellowships or grants administered by New Music USA. In this way, financial support for one project does not guarantee future support from the same source. Precarity forces artists to seek multiple sources of funding, many of which are only available (by regulation or simply by practicality) only once. Given the competition between many agents for one opportunity, grant proposals must somehow distinguish themselves from other applicants, creating a kind of systematized inequality for seekers of subsidization. ${ }^{48}$ Friedman acknowledges the inequality in his vision, that the

\footnotetext{
${ }^{46}$ Smith, "Foundations as Cultural Actors," 265.

47 Andrea Moore, "Neoliberalism and the Musical Entrepreneur," Journal of the Society of American Music 10, no. 1 (2016): 51 .

48 Ibid.
} 
competitive nature of the economy means, inevitably, someone must lose. From his perspective, competitive capitalism was "a system of economic freedom and a necessary condition of political freedom." 49

Andrea Moore observes that Friedman's conflation of market values with freedom and autonomy is problematic. ${ }^{50}$ He propagates the idea that autonomy can only really be enacted by having more power than someone else- by winning. Positioning neoliberalism as an unfortunate circumstance that has been rationalized into normalcy, Moore argues that musicians have gone so far to embrace their new economic reality that they have valorized the ideas which put their financial sustainability in danger. ${ }^{51}$ From Karl Marx's creative destruction, in which visionaries “incessantly revolutionize the economic structure from within, incessantly destroying the old one, incessantly creating a new one" value the cutting-edge. "Innovation" and "adaptation" become buzzwords, heralding creative visionaries who have the drive to overcome the perilous economic circumstances of contemporary life. ${ }^{52}$ The image is admittedly an attractive one. Its quick spread to music programs has produced degrees and specializations in arts entrepreneurship and music business. In the midst of this transition toward musical entrepreneurship, culture prizes do a great deal to imply the economic viability of their winners. If a composer can win a prize, their increased likelihood of exposure to their audiences makes further financial support seem more meaningful; rather than fund a venture that might not come to fruition, a second run of a prize-winning opera seems like more of a sure bet.

\footnotetext{
49 Ibid.

${ }^{50}$ Other musicological studies of neoliberalism include Robin, "Balance Problems: Neoliberalism and New Music in the American University and Ensemble”; Marianna Ritchey, “Amazing Together': Mason Bates, Classical Music, and Neoliberal Values," Music \& Politics 11, no. 3 (2017): 1-23.

${ }^{51}$ Ibid.

52 Marianna Ritchey similarly notes the common universalizing rhetoric that unify music and technology in the operas of Mason Bates. See Ritchey, “Amazing Together,” 4.
} 
Today, we find these economic complexities play out in interesting ways in the landscape of contemporary opera. Prizes notwithstanding, new opera is a messy and unstable playing field. While rarely finding creative license in institutionalized opera houses, such as New York's Metropolitan Opera or the Lyric Opera of Chicago, composers do have a chance at being performed by regional or local opera troupes. Boston's Guerilla Opera, Opera Philadelphia, and MacArthur Fellow Yuval Sharon's The Industry have all produced major premieres within the last five years by Kevin Puts, Christopher Cerrone, Ken Ueno, Missy Mazzoli, and others. ${ }^{53}$ Increasingly, these smaller-scale, flexible models are being used not only in the United States, but internationally as well. Opera scholar Nicholas Payne contrasts the current paradigm for funding opera with the historic, European model, observing that European opera flourished with heavy subsidy from the state, but companies performed only a narrow range of works because the oligarchy of board members would allow nothing but canonic works into their seasons. ${ }^{54}$

State subsidy was treated much differently in the United States. In the early twentieth century, the majority of government support for the arts was given indirectly via tax exemptions, rather than directly with major grants. ${ }^{55}$ At this point, the field of American opera was supported (or controlled) in much the same way that European opera was. Broader opportunity outside the hands of the elite few emerged with the creation of an arm of the federal government, the National Endowment of the Arts in 1965. The NEA inspired many local and regional level imitators, pushing this growth even further. A mutually beneficial partnership developed

\footnotetext{
${ }^{53}$ Opera Philadelphia premiered Elizabeth Cree (2017) by Kevin Puts and Breaking the Waves (2016) by Missy Mazzoli; Boston's Guerilla Opera premiered Gallo (2014) by Ken Ueno; and The Industry premiered Invisible Cities (2014) by Christopher Cerrone.

${ }^{54}$ Nicholas Payne, "The Business of Opera," in Cambridge Companion to Opera Studies, ed. Nicholas Till, (Cambridge: Cambridge University Press, 2012), 307.

${ }_{55}$ Stefan Toepler, "Roles of Foundations and Their Impact in the Arts," in American Foundations: Roles and Contributions, eds. Helmut K. Anheier \& David C. Hammack (Washington, D.C.: Brookings Institution Press, 2010), $283-304$ at 285.
} 
between artists who were now receiving much-needed income, and their sponsors the corporations, who received tax breaks for charitable giving in return. ${ }^{56}$ As the economy flourished between 1955 and 1970 the number of American arts grants grew exponentially, from under 500 to more than 2000 .

The events of the 1950s and 1960s caused a change in the way that operas of the future would be funded. Even with a dedicated body in the vein of the NEA, the Republican government did not have strong ties to a tradition of patronage. Throughout the following decades, they distanced themselves further from such responsibility by shifting the burden of patronage away from the state and into the hands of private foundations and the companies themselves. ${ }^{57}$ The results of this shift are mixed. Nicholas Payne writes, "The American contribution to opera, has been, above all, its financing. Its aggressive capitalist stance has successfully broken the hegemony of the European subsidized model."58 From Payne's perspective, American opera has triumphed over the long-held hegemony of opera to mimic the market it lives in — free and deregulated. However, economic policy always remains in the hands of the government; unrestricted freedom of private foundations ended with the Tax Reform Act of 1969. Private non-profit foundations were finally given a strict legal definition, then found themselves taxed both on income and capital gains. This, combined with a recession in 1970 forced private foundations to reconsider their "grant disbursements, both in kind and quantity." 59 As participants in this economic model, culture prizes are deeply problematic. The scaling back of private foundations' grant operations is one factor that has led to the neoliberal

\footnotetext{
56 Ibid.

57 Ibid.

${ }^{58}$ Payne, "The Business of Opera," 310.

${ }^{59}$ Rachel Vandagriff, "American Foundations for the Arts.” Oxford Handbooks Online http://www.oxfordhandbooks.com/view/10.1093/oxfordhb/9780199935321.001.0001/oxfordhb-9780199935321-e112\#oxfordhb-9780199935321-e-112-bibItem-14
} 
economic landscape opera companies face today ${ }^{60}$ Both thrive on and systematize inequality, but that knowledge is obscured by the rhetoric surrounding neoliberalism. The "internal discourse of competition naturalizes these inequalities as an acceptable (for the moment) community condition... [Competing] consolidates cultural identities and community commitments even as it produces sharp differences in material well-being." ${ }^{\circ 1}$ Grantmaking institutions misleadingly couch the rejection of applicantions in a language of objectivityadministrators can easily deflect blame by referring to the expertise of their juries. Their logic speaks to the pervasive "American dream" sentiment that hard work and tenacity will be rewarded with success, but does not recognize that a winning work and a losing work can both still be outstanding.

Acting under the capitalist conjecture that money is an indication of prestige, they reward their winner with considerable prize purses in hopes that it will reinforce the public's perception of their seriousness. Far from being peripheral, prizes' participation in both the economic and rhetorical discourse of competition is their most essential function, though one which prizes actively try to obscure from the public. By the nature of separating winners from losers, prizes are unable to detach themselves from the competitive market values that support them, yet they continue to position themselves as a mechanism for cultural altruism. Their rootedness in neoliberal values necessitates a frank observation: as much as the transfer of money from one cultural entity to another is often a positive catalyst for new art or support for new artists, prizes can self-consciously perpetuate these inequalities. ${ }^{62}$ If culture prize institutions are cognizant of these biases, they can acknowledge this rightful moral discomfort and use their resources to

\footnotetext{
${ }^{60}$ The Ford Foundation's commissioned study on the decline of the viability of ticket sales in arts funding exemplifies the prescient economic concerns even in 1972. See Uy, "The Big Bang in Arts Patronage," 57.

${ }^{61}$ Colloredo-Mansfield, "An Ethnography of Neoliberalism," 114.

${ }^{62}$ The basis of prizes in "philanthrocapitalism" will be addressed in more detail in Chapter 6 .
} 
remedy some of its problems. The way prizes operate within economic systems (and decide to whom their resources are distributed) is dictated principally by the prize's function. In the following section, I will outline different types of prizes, describing the varied ways prizes can influence the careers of their winners.

\section{Types of Prizes}

Prizes can affect the compositional process at any stage of the process - they can fund or inspire the creation of new works, give an impetus for subsequent productions of alreadycompleted works, and they can put old works in new contexts. The Pulitzer routinely does all three. While the Pulitzer is in many ways a very typical prize, the proliferation of prizes over the twentieth century has brought with it many strategies for organizing and administering prizes. Benefactors are all unique, having distinct sets of priorities and instructions that come with their bequest, which may even change over time. While the bulk of this chapter has explored some of the mechanics behind the larger category of culture prizes, following sections will deal specifically with prizes for music composition.

Following their counterparts in other fields, composition prizes have also proliferate to a startling degree. Competitions and competitive calls-for-scores are hosted by nearly every major orchestra and an increasing number of well-known chamber ensembles; professional organizations for composers, such as SCI (Society of Composers, Inc.), ASCAP (American Society of Composers, Authors, and Publisher), and the Academy of Arts and Letters, host innumerable awards, prizes, and honors. So many of these opportunities exist that some organizations have created centralized databases in order to compile them. ${ }^{63}$ Each of these

\footnotetext{
${ }^{63}$ Some of these include https://composerssite.com/opps/results/taxonomy\%3A2; http://www.compositiontoday.com/opportunities/
} 
opportunities is driven by a specific purpose, and for that reason, it will be helpful to tease out what makes each unique.

Awards can most productively be categorized by their goal— to what ends will an award be used? Construed broadly, many nonprizes operate in a way roughly similar to composition prizes. For example, fellowships, residencies, commissions, and calls for scores are all accolades initiate similar interconversions of capital. Common to all these forms is their adjudication-as I discuss in the beginning of this chapter, judges are an integral party in determining who receives opportunities when there are more applicants than resources. What separates these honors is their underlying purpose. Calls for scores elicit only music for specific performing forces, typically to be performed by the hosting organization, or else a close affiliate. Though it may be an honor for a composer to be selected, calls for scores are less about the specific piece or composer than it is about the ensemble's program, or even the ensemble itself. Residencies and commissions reverse this priority, placing the focus on the composer. Commissions and residencies are a vote of confidence in a composer's abilities, ensuring that the winner has the resources (and in the case of residencies, the dedicated time) to create new and presumably successful work. Fellowships, while potentially lucrative, may also come with additional obligations for teaching, presenting, or workshopping. Composition prizes thus stand out as evaluations of not the composer or ensemble, but the music itself.

Composition prizes must first decide how much of a composer's work they will evaluate to make their decision. Many use a single example of the artist's work, like the Pulitzer Prize or the Grawemeyer Award. In this single-work model, the juries can only evaluate what is in front of them - any of the artist's previous works, no matter how important or well-publicized will not 
affect the outcome of these prizes. In many ways, this leaves room for young upstarts. For Caroline Shaw, Kendrick Lamar, or others like them, a lack of cultural capital in the field of music composition might have ordinarily prevented them from receiving national recognition. With the limited number of entrants submitting only one representative work for evaluation, they stood a much better chance of recognition, both statistically and artistically.

The opposite of a single-work prize is one that considers a body of work. The Rome Prize and the Academy Award from the American Academy of Arts and Letters function in this way. Juries consider the music of a composer's whole career rather than just one work to make their decision. By considering the corpus, jurors are able to typify a composer's work, which is helpful in predicting the kind of work that composer might produce in the future. Although they are not necessarily prizes, prestigious commissions and residencies also use this logic to arrive at a decision. Moulin's idea of deferred success is at play here: a continuous record of artistic quality and success indicates that similar levels of quality and success will be had in the future. For this reason, body of work prizes tend to favor more experienced composers; in this case, having won other prizes is an important indication of experience. Experience is typically equated with age, although this is not always the case. When Ashley Fure won a Rome Prize in 2017, she was only recently graduated from doctoral studies at Harvard University. At a young age, she had already won or been shortlisted for several other major prizes, even though the 2017 body-of-work Rome Prize only included four years since earning her Ph.D.

Identity is also a major classifier of composition prizes. Emerging composer prizes, such as the many given by ASCAP often have an age limit in their eligibility requirements. To be clear, Ashley Fure is an anomaly_most "young composers" (young as defined by the age limit) have not had so much high-profile attention at such a young age. The logic underlying a young 
composer's award is that all the applicants are on something of an equal playing field. Emerging composer prizes are meant to be winnable by a composer at the earliest stages of their career, though their other requirements can skew the pool of applicants in either direction, which will be discussed further below. Other prizes consider themselves to be lifetime achievement prizes. The MacArthur Fellowship, the Swedish Polar Prize, and even more explicitly, the Grammy's Lifetime Achievement Award are a few such prizes. All these prizes look for a significant record of artistic contribution over a large span of time. Obviously, by these standards, young composers are not eligible. To use Ashley Fure's example again, despite a significant record of success, recent MacArthur grantees, including Julia Wolfe or George Lewis, have been writing music longer than she has been alive. Increasingly, awards for underrepresented composers are being initiated by new organizations. The Hildegard Competition, established in 2017, brands itself as the "premiere competition for emerging female, trans, and nonbinary composers." These prizes seek to help rectify the disproportionally white and male upper echelons of composition by creating a credential only for populations who have historically been prevented from acquiring them.

The various types of prizes can work together to create unique winner profiles. Agerelated prizes are a distinct classification from the first two categories, the single-work or the body-of-work prizes discussed above. Therefore, if an age-related prize jury chooses to decide their winner by a single work, they are more likely to allow less experienced composers to be considered seriously. If an age-related prize were to choose a winner based on the body of work, however, the results would be skewed toward composers with more experience and therefore more music to show for it.

64 “Competition Overview," National Sawdust, https://nationalsawdust.org/hildegard/. 
The Pulitzer fits easily within the confines of these categories. As a single-work composition prize with no particular age requirements and mid-sized prize purse, its goal is not necessarily to generate new work. For many Pulitzer-winning composers, the $\$ 15,000$ they win will not affect their financial standing in a substantial way, especially in comparison with the Grawemeyer's $\$ 100,000$ award or the Polar Prize's $\$ 165,000 .{ }^{65}$ What the Pulitzer does well is fix the public's attention on the winning work, supporting its dissemination and popularization. This can have positive financial ramifications for the composer, but those effects are subsidiary; its primary purpose is to bestow the winner with cultural capital.

\section{Prizes Like the Pulitzer}

As a high-profile single-work prize, there are many awards of comparable procedure and stature to the Pulitzer. In the following section, I will describe two of these prizes, the Grawemeyer Award hosted by the University of Louisville and the now defunct Prix de Rome, of the French Académie de Beaux-Arts, awarded between 1803 and 1968.

The Grawemeyer Award is an international award for "outstanding achievement by a living composer." ${ }^{66}$ The Award was founded in 1984 and first awarded in 1985 by H. Charles Grawemeyer. Music was the first field that the prize awarded, but akin to the Pulitzer, also expanded to include five other categories: education, world order, psychology, religion, and spirit.

\footnotetext{
${ }^{65}$ The Polar Prize is worth 1,00,000 Swedish kronin, which causes the USD amount to fluctuate with the kronin's worth against the dollar. $\$ 165,000$ reflects the 2018 prize amount. Forbes,

https://www.forbes.com/sites/markbeech/2018/02/14/metallica-adds-nobel-prize-of-music-to-152-million-bonanzayear/\#28f4fb665119

${ }^{66}$ The Grawemeyer Award has been treated by Karen R. Little and Julia Graepel, Grawemeyer Award for Music

Composition: The First Twenty Years (Lanham, MD: Scarecrow Press, 2007).
} 
Table 2. Grawemeyer Award for Music Winners, 2008-2018.

\begin{tabular}{|c|c|c|c|}
\hline 2008 & Neruda Songs (2005) & Peter Lieberson & Mezzo-soprano and Orchestra \\
\hline 2009 & $\begin{array}{l}\text { The Lost Art of Letter } \\
\text { Writing (2006) }\end{array}$ & Brett Dean & Violin and Orchestra \\
\hline 2010 & Sphären (2001-2006) & York Höller & Orchestra \\
\hline 2011 & $\begin{array}{l}\text { La Commedia (2004- } \\
\text { 2008) }\end{array}$ & Louis Andriessen & Multimedia opera \\
\hline 2012 & $\begin{array}{l}\text { Violin Concerto (2008- } \\
2009)\end{array}$ & Esa Pekka Salonen & Violin and Orchestra \\
\hline 2013 & Up-Close (2010) & Michel van der Aa & Cello and Orchestra \\
\hline 2014 & $\begin{array}{l}\text { On the Guarding of the } \\
\text { Heart }\end{array}$ & Đuro Živković & Chamber Orchestra \\
\hline 2015 & No Award & & \\
\hline 2016 & let me tell you (2013) & Hans Abrahamsen & Soprano and Orchestra \\
\hline 2017 & Play $(2013 / 2016)$ & Andrew Norman & Orchestra \\
\hline 2018 & L'isola della Città (2016) & Bent Sørensen & Violin, Cello, Piano, and Orchestra \\
\hline
\end{tabular}

The Grawemeyer is an award for a single work, but as an international award, there are no specific citizenship requirements. Its only eligibility requirements relate to the kinds of works composers are allowed to submit: "large musical genres - choral, orchestral, chamber, electronic, song-cycle, dance, opera, musical theater, extended solo work, etc." ${ }^{67}$ Composers are not allowed to self-nominate, as one may with the Pulitzer. The entry form requires a signature from the nominator, who may be anyone with reasonable knowledge of the composer's work, including conductors, ensemble directors, and academics. After an initial screening of the nominees, three jurors are chosen. Usually, the jury is comprised of a composer (frequently a Grawemeyer winner), a conductor, and a critic. All nominated works are viewable on a database hosted by the University of Louisville's library, after the awards are announced. ${ }^{68}$

\footnotetext{
67 Ibid. 12

68 “Entry Lists by Year,” University of Louisville Libraries, Accessed March 26, 2019, https://library.louisville.edu/music/grawemeyer/entries
} 
A few marked differences stand out between the past decade of Grawemeyer winners above and the past decade of Pulitzer prize winners. Strikingly, the Grawemeyer has a distinct preference for Scandinavian and Dutch composers — of the eleven winners between 2008 and 2019, there are seven. Among these are shared teachers and institutions: Andriessen and van der Aa are a teacher-student pair, and Abrahamsen and Sorensen both studied at the Royal Danish Academy under Per Norgard. In the Grawemeyer winners more generally, there is also a tendency towards concertos. Again, there are six concertos, and all but three are purely instrumental. This is the reverse of the Pulitzer, which privileges voice much more heavily over instrumental music.

Another prize worthy of comparison is the Prix de Rome, sponsored by the Académie de Beaux-Arts from 1803 to $1968 .{ }^{69}$ For architecture and sculpture, the Prix de Rome was initiated centuries earlier, in 1663 by Louis XIV, making musical composition quite a late addition. It was added after the Académie was reorganized in the wake of Napoleon's restructuring of the French government after the revolution, for the purpose of fostering French musical culture. The Prix de Rome is a single-work prize, but its process was a little different from either the Pulitzer or the Grawemeyer. Composers who entered the competition first had to pass through and elimination round of exercises in counterpoint, then the finalists would write an entirely new piece under a strict time limit, usually a cantata. ${ }^{70}$ The pieces were to be judged by the musicians in the Académie, thus the jury stayed mostly the same from year to year. With more than a hundred and fifty years of prizewinners, including Claude Debussy, Hector Berlioz, Jules Massanet, Nadia

\footnotetext{
${ }^{69}$ Studies of the Prix de Rome include Jann Pasler, "State Politics and the 'French' Aesthetics of Prix-de-Rome Cantatas, 1870-1900," in Musical Education in Europe (1770-1914): Compositional, Institutional, and Political Challenges, vol. 2, eds. Michel Noiray and Michael Fend (Berlin: Berliner Wissenschafts-Verlag, 2005), 585-622; Fauser, "La guerre en dentelles"; Bloom, "Berlioz and the Prix de Rome of 1830."

70 Bloom, "Berlioz and the Prix de Rome of 1830," 282.
} 
Boulanger, and Lili Boulanger, the prize was among the most prestigious musical awards in France. The winners received a period of paid residency in Rome, with additional stipends provided in the following three years.

A few unique aspects of the Grawemeyer and the Prix de Rome are good points of comparison with the Pulitzer Prize. For example, the Grawemeyer has a two-year cutoff on possible submissions, where the Pulitzer only has a one-year cutoff. This means that composers are able to resubmit the same piece for consideration multiple times; several have won after extended periods of application with the same piece. Another notable point of departure is its large genre requirement. Interestingly, the Pulitzer used to have the same requirement, but the language was removed from the eligibility description for the 2001 prize. This situation is the reverse of the Grawemeyer, where the large-genre requirement did not originally exist, as evidenced by the fact that György Ligeti's Etudes for solo piano won in 1986. Although the Pulitzer's explicit requirement has vanished, the predilection for large genres remains. Smaller chamber works resembling Kate Soper's Ipsa Dixit and Andrew Norman's Companion's Guide to Rome have been nominated, and Henry Threadgill's five-member ensemble Zooid won in 2015, but for the most part, operas and concertos make up the vast majority of winners.

Another important difference among the three prizes is by whom they are judged. The Pulitzer appears to be unique among prizes that the final choice is left to a body of nonspecialists. The Grawemeyer's regulations stipulate that there must be a lay person involved in the selection, most other prizes for musical composition tend to be left to musicians. ${ }^{71}$ Here, the Pulitzer is more comparable to fellowships and grants that are awarded to multiple disciplines

\footnotetext{
71 "The History of the Grawemeyer Awards," Grawemeyer Awards, http://grawemeyer.org/award-categories-
} recipients/ 
(as in the Guggenheim Fellowships, and historical grants from the Ford Foundation or Rockefeller Foundation). In this model, broad disciplinary representation is a practical matter; because they are expected to fairly award in art, architecture, and other fields, juries are built from a combination of specialists and non-specialists. As we shall see in the coming chapters, the makeup of juries and the processes they follow are integral to determining which works win.

As an initiation of the transfer of cultural, political, and financial capital, culture prizes must be understood to be embedded within their field, influencing and being influenced by it in every moment. For this study of the Pulitzer, the mechanisms and function of culture prizes illustrates the reciprocal impact that the operatic winners of the Pulitzer and field of new opera have upon one another. However, an even fuller appreciation of their interaction can be gained with an in-depth knowledge of the history of the Pulitzer Prize. Joseph Pulitzer's vision for his prize, as well as the conflict between the prize's administrative board and various other institutions in the wake of Pulitzer's death are integral to understanding why the Pulitzer Prize for Music has picked the works it has, and how the winners have affected the musical landscape. 


\section{A History of the Pulitzer Prize \& Music}

"It's an American piece, but don't ask me to define that."1

Richard Wernick, Chair of the 1996 Pulitzer Prize for Music jury

American-ness, if not outright patriotism, has been central to the Pulitzer Prizes in all categories since their founding in 1911, yet neither Joseph Pulitzer nor his reluctant right-hand Nicholas Murray Butler ever articulated what that might mean. Interpretation was left to the juries and administrators of its early years, enacted by their selection of works such as Street Scene by Elmer L. Rice and The Age of Innocence by Edith Wharton. Prizes marked "American" stories and "American" values as they stood in Pulitzer's lifetime. Music, especially un-texted music, could not have succeeded by these standards, but a growing body of music by American composers began to imply that "American" music might have potential.

The Pulitzer Prize for Music was not part of Joseph Pulitzer's original bequest, but its creation in 1943 was justified by his legacy. The music prize was predated by a scholarship for students pursuing composition at Columbia University. The funding, which already existed was simply reallocated to a prize in music. As this chapter will show, however, the prize in music was tied both the original prizes' Victorian moral standards, as well as to the pugnacious stance toward a new notion of American music held by the administrators, and earlier by Pulitzer himself. I begin with a brief account of the origins of the Pulitzer Prizes, with specific attention to the establishment of the music prize in 1943.

\footnotetext{
1 Ralph Blumenthal, “A Pulitzer Winner's Overnight Success of 60 Years,” New York Times April $11,1996$. https://www.nytimes.com/1996/04/11/arts/a-pulitzer-winner-s-overnight-success-of-60-years.html
} 


\section{Joseph Pulitzer's Prize}

At the turn of the century, extravagant monetary gifts served not only as a declaration of one's wealth, but as a social obligation of the elite. Steel titan Andrew Carnegie exemplified this philanthropic bent, "holding that rich men are in effect the 'trustees' of their wealth and should administer it for the public's benefit." 2 To that end, Joseph Pulitzer hoped to achieve two goals: first, to prove that he stood among the elite, and secondly, to uphold the much-disparaged field of journalism. As a lifelong newspaperman, Pulitzer felt that journalism deserved recognition as "one of the great intellectual professions," having such prestige "exactly as if it were the profession of law or medicine." ${ }^{3}$ With his name and ostensibly, his values, Pulitzer's school of journalism and his prizes have memorialized his legacy for more than a century since his death in 1911.

Following Alfred Nobel more than a decade later, Joseph Pulitzer never intended to see the realization of his bequest. In an August 1902 memorandum, Pulitzer shared the germinal inklings for Columbia's school of journalism and the Pulitzer prizes; even nine years before he would die, he stipulated that no money was to be exchanged until five years after his death. Biographers speculate that the tumult of his final years, marred by his rapidly deteriorating health and a bitter, public feud with rival newspaperman William Randolph Hearst prompted this concern for his legacy. ${ }^{4}$ Although American life has changed immeasurably in the last hundred years, the main authoritative body of the Pulitzer Prizes, the Advisory Board, has adhered as

\footnotetext{
${ }^{2}$ Smith, "Foundations as Cultural Actors," 263-264. See also Hohenberg, The Pulitzer Prizes, 10. For the paradoxical moral shortcomings of Carnegie's perpetuation of a closed circuit of wealth distribution, see Joseph Wensink, "Literary Philanthropy: The Pulitzer Prize, Oprah's Book Club, and Contemporary U.S. Fiction" (Ph.D. diss., Brandeis University, 2012), 20-23.

${ }^{3}$ Hohenberg, The Pulitzer Prizes, 11.

${ }^{4}$ Douglas Bates, The Pulitzer Prize: The Inside Story of America's Most Prestigious Award (New York: Birch Lane Press, 1991), 11.
} 
strictly as possible to Joseph Pulitzer's original plan for his prizes. Even throughout the nine-year gap between the first memorandum and his will, which outlined much more specifically the structure of the prizes, the spirit remained the same.

As his own journalism was characterized as "unsparingly rigorous," and "public-spirited" Pulitzer's prizes sought to reward writing with the same kinds of qualities. ${ }^{5}$ Especially in the arts and letters, the phrasing of the awards upheld "a high-flown sense of morality, a sense of uplift, and self-sacrifice." 6

Annually, for the American novel published during the year which shall best present the whole atmosphere of American life, and the highest standard of American manners and manhood, One thousand dollars $(\$ 1,000)$.

Annually, for the original American play, performed in New York, which shall best represent the educational value and power of the stage in raising the stand of good morals, good taste, and good manners, One thousand dollars $(\$ 1,000)$.

Annually, for the best book of the year upon the history of the United States, Two thousand dollars $(\$ 2,000){ }^{7}$

These statements may seem innocuous and trivial, but in fact they defined the character and the scope of the Pulitzer Prizes for nearly fifty years. From these early days of the Pulitzer Prizes, the moralism displayed above, as well as the institutional collisions with Columbia University and the American Academy of Arts and Letters would have an indelible effect on their administration. In the 1920s and 1930s the rise to prominence of young writers brought with it an increased usage of, if not tolerance for foul language and once-taboo subjects such as violence, sex, and alcohol. ${ }^{8}$ This generational clash ignited a war between the juries who

\footnotetext{
5 Seymour Topping, "The Biography of Joseph Pulitzer." The Pulitzer Prizes. Accessed March 23, 2019. http://www.pulitzer.org/page/biography-joseph-pulitzer

${ }^{6}$ John Hohenberg, The Pulitzer Prizes, 19.

${ }^{7}$ Ibid.

${ }^{8}$ Numerous scandals surfaced surrounding the prizes in Fiction and Drama. When Sinclair Lewis was publicly revealed as the jury's first selection (which the Administrative Board had ignored) the Pulitzer Prize was thrust into
} 
submitted nominees for consideration and the prize's administrative board who ultimately selected the winners. This power struggle between the juries and the administration board was further compounded by the question of what role in awarding the prizes Columbia University's Board of Trustees ought to have.

From the beginning, Joseph Pulitzer and Columbia's president, Nicholas Murray Butler, did not see eye to eye on which entity should have the controlling interest. ${ }^{9}$ The School of Journalism and the Pulitzer Prizes were both proposed under the same $\$ 2,000,000$ gift, so Pulitzer recommended a brand-new governing body, to be called the Advisory Board. $\mathrm{He}$ thought the Advisory Board should oversee the both the school and the prize, sidestepping the authority of Columbia University and its Board of Trustees. Butler pushed back against this idea, arguing instead that the Advisory Board could exist, but ought to remain under the purview of the Board of Trustees. This debate quickly grew heated, and neither Pulitzer or Butler were willing to budge. Pulitzer described his exasperation in a letter to his friend George L. Rives, the chairman of Columbia's Board of Trustees:

You can scarcely conceive the worry I have had over the effort to satisfy myself about the character and the very limited powers of the Advisory Board...the unfortunate difference with Dr. Butler...compel me, although with great reluctance and unwillingness to adhere to the conclusions...to postpone the execution of the plan till after my death in order to save myself the vexation and disappointment. ${ }^{10}$

Further discussion of Pulitzer's donation was tabled until Pulitzer wrote the specifications for his prize into his will in 1911, essentially browbeating Butler into following his wishes. After

the spotlight on a local and national level. See Michael Schueth, "Willa Cather and Celebrity: The Writer's Self -image and the Literary Marketplace" (Ph.D. diss., University of Nebraska at Lincoln), 129-135.

${ }^{9}$ Nicholas Murray Butler was a powerful, forceful leader inside and outside the Pulitzer Prize. Parallel his role at Columbia University, he was a perpetually unsuccessful politician, running unsuccessfully as a Republican vicepresidential candidate (with the incumbent William Howard Taft) in 1912 and two subsequent runs for president in 1920 and 1928. Butler was also the recipient of the Nobel Peace Prize in 1931. See Steven Swayne, "William Schuman, World War II, and the Pulitzer Prize,” The Musical Quarterly 80, no. 2 (2006): 285.

${ }^{10}$ Hohenberg, The Pulitzer Prizes, 17. 
Pulitzer died, Butler was completely unable to sway his grieving estate, and thus all that Pulitzer wrote about the prizes in his will was taken as absolute authority. ${ }^{11}$ The inaugural Pulitzer Prize was slated to occur in five years.

Joseph Pulitzer's posthumous victory fostered a close relationship between his prizes and the Advisory Board, yet the relationship between the Advisory Board and the Columbia Board of Trustees was not addressed until preliminary meetings to initiate the prizes in 1915. Under the scrutiny of four members of the Advisory Board, President Butler began a draft of the official Plan of the Award, which with some modification is still used to administrate the Pulitzer Prizes today.

The first Pulitzer Prizes were awarded in 1916, under the supervision of Nicholas M. Butler and the Advisory Board. The proceedings ran smoothly, albeit without much press. Cowed by Pulitzer's stringent wording in his Plan of Award, jurors first made their decisions cautiously. They refused to award prizes rather than bully their way through more their more conservative colleagues. Letters prizes were prone to these issues; 1919 was a particularly difficult year, seeing no jury recommendation in Fiction, History, or Drama. ${ }^{12}$ Tired of their searches bearing frustratingly little fruit, some jurors began to test the waters. Fiction's Stuart Pratt Sherman, Biography's Paul Elmer More, and the majority of the drama jury made early moves to construe Pulitzer's phrasing broadly, if not ignore it altogether. They were put in a difficult position: remaining faithful to the original Plan of Award and rewarding the truly great

\footnotetext{
${ }^{11}$ A few edits were made by Nicholas Butler, who characterized them as minor and inconsequential. However, his change in the Fiction description from Pulitzer's original "whole" to "wholesome" set forth a fairly contentious debate with Fiction juror Stuart Pratt Sherman. Ibid., 55-57.

${ }^{12}$ A Fiction prize was in fact awarded in 1919, but only by an eleventh-hour intervention by Dr. Phelps, the chair of the committee, whose jury went along with a desperate and previously unconsidered suggestion (Booth Tarkington's The Magnificent Andersons) rather than not award the prize at all.
} 
work of their contemporaries would produce radically different results. ${ }^{13}$ Joseph Pulitzer was the product of a different America; the culture was changing fundamentally, and novels and plays were already reflecting a more tolerant attitude toward profanity and "the unwholesome".

Other jurors fought back against what they saw as a lapse in moral judgement. Drama juror Hamlin Garland vehemently refused to forsake the rules that Pulitzer wrote, which were especially specific in his home category. He referred constantly to its inclusion of the phrase "good morals, good taste, and good manners," using the words as proof positive that prizes for playwrights including Eugene O'Neill were entirely undeserved. O’Neill, who won twice within the first five years of the award (1920 and 1922 respectively) was known for his reinvigoration of American drama. His plays were brutally honest depictions of provincial life, characterized by Hohenberg as "harshly realistic" and "uncompromising". 14

The staunchly conservative Mr. Garland would not condone work so divergent from Pulitzer's wishes. As they were considering O'Neill for the Prize in 1922, a friend wrote of Garland, "Mr. Hamlin Garland has not seen Anna Christie, but feels sure that he would not like it and will not vote for it." ${ }^{15}$ O’Neill won nonetheless, but Garland's argumentation had consequences for the administration of prizes in the future. Hohenberg writes of the event: “Ignoring what Garland called the 'noble' and 'uplifting' terminology that Joesph Pulitzer had drafted for the drama prize, pointed to the direction in which future prizes would have to go if they were to reflect truthfully the growth of American theater."16

\footnotetext{
${ }^{13}$ As novelists embraced a more realistic approach to literature and turned their attention less to matters of the social elite and more toward perspectives of average citizens, their content conformed increasingly less to Joseph Pulitzer's stringent moral values. See Schueth, "Willa Cather and Celebrity," 130; See also Paul Fireston, "Educational Value and Power of the Pulitzer Prize Plays" (Ph.D. diss., Columbia University, 1969).

${ }^{14}$ Hohenberg, The Pulitzer Prizes, 45.

${ }^{15}$ Ibid., 53.

${ }^{16}$ Ibid., 49.
} 


\section{A Pulitzer Prize for Music}

After nearly thirty years of the Pulitzer Prize, the Advisory Board finally began to consider an additional prize for music composition. This was not at all due to any negativity on the behalf of the late Joseph Pulitzer. The European emigré was known to be a devoted attendee of the New York Philharmonic, bequeathing them $\$ 500,000$, an equal amount to what he promised Columbia University. ${ }^{17}$ Upon Pulitzer's arrival in the United States he, like many of his contemporaries, was dismayed by the nation's reliance on European musical talent. What he had hoped to find instead was a rousing American tradition. To that end, during his lifetime he established a scholarship fund for Columbia music students. His hope was to aid the bourgeoning attempts at establishing a musical style that was distinctly American.

In the 1940s, the situation had changed drastically. Not only had American students of composition entered a period of heightened productivity, there were more opportunities for American music students both in the United States and abroad than ever before. Columbia itself became home to the first doctoral program in composition, proposed by Roger Sessions at the behest of Milton Babbitt. ${ }^{18}$ Seeing an opportunity, Advisory Board member Douglas Moore suggested that they funnel the money from the scholarship fund into a new Pulitzer Prize for Music Composition instead. ${ }^{19}$ Citing the Prix de Rome, composition fellowships at Juilliard and the Curtis Institute, and the Guggenheim Fellowship, Moore admitted that "the amount of

\footnotetext{
${ }^{17}$ Heinz-Dietrich and Erika Fischer, Musical Composition Awards 1943-1999: From Aaron Copland and Samuel Barber to Gian-Carlo Menotti and Melinda Wagner (Munich: De Gruyter Saur, 2011), xvii.

${ }^{18}$ Using a model based upon doctoral programs in the hard sciences, Milton Babbitt proposed the creation of a Ph.D. in music at his home institution, Princeton University. The instantiation of this program channeled resources and prestige, consolidating an elite group of composers within the same network. See Rachel Vandagriff, "Perspectives and the Patron: Paul Fromm, Benjamin Boretz and Perspectives of New Music," Journal of the Royal Musical Association 142, no. 2, (2017): 327-365.

19 Douglas S. Moore was himself a composer, and a previous recipient of the Pulitzer Scholarship in music composition, which afforded him the opportunity to study in Paris with Nadia Boulanger in 1926. See Donald Reagan, "Douglas Moore and his Orchestral Works" (Ph.D. diss, Catholic University of America, 1972), 9.
} 
opportunities somewhat exceed the amount of available talent." ${ }^{20}$ By advocating for a Pulitzer Prize in Music, he hoped to promote the most superlative American music, especially important at a time when the United States was entering into a period of global cultural instability. ${ }^{21}$

The first prizes for music composition were given in 1943, following a newly composed guideline: "For a distinguished musical composition by any American in any of the larger forms, including chamber, orchestral, choral, opera, song, dance, or other forms of musical theatre, which has had its first performance in the United States during the year."22 The first jury comprised Chalmers Clifton, Quincy Porter, and Alfred Wallenstein, who set about soliciting applications. Their position was unique among Pulitzer juries, as they were required to select a winner without first having secured a pool of applicants; the jurors made a careful survey of all the works performed or published in 1943, unanimously agreeing that William H. Schuman's "Secular Canata No. 2, A Free Song" should win. ${ }^{23}$ William H. Schuman was a 1935 graduate of the Teacher's College at Columbia University, and already highly visible in a prominent position teaching composition at Sarah Lawrence. The jury's selection of an ivy-league educated composer would have resounding consequences far, far into the Pulitzer for Music's future.

If the jurors were looking to prove music's American-ness in the first award, they found a rousing success in Schuman's Secular Cantata. ${ }^{24}$ It was a logical choice not only for the political and patriotic themes in the text (drawn from Walt Whitman's Leaves of Grass) but also in the

\footnotetext{
20 Ibid.

${ }^{21}$ Steven Swayne argues that World War II, rather than the recently announced Stalin Prize may have contributed to their seeing the prize as a "national obligation." See Steven Swayne, "William Schumann, World War II, and the Pulitzer Prize," Musical Quarterly 89, no. 2 (2006): 287.

${ }^{22}$ The music composition description followed the example set by revisions to the Fiction prize, for which the word "best" was replaced with "distinguished" in 1936. See Winsink, "Literary Philanthropy," 49.

${ }^{23}$ The jury solicited works from a number of composers. Although Schuman's "A Free Song” won the prize, the work that the jury recommended for submission was actually his symphony. Heinz-Dietrich \& Fischer, Musical Composition Awards, xviii.

24 Even William Schuman himself was well-known for his quasi-propagandist efforts to use music to promote democracy. See Swayne, "William Schuman," 277-280.
} 
story of its origin. In 1942, the second world war was well underway and the American call for enlistment was beginning to pick up steam. William Schuman plead desperately to be allowed entrance into the ranks of United States Army's Specialist Corps, directed by Harold Spivacke. In a letter to Spivacke, Schuman wrote: "I feel that part of being patriotic is to continue to do creative work as long as it is humanly possible to do so. If, however, this can be coupled with a direct war job in music, I am prepared to offer my services." 25 Even after repeated attempts and months of correspondence, Schuman's numerous and not-insignificant maladies forced the army to reject his application out of hand. ${ }^{26}$

Undeterred, Schuman made his musical contribution instead from the ranks of the civilian supporters. The resulting work, which had undergone multiple changes in title, was finally christened A Free Song: Secular Cantata No. 2. He proffered this work to Spivacke, hoping one final gesture of patriotism would move the man to allow him entrance, but again Schuman was denied.

Table 3. The Pulitzer Prizes in Music, 1943-1953, and the Prize Juries.

\begin{tabular}{|l|l|l|}
\hline Year & Winner and Winning Work & Members of the Music Jury \\
\hline 1943 & $\begin{array}{l}\text { William H. Schuman, Secular Canata } \\
\text { No. } 2\end{array}$ & Chalmers Clifton, Quincy Porter, Alfred Wallenstein \\
\hline 1944 & $\begin{array}{l}\text { Howard Hanson, Symphony No. 4, Op. } \\
34\end{array}$ & Chalmers Clifton, Philip James, Otto C. Luening \\
\hline 1945 & Aaron Copland, Appalachian Spring & Chalmers Clifton, Henry Cowell, Otto C. Luening \\
\hline 1946 & Leo Sowerby, Canticle of the Sun & Chalmers Clifton, Aaron Copland, Howard Hanson \\
\hline 1947 & Charles Ives, Symphony No. 3 & Chalmers Clifton \\
\hline
\end{tabular}

${ }^{25}$ Joseph Polosi, American Muse: The Life and Times of William Schuman (New York: Amadeus Press, 2008), 70. ${ }^{26}$ Ibid. 


\begin{tabular}{|l|l|l|}
\hline 1948 & Walter Piston, Sympony No. 3 & $\begin{array}{l}\text { Nicolai Berezowsky, Chalmers Clifton, Beveridge } \\
\text { Webster }\end{array}$ \\
\hline 1949 & $\begin{array}{l}\text { Virgil Thomson, soundtrack to } \\
\text { Louisiana Story }\end{array}$ & Chalmers Clifton, Henry Cowell, Beveridge Webster \\
\hline 1950 & Gian-Carlo Menotti, The Consul & Chalmers Clifton, Isadore Freed, Otto C. Luening \\
\hline 1951 & Douglas S. Moore, Giants in the Earth & Chalmers Clifton, Norman Lockwood \\
\hline 1952 & Gail T. Kubik, Symphony Concertante & Chalmers Clifton, Norman Lockwood \\
\hline 1953 & No Award & Chalmers Clifton, Wallingford Riegger, Bernard \\
& & Wagenaar \\
\hline
\end{tabular}

On the musical front, Schuman's work met with middling success. Critic Virgil Thomson lambasted the premiere performance, writing:

The title...refers, I take it, since the composition is partly fugal in style, not to musical freedom but to freedom of some other kind, economic, social, religious, amorous, or political, no doubt...The music's intrinsic interest seemed...to add up to a not high figure. ${ }^{27}$

Thomson's 4 April 1943 review was dismissive of the work's purely musical merits, implying that its success was owed to its social and political context. Yet, the following week, it was unanimously confirmed as the first winner of the Pulitzer Prize for Music by a jury chaired by Chalmers Clifton. Although the exceedingly short duration between Schuman's premiere and his Pulitzer win did not allow jurors to evaluate the work with the aid of critical response, Schuman and his previous works were likely well known. He had won the inaugural New York Music Critics' Circle Award in 1942, as well as a Guggenheim Fellowship. In addition to the rousing success of his first "Secular Cantata," he was also a recent recipient of the a Ford Foundation

\footnotetext{
${ }^{27}$ Quoted in Swayne, "William Schuman," 277.
} 
grant administered by its Young Composers Program, which sent him into the public schools to educate young musicians, a task which Schuman undertook with enthusiasm. ${ }^{28}$

As exemplified by the case of William Schuman, the juries chose works that represented what to them was the height of American composition, an idea which shifted with successive generations of composers. However, the construction of these juries led it down a problematic route - the juries tended mostly to repeat themselves. These juries were decided by the first Prize Administrator, Frank Diehl Fackenthal, the de facto administrator from 1917 until 48. The repetitiousness of his selections may be due to simplicity's sake, given that he was also tending to, corralling, and cajoling the jurors of the other categories. ${ }^{29}$ The model of the Pulitzer's early years in the 1910s and 1920s seemed, and by the initiation of awards for music, it is clear that the juries were usually more the same from year to year than they were different.

Personal ties made important connections in securing the first Pulitzer jurors. Inaugural chairman Chalmers Clifton was an adjunct faculty member at Columbia University, a colleague of Board members Douglas Moore and Fackenthal. ${ }^{30}$ Additionally, Clifton had served as the New York director of the Federal Music Project, an extension of Franklin Deleano Roosevelt's Works Progress Administration, an experience common to both Moore and Schumann. Because Clifton served on the panel for seventeen consecutive years, from the Prize's inception in 1943 through 1960, he quickly became a trusted Pulitzer affiliate; his own connections were integral in

\footnotetext{
${ }^{28}$ Paul Covey, "The Ford Foundation-MENC Contemporary Music Project (1959-1973): A View of Contemporary Music in America" (Ph.D. diss., University of Maryland, 2013), 6.

${ }^{29}$ The similarity in jury construction is even more apparent in the very beginnings of the Prizes for Fiction, Biography, Drama, etc, given that the whole jury could stay the same for several consecutive years. See Heinz-Dietrich and Erika Fischer, Chronicle of the Pulitzer Prizes in Fiction: Discussions, Decisions, and Documents (Munich: De Gruyter Saur, 2011), 44-64.

${ }^{30}$ Swayne, "William Schuman," 300.
} 
identifying future jurors. ${ }^{31} \mathrm{~A}$ constellation of other composers surrounded Clifton, although their participation was more intermittent. ${ }^{32}$

The first decade of the music prize displays two important themes which would recur for nearly 50 years. First, that its juries became increasingly more stagnant; the majority of jurors were Pulitzer affiliates, following a nomination to finalist or a win with multiple jury services, stretched over long periods of time. ${ }^{33}$ Secondly, that juries responded well to vocal works, which would become a significant proportion of its awards through the 1970s. Importantly, these works were not confined just to operatic genres, and represented many different strategies for the treatment of the voice. Although opera would be a dominant genre until Samuel Barber's 1958 Vanessa the surfeit of operatic works would eventually be replaced by vocal-orchestral combinations in the decades to come.

\section{Opera of the Mid-Century and Beyond}

The Pulitzer's treatment of narrative vocal works, especially opera, ran mostly parallel to the state of opera in the field at large. While there was a strong model for opera in the century before, it was becoming increasingly clear that the grand opera of the nineteenth century was not as attractive to middle-class American audiences of the mid-twentieth century. ${ }^{34}$ However, many of the operatic institutions of the early twentieth century did not appear to factor such societal

\footnotetext{
${ }^{31}$ Heinz-Dietrich and Fischer, Musical Composition Awards, xviii-xxvi.

${ }^{32}$ Nearly all of the first decade's jurors were board members of the recently-initiated American Composers Alliance, had ties to the Franklin Deleano Roosevelt's Works Progress Administration's music arm, the Federal Music Project. See Susan Richardson, "Defining a Place for Composers: The Early Histories of the American Composers Alliance and the American Music Center, 1937-1950" (Ph.D. diss., Indiana University, 1997), 167.

${ }^{33}$ Composer Robert E. Ward's service was more sporadic, but his fourteen decisions spanned a period of 50 years. See appendix; See also Chapter Three.

${ }^{34}$ At the time, "grand opera" was the general term of choice for serious opera of the previous generation, rather than a specific term for $19^{\text {th }}$ c. French opera. See Christopher Lynch, "Opera and Broadway: The Debate over the Essence of Opera in New York City, 1900-1960" (Ph.D. diss., State University of New York at Buffalo, 2013), 20.
} 
preferences into their programming. Although strong commissioning programs during the 1910 20s gave American opera a strong start, the Metropolitan Opera of New York City would begin to restrict their programming, increasingly turning to foreign-language productions of Italian and German serious opera. ${ }^{35}$ This coincided with a strong presence of light, comic opera or operetta which were beginning to move from opera houses to Broadway. Their convergence provided the fertile ground for a new vision of American opera of the midcentury to flourish.

The 1930s were a breaking point for opera composers; it was becoming obvious that they could no longer rely on European operatic models of the past, and they were unsure where to turn for inspiration moving forward. The confusion (of composers and critics alike) was reflected in the discourse-Theodor Adorno, Hans Heinsheimer, and William Saunders all wrote speculative essays attempting to discern the emergent identity of American opera. ${ }^{36}$

Table 4. Vocal Music Works Winning the Pulitzer Prize before 1960.

\begin{tabular}{|l|l|l|l|}
\hline 1943 & Secular Cantata No. 2 “A Free Song” & Cantata & William Schuman \\
\hline 1946 & Canticle of the Sun & Choir & Leo Sowerby \\
\hline 1950 & The Consul & Opera & Gian Carlo Menotti \\
\hline 1951 & Giants in the Earth & Opera & Douglas S. Moore \\
\hline 1955 & The Saint of Bleecker Street & Opera & Gian Carlo Menotti \\
\hline 1958 & Vanessa & Opera & Samuel Barber \\
\hline
\end{tabular}

The Pulitzer's early operas, including Gian Carlo Menotti's The Consul and Samuel Barber's Vanessa, demonstrate the organization's artistic preferences at the time. In The Consul, Menotti

\footnotetext{
${ }^{35}$ Later commissioning programs, including the New York City Opera's commissions between 1958-1960 were direct contributors to Pulitzer affiliates, including the 1967 Pulitzer winner The Consul by Gian Carlo Menotti, in addition to new works by prizewinner Douglas Moore, The Ballad of Baby Doe and The Devil and John Webster. See Tedrin Blair Lindsay, "The Coming of Age of American Opera: New York City Opera and the Ford Foundation" (Ph.D. diss, University of Kentucky, 2009).

${ }^{36}$ In chronological order, the essays referred to are Theodor Adorno's 1930 review of Brecht \& Weill's "Mahoganny"; William Saunders "Opera: Has it arrived?" in 1932; and a series of articles by Hans Heinheimer called "Opera Today" in 1945, 1947, and 1951. See Lydia Goehr "Amerikamüde/Europamüde: The Very Idea of American Opera," Opera Quarterly 22, no. 3 (2006): 426-429.
} 
contributed both the score and the libretto. The basis for the opera's plot is an opposition to "faceless bureaucracy" of American politics—a sentiment likely fresh in the minds of its viewers in the wake of the Great Depression, and the numerous and costly government programs that remained after it ended. Certainly, among a general theater-going audience, it was popular, although it "moved toward a more art house orientation before disappearing out of sight". ${ }^{37}$ Indeed, after eight months in New York City, The Consul premiered at La Scala in 1951, garnering a New York Drama Critics' Circle Award in addition to its Pulitzer.

Lydia Goehr notes that this strategy of introducing a politically engaged plot was something of a trope in early American opera, and one that Pulitzer juries were interested in maintaining. ${ }^{38}$ Based on ideas laid out in Hans Heinsheimer's essays on the history and state of American opera in the mid-nineteenth century, a democratic narrative should be "more popular in appeal and more suitably directed toward the full range of American interests and tastes." ${ }^{39}$ The Consul's "Broadway melodic charm" and explicitly political dramatic content represent a distinct shift from the elitism on which the Metropolitan Opera was founded. ${ }^{40}$ For these reasons, it exemplified in a more concrete and moving way that a differentiable American music was forming; it made a very convincing Pulitzer candidate, and as the first opera in name, a foundational choice to which Pulitzer juries would look back. Other operatic winners also reflected the Pulitzer's preference for depictions of American life in other categories. Douglas S. Moore's Giants in the Earth (1951 winner) follows the lives of Norwegian immigrants to the

\footnotetext{
${ }^{37}$ Edward Clark, "Gian Carlo Menotti's 'The Consul”" Musical Opinion, 1.

${ }^{38}$ This would be classified as a Democratic Narrative of American opera. For a more detailed explanation, see Goehr "The Very Idea of American Opera," 418-22.

${ }^{39}$ Ibid.

${ }^{40}$ Edwards, "The Consul," 1; Goehr, "The Very Idea of American Opera," 418.
} 
Dakota Territories, and 1952 finalist Letters to Emily by Lockrem Johnson depicted the feminist rebellion against Victorian norms in the life of Emily Dickinson.

Coincidentally, Gian Carlo Menotti also had his hand in another early operatic Pulitzer winner, Samuel Barber's Vanessa. It was Barber's first full-length opera, and after failing to find a suitable libretto for several years, Menotti volunteered to provide the text. ${ }^{41}$ Interestingly, the story that Menotti chose for the work does not conform to the American "by Americans, for Americans" approach discussed above. Instead, the story is "European-based, presumably Scandinavian...According to Barber, Menotti chose a European setting because of the difficulty he encountered while writing in an 'American dialogue.",42 While Vanessa was hugely successful in its premiere, its reception at the Salzburg Festival and a second run at the Metropolitan opera in 1958 were disastrous. ${ }^{43}$ Close on the heels of Barber's Pulitzer win, these failures could indicate that Europeans were not yet ready to accept American opera.

Why would a work whose critical success was so sporadic and whose plot so unpatriotic win a Pulitzer? The jury's commentary on the subject is telling: Chalmers Clifton, Norman Dello Joio, and Paul H. Lang wrote that Barber "has a great talent for the lyric theater and [an] amazing understanding of operatic techniques." ${ }^{44}$ A possible explanation lies in a shift from the justificatory stance of a newly founded prize to one which no longer felt pressured to conform to non-idiomatic standards in other disciplines. An opera like Vanessa could certainly display American themes and values, but how could a juror compare a texted, dramatic, staged work to a symphony or a string quartet? Given the lack of attention brought to political themes after the

\footnotetext{
${ }^{41}$ Poxon, "From Sketches to Stage," 2.

42 Ibid., 3.

43 Ibid., 11.

${ }^{44}$ Heinz-Dietrich and Fischer, Musical Composition Awards, xxiv.
} 
first few years of the Pulitzer Prize for Music and their emphasis on formal attributes, it is possible that Pulitzer jurors were becoming less attached to the priorities expressed at its outset.

After Barber's 1968 win, another work explicitly termed an opera would not win again until the year 2000. During that period between the late 1960s and the early 1970s, the Ford Foundation actually redoubled its efforts towards opera, seeing that its orchestral programs were not effective. ${ }^{45}$ Following a successful partnership with Julius Rudel, the director of the New York City Opera Company, the Ford Foundation was eager to build upon what its previous efforts' establishment of a "core repertory" of American operas. In what they called the second phase of their project, four major opera companies were to receive large sums explicitly for commissioning and staging new American operas: The Chicago Lyric Opera, the Metropolitan Opera, the New York City Opera, and the San Francisco Opera. ${ }^{46}$

Following the Tax Reform Act of 1972, private foundations severely curtailed their programs - in 1974, the Rockefeller Foundation considered pulling out of music altogether. ${ }^{47}$ In the same year, W. McNeil Lowry retired as president of the Ford Foundation, and the following president reduced the music budget by more than two-thirds. ${ }^{48}$ Opera was not a very costeffective musical outlet, and with less support for programming and running the day-to-day affairs, commissions quickly became less important. Yet, opera's disappearance from the field and from the Pulitzer did not equate to an absence of works for voice. The six non-theatrical vocal works represent nearly $20 \%$ of Pulitzer winners between 1968 and 2000, and the gaps between wins span nine years at maximum, and typically between two and four.

\footnotetext{
${ }^{45}$ Uy, "The Big Bang in Arts Patronage," 52-53.

${ }^{46}$ The two programs (the first only for the NYC Opera beginning in 1957 and the second expanded one beginning in 1959) were not originally connected, but retroactively bound together by Ford Foundation president W. Lowry. Tedrin Blair Lindsay, "The Coming of Age of American Opera," 392.

${ }^{47}$ See Uy, "The Big Bang in Arts Patronage," 46.

${ }^{48}$ Ibid., 62-3.
} 
Table 5. Vocal Music Works Winning the Pulitzer Prize between 1975 and 1996.

\begin{tabular}{|l|l|l|l|}
\hline 1975 & From the Diary of Virginia Woolfe & $\begin{array}{l}\text { Medium Voice \& } \\
\text { Piano } \\
\text { song cycle }\end{array}$ & Dominick Argento \\
\hline 1977 & Visions of Terror and Wonder & $\begin{array}{l}\text { Mezzo Soprano and } \\
\text { Orchestra } \\
\text { (song cycle) }\end{array}$ & Richard Wernick \\
\hline 1980 & In Memory of a Summer Day & Soprano and Orchestra & David Del Tredici \\
\hline 1984 & Canti Del Sole & $\begin{array}{l}\text { Tenor and Orchestra } \\
\text { Song cycle }\end{array}$ & Bernard Rands \\
\hline 1987 & Flight into Egypt: Sacred Ricercar & $\begin{array}{l}\text { Solo soprano and } \\
\text { baritone, chorus, and } \\
\text { chamber orchestra }\end{array}$ & John Harbison \\
\hline 1996 & Lilacs & Soprano and Orchestra & George Walker \\
\hline
\end{tabular}

Akin to their instrumental counterparts, the vocal winners during this period conveyed narrative only abstractly, by separating themselves from theatricality. Many of the pieces mentioned above told stories and found their basis in literature and poetry, but importantly, they remained unstaged. This emphasis on purely musical matters (rather than extramusical associations) runs through the jury's commentary in each of these pieces. George Walker's Lilacs is described as a piece which is "masterful and rigorous, one that deepens with successive hearings yet grips an audience from the first." 49 Similarly, David Del Tredici's music was considered notable for its accessibility. Critic John Rockwell reported that "What makes his music epitomize the trend toward a greater openness is its unashamed tonal harmonies." ${ }^{50}$ While descriptions of these Pulitzer wins may mention in one sentence or less the subject matter at hand

\footnotetext{
${ }^{49}$ Ralph Blumenthal, "Pulitzer Prize Winner - No Electronics, All He Needs is a Piano: American Composer George Walker is the First Black Recipient of the Prestigious, Annual Award for Music," Vancouver Sun, April 12, 1996.

${ }^{50}$ John Rockwell, "Del Tredici-His Success Could be a Signpost," The New York Times, October 26, 1980.
} 
(literary themes from Alice and Wonderland, religious texts, and the celestial movement of the sun, for example) they focus mostly on the details of their premiere. ${ }^{51}$

With the 2000 win of Life is a Dream by Lewis Spratlan, the dearth of operatic works became the subject of some debate. A concert performance of the opera was indeed premiered in 2000 by members of the Boston-based chamber ensemble Dinosaur Annex, but the work was completed in the mid-1970s. The piece sat on a shelf for nearly two decades before Spratlan could find a company to perform it:

I was at the time in my 30s, and I did not have any kind of track record as an opera performer. Operas are expensive to put on, as you know, and opera companies are a bit nervous about going into territory which they consider to be uncharted as far as the general public and their familiarity with the composer. I think that's part of it. Part of it is also that it's a difficult piece. I don't think it's any more difficult than many other operas, but there was a certain amount of risk involved, and there may have been factors even beyond that, that I wasn't aware of. $^{52}$

Spratlan's statement captures the difficulty operatic composers faced at the end of the twentieth century. Scarce resources were distributed to those who were seen as having the most likelihood of success, that is, large orchestras. ${ }^{53}$ The rise of capable chamber ensembles and their implantedness in entrepreneurial models changed the state of affairs, evinced by the Pulitzer winners of the $21^{\text {st }}$ century. ${ }^{54}$

\footnotetext{
${ }^{51}$ This stands in contrast to the jury descriptions at present, which will be treated in more detail in Chapters Four and Five.

${ }^{52}$ Lewis Spratlan, in interview with Elizabeth Farnsworth of The NewsHour with Jim Lehrer, April 18, 2000.

${ }^{53}$ Several momentous operas were premiered in the United States, and therefore eligible for Pulitzer Prizes, but were not acknowledged as finalists or winners. These include most notably minimalist works, like Philip Glass's operas Einstein on the Beach in 1976 and Satyagraha in 1980, as well as Steve Reich's video opera The Cave in 1993 among others. For the more on these works and their reception, see Ryan Ebright, "Echoes of the Avant Garde in American Minimalist Opera" (Ph.D. diss., University of North Carolina at Chapel, 2014).

${ }^{54}$ Entrepreneurial models espoused by chamber ensembles like the International Contemporary Ensemble and Eighth Blackbird are credited with a revival of the contemporary concert tradition. See Moore, "Neoliberalism and the Musical Entrepreneur," 34.
} 


\section{The Pulitzer Prize of the $21^{\text {st }}$ Century: Process}

In the present day, the process of awarding a Pulitzer Prize for music takes nearly a year to complete. Any work premiered in the United States between January 1 and December 31 are eligible for the next year's prize, so the portal for entry opens sooner than for many of the other disciplines, around mid-May. Anyone can nominate a work, so long as it reflects their "current creative activity," a phrase likely included in the eligibility requirements to prevent the submission of works which were written much earlier, but not premiered until more recently. ${ }^{55} \mathrm{It}$ is also possible to submit recordings of works, which is typical of composers who are submitting non-notated works (including jazz and popular music) for consideration, although eligibility is limited to recordings "first performed and recorded not earlier than two years prior to its public release date. ${ }^{~}{ }^{56}$ An entry fee of $\$ 50$ is required, an entry form (including the date and location of premiere performance, length, and instrumentation), recordings, a biography and picture of the composer, and if appropriate, the score. Physical materials are sent to the Pulitzer Prize Office, housed at Columbia University. ${ }^{57}$

Once all the submissions are collected and the submission portal closes on December 31, the review of submissions begins. At this point, a jury is assembled by the prize administrator; its membership includes three composers (one of whom is guaranteed to be a previous Pulitzer winner), one music critic, and "one presenter of musical work". ${ }^{58}$ Throughout the year, these five jurors begin to sift through a gargantuan number of submissions. They are coordinated by one member of the jury who is designated as the chair, and guided by a statement which has been left

\footnotetext{
55 "Music Submission Guidelines and Requirements." The Pulitzer Prizes. Accessed May 252018 http://www.pulitzer.org/page/music-submission-guidelines-and-requirements

56 "How to Enter," The Pulitzer Prizes, Accessed May 25, 2018 http://www.pulitzer.org/page/how-enter

${ }^{57}$ Starting in the 2019 prize cycle, the fee has been increased to $\$ 75$ per entry.

${ }^{58}$ The presenter is an ambiguous term, and has been interpreted variously to mean a performer, curator, a scholar, or an arts administrator.
} 
mostly unrevised since the music prize's inception in 1943: "For distinguished musical composition by an American that has had its first performance or recording in the United States during the year." 59

A few months after the submission deadline, the music jury meets at Columbia University. Where over the preceding months, they had been compiling their lists of individual preferences, their task now is to narrow the pool of contestants down to three finalists. Their discussions at Columbia are of utmost importance to the selection of the three because it is the collective identity of the jury, guided by the statement for music in the Plan of Award that dictates who the finalists are. The jurors make a list of three unranked nominations, and are allowed to write comments detailing their opinions of the selections.

Jurors are not, however, voting members - their list of finalists are simply recommendations to the Advisory Board. One weekend in early April, the Advisory Board then convenes at the Pulitzer offices at Columbia, and at this time they make the decisions for all 21 Pulitzer categories. It's an arduous and time-consuming process. The Advisory Board, made up mostly of distinguished journalists, must be thorough beyond reproach, taking care to consider each nominated work (usually between 100 and 150 in all) in great detail. They listen to each of the three musical selections and discuss in great detail, relying on the jury's written commentary to help guide them through the process. The jurors are not present during these discussions, which leaves the Administrative Board to arrive on a decision more on their own authority and opinion. The winner is decided by majority vote, but the board members retain the options to determine "no award" or select another work that was not nominated by the jury, needing a three-fourths majority for the latter option. In the case that the Board is unhappy with all three of

\footnotetext{
59 The only change was the word "distinguished" had previously been "the best."
} 
the jury's recommendations, the Prize Administrator may call the chair of the jury, who may make alternative suggestions. Finally, the Administrative Board votes and submits their choices to the Prize Administrator.

In mid-April, one week after the Administrative Board's decision is made, the winners are announced to the public in a scripted press release, live-streamed for free to the public. Music is announced last, and in addition to the winning composer and work, the Prize Administrator reads the jury comments that provide something of a rationale for their choice. The shortlist is released a few hours later on the Pulitzer's website, providing yet more fodder for the op-ed journalists and think-piece writers who have already begun a frantic storm of commentary. From the beginning of the submissions to the announcement of the winner, the results are dictated largely by the process. At every step, there are specific roles and requirements that the participants (be they entrant, juror, or administrator) must follow strictly, which by definition throw some compositions out of the running and thrust others into the spotlight. These matters of decision making (and occasionally, subterfuge) will be described in detail in the following chapter.

Even within the short span of just over 50 years, the Pulitzer Prizes from 1943 until 2000 reflect the changing priorities of Pulitzer juries. From an insistence upon political contexts and a diverse array of musical media to a more consolidated, traditional view of genre, the prizewinners evince key shifts of the musical landscape, albeit from only one perspective. At its very beginning the Pulitzer Prize was influenced by reigning ideals of music as exemplified by 
those in power at the midcentury. As Chalmers Clifton and Otto Luening faded from view, they were replaced by the winners they chose, creating a conservative and consolidated view of American music at the time. In the twenty-first century, it is clear that changes in policy and administration have resulted in a widening of truly eligible possibilities. In some ways, Pulitzer juries and Boards have taken advantage of this diversification; yet somehow, a consolidation of different priorities has taken place. In the following chapters, I will discuss the similarities and divergences of the body Pulitzer finalists. 


\title{
3
}

\section{Winners in Waiting: Pulitzer Juries and Finalists}

\author{
March 3, 2017
}

As the close-of-business foot traffic floods the sidewalks of Manhattan, more people than usual are attempting to fight their way through the throng. A line of pedestrians fills out into a crowd at the corner of Broadway and $W .116^{\text {th }}$, where journalism students and their professors are waiting to cross the street to the nearby subway station. Today, however, five conspicuously out-of-place musicians are dispersed among them..

Evan Ziporyn, Carol Oja, John Brown, and Jennifer Higdon will soon leave the city. Only critic Alex Ross will remain in New York, leaving behind the three pieces still buzzing in his head to focus on the imminent premiere of Esa-Pekka Salonen's new cello concerto. It is no easy task; after weeks of intense concentration on Kate Soper's "philosophy opera," how can anything displace it? His review of the event was just published, and happily, the piece has earned a place among the three finalists. For now, that fact is unknown to all except Ross and his colleagues on the jury. But their obligation - and their influence - is now behind them. Soon, Kate Soper's work, along with an opera by Du Yun and a symphony by Ashley Fure will be forwarded to the Board. At this point, the jury's preferences, however strong, are rendered moot. When the dust settles, a winner will be declared. But for the moment, these pieces are all winners in waiting.

Over the next few weeks, the Pulitzer's Advisory Board began to sift through not just three musical finalists, but a seemingly endless stream of op-ed articles, features, cartoons, breaking news, Broadway shows, and books. For the nineteen individuals on the 2017 Pulitzer Board, it was an immensely time-consuming process, but a necessary sacrifice to make their forthcoming April meeting productive enough to choose winners in seventeen categories. No circumstances surrounding these pieces' commissioning and performance would elicit comparison, but the Pulitzer's jury submitted them to an artificial competition, where they were not evaluated individually, but against one another. In the weeks following the imagined account above, the Board's comparisons of apples to oranges surely inspired ideological battles. 
As the Pulitzer's rules stipulate, the equal finalists must be chosen unanimously, requiring all the jurors to agree that any one of the three is deserving of a Pulitzer Prize. Reviewing the list of 33 finalists (at least since 2008) elucidates a slightly broader picture of "distinguished" works of American music, as evaluated by the jury of music specialists, on whose expert judgement the Pulitzer's legitimacy relies. Before the official announcement of a winner, the finalists for the Prize (including those not-yet-named winners) represent more abundantly the evidence for the Pulitzer's the state of American music than the winners alone. This chapter will turn first to the jurors, the Pulitzer's ambassadors to the musical field who select the finalists. I will discuss their role as musical experts, the process of mediation through which they render their decisions, and the Pulitzer administration's changes to the jury's structure. Finally, I will discuss the finalists chosen between 2008 and 2018, positing certain important similarities that recur throughout the decade.

\section{The Role of the Juries}

The Board may be responsible for choosing the next representative of American music, but the jury completes a task which is arguably more crucial. In winnowing more than one hundred applicants to three equal finalists, the jury's responsibility is essentially, to determine which works will not win. As such, their role necessitates a close relationship to the field. ${ }^{1}$ As people with deep, practical experience in the musical field, juries are "contributory experts," whose knowledge is contingent upon long periods of social immersion or "extensive personal

\footnotetext{
${ }^{1}$ Sociologists Harry Collins and Robert Evans have created a graphical representation of different varieties of expertise, which they have labelled The Periodic Table of Expertise. See Harry Collins and Robert Evans, Rethinking Expertise (Chicago: University of Chicago Press, 2007). A copy of the table can be found in the Appendix.
} 
and social contact" with other musical practitioners. ${ }^{2}$ Their role is to enact what Bourdieu calls the arbitration of taste- by eliminating most of the works from consideration by the Advisory Board, they determine that some are more valuable than others.

Necessarily, juries are comprised of several individuals. ${ }^{3}$ At present, the Pulitzer's jury totals five members. This is a valuable safeguard for the validity of the prize; no one juror's biases can skew the selection. Jurors come from different backgrounds with different musical values and priorities, and they must mediate these against the identities of their colleagues. Pulitzer juries of the twenty-first century have incorporated specialists in jazz (including David N. Baker, 1995-2007, and Regina Carter, 2016 and 2018) with the hope that the mixing or blending of aesthetic identities would lead to diverse choices, in contrast with other awards where such diversity is not present. ${ }^{4}$ Juries' individual musical identities are mediated by their amalgamation, as well as by the Pulitzer's mission. As a collective, the jury thus arrives at a new aesthetic identity.

Although culture prizes find a model in more objective competitions of the sciences and athletics, they are inherently unable to achieve such levels of objectivity. Juries make decisions about which works to consider for the shortlist and which to ignore based upon their own biases, the biases of their fellow jurors, and the institution they represent. This is, emphatically, a fraught process, and one that can be problematic to those who take the Pulitzer's winners too seriously. Bourdieu wrote that "culture is only achieved by denying itself as such, namely, as

\footnotetext{
${ }^{2}$ Ibid.

${ }^{3}$ In the field, jury sizes are subject to wide variation. Grawemeyer juries are set at three, the ASCAP Morton Gould Young Composer Awards are determined by a panel which hovers around seven or eight, and the Nemmers Prize in Music uses three jurors. Prizes, Fellowships, and Grants which are part of large organizations, like the Pulitzer, Guggenheim, and historic awards from the Rockefeller and Ford Foundations are typically arbitrated by an even larger population, and may include up to twenty.

${ }^{4}$ Annie Janiero Randall contends that the disparity between men and women's composition prize wins was largely due to the stocking of juries from "the halls of academe and the ranks of major arts organizations," necessitating that winners would be drawn from similar pools of people. See Randall, "Eyes on the Competition Prize," 108.
} 
artificial and artificially acquired." ${ }^{5}$ The process of competition turns the Pulitzer from a contrived choice based on the jury's taste to something "artificial and artificially acquired." Competition launders the questionable moral and aesthetic aspects of their choice, making it appear "artificial and artificially acquired", and therefore legitimate and beyond reproach. Under ordinary circumstances, the proclamation by five individuals that they have identified one outstanding piece would be wholly unremarkable. Juries, however, as representatives of the Pulitzer, have authority that ordinary people do not; their musical opinions are supported and upheld by an institution, which are then marketed to the American public.

Such institutional affiliations are one of the primary venues through which individuals can attain such positions of authority to begin with. As Michael Uy describes, powerful networks of closely-related experts have an enormous amount of power upon the kinds of music that are seriously considered. ${ }^{6}$ Grants and prizes are also founded in the discourse of meritocracy, in which resources are allocated to a single winner, rather than dividing them equally among all deserving applicants. For the Pulitzer jury, expertise is therefore imperative. Where members of the Pulitzer's Board have not typically been fluent or even engaged with musical practice or discourse, the jury's knowledge about the field of music serves a legitimizing function. ${ }^{7}$ Yet even for experts, the process is still intensely subjective. Because jurors are contributory experts,

\footnotetext{
5 Jenkins, Bourdieu, 126-144.

${ }^{6}$ Although it is true that experts are closely related, the methods he employs in his discussion of networks of power are not purely relational, where power is gained by contact and mutual influence. Instead, he posits a real value attached to expertise. See Uy, "The Big Bang in Arts Patronage," 81.

${ }^{7}$ Sociologist Robert Merton describes a phenomenon he named the "Matthew Effect," wherein grants are awarded to people who have received some kind of adjudicated recognition in the past. Similarly, Edward Thorndike theorized a "halo effect," which describes the prestige received by confirmation bias of association with a prestigious institution. Ibid., 84 .
} 
their understanding of the field's nuances, and especially, its disputes is integral to judging unlike compositions. ${ }^{8}$ Of this process, Pulitzer Fiction juror Michael Cunningham reflected:

Utter objectivity, however, is not only impossible when judging literature, it's not exactly desirable. Fiction involves trace elements of magic; it works for reasons we can explain and also for reasons we can't...A great work of fiction involves a certain frisson that occurs when its various components cohere and then ignite. The cause of the fire should, to some extent, elude the experts sent to investigate. ${ }^{9}$

Above, Cunningham describes his inability to reduce these individual artistic expressions to a rubric. Certainly, historical juries may have operated using systematic rankings, but as deliberations today are also affected by the rankings of four independent others, mathematical scores may not be helpful in crafting a unanimous recommendation. Where Cunningham concentrated on initial or general impressions of an individual, Annie Gosfield, a juror for the 2013 Gaudeamus Composition prize, elaborates on the process of mediation:

We were confident that if there was something we missed, one or two of the others would draw our attention to that particular piece. This happened a few times. Some things I chose were of no interest to my fellow jurors, but others were really raised from the ashes. As in many of these situations, I think we totally agreed on about $75 \%$ of the entries, and then we agreed pretty much up to $90 \%$. After this you start pulling out the knives - over the last two or three pieces the jurors themselves tend to become a bit competitive. ${ }^{10}$

Integral to understanding jurors' evaluative processes is Bourdieu's idea that judges' selfconcept plays an important role in determining their evaluative behavior. ${ }^{11}$ Where Bourdieu's

\footnotetext{
${ }^{8}$ Collins and Evans argue that the difference between a popular understanding of a field and an expert's is their "tacit knowledge," or the deep understanding of a subject gained through social immersion. See Collins and Evans, Rethinking Expertise, 19-21.

${ }^{9}$ Michael Cunningham, "Letter from the Pulitzer Fiction Jury: What Really Happened This Year," New Yorker July 9, 2012, https://www.newyorker.com/books/page-turner/letter-from-the-pulitzer-fiction-jury-what-really-happenedthis-year.

${ }^{10}$ Thea Derks, " 5 questions to Annie Gosfield (composer), jury member for the Gaudeamus Competition," I Care if You Listen, September 7, 2012, https://www.icareifyoulisten.com/2012/09/five-questions-to-annie-gosfield-jurymember-gaudeamus-competition/.

${ }^{11}$ Stefan Beljean, Phillipa Chong, and Michele Lamont, "A Post-Bourdieusian Sociology of Valuation and Evaluation for the Field of Cultural Production," in Routledge International Handbook of the Sociology of Art and Culture, ed. Laurie Hanquinet (New York: Routledge, 2015), 38-48 at 41.
} 
original argument stated that judges act out of self-interest, Phillipa Chong asserts that there are a multitude of competing factors which determine how people evaluate. The process is "a complex mix of pleasure and anxiety, competition and stewardship, empathy and self-preservation." ${ }^{12}$ For Gosfield and other jurors, the decisions made after "you start pulling out the knives" can be very personal, fueled as much by personal predispositions as the material details of the pieces they are judging.

As much authority as expert juries possess, The Pulitzer's jury practices are dependent upon this inconsistency. Ultimately, the jury is beholden to the Prize Administrator-they are formulated at the administrator's discretion, on whom lies the burden of ensuring a fair and balanced result. If the self-concept or identities that determine how submissions are evaluated changes from year to year, this structural component makes the selection of finalists unpredictable. This is contrasted, however, with a structural component aimed at making the selection more fair or equitable.

While it may seem like an obvious thought, former Stirling architecture prizewinner Simon Allford's observation that "Different judges will pick different winners in different years" exemplifies the problem presented by this approach. Although the diversity of perspectives offered by jurors who are music scholars and practitioners might seem desirable, the "wild card" nature of jury composition means that the pool of pleasures, anxieties, and competitions described by Chong above remain largely unregulated. Indeed, even the larger list of finalists does not include any composers of spectral music, musical performance art, or video game music, for example. The slippage between the theory and practice does not disprove Bourdieu or Chong, but instead indicates that the jury's randomness is not equivalent to a sense of fairness

\footnotetext{
${ }^{12}$ Ibid. 42.
} 
that the Pulitzer implies they desire. As I will show in the following section, a shift in the jury's membership away from modernist and neoromantic composers has not yet resulted in awards for all kinds of composition, but rather a new skew towards post-minimal and post-genre composers.

\section{Who are the Juries?}

When Prize Administrator Dana Canedy chooses the next year's jury, she is, to some extent, following a formula. Since Seymour Topping instigated a reform of the music juries in the mid 1990s, the official requirement is that jurors must come from a variety of musical practices. Topping specified that among the five members, there will be one "presenter of musical work," one music critic, and three composers. ${ }^{13}$ In practice, their titles or designations are somewhat divergent. Former administrator Mike Pride has included musicologist Carol Oja, arts administrators Ara Guzelimian and Pamela Tatge, and entrepreneur Jeremy Geffen.

Historically, no such guidelines existed, and so the juries were comprised overwhelmingly of composers.

Pulitzer juries of the twentieth century were also intensely consolidated. Drawing from the practices of other high-profile foundations in the arts, early administrators relied heavily upon first-degree connections in order to recruit future jurors. ${ }^{14}$ The first decade evinces an extreme reliance on composers affiliated with Columbia University — the instigator of the Pulitzer Prize for Music, Board Member Douglas S. Moore, was a Columbia faculty member.

\footnotetext{
${ }^{13}$ This format was instigated by Prize Administrator Seymour Topping, and eventually became folded into the documentation for the administration of the prizes. To date, this statement still exists on the Pulitzer's website, although the practices of future administrators have diverged.

${ }^{14}$ Michael Uy describes the close connections between music consultants of the Ford Foundation, Rockefeller Foundation, and the National Endowment for the Arts. Significant overlap between the three foundations has occurred, notably for Gunther Schuller (7-time Pulitzer juror; 1994 Pulitzer Prizewinner) who was involved in all three. Uy's research also demonstrate the concerted absence of otherwise ubiquitous figures like Leonard Bernstein. See Uy, "The Big Bang in Arts Patronage," 118.
} 
Moore recruited Chalmers Clifton, a lecturer in the department who would go on to serve seventeen consecutive years on the Pulitzer juries. Quincy Moore, another composer on Columbia's faculty, was also selected as an inaugural juror, and would go on to win the Prize himself in 1951. Despite this, awards were given to a wide array of musical forms and genres, although the administrators' proclivity for choosing previous winners and previous jurors has only recently begun to shift. ${ }^{15}$

Table 6. Most Frequently Serving Jurors for the Pulitzer Prize in Music.

\begin{tabular}{|c|c|c|}
\hline Juror & Number of Juries & Years \\
\hline Chalmers Clifton & 17 & $1943-1960$ \\
\hline Robert E. Ward & 15 & $1954-1997$ \\
\hline Joseph Schwantner & 7 & $1985-2010$ \\
\hline Gunther Schuller & 7 & $1970-2005$ \\
\hline Miles Kastendieck & 7 & $1956-1967$ \\
\hline David N. Baker & 6 & $1995-2007$ \\
\hline John Harbison & 6 & $1994-2003$ \\
\hline David Hamilton & 6 & $1987-2000$ \\
\hline
\end{tabular}

A data-driven approach may present further evidence for Pulitzer jurors' insularity. Through the 2018 prize, a total of 116 different people have served on the Pulitzer Music juries under nine different Prize Administrators. ${ }^{16}$ A few have achieved notable numbers. As evidenced by the chart above, Chalmers Clifton and Robert E. Ward were the two most frequent jurors, and both served over long stretches of time. Ward is especially significant: he was intimately involved through nearly the whole gamut of Pulitzers from their inception until the time of his death. Along with Clifton and Ward, an additional 60 people have served on multiple juries: more than

\footnotetext{
${ }^{15}$ Within the first decade, a ballet, film score, orchestral, operatic, and choral works were represented on the winner's roster, and in 1953, no award was given despite the jury's nomination of pieces by Heinz-Dietrich and Fischer, Musical Composition Awards, xxiii.

${ }^{16}$ A complete list of Prize Administrators can be found in the Appendix.
} 
half of all Pulitzer jurors have had the opportunity to make the decisions multiple times. These multiple jury services are even more influential in light of the number of years they spanned. While Chalmers Clifton and Robert E. Ward were both involved in the Pulitzer's selections over multiple decades, John Harbison's and David N. Baker's six services in a little more than one decade indicate their significant influence over several of the Pulitzer's awards. For these two composers to feature so prominently during roughly the same time-frame leaves little room for other jurors to exert their own influence. Historically, the representation of differing fields and networks was not of concern to the Pulitzer Prize, and thus the jurors represented a consolidated pool of individuals who all belonged to similar networks. ${ }^{17}$

Prize Administrators are sensitive to the power they have over the selection process. In the early days of the Pulitzer, juries were likely to remain mostly intact from year to year, with the Administrator naming replacements one at a time. Today, the membership of the music jury is different each time, and the Administrators are always responsible for finding new replacements. In 1995, when the administration finally landed on five total jurors, the majority were still composers who had previously won a Pulitzer Prize. Gissler's first juries display the beginnings of a move away from composer-centricity, both in their numbers on the jury and in the weight of their opinions. Around this time, the music juries began to see non-composers occupying the chair position, in addition to more performers, conductors, and scholars.

\footnotetext{
${ }^{17}$ In the mid-twentieth century, Michael Uy observes a clustering of composers around east-coast universities and institutions such as Eastman, Julliard, Tanglewood, Princeton, Harvard, and others; Pulitzer jurors follow a similar pattern. See Uy, “The Big Bang in Arts Patronage," 118. See also Appendix for a list of jurors by affiliation.
} 
Table 7. The First Four Juries of the Pulitzer Prize in Music under Sig Gissler, 2003-2006.

\begin{tabular}{|l|l|}
\hline Year & Jurors \\
\hline 2003 & John Harbison*, David Baker, Justin Davidson*, Stephen Hartke*, Joseph Schwantner* \\
\hline 2004 & Robert Ward*, David Baker, Ara Guzelimian, Tim Page*, Wayne Peterson* \\
\hline 2005 & Gunther Schuller*, Muhal Richard Abrams, Christopher Rouse*, Mark Swed, David Zinman \\
\hline 2006 & Ara Guzelimian, Muhal Richard Abrams, William Bolcom*, George E. Lewis, Howard Reich \\
\hline
\end{tabular}

Where Gissler's move was a slight shift away from composer-centricity, 2015-2018 Administrator Mike Pride's juries might altogether constitute a break. Although his tenure as Prize Administrator saw him oversee just four prizes (a brief span, especially in comparison with John Hohenberg's twenty-two years or Frank D. Fackenthal's thirty-two years) he added eight first-time jurors from a variety of musical practices. Pride's juries have taken great care to choose only one previous Pulitzer winning composer at a time, and only once was that previous winner the chair. ${ }^{18}$ Pride's juries have increasingly included music scholars, or scholars whose work deals with music, curators and commissioners, directors, and performers, not just composers. In Pride's last year as Prize Administrator, he chose a jury that only included one composer, previous Pulitzer winner David Lang. The other members were violinist Regina Carter (chair), Metropolitan Opera Director Paul Cremo, African-American culture and music specialist Farah Jasmine Griffin, and music journalist David Hadju. ${ }^{19}$ That the resultant winner, $D A M N$. by Kendrick Lamar could be considered, let alone win, was almost certainly dictated by the diversity of the jury.

\footnotetext{
${ }^{18}$ For a complete list of juries by Prize Administrator, see Appendix.

${ }^{19}$ The latter three were first-time jurors, while 2018 was the second time for both Regina Carter and David Lang.
} 


\section{Table 8. Jurors' First Services.}

\begin{tabular}{|l|l|l|}
\hline Year & Jurors & Administrator \\
\hline 2018 & Paul Cremo, Farah Jasmine Griffin & Mike Pride \\
\hline 2017 & John V. Brown, Evan Ziporyn, Alex Ross* & Mike Pride \\
\hline 2016 & Scott Cantrell, Regina Carter, Pamela Tatge & Mike Pride \\
\hline 2015 & Steven Mackey & Mike Pride \\
\hline 2014 & Caroline Shaw*, Jason Moran, Julia Wolfe* & Sig Gissler \\
\hline 2013 & Carol Oja, Gerald Levison & Sig Gissler \\
\hline 2012 & Jennifer Higdon*, Jeremy Geffen, Kenny Werner, Steven Smith & Sig Gissler \\
\hline 2011 & Anne Midgette, Paul Moravec*, William Banfield & Sig Gissler \\
\hline 2010 & Delta David Gier, Maria Schneider, Chuck Owen & Sig Gissler \\
\hline 2009 & David Lang* & Sig Gissler \\
\hline 2008 & Dwight Andrews, Steven Blier, Steven Stucky & Sig Gissler \\
\hline
\end{tabular}

As rosy a picture as these reforms might paint, the Pulitzer Prize administration has not yet managed to turn completely away from a consolidated pool of juries. Although the juries are no longer inundated with former Pulitzer affiliates as they were in its earlier years, repeat jurors still figure prominently. The chart below shows how even still, the past decade's new jurors have gone on to serve multiple times. Of the 28 new jurors, eleven have gone on to serve multiple times; in a span of eleven years, one third of its new additions recur.

Consolidation poses an important problem for the Pulitzer Prizes: any perspective of American music narrowed to the same small group of expert musicians will necessarily miss important sectors of American music. Although new jurors are more likely than historical jurors to represent diverse points of view, the Pulitzer persists in maintaining a tight core of jurors who rotate, but overall do not change. At the moment, the recurrence of figures such as Jennifer Higdon, David Lang, or Carol Oja is unlikely to spark controversy. As beloved, well-regarded, and widely-acknowledged members of the musical community, they are aptly chosen experts on whom the Pulitzer can rely to make widely accepted choices. Yet, how long can these jurors serve without limiting the Pulitzer's flexibility in incorporating change? Because jurors are integral to narrowing the Pulitzer Board's range of consideration, it is well worth considering 
how the long-standing influence of even Higdon, Lang, or Oja might affect the Pulitzer Prize in the long run.

Table 8. New Jurors 2008-18 Who Have Served Multiple Times

\begin{tabular}{|l|l|l|}
\hline 2018 & Paul Cremo, Farah Jasmine Griffin & Mike Pride \\
\hline 2017 & John V. Brown, Evan Ziporyn, Alex Ross* & Mike Pride \\
\hline 2016 & Scott Cantrell, Regina Carter, Pamela Tatge & Mike Pride \\
\hline 2015 & Steven Mackey & Mike Pride \\
\hline 2014 & Caroline Shaw*, Jason Moran, Julia Wolfe* & Sig Gissler \\
\hline 2013 & Carol Oja, Gerald Levinson & Sig Gissler \\
\hline 2012 & Jennifer Higdon*, Jeremy Geffen, Kenny Werner, Steven Smith & Sig Gissler \\
\hline 2011 & Anne Midgette, Paul Moravec*, William Banfield & Sig Gissler \\
\hline 2010 & Delta David Gier, Maria Schneider, Chuck Owen & Sig Gissler \\
\hline 2009 & David Lang* & Sig Gissler \\
\hline 2008 & Dwight Andrews, Steven Blier, Steven Stucky & Sig Gissler \\
\hline
\end{tabular}

\section{Who are the Finalists?}

Finalists are the fruit of the jury's hard labor: three equal, unranked candidates, any of whom could be chosen as the next winner of the Pulitzer Prize. During the period between the jury's meeting in February and the Board's meeting in April, each of the finalists are evaluated against one another, and unlike typical competitions, the Pulitzer's players are not necessarily playing the same game. In 2016, the finalists were Timo Andres's chamber piano concerto The Blind Bannister, Carter Pann's saxophone quartet Six from the Shop Floor, and Henry Threadgill's jazz composition, In for a Penny, In for a Pound. It is a difficult comparison, considering each of the works might conform to differing standards, based upon differing priorities. An entirely notated work such as The Blind Bannister encourages fixity and demands fidelity to the score; the improvised sections of In for a Penny, In for a Pound suggest only intervallic relationships. Irrespective of their differences (or perhaps even because of them) a 
panel of expert musicians recommended these works specifically because they felt that the music was, in some way, exemplary of American music. While only one work will win, being chosen as a finalist is still evidence of their consecration, albeit to a lesser degree than of the winners. ${ }^{20}$

Although their future evaluations will be predicated on the idea that there are important differences between the finalists, there are a number coincidental similarities. The performing forces, collaborators, and technologies underlying the Pulitzer finalists underscore their implicit value to American music. Through the Pulitzer's consecration of the works that use them, it also perpetuates their significance to the field. With the broader picture of American music's possibilities presented by Pulitzer Finalists, it is easier to see how the Pulitzer Board has constructed its own vision through its winners.

\section{Performing Forces}

Notably, the Pulitzer's penchant for narrative vocal or quasi-operatic works extends into the finalists, but they dominate far less than among the set of winners: seven of twenty-two involve voice as an integral part of the piece. Interestingly, though, where the winners lean toward more operatic settings with premieres given by professional opera companies, several of the finalists have been premiered instead by chamber ensembles with voice as a constituent member. Many of the winning works for voice have also featured instrumental writing, but in a more limited, accompanimental role. The finalists, in contrast, seek to use the voice in combination with the instrumental textures, instead of hovering over them as a backdrop. These

\footnotetext{
${ }^{20}$ Pulitzer finalists often enjoy some of the same benefits as their winning counterparts; finalist Kate Soper describes the surge of commission requests she has received since May 2017 announcement, lamenting, "I've been saying no a lot, and that feels weird, but it's just because no one was asking me before." See Zachary Woolfe, "She Tackled Aristotle in an Opera. Next Up: Medieval French Couplets," New York Times 26 January, 2018, https://www.nytimes.com/2018/01/26/arts/music/kate-soper-here-be-sirens.html.
} 
chamber settings are varied, but Ipsa Dixit by Kate Soper in particular stands out as an excellent example of part equality.

Table 9. Narrative Vocal Finalists 2008-2018

\begin{tabular}{|l|l|l|l|}
\hline 2018 & Sound from the Bench & Ted Hearne & $\begin{array}{l}\text { SATB choir, two electric guitars, } \\
\text { drums/percussion }\end{array}$ \\
\hline 2017 & Ipsa Dixit & Kate Soper & Soprano, flute, violin, percussion \\
\hline 2014 & The Gospel According to the Other Mary & John Adams & Choir and orchestra \\
\hline 2014 & Invisible Cities & Christopher Cerrone & Opera \\
\hline 2012 & Death and the Powers & Tod Machover & Opera \\
\hline 2011 & Comala & Ricardo Zohn-Muldoon & Cantata \\
\hline 2010 & Steel Hammer & Julia Wolfe & Oratorio \\
\hline
\end{tabular}

Ipsa Dixit was written by Kate Soper for the Wet Ink Ensemble, of which she is a founding member. The piece sets classical and contemporary texts by Plato, Aristotle, and Judith Butler, among others, and all four players utilize theatrical techniques. While the texts are influential in the narrative of the piece, it was especially shaped by her interactions with her collaborators: flutist Erin Lesser, violinist Joshua Modney, and percussionist Ian Antonio. She wrote, "The spark for IPSA DIXIT came from my realization that a handful of works I had written separately were in fact deeply intertwined, and my desire to make this connection explicit by weaving them together with newly-composed works to make a single experience." Its narrativity is reminiscent of opera; in fact, Alex Ross's review calls it a "philosophy opera." However, its compact, economical performing forces necessitate a more prominent role for the instrumentalists. Soper's interactions with the rest of the ensemble are an integral facet of the experience - as in more traditional varieties of chamber music, no one part could stand on its own.

Similar tendencies can be seen in Steel Hammer by Julia Wolfe. The oratorio only contains three vocal parts (SSA) and five of the Bang on a Can All-Stars round out the rest of the 
ensemble. The size of performing forces in not always a reliable indicator of part-independence or musical role; it is interesting, though, that so many nominees are of a reduced number or instrumentation from traditional large-form genres. The presence of chamber pieces also persists beyond a restriction to narrative vocal music. Among the chamber finalists are a saxophone quartet, Six from the Shop Floor (Carter Pann, 2016 finalist); a string trio, The Companion Guide to Rome (Andrew Norman, 2012 finalist); a piano trio, The Aristos (John Zorn, 2015 finalist), and even Pierrot-plus-percussion Eighth Blackbird's, for whom Pieces of Winter Sky was written by Aaron Jay Kernis (2013 finalist) and Double Sextet by Steve Reich (2009 winner).

Although the size of performing forces may seem like a trivial detail, it represents a large shift for the Pulitzer Prize. Historically, the limitation to works of the "larger forms" was built into the eligibility requirements. From the time of the music prize's inception in 1943 through 1998, the "larger forms" designation grew increasingly more specific: what began as a call for orchestral, operatic, choral, chamber, and ballet went on to include "chamber, orchestral, choral, opera, song, dance, or other forms of musical theatre."21 From 1999-2003, the "larger forms" phrase gave way to the more ambiguous "significant dimension" before finally being dropped altogether. From 2004 to the present, the eligibility requirements state: "For distinguished musical composition by an American that has had its first performance or recording in the United States during the year."

These changes indicate that the Pulitzer acknowledged chamber music as an important constituent of American music. Such recognition was, however, largely nominal. Despite its inclusion in the Pulitzer's eligibility statement throughout the full course of the prize, the vast majority of pieces were orchestral or operatic until the very end of the twentieth century. As

${ }^{21}$ Although musical theatre was explicitly included in the eligibility requirements for applicants to the Music Pulitzer, all Pulitzer-winning works in that genre have won in the Drama category. For a complete list, see Appendix. 
Figure 2 shows, the rise of chamber pieces in the decade between 2003 and 2012 happened quite suddenly. After a twenty-year period during which just two chamber pieces were chosen, it surges to eight pieces over a period of fifteen years. This coincides with the massive drop in orchestral wins. They reached a peak at nine in a period of ten years during the 1980s, then fell sharply to just five in a period of fifteen years. Between 2003 and 2012, chamber music finally eclipsed orchestral music.

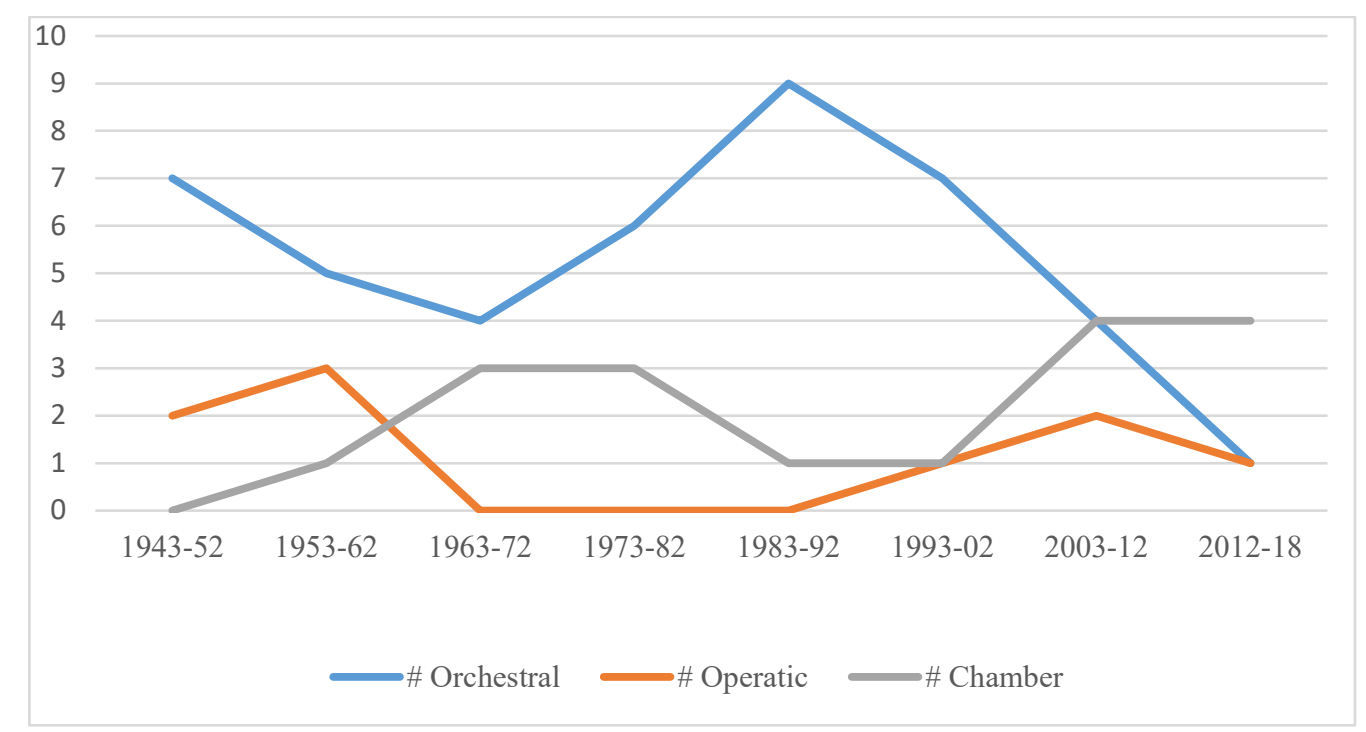

Figure 2. Pulitzer Prize in Music Winners by Performing Forces.

Of course, the larger forms are still present. John Adams's The Gospel According to the Other Mary, for example, is gargantuan in both number of performers and total run time. But what the data really shows is not a role-reversal, as though orchestral music has been replaced by chamber music, but instead a diversification of genre and size of performing forces. To take the fifteen-year period from 2003 to 2018 in closer focus, three winners were operatic, five were orchestral, and eight were chamber settings of varying size — none of these three categories are woefully lacking. Especially considering the Pulitzer's inclusion of recorded media and the prevalence of ensembles with nonstandard instrumentation (such as Wet Ink) and even solo 
instrumental works (such as Don Byron's 7 Etudes for Solo Piano) the wide range of eligibility is being reflected in the finalists, if not yet acknowledged as a winner.

\section{Influential Collaborators}

How has it come to be that so many of the Pulitzer's nominees have been premiered by well-known ensembles? Eighth Blackbird (whose commissions have been nominated three times between 2008 and 2018, including one Pulitzer win), the New York Philharmonic, the Los Angeles Philharmonic, The Industry, the Bang on a Can All-Stars have commissioned Pulitzernominated works. On one level, funding commissions from well-known and successful composers requires the performers to have sufficient credentials to successfully secure capital from grants and donors - this means that the performers, too, must already be prestigious. On another level, it is arguable that the Pulitzer highly values exemplary performances, as scores are not a submission requirement. Although the jury's task is to judge works based solely on compositional prowess, it is difficult to escape the bleeding over of prestige from knowledge of an influential collaborator. ${ }^{22}$ Beyond just popular ensembles, though, influential creative partners have left indelible marks on Pulitzer-nominated works of the past decade.

In each of the following cases, artists relied upon major contributors whose expertise, funding, and audience base helped to push the works into existence and into public knowledge, bringing with them a necessary boost in resources and prestige. In fact, there are some cases in which the popularity of the collaborators superseded the popularity of the composers themselves - for this reason, the vote of confidence given to the composers by these entities should not be understated. It is important, too, to note that the prevalence of well-known

\footnotetext{
${ }^{22}$ The Halo Effect and Matthew Effect (as described earlier in this chapter) are two examples of well-known heuristics that explain how opportunities are arbitrated on an uneven playing field.
} 
collaborators extends into the stories of the Pulitzer finalists, as well. However much Caroline Shaw or Christopher Cerrone (2014 finalist) may have been considered young upstarts, they were not totally unknown. In this section, I will explore how the composers' interactions with well-known collaborators may have helped their work to gain prestige and be taken more seriously.

In the Pulitzer's texted music, composers have frequently enlisted the help of librettists and dramaturgs. John Adams, for instance, chose to do so for The Gospel According to the Other Mary. Adams and infamous playwright and director Peter Sellars have had a fruitful artistic partnership, together producing some of the most well-known operas of the past twenty-five years, including Nixon in China and Doctor Atomic. New York Times reviewer Zachary Woolfe described the libretto's source material as a "collage of pre-existing material, much of it from the Bible but also including poetic and prose texts by Dorothy Day, Louise Erdrich and others." ${ }^{23}$ So too was Yuval Sharon just as important to the development of Christopher Cerrone's score for Invisible Cities. Though the opera was indeed billed as “by Christopher Cerrone," Sharon's innovative staging involved several rooms throughout Los Angeles's Union Station, leading to one of the opera's most unique features: that audience members are connected to the action via headphones. Cerrone's score was therefore composed to take advantage of the nuance and depth of sound that personal headphones allowed. ${ }^{24}$

In many cases, the presenter as a vehicle for promotion imparted an additional amount of prestige to the project. The works of Kendrick Lamar, Caroline Shaw, and Julia Wolfe were all

23 Zachary Woolfe, “Composer's New Passion Unspooled," New York Times, June 1, 2012, https://www.nytimes.com/2012/06/02/arts/music/the-gospel-according-to-the-other-mary-by-john-adams.html.

${ }^{24}$ Nina Eidsheim relates the experience of viewing two performances of Invisible Cities, one performance with headphones and the other without. She describes the disorientation of the headphone performance, observing that spatialized sound cues typically point a listener in the direction of a performance, but for Invisible Cities, listeners had no physical cues, enveloped in the same soundscape no matter the visual perspective. See Eidsheim, Sensing Sound, 85. 
presented to wider audiences because of their affiliations with nationally and internationally known contributors. For Lamar, Interscope Records was an important step toward bringing his career from mostly known in the Los Angeles hip-hop scene to the national stage. This jump from local to national recognition was also mirrored by Caroline Shaw, whose New York City fame was expanded on the national level when her piece was recorded by Roomful of Teeth. The internationally-renowned Bang on a Can All-Stars aided Julia Wolfe's efforts, and with Anthracite Fields's twin performances in Pennsylvania and New York City (and additional touring abroad with Steel Hammer) the press followed along. (In fact, Julia Wolfe stipulates that any future performances of Anthracite Fields must contract the Bang on a Can All-Stars as the ensemble. $)^{25}$

It is not simply visibility that makes well-known collaborators a powerful force-Pulitzer Prizes are not judged using press clippings. Rather, it is that performers have the same kind of power to arbitrate compositional excellence that the Pulitzer Prize itself displays. If performers of a high caliber have the choice of every composer's music to play and the only perform the music of a select few, they too become tastemakers, lending the works they play some of their pre-existing prestige. That the International Contemporary Ensemble played for Du Yun, or that Theatre of Voices sang for David Lang is the enactment of the opinion that those composers are excellent, and that their work should proliferate. As the Pulitzer juries judge the selections, regardless of whether or not the composer is familiar, well-known collaborators give Pulitzer entrants a vote of confidence.

Importantly, collaborators can bring additional funding to a project, both from nationallevel and local-level sources. Some collaborations derive from institutions, such as the Beth

25 The catalog entry for Anthracite Fields states explicitly "This work is only available for SATB chorus in performance with the Bang on a Can All-Stars." https://juliawolfemusic.com/music/anthracite-fields 
Morrison Project, which bills itself as "an industry disruptor and tastemaker at the forefront of musical and theatrical innovation. ${ }^{26}$ Essentially, BMP is a gatekeeper-they redistribute funding from large-scale federal grants and private donors, and use that money to support the projects that they feel are most promising. The recording of Ted Hearne's Sound from the Bench, which would go on to be a 2018 Pulitzer Finalist, was also produced by BMP. For Angel's Bone and Ouroboros, the influx of cash provided by BMP allowed them to pay for the Trinity Wall Street Choir, Novus New Music Ensemble, Paola Prestini, all of whom were instrumental to their further success. Where grant recipients are given a one-off lump sum, BMP instead oversees the development and production of an opera from germinal stages through workshops to their world premieres, providing as much support as they can over an extended period.

A different organization, though, has been strangely even more influential to the development of Pulitzer winners: Philadelphia's Pew Center for the Arts \& Heritage, subsidiary of the Pew Charitable Trusts. In total, the Pew Center has contributed $\$ 370,000$ towards commissioning three Pulitzer-winning projects: $\$ 100,000$ for Du Yun's Angel's Bone (originally produced by the Mann Center); $\$ 200,000$ for Kevin Puts's Silent Night (co-commissioned by Opera Philadelphia); and \$70,000 for Julia Wolfe's Anthracite Fields (commissioned by the Philadelphia Mendelssohn Club). Since the Pew Charitable Trusts are headquartered in Philadelphia, it is unsurprising that Philadelphia-based ensembles and venues would be so well funded.

Although the Pulitzer Prize does not recognize collaborators, many works that have won the Pulitzer are the confluence of many creative minds and musical strategies. For all seven of the composers profiled in the next chapter, partnership proved invaluable to the final product.

26 “About," Beth Morrison Projects, Accessed March 25, 2019, https://www.bethmorrisonprojects.org/about. 
Sadly, the Pulitzer Prize has never recognized the librettists for operatic winners, unlike the Charles Ives Award for Opera given by the American Academy of Arts and Letters. Nor does it account for the creative team at Beth Morrison Projects or the improvisational talents of Henry Threadgill's Zooid ensemble, nor does it credit the producers who shaped Kendrick Lamar's DAMN. This may be one of the Pulitzer Prize's most glaring flaws, considering the kind and quantity of contributions that the above creative partners have made.

\section{Incorporation of technology}

Technological advances have reshaped the music of the twenty-first century just as emphatically as in other cultural domains. ${ }^{27}$ Music has become increasingly more mobile (now unbound from the restriction physical location and able to take advantage of a multitude of networks) and fluid (dynamic, and not confined to the limitation of a score or a single context). ${ }^{28}$ Technology has the capacity to amplify, displace, and distort sound, and combine with other sensorial input. Especially in the domain of contemporary opera, its multimodality offers fruitful possibilities for enhanced visual effects that video, stage design, and even robots can provide. ${ }^{29}$

\footnotetext{
${ }^{27}$ Mark Katz, Capturing Sound: How Technology has Changed Music (Berkeley: University of California Press, 2010), 177.

${ }^{28}$ Timothy Rutherford-Johnson, "Mobility: Worldwide Flows, Networks, and Archipelagos," in Music After the Fall: Modern Composition and Culture Since 1989 (Berkeley: University of California Press, 2017), 120-161.

${ }^{29}$ By incorporating extraordinary visual cues, opera can heighten the multimodal possibilities of the sensory experience. When read as a "thick" experience, that integration of sensory stimuli can add emotional depth and nuance to the literal, semantic information conveyed by the text, and the possibility of affective information carried by the score. For more on multimodality in opera, see Yayoi Uno Everett, "Toward a Multimodal Discourse in Opera," in Reconfiguring Myth and Narrative in Contemporary Opera (Bloomington: Indiana University Press, 2015), 1-40. For more on a thick reading of vocality, see Eidsheim, Sensing Sound, 1-2.
} 
Table 10. Pulitzer-Nominated Electroacoustic Works.

\begin{tabular}{|l|l|l|l|}
\hline Year & Piece & Composer & Result \\
\hline 2018 & DAMN. & Kendrick Lamar & Winner \\
\hline 2017 & Angel's Bone & Du Yun & Winner \\
\hline 2017 & Bound to the Bow & Ashley Fure & Finalist \\
\hline 2014 & Invisible Cities & Christopher Cerrone & Finalst \\
\hline 2012 & Death and the Powers & Tod Machover & Finalist \\
\hline 2004 & Cello Counterpoint & Steve Reich & Finalist \\
\hline 2003 & On the Tranmigration of Souls & John Adams & Winner \\
\hline 1971 & Synchronisms No. 6 & Mario Davidovsky & Winner \\
\hline 1970 & Time's Encomium & Charles Wuorinen & Winner \\
\hline
\end{tabular}

Electronic sound is a medium that has only rarely been embraced by the Pulitzer Prize in any capacity. Two consecutive winning pieces, Time's Encomium by Charles Wuorinen (1971 winner) and Synchronisms No. 6 by Mario Davidovsky (1972 winner), were the first Pulitzer recipients to use fixed media playback. Following these, the jurors went immediately back to selecting more conventional pieces, and it was decidedly not for a lack of notable electronic works to be composed in that period. It was only after a thirty-year hiatus that another piece involving electronics would win - John Adams's On the Transmigration of Souls (2002 winner). Since 2002, however, pieces with electronics have ended up on the shortlist much more frequently.

Of these, one notable example is Tod Machover's "robotic opera" Death and the Powers. The plot follows a dying entrepreneur and inventor, Simon Powers, through his endeavor to preserve himself by uploading his consciousness into the walls and objects in his room. To create the electronically-enhanced environment for the staging, Tod Machover's scoring is unconventional. The instrumentation requires additional equipment for a few of the opera's characters: "Chandelier (robotic multi-stringed instrument), System (interactive and responsive set), Disembodied performance (real-time voice transformation for Simon, and interactive body- 
monitoring systems for Simon and Nicholas)." Machover's stints as IRCAM's Director of Musical Research and head of MIT's Opera of the Future Lab gave him all the tools and experience he needed to take on such a technologically-centered musical work. Unique to the Pulitzer's shortlisted works, among creative executives who crafted Death and the Powers are "computer designers, researchers, and technicians."

While Christopher Cerrone's opera Invisible Cities also uses electronics, a more salient aspect of its relationship with technology is its production. Singers sing it and an orchestra plays it, but throughout most of the work, none of these performers are visible to the audience. Instead, the flashmob-style experience, set in the Union Station of Los Angeles, was billed as a "headphones opera". Cerrone, in collaboration with Yuval Sharon's The Industry and the Los Angeles Dance Company, envisioned Invisible Cities as a unique experience for ever viewer. It becomes a unified performance with the use of real-time audio streaming, the tools for which were provided by an ideal corporate sponsor, Sennheiser. Each audience member was given a pair of Sennheiser headphones and suggestions by Sharon for places which might provide for a rich viewing experience, and then were left to wander the building freely. The performance took place in multiple rooms, the performers moving from space to space just as the audience did.

The inclusion of video, digital projections, and other visual media are also becoming more frequently used, even outside of staged productions. In 2003, Steve Reich's video opera Three Tales was nominated as a Pulitzer finalist. Rather than the dramatic live performance of a traditional opera, the video opera involves small contingent of performers who sing along to the rhythm of speakers who were filmed in an interview, which is projected above the stage; this interview constitutes the dramaturgy of the video opera. Reich had originally pioneered this technique in a similar work, The Cave, which he wrote between 1990 and 1993. 
In fact, one of the major differentiating factors between Julia Wolfe's Steel Hammer and Anthracite Fields (winner, 2015) was the latter's use of photographic projections and video as opposed to live action. The full chorus needed for Anthracite Fields dramatically reduces the viability of full-out staging throughout most of the work. The space is simply already spoken for,

and furthermore, the video medium is much more conducive to displaying the necessary kinds of spaces and objects: the interior of mines, heavy machinery, and the real miners who used them.

Outside the scope of the Pulitzer, the video medium has been used in combination with live performance to great effect. Several works by Dutch composer Michel van der Aa incorporate fixed or live-interaction electronics, acoustic instruments or vocalists, and video simultaneously. His cello concerto with visuals (including both video and a live actor) entitled Up-close won the 2013 Grawemeyer Award for its "highly innovative fusion of musical and visual art". Van der Aa's has also created The Book of Sand, an interactive app which synchronizes different settings of text by Jorge Luis Borges depending upon which video of his collaborator, dancer Kate Miller-Heidke, the user has chosen; the user may switch between these settings in real time, crafting an infinite number of end results. The musical differences between these two works are slight, but their mode of presentation makes one an eligible contestant and casts one out of contention.

\section{Conclusion}

Although this chapter has focused on the similarity of Pulitzer nominees, it is not because their similarities are inherent. The artificial environment of competition juxtaposes finalists, exposing the unpremeditated nodes of their similarities. They can show the breadth of the field just as much as they can show the unique vision of different composers within the same medium 
or aesthetic. Yet, even from this larger pool of nominated works, there remains a wide swath of the musical field that remains untouched. In aesthetic, the Pulitzer does not acknowledge any spectralist, neoromantic, or purely electronic work. The Pulitzer Prize has also limited itself to recognizing concert works, but technological collaboration has also brought new forms of consumption, such as van der Aa's musical app described above.

American music now is created and reified by its composers' participation in conflicts over musical style and influences in a fashion similar to debates during its development through the early twentieth century. ${ }^{30}$ As composers wade through innumerable external influences and lineages, their choices create a landscape of American music with almost infinite gradation. ${ }^{31}$ Still, some of these choices result in similar music, which are shared with and influenced by certain musical communities. The Pulitzer Prize, then, presents a question: Whose nodes are being supported, and how do we react to them? In their consistent use of a similar body of technologies and collaborators and operating within the same infrastructure, Pulitzer nominees express their connection to these elements of American music, and expert jurors strengthen and legitimize them. In this way, their similarities may give observers a hint at some of American music's dominant priorities from the perspective of a small pool of influential musicians. Those works that go on to win, however, enact the musical priority of an extremely different group. In

\footnotetext{
${ }^{30}$ Charles Hiroshi Garrett embraces the conflict of Charles Ives's musical borrowing, observing that his racialized understanding of ragtime and its combination with traditional (white) American hymn tunes creates a messy interpretation of his Four Ragtime Dances. Importantly, the coexistence of Ives's appropriation and his progressive views on race remain unresolved for Four Ragtime Dances, but the tension between conflicting histories of American music (one of African American origin and one of essentially European origin) provides an honest articulation of an "American" musical lineage. See Charles Hiroshi Garrett, "Charles Ives's Four Ragtime Dances and 'True American Music," in Struggling to Define a Nation: American Music and the Twentieth Century (Berkeley: University of California Press, 2008), 18-47.

${ }^{31}$ Despite the insistent presence of musical conventions, idioms, and styles shared across geographic, cultural, religious, national, or political settings, musical communities still display a level of heterogeneity. This tension is at the root of a resistance toward the Pulitzer's reductionist categorization of its winners. For further discussion of methodological problems confronting the study of community and related terms, see Kay Kaufman Shelemay, "Musical communities: Rethinking the collective in music," Journal of the American Musicological Society 64, no. 2 (2011): 349-390.
} 
the following chapter, I will turn to the role of the Pulitzer's Administrative Board and their journalistic priorities for music. 


\section{4}

\section{Winners and Boards}

Winning in music is a very different activity than winning competitions of science or sport. Far from tangible, concrete criteria as in points or time to the finish line, the qualifications of music's winners are often barely differentiable from the losers: for composers, there is no such thing as "winning by a mile." As the previous chapter explored, winners are determined by the subjectivities of the people whose task it is to choose them. The Pulitzer's structure routes applicants through two different sets of judges, creating a matrix of winners who are meant to be appreciable by specialist audiences and musical amateurs alike. With the changing priorities of American music and the changing distribution of power between juries and Administrative Boards, the kinds of works that are likeliest to win have shifted. Whereas Chapters One and Two have addressed the historical winners, I will describe in this chapter what kinds of works win today. I will explore each winner's path to success, positioning the Board's selections between 2008 and 2018 in relation to their historic counterparts.

The seven profiles of Pulitzer-winning composers that follow build a chronology of each individual's winning piece, tracing its development from the perspective of critical reception. Within this timeline, the winning piece itself will be addressed as thoroughly as possible from its commissioning to its premiere to the aftermath of its win. ${ }^{1}$ In the context of an individual composer's body of work, both of these chronologies will help direct the reader's attention

\footnotetext{
${ }^{1}$ With the exception Kendrick Lamar's $D A M N$, which will be treated through its release. The reception of the album and the press that followed its Pulitzer win is detailed in Chapter 6.
} 
toward trends in the composer's career, demonstrating the interconversion of capital following their Pulitzer win.

Are there markers of success clustered in a narrow span of time? In what order do these honors occur? These questions are best answered by incorporating commentary from multiple perspectives. To make a case for the reception of each of these pieces, critical commentary and reviews will comprise a large part of the evidence. By comparing the reviews of the winning pieces at their premiere to their treatment after they win, the Pulitzer name's influence in the characterization of the pieces and composers will become clearer. ${ }^{2}$ In addition to commentary from an outside perspective, interviews with the composers will help to situate more explicitly what impact they feel the Pulitzer had on their career. Where available, records of the performances of these works can help elucidate the power the Pulitzer has to direct attention to works — generally speaking, after winning the Pulitzer, pieces typically receive another round of programming and performance, usually to a wider audience.

Following these case studies will be a section devoted to comparison, expanding the scope from the experiences of an individual composer to account for similarities in the chronologies of multiple Pulitzer-winning composers. On many fronts, an encouraging level of diversity will be found in the treatment of the voice, other performing forces, collaborators, thematic content, texts, and markers of style or idiom. However, underlying the differences among the seven pieces addressed in this chapter are certain elements that are somewhat more formulaic. The trends and trajectories discussed here will address the question, "Who wins?" and

\footnotetext{
${ }^{2}$ Of winners from 2008 to 2018, eight composers reference the Pulitzer Prize within the first paragraph. (David Lang and Steve Reich do highlight their win, but later in their biographies.) In the biographies of Du Yun, Jennifer Higdon, Henry Threadgill, and Kevin Put, the word "Pulitzer" is mentioned even before their names.
} 
even more importantly, "Why do they win?"

\section{the little match girl passion, David Lang (2008 winner)}

David Lang (b. 1957) is a New York-based composer who is known primarily for his work with Bang on a Can, originally a music festival designed to promote the work of living composers. ${ }^{3}$ With the growth of Bang on a Can and the development of a resident ensemble (the Bang on a Can All-Stars) and commissioning fund, Lang and partners Julia Wolfe and Michael Gordon have become representatives of an iconoclastic, minimalist "downtown" school of composition. It therefore came as a surprise that Lang would write a piece emulating J.S. Bach's St. Matthew Passion. The resultant the little match girl passion was written at the suggestion of Theatre of Voices director Paul Hillier. He was interested in commissioning Lang for a sort of religious opera, and Lang was enthusiastic about the possibility. As a Jewish composer, David Lang notes that he has nearly always had a troubled relationship with sacred music, given that so much of it, including Bach's St. Matthew Passion, portrays his faith in such a negative way. ${ }^{4}$ In the little match girl, Lang's response was to alter the story to where it was not a Passion story in a literal sense, but instead an allegory. The libretto is a slightly altered version of Hans Christian Anderson's fable "The Little Match Girl," in which a small child stands outside on a cold winter's night, begging for food. The next morning, she is found frozen to death.

Although the tale is different, Lang forges a strong relationship between the little match girl and Bach's St. Matthew Passion, building a connection to faith and spirituality, resulting in

\footnotetext{
${ }^{3}$ For more on the early biography of David Lang, see Julia Wolfe "Embracing the Clash" (Ph.D. diss., Princeton University, 2012).

4 "David Lang Wins Music Pulitzer for 'Little Match Girl Passion," Jerusalem Post, April 8, 2008, https://www.jpost.com/Arts-and-Culture/Entertainment/David-Lang-wins-music-Pulitzer-for-Little-Match-GirlPassion.
} 
an even more heightened emotionalism. ${ }^{5}$ The piece was premiered by Theatre of Voices at Carnegie's Zankel Hall in 2007. Anne Midgette's original review of the work is not overly adulating: "Touched with the frost of chimes and tubular bells, the piece goes a little over the top, and the four singers looked for guidance to Mr. Hillier." ${ }^{96}$ In fact, Midgette was not there to review the premiere of the work, but instead to review the ensemble, following their recent highprofile recording of Karlheinz Stockhausen's Stimmung, released on the Harmonia Mundi label.

The lack of attention notwithstanding, the piece won David Lang his Pulitzer Prize in 2008. The jury's membership included Ingrid Monson, Dwight Andrews, Steven Blier, Tim Page, and Steven Stucky. Page's commentary in particular sheds some light on their choice: "I don't think I've ever been so moved by a new, and largely unheralded, composition as I was by David Lang's the little match girl passion, which is unlike any music I know." ${ }^{77}$ With the Pulitzer win, Lang's piece was thrust from a "largely unheralded" state into greater public attention, inspiring Hillier to make a recording, for which Theatre of Voices captured the 2010 Grammy Award for Best Chamber Music/Small Ensemble Performance. Its success as a chamber work also prompted Lang to expand the piece, creating an alternative version for choir, percussion, and four soloists. In the wake of these awards, the little match girl passion has been sung frequently. ${ }^{8}$

Lang's relationship with his Pulitzer win has often been tinged with frustration. In one interview, he stated:

\footnotetext{
${ }^{5}$ Lang has made statements asserting that he sees a strong connection between the little match girl and the St. Matthew Passion, see Johann Jacob van Niekirk, "David Lang's 'the little match girl passion': A Conductor's Guide," Choral Journal 56, no. 2 (2015): 9. For a competing perspective, see Dominic Wells, "In the Footsteps of Bach's St. Matthew Passion: The Passion Settings of David Lang and James Macmillan," Tempo 67, no. 264 (2013): 45-46.

${ }^{6}$ Anne Midgette, "Songs, Poems and Burps in a Theater for the Ear," New York Times, October 27, 2007.

${ }^{7}$ Tom Huizenga, "David Lang Wins Pulitzer Prize for Music," National Public Radio, April 7, 2008, https://www.npr.org/2011/01/24/89442735/david-lang-wins-music-pulitzer

${ }^{8}$ Notable performances include two 2016 stagings by R.B. Schlather at the Metropolitan Museum of Art and Pérez Art Museum Miami with IlluminArts and the Trinity Wall Street Choir.
} 
To tell the truth, I had mixed feelings about it [the Pulitzer]. The very next day people started thinking I was smart and a good composer and listening to my older music, which is a lot like the music they suddenly liked because someone told them it was good. I got a little cynical, and immediately people contacted me to write very traditional pieces, a string quartet and so on. ${ }^{9}$

For a composer whose early years were marked by the struggle to find acceptance from the mainstream of composition, the public's sudden and complete embrace of his music was irksome. Lang pointedly notes the resurgent interest in his earlier music, which had been treated scornfully before being his being honored by the Pulitzer.

Directly following David Lang's Pulitzer win, he received several offers for academic teaching jobs, among them his alma mater Yale University. Interestingly, Lang had already applied for and been denied the vacant position now offered by Yale. Lang is very frank about what won him the job, stating explicitly that "I'm only on the faculty because of the Pulitzer Prize." ${ }^{10}$ This belated institutional acceptance of Lang's music is also reflected in Julia Wolfe's career. In 2009, shortly after David Lang began his position at Yale, Julia Wolfe was hired as a full-time assistant professor at New York University.

\section{Anthracite Fields, Julia Wolfe (2014 winner)}

Like Lang, Julia Wolfe (b. 1958) is associated with the Bang on a Can organization, and it is through her work with the Bang on a Can All-Stars that her associations with the Pulitzer were developed. Before Anthracite Fields was ever proposed, a different work of striking similarity was selected as a Pulitzer finalist in 2010. Steel Hammer, written for the Bang on a

\footnotetext{
${ }^{9}$ Pierre Ruhe, "Interview: Composer David Lang On 'Little Match Girl Passion' And Downside Of The Pulitzer Prize," Artsatl, Accessed March 24, 2019, https://www.artsatl.org/talking-with-david-lang-about-the-little-matchgirl-passion/.

${ }^{10}$ Libby van Cleve, "Major Figures in American Music: David Lang," Yale Oral History of American Music, 19; This belated institutional acceptance of Lang's music is also reflected in Julia Wolfe's career. In 2009, shortly after David Lang received his position, Julia Wolfe was hired as a full-time assistant professor at New York University, after teaching adjunct composition lessons at the Manhattan School of Music from 2002 to 2009.
} 
Can All-Stars and Trio Medieval, was inspired by the American folk tale "John Henry," a story about a fictional African-American railroad worker who laid railroad ties so well that he competed with a steam-powered machine and won. Reviews highlighted the piece's roots in folk music and its associations with Appalachia. After the work's premiere, Julia Wolfe would go on to compose a concerto for body percussionist and a violin quintet and voice whose program notes connect the works explicitly back to her love of folk music and Steel Hammer. ${ }^{11}$ Folk had historically been a pervasive influence in Wolfe's music. Steel Hammer's recognition by the Pulitzer jury served to refocus critical attention on that theme.

On a commission from Philadelphia's Mendelssohn Club, Wolfe wrote Anthracite Fields, an accompanied oratorio set in the anthracite coal fields of rural Pennsylvania. The relationship between Anthracite Fields and Steel Hammer is pronounced; both were commissions for longduration ensemble vocal works, and she envisioned the accompaniment for both pieces in terms of the easiest available resource, Bang on a Can. Both works' reference to the American folk tradition further solidify their connection. The concurrent flurries of activity surrounding the two pieces made transition for critical coverage of Steel Hammer to Anthracite Fields an easy one.

Between its world premiere in Philadelphia and its New York premiere at the biennial of the New York Philharmonic a mere three days later, Anthracite Fields was treated in a number of high-profile previews and reviews, including the Philadelphia Inquirer, the New Yorker, and the New York Times. ${ }^{12}$ The piece was well-received, then performances stopped as Wolfe turned her

\footnotetext{
${ }^{11}$ Rise and Fly (2012) and With a Blue Dress on (2010) mention their connection to Steel Hammer and other, older works based in American folk tales in their program notes.

${ }^{12}$ For reviews of the premieres of Anthracite Fields, see Rebecca Lentjes, "Bang on a Can and New York Philharmonic bring enormous new works to the Biennial," Bachtrack, June 2, 2014, Accessed March 24, 2019. https://bachtrack.com/review-bang-can-nypo-biennial-may-2014; Russell Platt, "Big Deal," New Yorker May 26, 2014, Accessed September 13, 2018, https://www.newyorker.com/magazine/2014/05/26/big-deal; Corinna da Fonseca-Wollheim, "For Ensembles and Singers, a Night of Backbreaking Labor," New York Times, June 1, 2014, Accessed September 13, 2018, https://www.nytimes.com/2014/06/02/arts/music/ny-phil-biennial-offers-themes-ofmining-and-building.html.
} 
attention to her other projects. Almost exactly a year later, Julia Wolfe won the Pulitzer Prize; it was the first prize she had won since 2002. This win was the first in a constellation of other honors that occurred within a relatively short span of time. First, an Anthracite Fields album was recorded by the Choir of Trinity Wall Street (also on the Cantaloupe label), which went on to be nominated for a 2016 Grammy for Best Contemporary Classical Composition. Shortly after the Pulitzer announcement, Wolfe also took another prize win, the 2015 Herb Alpert Award in the Arts from the Herb Alpert Foundation and CalArts. ${ }^{13}$ The culmination, however, was the announcement that Wolfe was selected as a 2016 MacArthur Fellow. ${ }^{14}$ At this time, Anthracite Fields performances have made a resurgence, with a strong record spanning from 2016 to the present. $^{15}$

\section{Partita for 8 Voices, Caroline Shaw (2013 winner)}

Caroline Shaw (b. 1982) began her musical career as a violinist with an interest in improvisation and composition, but as she progressed through her career, the balance shifted. After receiving degrees in violin from Rice University and Yale University, she was accepted in Princeton University's $\mathrm{PhD}$ in composition program. In New York, Shaw sought out performance opportunities, and found work as a vocalist in the eight-piece ensemble Roomful of Teeth. From the very beginnings of her involvement in Roomful of Teeth, Caroline Shaw was composing her Partita for 8 Voices, movement by movement. As Roomful of Teeth began to

\footnotetext{
${ }^{13}$ As her Pulitzer is explicitly referenced in the award announcement for the Herb Alpert Award, the piece and the attention she received because of it likely played into her selection.

${ }^{14}$ Anastasia Tsioulcas, "Composer Julia Wolfe Awarded MacArthur 'Genius Grant,"” National Public Radio, September 22, 2016, Accessed September 10, 2018, https://www.npr.org/sections/therecord/2016/09/22/495008084/composer-julia-wolfe-awarded-macarthur-geniusgrant; https://www.newyorker.com/culture/culture-desk/a-macarthur-for-the-composer-julia-wolfe.

15 "Performances," G. Schirmer, Accessed September 20, 2018, http://www.musicsalesclassical.com/composer/work/1757/49200.
} 
plan a debut self-titled debut album on the New Amsterdam label to feature their commissions, they decided to break up the four movements of Shaw's piece, using it as a bridge to reorient listeners as they travel from the disparate sound worlds of William Brittelle's Amid the Minotaurs (2010) and Judd Greenstein's AEIOU (2009).

Critics in the wake of the Pulitzer win have referred to the Partita as Shaw's "breakthrough piece," but its treatment as part of the album was consistently outshone by Merill Garbus's Quizassa, in particular. Leading up to the album's release, Roomful of Teeth performed at several concerts, including the 2012 Ecstatic Music Festival. It is clear that Shaw's Partita was performed on this program, but reviews do not mark it as particularly exceptional. ${ }^{16}$ An NPR review of the album shortly before its debut on October mentions the work's exuberance, but takes care to highlight the piece by Merill Garbus; similarly, Pitchfork notes the overwhelming nature of Shaw's texts, but doesn't single the piece out for praise. ${ }^{17}$ On 18 March 18 2013, Roomful of Teeth performed in an album release concert at the Atlas Performing Arts Center in Washington, D.C. Anne Midgette reviewed the concert, but it is not clear whether the Partita was performed on this program. Neither the piece nor Caroline Shaw is mentioned explicitly, while Judd Greenstein's AEIOU and Garbuss's Quizassa are both highlighted. ${ }^{18}$ Just two and a half weeks later, Caroline Shaw won the Pulitzer Prize for Partita for 8 Voices. Interestingly, Shaw submitted the Partita on a whim, hoping that the powers-that-be on the jury might take interest in the ensemble more so than the piece. For this reason, Shaw

\footnotetext{
16 “Glasser and Roomful of Teeth,” Q2, February 28, 2012, Accessed August 28, 2018, https://www.wqxr.org/story/188701-live-ecstatic-glasser-and-roomful-teeth/.

${ }^{17}$ For the album review, see Anastasia Tsioulcas, "Roomful Of Teeth: Experimental Singing, Smiles Guaranteed," National Public Radio, October 23, 2012, Accessed August 28, 2018, https://www.npr.org/sections/deceptivecadence/2012/10/22/163426225/roomful-of-teeth-experimental-singingsmiles-guaranteed.

${ }^{18}$ Anne Midgette, "Roomful of Teeth, a cappella," Washington Post, March 19, 2013, Accessed August 30, 2018, https://www.washingtonpost.com/entertainment/music/roomful-of-teeth-a-capella/2013/03/19/f6038c48-90cb-11e2bdea-e32ad90da239_story.html?utm_term=.597b3f164826.
} 
submitted the recording from Roomful of Teeth's album. Thus, the official Pulitzer

announcement refers to the piece as a part of this album (akin to jazz winners Ornette Coleman and Henry Threadgill) and not as an independent work that Shaw has published. In fact, the version recorded on the album and the published version are not entirely identical. Since the album splits and reorders the movements of Shaw's piece, and the album is all they were given to listen to, the jury would have undergone an unconventional listening experience-was the piece indeed meant to be a "piece"? Were the disparate movements meant to be unified? The full version, contiguous version of the Partita was not premiered until months after Shaw's Pulitzer win. ${ }^{19}$

Since then, both the Partita and Caroline Shaw have been presented been presented as the album's standout, and Shaw's career has undergone a major transformation. ${ }^{20}$ She has since received orchestral commissions from the Baltimore Symphony Orchestra and the Greenville Symphony Orchestra in North Carolina, as well as residencies at Dumbarton Oaks in 2014 and Music on Main in 2016. A particularly notable collaboration occurred in 2015, when Caroline Shaw was approached by rap artist Kanye West with the idea that she contribute to an upcoming live show supported by an orchestra. Shaw decided to remix West's Say You Will, and the track

\footnotetext{
${ }^{19}$ This situation is not without precedent. The 2000 Pulitzer for Lewis Spratlan's opera Life is a Dream was not complete, nor did it receive a full staging until 2010. It subsequently won Spratlan and librettist James Maranis the first and only (to date) Charles Ives Opera Award from the American Academy of Arts and Letters. See David Belcher, "What Dreams May Come," Opera News 75, no. 1 (2010): 40-41. For details of Shaw's full premiere, see Anthony Tommasini, "The Pulitzer Prize Was Nice and All, but a Work Is Finally Fully Heard," New York Times, November 5, 2013, https://www.nytimes.com/2013/11/06/arts/music/caroline-shaws-partita-has-premiere-by-roomful-ofteeth.html.

${ }^{20}$ Selected Pulitzer announcements. See J. Bryan Lowder, "The Strange, Beautiful Music that Won the Pulitzer This Year," Slate, April 17, 2013, Accessed March 24, 2019, http://www.slate.com/blogs/browbeat/2013/04/17/partita_for_8_voices_pulitzer_prize_winning_composition_by_ca roline_shaw.html; Jamie Saxon, "Update: Princeton's Caroline Shaw wins Pulitzer Prize for music," Columbia University, April 15, 2013, Accessed August 27, 2018, https://www.princeton.edu/news/2013/04/15/updateprincetons-caroline-shaw-wins-pulitzer-prize-music; Anastasia Tsioulcas, "Caroline Shaw, 30, Wins Pulitzer for Music," National Public Radio, April 15, 2013, https://www.npr.org/sections/deceptivecadence/2013/04/15/177348405/caroline-shaw-30-wins-pulitzer-for-music.
} 
was released in 2015. This led to several more collaborations, including an onstage appearance at West's 2016 performance at the Democratic National Convention, as well as contributing vocals on his seventh album The Life of Pablo. ${ }^{21}$ Virtually unknown, and only two years into formal composition training at the time of her Pulitzer, Caroline Shaw's win is among the more impactful of all Pulitzer winners in terms of generating success. She now serves on the faculty of New York University and is a Creative Associate of the Juilliard School.

\section{Angel's Bone, Du Yun (2017 winner)}

As one of the founding members of the International Contemporary Ensemble, Du Yun's (b. 1977) compositional career was closely tied to the ensemble's success. Following her graduation from Harvard's Ph.D. in Composition program in 2006, she went on to win a 2007 Fromm Foundation Commission and an affiliation with Boosey \& Hawkes, further solidifying her image as a composer who was known to blur genre lines and blending styles.

Collaboration, dialogue, and social issues are at the forefront of many of Du Yun's works; the genesis of Angel's Bone and its subsequent developments between 2011-2016 were the result of many artistic partnerships, beginning with Philadelphia's Mann Center, then librettist Royce Vavrek, opera companies Beth Morrison Projects and the Choir of Trinity Wall Street, and culminating in performances at the 2014 and 2016 Prototype Festivals. In Angel's Bone, two angels fall to earth and become captured and enslaved by suburban homeowners, Mr. and Mrs. XE. As an allegory for the exploitation of human trafficking and sexual slavery, Du Yun's opera falls squarely within the confines of her statement of artistic vision above.

\footnotetext{
${ }^{21}$ Stacey Anderson, "Is Caroline Shaw Really the Future of Music?" Guardian, June 9, 2016, https:/www.theguardian.com/music/2016/jun/09/caroline-shaw-classical-music-kanye-west
} 
Angel's Bone is a perfect example of how critical attention can build slowly over time. Its Pulitzer is the result of its January 2016 world-premiere performance at New York City's Prototype Festival — but its original world premiere occurred in 2011, the very first commission of Philadelphia's Mann Center for the Arts. When Catherine M. Cahill became the president and CEO of the Mann Center in 2008, the venue re-envisioned itself as an institution which provides not only high-level classical music concerts, but other informal concerts, ranging from audiovisually enhanced classical music to pop music to crossover events, such as the "Indie Pop Dance Party," which the premiere of Angel's Bone headlined. ${ }^{22}$ Funded by a grant from the Philadelphia Music Project and the Pew Center for Arts \& Heritage, their intent was originally to commission a chamber piece. As part of the "Indie Pop Dance Party" the premiere had a sort of grungy flair; the event also boasted an opening act that featured a "DJ battle between Lee Mayjahs and Phil Moffa and a dance after-party on PECO Plaza.”23

The idea for the collaboration between Du Yun and librettist Royce Vavrek was conceived even before the Mann's commission. Vavrek described his meeting Du Yun in 2010, when they were both represented in the New York City Opera's VOX Contemporary American Opera Lab, writing "We both fell in love with each other's work." ${ }^{24}$ They knew a collaboration was imminent, but decided upon being by the Mann that it was the perfect excuse to begin a

\footnotetext{
${ }^{22}$ Alternative or "DIY" venues in contemporary music exist outside of established and institutionalized "concert hall" culture, representing "communities of composers, performers, and listeners that maintain that this music scene is not only outside of the 'authorized' physical, economic, and media spaces of music," but also outside their aesthetics. See Andrew Kluth, A Study of the Los Angeles DIY Experimental Music Scene: Reflections on the Promise of the Possible" (Ph.D. diss., University of California Los Angeles, 2018), 5.

${ }^{23}$ Silvana Pop, "World-Renowned Experimental Composer Du Yun To Headline an Indie Pop Dance Party at The Mann Center Friday, September 23," Uwishunu Philadelphia, September 22, 2011, https://www.uwishunu.com/2011/09/world-renowned-experimental-composer-du-yun-to-headline-an-indie-popdance-party-at-the-mann-center-friday-september-23/.

24 “A Concert Reading of Angel's Bone," Program notes for Angel's Bone, Beth Morrison Projects, Julian Wachner, New York: Trinity Wall Street Church, Accessed April 24, 2019, https://www.trinitywallstreet.org/sites/default/files/Angel\%27sBoneForTrinityPRINT2.pdf.
} 
project. Shortly thereafter, Vavrek proposed a story about angels, to which Du Yun countered with a story about human trafficking: they synthesized these two ideas into an original narrative, and shortly thereafter, Du Yun wrote the first piece from the opera, "Brick J".

The original premiere in 2011 went largely unheralded, with only two announcements of the show in local media outlets and no reviews to speak of, despite the involvement of Du Yun, Vavrek, and members of ICE (including Claire Chase) in the orchestra. It was at this point that Beth Morrison Projects, stepped in to commission a full-evening version of Angel's Bone. Beth Morrison, who began the organization, is an opera impresario for the twenty-first century; she views her place in the world of opera as a support system for emerging and established artists alike, providing financial feasibility for premiere and repeat stagings of contemporary opera. ${ }^{25}$ Typical of Beth Morrison's process, the process has a long 3- to 4-year period of "incubation" and it was this catalyst that inspired late-stage and fully completed presentations of Angel's Bone at the 2014 and 2016 Prototype Festivals. ${ }^{26}$ The 2014 reading changed hands from the Philadelphia-based groups to New York-based ones, directed Julian Wachner and sung by the Trinity Wall Street choir. Novus NY, the Trinity Wall Street church's resident new-music chamber ensemble served as the pit orchestra, replacing the original performers, ICE. ${ }^{27}$ As a preview, the production was not supposed to be reviewed, though the Wall Street Journal did mention it anyway. ${ }^{28}$

\footnotetext{
25 "About," Beth Morrison Projects, Accessed March 24, 2019, https://www.bethmorrisonprojects.org/about.

${ }^{26}$ Ebright, "Echoes of the Avant Garde in American Minimalist Opera," 7.

${ }^{27}$ The Protytpe Festival itself is sponsored and produced by Beth Morrison Projects, serving as a vehicle for lessexpensive production coupled with heightened critical coverage in the press.

${ }^{28}$ Heidi Waleson writes "The wildest items in the festival were Du Yun and Royce Vavrek's Angel's Bone," still a work in progress and not for review, but intriguing in its mix of musical styles and its fantasy take on the subject of sex trafficking." See Heidi Waleson, "An Ambitious Sophomore Effort," Wall Street Journal, January 21, 2014, https://www.wsj.com/articles/an-ambitious-sophomore-effort1390344853 ? $\mathrm{mod}=$ searchresults \&page $=1 \&$ pos $=2 \&$ tesla $=y$.
} 
The official world-premiere staging occurred at the 2016 Prototype Festival, still supported by BMP. Buildup for the Protoype Festival begins well in advance, with some preview coverage as early as July of the previous year-adding to the anticipation, Du Yun even sang the quintessential piece, "Brick J" as part of her set in the 2015 Resonant Bodies Festival. ${ }^{29}$ Angel's Bone was set to be the festival's opener, and with David T. Little's Dog Days, represented the majority of the attention. The 2016 full staging retained its female leads, Abigail Fischer and Jennifer Charles, but substituted Kyle Pfortmiller and Kyle Bielfield for the male leads. The ensembles, comprising the Choir of Trinity Wall Street and Novus NY were also featured again, but this time under the direction of Michael McQuilken. The 2016 Prototype Festival as a whole, and especially Angel's Bone was a rousing success. ${ }^{30}$

Unlike other non-staged genres of narrative vocal music, the difficulty of presenting a fully-staged opera meant that after its premiere performance, Angel's Bone was not likely to receive a full revival any time in the near future. All that changed when it won the 2017 Pulitzer Prize. Throughout the rest of 2017 and stretching into 2018, the music of Angel's Bone was recorded and released on the New Amsterdam label in September 2017, spawning a music video for what now has come to be its workhorse piece, "Brick J", which was premiered on the online new music magazine I Care if You Listen in January $2018 .{ }^{31}$ Du Yun's alma mater, Oberlin

\footnotetext{
${ }^{29}$ For preview coverage, see Russell Platt, "The Prototype Festival," The New Yorker, January 11, 2016, https://www.newyorker.com/magazine/2016/01/11/fully-committed; American Theatre Editors, "Enda Walsh and Heidi Rodewald to Present at Prototype Festival," American Theatre, July 22, 2015, https://www.americantheatre.org/2015/07/22/enda-walsh-and-heidi-rodewald-to-present-at-prototype-festival/; For reviews of the 2015 Resonant Bodies Festival, see David Allen, "Review: The Resonant Bodies Festival Completes Its Third Year," New York Times, September 11, 2015, https://www.nytimes.com/2015/09/12/arts/music/review-theresonant-bodies-festival-completes-its-third-year.html.

${ }^{30}$ For reviews of the 2016 World Premiere, see Heidi Waleson, "Dystopia on Stage at Prototype Festival," The Wall Street Journal, January 11, 2016, https://www.wsj.com/articles/dystopia-on-stage-at-prototype-festival-1452549439; Corinna da Fonseca-Wollheim, "Review: In 'Angel's Bone,' Terrified Seraphim at the Mercy of Mortals," The New York Times, January 7, 2016, https://www.nytimes.com/2016/01/08/arts/music/review-in-angels-bone-terrifiedseraphim-at-the-mercy-of-mortals.html.

${ }^{31}$ Amanda Cook, "Video Premiere: Angel's Bone Music Video featuring Du Yun," I Care If You Listen, January 9, 2018, https://www.icareifyoulisten.com/2018/01/video-premiere-angels-bone-music-video-featuring-du-yun/.
} 
Conservatory announced that they would undertake the second staging in January $2018 .{ }^{32}$ In 2017, she left her position at SUNY Purchase for a composition faculty position at the Peabody Institute of Johns Hopkins University and a distinguished visiting professorship at the Shanghai Conservatory of Music. Despite the span of less than two years between Du Yun's Pulitzer win an the writing of this thesis, Angel's Bone has already enjoyed a rich afterlife and another round of critical attention.

\section{Silent Night, Kevin Puts (2012)}

Kevin Puts (b. 1972) is known primarily as a composer of orchestral music. Following his 1999 Barlow International Prize in Orchestral Music, a 2001 Guggenheim Fellowship, the 2001-2002 Rome Prize, and the 2003 Benjamin Danks Award, Puts received many early opportunities for orchestral premieres. It was a unique opportunity, then, that the Minnesota Opera's artistic director Dale Johnson decide to commission Kevin Puts's first opera. Although Puts was inexperienced as a composer for voice, a nonplussed Johnson was certain that Puts's talent as an orchestrator and melodist would be the ideal person to set an operatic version of the film Joyeux Noël. The film takes place during a spontaneous three-day ceasefire leading up to Christmas Eve 1914, in the midst of World War I. After watching the film, Puts agreed to write the opera, but approached Johnson with trepidation. Soon after, Johnson hired veteran librettist Mark Campbell.

The world premiere was given by the Minnesota Opera on November 12, 2011. The performance was reviewed well by local media, as well as WQXR and Opera News, but soon

\footnotetext{
${ }^{32}$ Jarrett Hoffman, “Oberlin to present Winter Term Opera Angel's Bone,” Cleveland Classical, January 29, 2018, https://clevelandclassical.com/oberlin-presents-winter-term-opera-angels-bone/.
} 
after the one-night-only run, the media went quiet. ${ }^{33}$ Nothing more was heard about Puts's first opera until the Pulitzer announcement in April of 2012. After the announcement, some critics were quite outspoken about the conservatism of the piece, especially in comparison to 2012's other two finalists, a "robotic opera" by Tod Machover and a string trio by Andrew Norman. Anne Midgette observed, “There's been a lot of talk about expanding the reach of the music Pulitzers over the years. To hear these excerpts, this piece seems to be tonal, lovely — and conservative. Jazz and pop will have to wait another year, or five." ${ }^{34}$ Here, Midgette's qualm appears to be that Silent Night did not go far enough into the realm of public-oriented or accessible music. ${ }^{35}$ Her assessment exemplified the critical consensus on Puts's work.

The lukewarm Pulitzer reception notwithstanding, the attachment of the Pulitzer name to Silent Night proved to be a powerful aid in eliciting repeat performances. Now, opera companies had an impetus to program a new work, and it was even more helpful that the music was not nearly as difficult to understand as the music of many of its contemporaries. ${ }^{36}$ Of all the operas surveyed in this chapter, Silent Night boasts by far the strongest record of repeat performances. In 2013, it was staged by Opera Philadelphia. In 2014, the Fort Worth, Cincinnati, and Calgary Operas staged multiple-weekend runs, while England's Wexford Opera Festival produced the European premiere and an additional concert staging was put on by the Frankfurt Philharmonic.

\footnotetext{
${ }^{33}$ Olivia Giovetti, "Kevin Puts's Opera Silent Night Evokes Grim Reality of War," WQXR, November 15, 2011, https://www.wqxr.org/story/170472-kevin-puts-silent-night/.

${ }^{34}$ Anne Midgette, "Puts Wins Pulitzer," Washington Post, April 12, 2012, https://www.washingtonpost.com/blogs/classical-beat/post/puts-winspulitzer/2012/04/16/gIQAywR3LT_blog.html?noredirect=on\&utm_term=.c722bd8aee4c.

${ }^{35}$ In the twenty-first century, "accessibility" has become a highly contentious buzzword, used by proponents and critics alike to describe programming or compositional practices that cater to a wider, potentially non-musical audience. See Ruth Akers, "Commercialism, Accessibility, Popularity, and Originality in American high-art music: Richard Danielpour, A Case Study" (Ph.D. diss., Florida State University, 2004).

${ }^{36}$ Take, for instance, another of the works in consideration for the 2012 Pulitzer, Tod Machover's Death and the Powers. The work's digital processing of the voice and almost totally synthesizer-based pit orchestra in tandem with its lack of periodic phrases and angular melodies result in a more esoteric and abstract take on the operatic genre.
} 
Since 2014, Silent Night has been performed by no fewer than nine other companies and festivals. In the wake of its huge success, one might expect Puts's subsequent efforts in opera to achieve similar results; in fact, the situation has turned out to be quite the opposite. Neither Puts's 2015 The Manchurian Candidate or 2017 Elizabeth Cree were reviewed particularly well, and the operas have only received one restaging each.

\section{Madame White Snake, Zhou Long (2011 winner)}

Like many Chinese composers of his generation, Zhou Long's musical career was stymied by the ascension of Mao Zedong, the Communist Party of China, and the Cultural Revolution they propagated. The systematic purge of any and all traces of capitalism began in May of 1966, when Zhou Long was just twelve years old. Until this point, he had studied piano, but during his coming of age in a radically altered nation, he was instead sent to work as a farmhand for the state. Eventually, the zeal and support for the movement began to lessen, and in the last three years preceding Mao's death, Zhou Long resumed his musical training. He was among the first students of western classical music at the Central Conservatory of Beijing, along with other emigré composers Chen Quigang, Guo Wenjing, Tan Dun, and Chen Yi. ${ }^{37}$

As China's musical institutions were just appearing or reconfiguring themselves when Zhou Long was young, there were only a few employment opportunities available for young composers. Just after finishing studies at the conservatory, Long was appointed composer-inresidence of the China Broadcasting Symphony Orchestra from 1983-85, but soon decided to seek opportunities abroad. In his travels in1984, he founded an ensemble to be based in New

\footnotetext{
${ }^{37}$ Collectively, this group is sometimes referred to as "The Class of "78". See "Madame White Snake," WQXR, Accessed March 25, 2019, https://www.wqxr.org/story/13971-madame-white-snake/.
} 
York City, and dedicated to performing Chinese music: Music From China. ${ }^{38}$ In 1985, he moved permanently to the United States, beginning doctoral studies at Columbia University in New York City. It was around this time in Zhou Long's life that the systematic opportunities in the well-established world of western classical music began to reward his efforts. He won the 1990 Erster Preis for the German festival Ensemblia in Mönchengladbach, the premiere prix in the French competition d'Avray in 1991. This success escalated after he earned his doctorate in 1993. He took first place wins in the 1994 Barlow Competition and the 1998 Masterprize Competition.

For western audiences, Zhou Long's music has often been described as a fresh and convincing synthesis of traditional Chinese sounds and narratives with the techniques and aesthetics of western art music. His popularity after arriving in the U.S. was not coincidental, and he even became a United States Citizen in 1999. The rapid expansion of globalization as communist regimes were abandoned — culminating in the fall of the Berlin Wall in 1989-meant that composers such as Zhou Long, who hailed from formerly Communist countries, were a new and fascinating addition to the new music scene. ${ }^{39}$ Obviously, with such a diverse collection of individuals whose priorities are all different, traditional Chinese themes, instruments, and idioms are of varying importance. For Zhou Long, Chinese music has remained intensely important to his compositions; for Du Yun, her Chinese influences remain peripheral. Long's Madame White Snake, in particular, embraces this attitude.

\footnotetext{
${ }^{38}$ Stephen Brookes, "Zhou Long Transcends Cultural Boundaries," The Washington Post, September 9, 2016, https://www.washingtonpost.com/entertainment/music/composer-zhou-long-transcends-culturalboundaries/2016/12/09/37b0ab6c-be4f-11e6-94ac-3d324840106c_story.html?utm_term=.ad07aa592c15.

${ }^{39}$ For more on music in China's Cultural Revolution, see Lei Ouyang Bryant, "New songs of the battlefield: Songs and memories of the Chinese Cultural Revolution" (Ph.D. diss., University of Pittsburgh, 2004).
} 
The plot of Madame White Snake is a centuries-old Chinese folk tale about a demon who transforms herself from the form of a snake to the form of a woman in order that she might experience earthly love. She falls in love with a mortal man, marries him, but when her secret is discovered, she is transformed back into a snake.

Originally born into a Chinese family living in Singapore, librettist Cerise Lim Jacobs came to know the White Snake myth as a child. The opera that Zhou Long scored, Madame White Snake, was her first foray into what would eventually become a trilogy of White Snakeinspired works, which she called the Ouroboros Trilogy. For nearly all the collaborators, Madame White Snake represented a first: it was the first opera for Zhou Long and Jacobs, and it was the Boston Opera's first commission, co-sponsored by the Beijing Music Festival Arts Foundation, for which the opera was its first partnership with an American company. ${ }^{40}$ The general director of the Boston Opera, Carole Charnow, read Jacobs's libretto and decided that she wanted to produce it. The last stage of this process was choosing a composer; Jacobs created a shortlist of ten composers, five of whom were American, and five of whom were ChineseAmerican. ${ }^{41}$ She set up personal interviews with each. During Zhou Long's interview, he told her, "I read your libretto and I can hear the music." At this point, Jacobs chose Zhou Long to write the music. ${ }^{42}$ Of this experience, he recounted:

I found freedom and flexibility in the English language, which, unlike Chinese, does not use intonation or variation in pitch to distinguish words. The scoring is inspired by some elements from traditional Chinese opera, musically and stylistically, with the integration of traditional instruments which brings in a fresh sound and illustrates a musically exotic style... The result is a genuine mixture: Chinese influences combined with Western operatic writing and orchestration,

\footnotetext{
40 “Madame White Snake," https://www.wqxr.org/story/13971-madame-white-snake/.

${ }^{41}$ The Friends of Madame White Snake, http://www.madamewhitesnake.org/html/MWS\%20Pulitzer\%20Press\%20release.pdf

${ }^{42}$ Originally, Jacobs's intention was to include Chen Yi, another well-known Chinese composer (and Zhou Long's partner) in the creation of Madame White Snake's music. See "Madame White Snake," https://www.wqxr.org/story/13971-madame-white-snake/.
} 
recitation combined with singing, tonal or atonal, and an international cast of Chinese and American singers. ${ }^{43}$

The premiere of Madame White Snake was a high-profile affair, garnering many reviews. Opera News, the American Record Guide, and the Boston Globe praised its performers, staging and music, though its libretto's reception was mostly negative. ${ }^{44}$ Nonetheless, the local media proclaimed it to be a rousing success, and it became the highest-grossing production in this history of the Boston Opera. Its second run at the Beijing Music Festival was also heralded as an important event, sparking another flurry of critical attention that lasted into the next calendar year. On 11 April 2011, the Pulitzer board made its announcement that Madame White Snake had won.

"Madame White Snake by Zhou Long has been awarded the 2011 Pulitzer Prize in Music."

"Chinese-America composer Zhou Long has won the Pulitzer Prize for music with his opera Madame White Snake." "The opera "Madame White Snake," by composer Zhou Long, has won the 2011 Pulitzer Prize for music." 45

In these announcements and all the ones that came after, the attachment of the Pulitzer name initiated a shift—not in tone as for Caroline Shaw or David Lang, but in attention. With Zhou Long's score for the opera now one of the biggest draws for attendance, critics began to refer to the whole opera as his, not just the music. Meanwhile, the driving creative force behind Madame White Snake had been erased. The musical specialists, whose interests and priorities

\footnotetext{
43 Ibid.

44 David Shengold, "Madame White Snake Worthwhile Effort from Opera Boston," Boston Musical Intelligencer, March 3, 2010, https://www.classical-scene.com/2010/03/03/madame-white-snake-worthwhile-effort-from-operaboston/.

${ }^{45}$ Frank J. Oteri, “Zhou Long Wins 2011 Pulitzer Prize,” New Music Box, April 18, 2011 , https://nmbx.newmusicusa.org/zhou-long-wins-2011-pulitzer-prize/; Tom Huizenga, "Zhou Long Wins Music Pulitzer For Fairy Tale Opera," National Public Radio, April 11, 2018, https://www.npr.org/sections/deceptivecadence/2011/04/18/135522931/zhou-long-wins-music-pulitzer-for-fairytale-opera; David Ng, "Composer Zhou Long wins Pulitzer Prize for 'Madame White Snake," The Los Angeles Times, April 18, 2011, http://latimesblogs.latimes.com/culturemonster/2011/04/composer-zhou-long-wins-pulitzerprize-for-madame-white-snake.html .
} 
were further narrowed by a musical prize, passed over the librettist and creator, Cerise Lim

Jacobs, altogether. Before the Pulitzer win, Jacobs was mentioned just as frequently, if not more so, than Zhou Long.

This situation is not without precedent: multimedia events at large have been similarly co-opted by their composers. ${ }^{46}$ But to deny the importance of Jacobs's contribution to the opera is to leave its future without an explanation. Madame White Snake led a long life after its Pulitzer win, due almost solely to Jacobs efforts, supported by Beth Morrison Projects. Jacobs envisioned a trilogy on the White Snake story, and Beth Morrison and her Prototype Festival supported the two additions through multiple years of development. The cycle as a whole, entitled Ouroboros, was premiered in 2016 .

\section{$D A M N$., Kendrick Lamar (2018)}

Kendrick Lamar (b. 1987) is a Los Angeles-based hip hop artist whose critical reception has often sparked controversy. Lamar's breakthrough came with his second album, Good Kid, M.A.A.D. City, produced by TDE and Aftermath Entertainment, but importantly, distributed by Interscope Records. ${ }^{47}$ Where his previous album was distributed online only via the iTunes store, Interscope backed Good Kid, M.A.A.D. City with an advance of five singles, a marketing campaign, and the name-brand recognition of producers such as Dr. Dre and Pharrell Williams. It gave Lamar immediate attention, debuting at number two in the Billboard 200. The accolades

\footnotetext{
${ }^{46}$ Igor Stravinsky has often been referred to as the sole incendiary of the 1913 riots at the premiere of Le sacre $d u$ printemps, but his involvement (and that of his music) was merely a part of, or even subsidiary to the other elements of the ballet, especially dance. See Richard Taruskin, "A Myth of the Twentieth Century:

The Rite of Spring, the Tradition of the New, and 'The Music Itself,"' Modernism/modernity 2, no. 1 (1995): 16.

${ }^{47}$ Interscope Records is one of the most famous labels in rap and hip-hop, having represented artists like Tupac Shakur, Dr. Dre, Snoop Dogg, Lady Gaga, and The Black Eyed Peas. See Diane Bailey, The Story of Interscope Records (New York: Simon \& Schuster, 2012).
} 
were numerous, including a nomination for the 2013 Billboard and American Music Awards, a win for the 2013 BET Hip Hop Awards, and five Grammy nominations.

Lamar's next album, To Pimp a Butterfly (2015) went even further toward redefining Lamar's hip-hop language. Terrace Martin, saxophonist and producer stated:

Way before we did the music, it was important that everybody [understood] what being black was really about ... It wasn't, "We're gonna do jazz, we're gonna do funk," we just wanted to be the soundtrack to [Kendrick's] experience. What other music to do behind that but black music. ${ }^{48}$

Kendrick Lamar's artistic risks paid off. To Pimp a Butterfly earned 11 Grammy Nominations, winning for Best Rap Album, in addition to Album of the Year awards from Pitchfork, Consequence of Sound, and Rolling Stone. Its acceptance was not unqualified, however. The album was nominated for the Grammy Album of the Year and was expected to win; instead, Taylor Swift's 1989 won amid a flurry of outraged press coverage.

In many ways, To Pimp a Butterfly initiated a shift in direction for Lamar. When Lamar began touring for his follow-up to To Pimp a Butterfly, which he entitled DAMN, he incorporated a set of short video clips, which when strung together, became a narrative. Its hero was Kung Fu Kenny, Kendrick Lamar's alter-ego, who was on a quest to master the art of rap and hip hop. Intertwined with Lamar's performance of the album, the videos equated the allegory of the video to the lyrics of the songs, and $D A M N$. became both the enactment and the product of the quest. As Lamar said, "I look at Kung-Fu Kenny as a master of the craft now. Now I have the ability to make songs, and still have the wordsmith technique, and intertwine it and have a

${ }^{48}$ Ibid. 
composed mentality on how to approach music." ${ }^{49}$ Almost a year to the day DAMN. was

released, Dana Canedy announced that the album had won the Pulitzer Prize for Music.

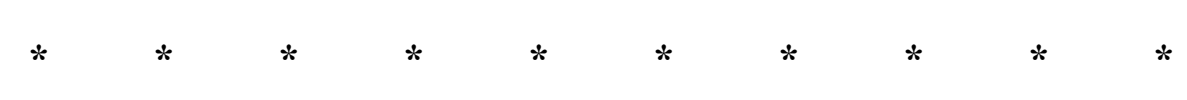

David Lang's gentle, yet unrelenting melodies, Du Yun's genre, wild and

uncategorizable, the caustic oratory of Kendrick Lamar...they tell us that there is no one way to win a Pulitzer Prize; the winning pieces are not cookie-cutter similar, nor are their composers. Despite the wide variation from case to case, a number of interesting comparisons can be drawn across this body of work. The following section will address the ways in which the narrative vocal works of the Pulitzer Prize resemble one another, and also demonstrate where they diverge. A discussion of these similarities will help the reader to identify trends in the Pulitzer's selections. While the main focus of this section will be the works and composers highlighted above, data from the instrumental winners, other decades of the Pulitzer, and even other prizes can provide a fuller and more contextualized understanding of the changes in each variable over time.

\section{Age and Experience}

From perspectives both colloquial and scholarly, society's value for age, expertise, and wisdom are being rapidly overtaken by innovation and youth. As society moves deeper into the twenty-first century, musicians in particular are beginning to take up debates about ageism. ${ }^{50}$

\footnotetext{
49 Brian Zisook, "Kendrick Breaks Down the Difference Between "K.Dot" and "Kung-Fu Kenny," DJ Booth, November 7, 2017, https://jbooth.net/features/2017-11-07-kendrick-lamar-the-difference-between-kdot-kung-fukenny.

50 See Bill Doerrfield, "Ageism in Composer Opportunities," New Music Box, June 5, 2013, https://nmbx.newmusicusa.org/ageism-in-composer-opportunities/; Daniel Kreps, "Madonna Accuses BBC Radio of 'Ageism' After Song Ban," Rolling Stone, March 14, 2015, https://www.rollingstone.com/music/musicnews/madonna-accuses-bbc-radio-of-ageism-after-song-ban-42426/; Ashton Applewhite, “You're How Old? We'll
} 
The tension between younger composers and older ones is unsurprisingly derived the same scarcity of resources that drives the need for competition in the first place. ${ }^{51}$ They are fueled even further by the implicit value of newness to many institutions, from college music curricula to grant applications. ${ }^{52}$ Thus, a seemingly unresolvable conflict occurs wherein both younger and older composers feel restricted from opportunities by the presence of the other party. Institutional missions may have an influence on how this dispute is decided; Northwestern University's Nemmers Prize, for example, seeks to reward achievement in a body of work, thereby privileging older composers with larger oeuvres. Conversely, emerging composer prizes are designed to award composers only up to a certain age. The Pulitzer's promotion of "distinguished" music exists outside the concern of experience and thus is an interesting venue to inspect the age of its winners.

All the more striking, then, is the decreasing average age of Pulitzer Prizewinners. In fact, if 2008 is to be taken as a breaking point, with roughly a decade in front and roughly a decade behind, the contrast between those decades is stark. From 1998 to 2008, the average age of the winners is 60.4 years old. The next decade sees a decrease to 50.9 years old, almost a $16 \%$ decrease. Such a skew between the two decades is likely a result of some of the oldest ages belonging to the first decade: Henry Brant won at age 89, and Ornette Coleman and Yehudi Wyner both won at age 77. Conversely, some of the youngest ages belong to the second decade:

\footnotetext{
Be in Touch," The New York Times, September 3, 2016, https:/www.nytimes.com/2016/09/04/opinion/sunday/yourehow-old-well-be-in-touch.html; Murray Forman, "Ice/age: Experience, achievement, and transformations of an OG," in Rapper, Writer, Pop-cultural Player: Ice-T and the Politics of Black Cultural Production, eds. Josephine Metcalf and Will Turner (New York: Routledge, 2014).

${ }^{51}$ Intergenerational disputes are increasingly based in "prescriptive stereotypes," which tell what ideal members of a certain generation should do, rather than descriptive stereotypes which tell what members of a certain generation are doing. One of the fundamental drivers of intergenerational tension is the prescriptive stereotype that older adults should retire to make space in the working population for younger workers, despite older adults' need for continued income to make a living wage. See Michael T. North \& Susan Fiske, "A Prescriptive Intergenerational-Tension Ageism Scale: Succession, Identity, and Consumption (SIC)," Psychological Assessment 25, no. 3 (2013): 707.

${ }^{52}$ Ritchey, “Amazing Together," 3.
} 
the three of the five youngest-ever winners, Caroline Shaw, Kendrick Lamar, and Kevin Puts all won between 2008 and 2018. ${ }^{53}$

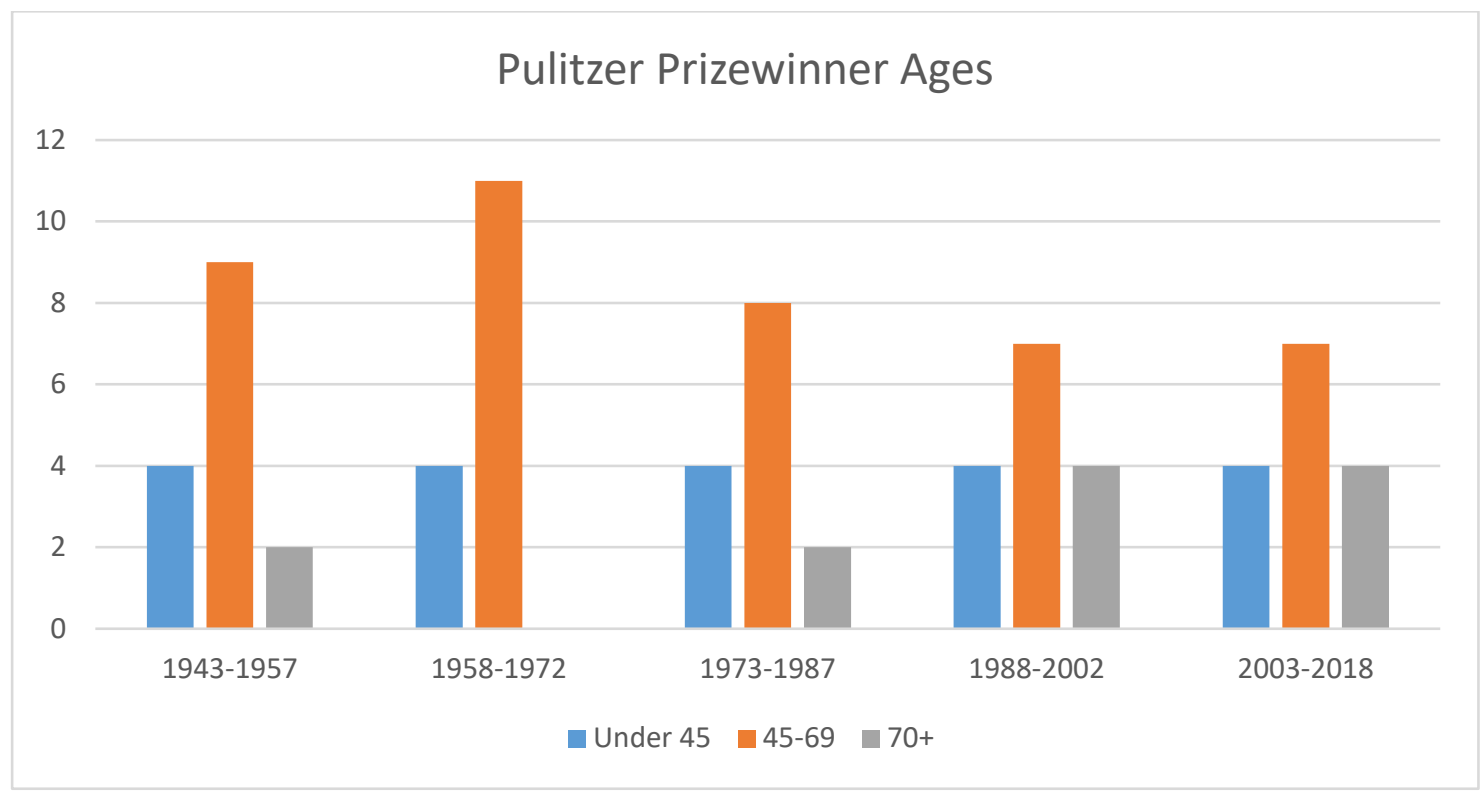

Figure 3. Pulitzer Prizewinner Ages.

In contrast, the Grawemeyer Award does not have nearly so many young outliers to weigh down the average age. Between 2008 and 2018 the average age of the ten winners is 54.7 years old, which means that the winners of the Grawemeyer Award are generally older than those of the Pulitzer Prize. In comparison, the historical Grawemeyer's winners from 1998 to 2008, have an average age of 52.6 the recent decade also represents a much less considerable shift in favor of young composersConsidering that the Pulitzer Prize and the Grawemeyer Award are comparable in terms of prestige and social capital, the age difference between the two is all the more notable. It is possible that the Pulitzer's emphasis on social justice and the neoliberal

\footnotetext{
${ }^{53}$ The force that these outliers possess is mitigated somewhat by the presence of Aaron Kernis (age 38) and Melinda Wagner (age 42) in 1998-2008 and Henry Threadgill (age 72) and Steve Reich (age 73) in 2008-2018.
} 
economy's emphasis on innovation and newness for the sake of newness puts older composers at a disadvantage. ${ }^{54}$ The last five years of this decade, from 2013 to 2018 , contains the two youngest winners, Caroline Shaw and Kendrick Lamar. Though it also contains Henry Threadgill, among the oldest winners, and Julia Wolfe, just above the average age, the last winner of this period, Du Yun, pushes the numbers back in favor of younger composers.

\section{Text and Narrative}

The strongest element of unification among Pulitzer winners of the past decade is the presence of text or narrative. All seven works feature text in some significant way, and six of the seven use the text to tell a story. ${ }^{55}$ For the Pulitzer, opera and other narrative genres more broadly have been an important part of its history, despite being generally outweighed by orchestral genres. ${ }^{56}$ In their use of words to convey concrete expressions of ideas or emotions, texted Pulitzer winners have historically used well known literary texts, from the poetry of Charles Baudelaire, Walt Whitman, or Virginia Woolf to religious texts. ${ }^{57}$ In the past five years, however, the Pulitzer's Board has almost exclusively chosen works with overt political statements.

Lydia Goehr establishes an inclusive view of political music apart from a purely "formalist" perspective, arguing for a middle ground between the purely musical and the purely political. She writes, "Behind the current tendency to socialize or politicize music lies a strong

\footnotetext{
${ }^{54}$ The value of innovation is rooted in Karl Marx's concept of "creative destruction," in which old models are perpetually subsumed by newer ones. For more on creative destruction see Chapter Two. See also Moore, "Neoliberalism and the Musical Entrepreneur," 37.

55 The exception in this case is Caroline Shaw's Partita for 8 Voices.

${ }^{56}$ For a more detailed discussion of the role of vocal music in the history of the Pulitzer Prize, see Chapter Two. See also Appendix.

${ }^{57}$ These works include Lilacs by George T. Walker (1996 winner), Visions of Terror and Wonder by Richard Wernick (1977 winner), and Canti del Sole by Bernard Rands (1984 winner).
} 
impulse: to pull music down from its romantic pedestal — to deromanticize it — to treat the music of Western high culture as we do any other kind of music or any other kind of cultural artifact."58 Uniquely among composition prizes, the Pulitzer's vocal works are derived from this politicizing impulse, which must speak especially clearly to the journalists who make up the Board. Just as music has drawn on the broader social fabric to include technological developments such as electronics, and influence from popular music, the stories composers are interested in telling are similarly indebted to contemporary society's commitment to social justice.

The Pulitzer's emphasis on the nation's political values dates back to its earliest winners. William Schuman's Secular Canata No. 2 and Gian Carlo Menotti's The Consul are both examples of the same kinds of politically-driven texts that are winning the Pulitzer currently. During the mid-twentieth century, the struggle in the United States to redefine itself as global authority led to overtly nationalistic political concerns. The Secular Cantata's deployment of patriotic imagery and The Consul's focus on the bureaucracy of immigration were both timely issues, and both articulated explicitly and eloquently. The narratives of recent Pulitzer-winning works cover a range of contemporary issues. Angel's Bone is an allegory for sex trade and human trafficking, $D A M N$. tells the story of a black man's struggle in America, and Anthracite Fields, while historical, is just as relevant for its critique on the egregious working conditions of the industrial age. Political texts are an easy way to connect with the public, irrespective of the musical language used to convey them. Of these three, Du Yun's Angel's Bone strays furthest away from the mainstream of popular music, but still maintains its ability to connect with a broad cross-section of the public due to the intelligibility of its text.

\footnotetext{
${ }^{58}$ Lydia Goehr "Political Music and the Politics of Music," Journal of Aesthetics and Art Criticism 51, no. 1 (1994):
} 101. 
Political narratives, however, frequently extend beyond the semantic content of the text. Pulitzer winners of the past decade show a tendency toward multimodality, infusing musica. depictions of American life with kinesthetic, tactile, and visual stimulus. Nina Eidsheim argues for a thick reading of music: rather than conceiving of music as purely notes and rhythms (or even notes, rhythms, and contextual meanings) she incorporates the visceral feeling of music as part of and extending from the body. Dramatic or operatic Pulitzer winners therefore engage the viewer more fully in their political critique than simply texted vocal music or the implication of instrumental music. They hew as closely as possible to the real, lived experienced of the themes each work addresses, and affectively prod recipients with appropriate scores. In effect, the narrative vocal winners of the Pulitzer Prize match the organization's values most primally, resulting in a version of music that is just as much "documentary" or "reportage" as its journalistic winners.

\section{Nationalism vs. Cosmopolitanism}

The tension between an American national vernacular and a cosmopolitan one that transcends the geopolitical boundaries has haunted American music in particular since its inception. Arguments over the meaning of the word "cosmopolitanism" are centuries old, and its connotation as a positive or pejorative descriptor of music has reversed several times. ${ }^{59}$ "Cosmopolitan" has been used to signify many different facets of a globalized perspective; it differentiates the urban from the rural as much as it points to a transcendence of national identities. On the opposite pole, "nationalism" is similarly contentious. Musical nationalism can embrace the fierce pride in localized traditions that have gone overlooked by canon-centric

\footnotetext{
${ }^{59}$ For a detailed description of the term's treatment over time, see Leon Botstein, "On the Uses of the Concept of the Cosmopolitan," Musical Quarterly 99, no. 2 (2016): 135-138.
} 
narratives of music history, but it can also be an exclusionary force that can be used to reject or other the work of displaced or transnational musicians. ${ }^{60}$

As I showed in Chapter Two, a Pulitzer Prize for music was only considered to be a viable option once there was a demonstrably "American" music, totally outside the realm of music of prominent European emigrés. The 1940s, when the music prize was initiated, was a period during which "ideas about national identity were consolidated in both internal discourse and internationally-oriented propaganda". ${ }^{61}$ World War II and the Cold War only fueled the drive towards American music even further. Therefore, the Pulitzer Prize's explicit mission as a prize for Americans further complicates this already complex and messy competition between nationalism and cosmopolitanism.

Of the seven composers profiled in this chapter, only two were born outside the United States: Zhou Long and Du Yun. Both were born in China, then left their home country to pursue a musical career in the United States in early adulthood. These two composers are ideal case studies through which to discuss problems of cosmopolitanism and nationalism, not only for their contrasting reactions to Chinese music.

Pulitzer Prize-winner Du Yun, born and raised in Shanghai and currently based in New York City, is a composer, multi-instrumentalist, performance artist, activist, and curator for new music, working at the intersection of orchestral, opera, chamber music, theatre, cabaret, musical, oral tradition, public performances, sound installation, electronics, visual arts, and noise. Hailed by The New York Times as a "leading figure in China's new generation of composers" and often cited as a key activist in New York's "new movement in new music," Du Yun's music is championed by some of today's finest performing artists, ensembles, orchestras, and organizations around the world. ${ }^{62}$

\footnotetext{
${ }^{60}$ See Sarah Collins and Dana Gooley "Music and the New Cosmopolitanism: Problems and Possibilities," The Musical Quarterly 99, no. 2 (2017): 139-165.

${ }^{61}$ Fauser The Sounds of War, 1.

${ }^{62}$ Du Yun, “About,” Accessed March 24, 2019, http://channelduyun.com/about/.
} 
The first sentence of Du Yun's official biography shows the expansive range of her output. Indeed, one of the most common words used by the press to describe her is "omnivorous". ${ }^{63}$ For this reason, she is an ideal example of the kind of cosmopolitan musical style that has developed in the wake of contemporary music's arguments over the relevance of generic boundaries. With the phrase "at the intersection" she emphasizes her music's existence between the cracks of genres; she writes operas that are part-cabaret or part-pop concert, not simply single works that are confined to the idioms of one tradition. These elements of intersectionality and a loose relationship with genre are touchstones of a particular community of contemporary music, and thus her biography helps to position her in terms of a larger network of composers, performers, and listeners. Her reference to her musical lives in New York City and in China are even-handed, and the final sentence of the excerpt highlights her music's global presence.

An important aspect of Du Yun's cosmopolitanism is her relationship with Chinese music. She does not give Chinese music a higher priority than any of her other influences—she notes that the most impactful part of her Chinese heritage is its philosophy. In interviews, she has stated that "I did not grow up completely with Chinese culture, so if my music were to have Chinese culture in it, it would not be a genuine reflection of who I was. I do not want to use that without understanding it." 64 This is not to say she has not composed using elements of Chinese music - her ouvre includes several works for Chinese instruments and on topics related to

\footnotetext{
${ }^{63}$ Interviews, reviews, and profiles tend to strengthen descriptions of Du Yun's non-conformance to genre with words like "omnivorous" or "interdisciplinary." Notable examples include Lara Pellegrinelli, "Composer Portraits: Du Yun," Miller Theatre, November 2, 2018, https://www.millertheatre.com/explore/program-notes/composer-portraits-duyun; Frank J. Oteri, "Du Yun: No Safety Net," New Music Box, September 17, 2014, https://nmbx.newmusicusa.org/du-yun-no-safety-net/; Seth Colter Walls, "Review: Du Yun Conjures a Musical World of Legos and Chants," The New York Times, November 19, 2018, https://www.nytimes.com/2018/11/19/arts/music/review-du-yun-miller-theater.html.

${ }^{64}$ Frank J. Oteri, “Du Yun: No Safety Net,” New Music Box, September 17, 2014, https://nmbx.newmusicusa.org/duyun-no-safety-net/.
} 
Chinese culture. What is notable about Du Yun's treatment of these works is that they are not foregrounded in a more specific way than any of her other works, given somehow a higher or more authentic status than her works for purely Western instrumentation. She does goes on to acknowledge that Chinese music has begun to play more of a role in her composition in recent years, and that even some of her earlier works have incorporated Chinese-language titles, and instruments such as the zheng, xiao, er-hu and yang-qin. ${ }^{65}$ However, while her Chinese heritage is usually mentioned in the press, it is not foregrounded so heavily. She does not eschew it, but the passage above makes it clear that she positions herself globally, not locally.

In contrast, Zhou Long's biography is built on a nationalistic duality: he is a ChineseAmerican composer. His biography states:

$\mathrm{He}$ is internationally recognized for creating a unique body of music that brings together the aesthetic concepts and musical elements of East and West. Deeply grounded in the entire spectrum of his Chinese heritage, including folk, philosophical, and spiritual ideals, he is a pioneer in transferring the idiomatic sounds and techniques of ancient Chinese musical traditions to modern Western instruments and ensembles.

Where Du Yun is "working at the intersection," Zhou Long is "deeply grounded." His musical style is heavily reliant upon idioms and instruments native to China, and the work for which he won the Pulitzer Prize is based upon a Chinese folk tale. His Chinese heritage is essential to his musical persona in a way that $\mathrm{Du}$ Yun tries actively to distance.

Biographies are only one small element of a composer's articulation of their identity, yet they are a powerful indicator of how composers claim cultural legitimacy. These devices of personal identification become especially important as media (including the Pulitzer) use them as the basis for their own interpretation and characterization of their work. ${ }^{66}$ At present, however,

\footnotetext{
${ }^{65}$ These works include ...like the euphillum blooming at night (2003); Lethean (2007); The Hidden Face (2012)

${ }^{66}$ For example, the media persistently locates Inuk-avant garde artist Tanya Tagaq's as caught between what they posit are two opposing poles: tradition and modernity. Such misrepresentation of Tagaq's stance toward traditional
} 
the marketing of classical music is so entrenched in neoliberal ideologies that racialized descriptions are commonplace ${ }^{67}$ How, then, can the Pulitzer attempt to participate from the outside in marking "distinguished" American music if they are themselves responsible in some way for defining American music? Their involvement with issues of race and ethnicity and its tension with cosmopolitanism are at the forefront of this discussion of Du Yun and Zhou Long. Many scholars mark the Eurocentrism inherent in universalist, cosmopolitan models of contemporary music. ${ }^{68}$ Simultaneously, however, the Pulitzer posits a hyphen in the national identity of its winners as a political device of expanding definitions of American music. For Du Yun, as for many others, "nation is only one among many possible entities or communities to which music can establish a sense of belonging." ${ }^{69}$ When the press puts emphasis on her Chinese background, they often fail to acknowledge the importance of her background as a performance artist or an activist. If she eases the conversation back to non-nationalistic middle ground, she is more easily able to communicate the parts of her musical identity which are more relevant to her expressed musical persona.

But what of Zhou Long's situation? Had he remained in China, Madame White Snake's use of zheng and Chinese folk tales would be wholly unremarkable. But since he moved to the United States and received citizenship in 1999, these expressions of his Chinese identity makes

Inuk singing has necessitated that she includes disclaimer statements during concerts. See Alexa Woloshyn, "Welcome to the Tundra: Tanya Tagaq's Creative and Communicative Agency as Political Strategy," Journal of Popular Music Studies 29, no. 4 (2017): 3-4.

67 "Old forms of cultural proprietorship and political domination still inform aesthetic judgements and can shape the reception of Asian musicians on the international as well as the American musical stage," yet stereotypes regarding Asian musicians' technical superiority still draw massive crowds. See Mina Yang, Planet Beethoven: Classical Music at the Turn of the Millenium (Wesleyan University Press, 2014), 81.

${ }^{68}$ In 1999, the Bach Academy's commission of four international composers (Tan Dun, Osvaldo Golijov, Sofia Gubaidulina, and Wolfgang Rihm) simultaneously articulated intensely local musical traditions (as in the Argentinian traditional music written by Golijov and Chinese traditional music written by Tan Dun) while positioning its composers as being derived from the same universal tradition of J.S. Bach. For more on the tension of globalism and its roots in $19^{\text {th }}$ century German musical discourse, see Moore, "Millennial Passions," 13.

${ }^{69}$ See Collins and Gooley "Music and the New Cosmopolitanism," 139. 
him unique. While uniqueness is not requisite to be a Pulitzer Prize winner, its freshness as compared with the general milieu of American contemporary music can make it striking to a juror whose task is to wade through more than one hundred pieces of music. What can be problematic, however, is the possibility that the Pulitzer Prize, in hopes of claiming its relevance to a broader vision of "America" might co-opt Zhou Long's identity and claim the social capital that comes with awarding a foreign-born composer for the institution.

While a fuller and more nuanced discussion of these issues falls outside the scope of my project, the Pulitzer's past and present is entangled in problems of American self-identification and interaction with new music on a global scale. The Pulitzer's power to articulate its position as part of the American cultural landscape can allow for the opportunity to make political statements regarding who is and is not American. Awarding composers who were born abroad contributes to such a mission on both the nationalistic and the global fronts. When composers with heritage and history elsewhere in the world come to win the Pulitzer Prize, both the prize and American music can benefit from the cultural capital those composers have received from prominent institutions elsewhere in the world. Conversely, a more inclusive definition of American music, which promotes the varying backgrounds of all its citizens (including Du Yun and Zhou Long) gives the Pulitzer the moral high ground, and the political capital that goes along with it, for better or worse. While the Pulitzer's citizenship requirement is an easy way around truly dealing with these problems with nuance and sensitivity, the current political and economic climate necessitates a deep examination of the Pulitzer's role in characterizing race and ethnicity. 


\section{Conclusion: Journalistic Music}

Although the Board members who choose the Pulitzer's winners in all categories are nonmusicians, they are far from musical neophytes. As a team comprised mostly of journalists, the Pulitzer's Advisory Board's relationship with music is one of "interactional expertise." Interactional experts participate in a field from the fringes. Unlike the music jurors, who are contributory experts, members of the Advisory Board are generalists; with a broad knowledge of many artistic spheres and deep expertise in their own field, the Board's multifaceted experience and years of experience administrating the Pulitzer lend "stability and consistency to programs and institutional goals." 70 While the field of music may seem particularly rarefied and difficult to approach from the outside, Board members are easily able to participate in the field's discourse without actually participating in the field themselves. Furthermore, their participation is essential to maintaining a sense of parity between the Music prize and other prizes in Fiction or Drama. Despite that their selection of winner is shaped by the choices provided to them by the jury, the Board's full immersion in up to nine years of the Pulitzer's affairs makes the winner truly representative of the Pulitzer's priorities and not solely music's.

Following the power struggles of the mid 1990s, the Board's authority has made the Prize susceptible to their influence. For the first fifty years of the Pulitzer Prize for Music, the Board's stamp of approval on the jury's first choice was all but a formality. With the attempts to restructure the jury's role, however, their own priorities found them awarding a different kind of work from historic awards. Especially in the past decade, regardless of the finalists the juries choose, the Board awarded to music which reflects similar sentiments to their work in the other

\footnotetext{
70 The administrators of the Ford and Rockefeller Foundations and the National Endowment for the Arts fit into a similar position as the Pulitzer's Advisory Board. 1950s foundation administrators See Uy, "The Big Bang in Arts Patronage," 128.
} 
categories. The concerns of American life, from issues of human trafficking to life as an African American man to multicultural identities are all represented in Pulitzer winners, and furthermore they are dramatically represented and staged, not simply scored. The Board's selections evince a journalistic music that seeks to depict American life just as realistically and concretely as editorial or investigative reporting. In the next chapter, I will address the consequences of choosing these winners. In considering the integral role that reception of the Pulitzer Prize plays in fostering the future success of its winners, I will argue that the prizewinners and Pulitzer itself become tied to one another beyond simply the confines of the year in which their competition took place. 


\section{5 \\ The Pulitzer and the Musical Field}

Music as a cultural object is embedded less in the context of composition than in its production, dissemination, and integration into the fabric of the field. While composition is indeed foundational to American music, the musical field (full of the listeners and performers needed to realize their music) is no less important. Where music history has been primarily concerned with "significant breaks in artistic tradition," there is still a vibrant, although less contentious musical community who "fully realize the aesthetic implications of new musical rules." Music criticism has for centuries proven its dedication to this task. Critics review concerts, conduct interviews with composers, performers, and producers of music, and communicate this information in a way that allows their readers to approach music, if even for the first time. Critics are often thought of as intermediaries who translate musical events into their place in society at large. For this reason, the musical press is one of the most direct assessments of how musicians are responding to the pressures and influences exerted upon them by the field.

Musical networks are incredibly helpful in illustrating the role that critics play. Howard Becker conceives of networks as a series of overlapping "art worlds," where he considers music as an activity, rather than a product. ${ }^{2}$ Becker's art worlds are roughly comparable to Bourdieu's field; both systems of thought describe the social mechanisms at play in the production of music. These theories account for mutual influence of individuals and music, but their observations

\footnotetext{
${ }^{1}$ Roka, "Making Order Out of Chaos," 1.

${ }^{2}$ Becker, Art Worlds, 2-6.
} 
must necessarily find support in the on-the-ground discourse in the field at present. How, then, can an understanding of the complexities of such complex networks of composers, performers, institutions, and countless others be obtained?

Few cities are equipped with teams of music journalists which are robust enough to cover the totality of its goings-on. It is an overwhelming task, considering that not only the regular operators, but that any "new composer, performing artist, or musical composition is news." 3 Nationally circulated newspapers, such as The New York Times, The New Yorker, The Washington Post, The Los Angeles Times, and others, all enjoy both a dedicated contingent of music reporters in addition to a sizeable readership, yet a significant portion of their day-to-day work involves the maintenance of their local scene. For events as significant as the Pulitzer Prizes, however, all of these media converge upon the subject, resulting in a furor of critical commentary, think-pieces, and state-of-the-field articles.

The Pulitzer is not unique in the amount of press attention it receives; other major prizes, such as the MacArthur Fellowships, Grawemeyer Award, and the Grammy Awards, are also treated on this national scale. Unlike these comparable awards, the Pulitzer's impact to the field of journalism leads it to be something of a spectacle for newspapers, and its music critics treat it similarly voraciously. ${ }^{4}$ This journalistic attention to the Pulitzer filters down into the public consciousness, resulting in a public which is particularly attuned to its participation in the changing landscape of twenty-first-century American music.

Previous chapters have addressed the various changes the Pulitzer has attempted to effect, delineating who and what is now different. The present chapter will return to the Bourdieusian

\footnotetext{
3 Ibid.

4 Jack Shafer, "You Won a Pulitzer. Whoop De Do," Slate, April 8, 2008, https://slate.com/news-andpolitics/2008/04/why-no-one-but-journalists-care-about-the-pulitzer-prizes.html.
} 
idea that prizes can rearrange hierarchies in the musical field, discussing how the Pulitzer effects these changes. There is a necessary element of translation between the Pulitzer's act of cultural consecration and the public's renewed appreciation for that particular work and composer. Often, this role belongs to music critics and journalists, who circulate the daily events, ideas, and developments concerning the musical field.

On a larger scale, however, what is integral about the press coverage of the Pulitzer is its ability to inspire (or provoke) a public discourse about music. These published articles are drawn into more informal, and often more intense dialogue on an individual level. Conversations on social media platforms, blogs, and in person have the ability to shape the public's thoughts and reactions to Pulitzer's selections. ${ }^{5}$ In these conversations, the veracity of the Pulitzer's claim to musical or aesthetic authority is evaluated, and alternatives are considered. While the Pulitzer is only one piece of an incredibly complex puzzle, its choices and their political implicationsintentional or otherwise — can reorganize and re-prioritize musical hierarchies in the field. ${ }^{6}$

Scandal has been a driver of the Pulitzer Prize for Music less often than for its other categories, but the past two decades have found the music Pulitzer involved in a number of them. ${ }^{7}$ These high-profile, loaded choices are treated by the musical press, creating a constant presence in musical discourse. Evidence from composer interviews, the characterization of the prize in press materials, and more recently, social media can provide a remarkably lucid picture of public sentiment. In the case of Kendrick Lamar's 2018 Pulitzer win for his hip-hop album

\footnotetext{
${ }^{5}$ In his definition of a generationally-defined movement of "indie classical" music, William Robin characterizes the internet as "indispensable" to the reorganization of the field, citing social media and blogs as the bridge between critics and musicians. Robin, "A Scene Without a Name," 26.

${ }^{6}$ The Booker Prize's rise out of obscurity was almost solely due to its administrator's efforts to create scandal around it. See English, The Economy of Prestige, 190, 203.

${ }^{7}$ Scandals erupted in 1992 over the Board's selection of Ralph Shapey over the jury's protestation, and in 2004 over the formal admission of recordings as submissions; For more on the music prize's lack of contention in relation to drama and fiction, see Hohenberg, The Pulitzer Prizes, 343.
} 
$D A M N$., many of these sources evoke a sense of hard-fought aesthetic victory. Constance Grady wrote for Vox that "Lamar is now not only the first person to win a Pulitzer for a hip-hop album but the first person to win a Pulitzer for any music that's not classical or jazz." ${ }^{8}$ Many characterize the Pulitzer's backwardness by drawing attention to its 1965 refusal of a citation for jazz legend Duke Ellington. ${ }^{9}$ By claiming the event as an indication of the longevity of the Pulitzer's aesthetic prejudices, they imply that even well into the twenty-first century, the Pulitzer was losing touch.

Even before the turn of the twenty-first century, the Pulitzer had been derided for its apparent shutout of non-academic composers. Kyle Gann, Howard Reich, and others have long been outspoken about the prize's bias. Gann wrote in 1991 that "The Pulitzer Prize for music has become a reward for conformity and compensation prize for ineffectuality." ${ }^{10}$ Even after selecting so-called mavericks like John Adams and John Corigliano in 2001 and 2003 respectively, the Pulitzer still struggled to disassociate itself from the academy. Both composers expressed mixed feelings about their prizes. In a 2003 interview with both composers, Anne Midgette clarifies the overwhelming sentiment towards the Pulitzer at that time: "The Pulitzer Prize is known as one of the greatest honors of American journalism, arts and letters. But not of American music. Not, at least, in the opinion of the composer John Adams." 11

Despite a fifteen-year gap between Adams's and Lamar's prizes, the 2018 Pulitzer decision to award the prize to a hip-hop album could hardly be regarded as inevitable.

Kendrick's inclusion as a finalist—let alone his win—was a momentous expansion. It triggered a

\footnotetext{
${ }^{8}$ Constance Grady, "Kendrick Lamar just became the first rapper to win a Pulitzer," Vox, April 16, 2018, https://www.vox.com/2018/4/16/17244186/kendrick-lamar-pulitzer-prize-damn-first-rapper.

${ }^{9}$ This incident has become nearly ubiquitous in media's description of the Pulitzer Prize for Music. For a detailed discussion of this event, see John Hohenberg, The Pulitzer Prizes, 284-288.

${ }^{10}$ Gann, "Pulitzer Hacks," 120-123.

11 Anne Midgette, "Dissonant Thoughts on the Music Pulitzers," The New York Times, April 9, 2003, https://www.nytimes.com/2003/04/09/arts/dissonant-thoughts-on-the-music-pulitzers.html.
} 
surge of public interest in the Pulitzer, proving that the prize had gone further than it had ever gone before to secure the admiration and attention of an audience it had spent more than a decade trying to coax back. The following section will explore the public reaction to the scandalous prize for $D A M N$.

\section{Status Quo and Scandals Through DAMN.}

Kendrick Lamar's 2015 album To Pimp a Butterfly was a radical new addition to the hiphop scene at its release. It debuted at number one in the Billboard 200 and earned the top spot for several prestigious publication's year-end Best Albums lists, including Rolling Stone, Billboard, and Pitchfork. In the wake of such acclaim, audiences were stunned and outraged when Kendrick Lamar's Grammy nomination for Album of the Year fell to 1989 by Taylor Swift. Critics for The Los Angeles Times, Vulture, and Billboard implied that Lamar's loss was yet another reflection of the racial injustice To Pimp a Butterfly was trying to confront. One wrote that the Grammy voters were "too old, too white and too out of touch" to choose fairly. ${ }^{12}$

Despite what many viewed as a snub by the Recording Academy, To Pimp a Butterfly solidified Lamar's status as an icon of hip-hop. Both in his “[articulation], in human terms, the intimate specifics of daily self-defense" of life in Compton, and the flood of commentary concerning the unfairness of his Grammy loss, Kendrick Lamar's follow up, DAMN. was in a prime position for attention. ${ }^{13}$ At the beginning of 2018, DAMN. was the quintessential hip-hop

\footnotetext{
${ }^{12}$ Gerrick D. Kennedy, "Kendrick Lamar didn't win the Grammy for album of the year, but he's moving rap to a bigger stage." Los Angeles Times, February 16, 2016. https://www.latimes.com/entertainment/music/la-et-ms-grammyskendrick-lamar-20160216-story.html; Frank Guan, Sam Hockley-Smith, Craig Jenkins, and Dee Lockett "The Greatest Grammys Snubs of All Time," Vulture, January 25, 2018, https://www.vulture.com/2018/01/the-greatestgrammys-snubs-of-all-time.html; Adelle Platton, "Kendrick Lamar Shrugs Off His 2014 Grammy Snub: It 'Would Have Been Upsetting If I'd Known That Was My Best Work,"” Billboard, February 4, 2016, https://www.billboard.com/articles/news/magazine-feature/6866119/kendrick-lamar-2014-grammy-snub.

${ }^{13}$ Matthew Trammell, “Kendrick Lamar: Damn,” Pitchfork, April 18, 2018, https://pitchfork.com/reviews/albums/23147-damn/.
} 
album, despite its defeat for the Grammy Award for Album of Year, falling to Bruno Mars. At the same time, the 2018 Pulitzer Prize for Music jury were beginning their deliberations. Of the process of narrowing down their selections, juror and scholar of African American Studies Farah Jasmine Griffin remarked, "the use of hip-hop was appearing in the other things, which also was part of our conversation. You would hear the influence of hip-hop in a classical piece, in a jazz piece, in an opera." ${ }^{14}$ Juror David Hadju identifies this topic of conversation as the moment in which they realized that if hip hop ought to be considered for the prize by its own right. ${ }^{15}$ The other jurors, Paul Cremo, David Lang, and chair Regina Carter assented, and $D A M N$. was added to the list of finalists. Together with Michael Gilbertson's Quartet and Ted Hearne's Sound from the Bench, DAMN. was forwarded to the members of the Pulitzer Board for their final decision.

The 2018 Pulitzer Prizes were announced on April 16, 2018. The press conference was led by the recently-elected Prize Administrator Dana Canedy, although the juries had been selected by her predecessor Mike Pride. Traditionally the music prize is announced last, and Canedy made no exception. What is notable, however, was the faint but unmistakable murmur that ran through the crowd the moment $D A M N$. was proclaimed the winner. ${ }^{16}$ In the hours that followed, The New York Times and The Washington Post, which had both come away from the announcements with a slew of their own awards to tout, released articles enumerating the results, as well as the prize citations delivered by the Pulitzer's Board.

The Prize's citation for $D A M N$. described the album as "a virtuosic song collection unified by its vernacular authenticity and rhythmic dynamism that offers affecting vignettes

\footnotetext{
${ }^{14}$ Rodney Carmichael, "How The Pulitzer Jury Opened Its Doors To Hip-Hop," National Public Radio, April 18, 2018, https://www.npr.org/sections/therecord/2018/04/19/603884855/how-the-pulitzer-jury-opened-its-doors-to-hiphop.

${ }^{15}$ Joe Coscarelli, "Kendrick Lamar Wins Pulitzer in 'Big Moment for Hip-Hop,” New York Times, April 16, 2018, https://www.nytimes.com/2018/04/16/arts/music/kendrick-lamar-pulitzer-prize-damn.html.

16 "2018 Pulitzer Prize announcement," YouTube video, 10:55, posted by "The Pulitzer Prizes," April 16, 2018, https://www.youtube.com/watch?v=ALQv-VTb0TI.
} 
capturing the complexity of modern African-American life." ${ }^{17}$ Although the citation mentions musical elements, including "virtuosity" and rhythmic dynamism," the statement decisively presents $D A M N$.'s depiction of "modern African-American life" as the justification for its selection. Media leapt upon the dissonance between popular and art music that the statement evinces—at worst, the Board's description was characterized as "starchy." ${ }^{18}$ On the whole, however, the public opinion on Lamar's win was extraordinarily positive.

The press coverage surrounding Lamar's victory was not limited to publications that regularly reported on contemporary classical music. Mainstream popular music media, such as Vox, Billboard, and Rolling Stone, also contributed to the media frenzy. In comparison, the two previous Pulitzer winners, Du Yun's Angel's Bone (2017) and Henry Threadgill's In for a Penny, In for a Pound (2016), were also well received, but given the less contentious nature of their victories, fewer outlets were writing about these winning works, and during a shorter window of time. In the weeks that followed the announcement of $D A M N$.'s win, the press and public waited for an onslaught of elitist critique that never emerged. There was some backlash, even from former winners. Charles Wuorinen, who won for his electroacoustic Time's Encomium in 1971 charged Kendrick Lamar's prize with being "the final disappearance of any societal interest in high culture." ${ }^{19}$ What, then, does it say about Lamar's win that it was heralded first and foremost as an all-around success, both by Pulitzer affiliates and the contemporary classical music community?

\footnotetext{
17 “DAMN., by Kendrick Lamar," The Pulitzer Prizes. Accessed April 25, 2019, https://www.pulitzer.org/winners/kendrick-lamar.

${ }^{18}$ Dorian Lynsky, "From street kid to Pulitzer: why Kendrick Lamar deserves the prize," The Guardian, April 22, 2018, https://www.theguardian.com/music/2018/apr/22/kendrick-lamar-wins-pulitzer-prize-damn-album.

${ }^{19}$ William Robin, "He Has Fans, Fame and an Acclaimed 'Brokeback Mountain' Opera. So Why Is Charles Wuorinen So Cranky?" The New York Times, May 25, 2018, https://www.nytimes.com/2018/05/25/arts/music/charleswuorinen-brokeback-mountain-city-opera.html.
} 
$D A M N$.'s Pulitzer Prize bears a weighty symbolic significance for the field of music composition. The Pulitzer Prize's cultural prestige was extended to a musical work that lay markedly outside the "contemporary classical" categorization it had so often embraced, overtly urging those who value the Pulitzer's aesthetic metric to grant hip-hop the same level of cultural capital. Even more importantly, however, is that the transaction is reciprocal. As one critic put it, "the Pulitzers won a Kendrick Lamar, and not the other way around." ${ }^{20}$ The Pulitzer's consecration of Kendrick Lamar's DAMN. is thus a gateway between what had once been seen as two separate fields with two separate institutional networks and currencies. That the Pulitzer could open this gateway after a decades of academicism is perhaps even more momentous, and a significant step toward reconciliation between audience and institution. The very maintenance of its prestige depended on it.

Beyond the prize itself, the criticism surrounding $D A M N$. also served to strengthen institutional approval of a growing lexicon of idioms in contemporary classical music. Lamar's win catalyzed "a new series of discussions and debates about the role of popular music in what some simplistically refer to as 'the art world." ${ }^{21}$ In the face of a community that doubted hip hop's musical legitimacy, $D A M N$. exemplified a height of artistic expression. Characterizations of the album, along with the rest of Kendrick Lamar's work, reflect the recognition, if not outright encouragement of broadly construed genre or genre-blending that scholars such as Alex Ross, William Robin, and others have observed.

Although the Pulitzer's press release foregrounded $D A M N$.'s virtuosity and rhythmic dynamism, many critics and composers went further in their justification of its worthiness. 2018

\footnotetext{
${ }^{20}$ Spencer Kornhaber, "Kendrick Lamar and the Shell Game of 'Respect,"” The Atlantic, April 17, 2018, https://www.theatlantic.com/entertainment/archive/2018/04/kendrick-lamar-pulitzer-prize/558197/

${ }^{21}$ Shana Redmond, "Rapper Kendrick Lamar winning the Pulitzer Prize for music: What does it mean?" UCLA Newsroom, April 25, 2018, Accessed March 26, 2019, http://newsroom.ucla.edu/stories/kendrick-lamar.
} 
finalist Ted Hearne gave a vehement defense of the win: "The work that's on that album is every bit as sophisticated and experimental as any [classical] music...The idea that that's not classical music, or that's not experimental music, or that's not art music is completely unfounded."22 Critic Phillip Martin argued that the album "demonstrates significant artistic evolution."23 Others, including Zachary Woolfe of The New York Times, drew attention not just to its musicality, but story, praising "its complexity and sensitivity, its seductive confidence and unity, its dense weaving of the personal and political, the religious and sexual." 24 The contemporary classical public defended $D A M N$. as one of their own by drawing direct comparisons on the basis of its experimentalism, representation of artistic evolution, and its evocation of a sense of community, elucidating which elements they found integral to their own musical practice. The foregrounding of these particular shared musical elements by a figure as unlikely as Kendrick Lamar opens the door even wider to the kinds of popular influences and "genre-bending" sought by some. $D A M N$. is therefore integral to both the public and the Pulitzer in its representation of a widening of aesthetic legitimacy and its blurring of boundaries between "high art" and "low art." For the public, Kendrick Lamar's win vindicates their own expressed desires for experimentalism that is still listenable. For the Pulitzer, Lamar's selection cements the notion that the Pulitzer is trying to eschew its historic bent for the overly-academic.

\footnotetext{
${ }^{22}$ Joe Coscarelli, "Kendrick Lamar Wins Pulitzer in 'Big Moment for Hip Hop,” New York Times, April 16, 2018, https://www.nytimes.com/2018/04/16/arts/music/kendrick-lamar-pulitzer-prize-damn.html.

23 Phillip Martin, "Yo Hip Hop: Meet Mr. Pulitzer," Arkansas Democrat Gazette, May 6, 2018, https://www.arkansasonline.com/news/2018/may/06/yo-hip-hop-meet-mr-pulitzer-damn-201805/

${ }^{24}$ Jon Pareles and Zachary Woolfe, "Kendrick Lamar Shakes Up the Pulitzer Game: Let's Discuss," New York Times, April 17, 2018, https://www.nytimes.com/2018/04/17/arts/music/kendrick-lamar-music-pulitzer-prize-damn.html.
} 


\section{Proselytizing the Pulitzer Prize}

As a competition, the Pulitzer Prize cannot be decoupled from value judgements. It relies on subjective evaluations to promote one work by excluding others. In the field, knowledge of the Pulitzer's exceptional and selective nature is used as an implicit qualifier of musical excellence_-if Henry Threadgill's piece was "better" than more than 150 others, the work and its creator must be good. Winners and the field at large use the Pulitzer as a justification and credential, supporting arguments toward winners' future employment and commissions. However, black-and-white value judgements beg disagreement, and many inside and outside positions of authority regard the institution itself as irrelevant and distasteful. The Pulitzer (or any prize, for that matter) can indicate commodification and artistic stagnation, or else reward the wrong segments of the field altogether; by both counts, prizes are emblematic of the systemic inequality on which economies of music are based.

These criticisms emerge at the forefront, when one considers that the early Pulitzer Prizes were known as some of the earliest promoters of celebrity culture in the United States. Michael Schueth contrasts the notion of "celebrity," which he asserts is driven by economic and media interests, with the neoclassical idea of fame. Fame is strongly associated with ideas of "birth, power, artistic skills, or other kinds of accomplishment." ${ }^{25}$ Although the Pulitzer Prizes are certainly based on varieties of artistic achievement, the winners their promotion is primarily suggestive of their prize's illustration of their excellence, not any of their specific artistic achievements. This is also not to say that the prizes are not deserved - they are simply tied so strongly to our modern awareness of cultural production that they owe just as much to their surroundings as to their creators" "genius."

\footnotetext{
${ }^{25}$ Schueth, "Willa Cather and Celebrity," 10.
} 
Although prize founder Joseph Pulitzer's newspaper empire was well-known at the time that his journalism school and prizes were posthumously founded, neither attracted immediate attention. The first prizes, awarded in 1917, passed without much comment in the press, and so this pattern continued until the prizes of 1920. Shortly after the Pulitzer Prize for Fiction was awarded to Edith Wharton's novel The Age of Innocence, it came to light that the jury had recommended Sinclair Lewis's Main Street. ${ }^{26}$ The press disputed the legitimacy of Wharton's prize, leading to a questioning of whether the Fiction Prize itself was itself fair; the eleventh-hour switch to Wharton's novel was due to the wording in the prize mandate that declared that winners must represent "the wholesome nature of American life."27

This was the beginning of the Pulitzer's celebrity, but its status was solidified following the 1923 Fiction Prize for Willa Cather's One of Ours. Cather's win came at a time when Alfred A. Knopf was beginning to consider strategies for marketing her next book A Lost Lady. Literary scholar Michael Schueth asserts that Knopf's shrewd choice to decorate the book jacket with the Pulitzer accolade was what cemented the Pulitzer's eminent stature. ${ }^{28}$ His strategy was predicated upon the fact that the public was wholly unfamiliar with the Pulitzer, and so its presumed (but not known) prestige combined with Willa Cather's celebrity seemed to prove both true.

Along with the Pulitzer's newfound prestige came what would become an inescapable accusation moving forward, expressed by Sinclair Lewis in his letter to the Pulitzer committee, refusing the 1926 Fiction Prize: "I invite other writers to consider the fact that by accepting the prizes and approval of these vague institutions we are admitting their authority, publicly

\footnotetext{
${ }^{26}$ Ibid., 141.

${ }^{27}$ Claudia Stone Weissberg, "Sinclair Lewis, 'The Main Street burglary' and a Rejection Notice," Pulitzer Prizes. Accessed March 25, 2019, https://www.pulitzer.org/article/sinclair-lewis-main-street-burglary-and-rejection-notice.

${ }^{28}$ Schueth, "Willa Cather and Celebrity," 141.
} 
confirming them as the final judges of literary excellence, and I inquire whether any prize is worth that subservience."29 All this, however, was "met with deaf ears in the business world as Lewis was flooded with a host of money-making offers." ${ }^{30}$ As it turned out, his remarks were carefully designed to be inflammatory, allowing him to claim a higher moral authority while simultaneously benefitting his own public image (and his book sales) with a large amount of press. $^{31}$

In the century since the Pulitzer Prizes began, similar criticisms are still levied against it. Edith Wharton wrote, "When I discovered that I was being rewarded [the Pulitzer Prize by one of our leading universities for uplifting American morals, I confess that I did despair." Wharton's disparaging comments are mirrored by historic and contemporary winners. In response to his 1947 Pulitzer Prize, Charles Ives responded that "prizes are for children." ${ }^{32}$ The vast majority of contemporary criticisms, however, find their basis in perceived inappropriateness of the Pulitzer's selections, converging from opposite poles. Contemporary critics echo Kyle Gann's earlier sentiments, calling the music prize "arbitrary barometer of classical music elitism." 33 However, even previous winners have bemoaned the inclusion of jazz and popular works. ${ }^{34}$

Where does this negativity originate? One potential explanation is that these scandals are well-remembered in the press. Especially when significant word-counts are devoted to the Pulitzer Prize in mainstream outlets such as The New York Times or The Chicago Tribune, critics often have the space to characterize the prize and discuss its history; many do so by turning to its

${ }^{29}$ Claudia Stone Weissberg, "Sinclair Lewis," 1.

${ }^{30}$ Schueth, "Willa Cather and Celebrity," 158.

${ }^{31}$ Ibid.

${ }^{32}$ Bret Johnson and Benjamin Lees, "Composer in Interview: Benjamin Lees," Tempo, no. 214 (2000): 30.

${ }^{33}$ Dennis Polkow, "Preview: The Pulitzer Project/Grant Park Orchestra \& Chorus," New City Music, June 10, 2010, Accessed March 26, 2019, https://music.newcity.com/2010/06/22/preview-the-pulitzer-projectgrant-park-orchestrachorus/.

${ }^{34}$ Stephen Hartke, John Harbison, Lewis Spratlan, Mario Davidovsky, Charles Wuorinen, Donald Martino, Ned Rorem, and others have explicitly decried the arrival of jazz in Pulitzer awardees. 
most recent scandal for evidence. It has become something of a convention to highlight the denial of Duke Ellington's 1965 citation, and many articles of the past decade refer to Anne Midgette's explanation of the plight of nonacademic composers exemplified by the 2001 and 2003 prizes for John Corigliano and John Adams. ${ }^{35}$ In the late 1990s, they focused on the 1992 award for Wayne T. Peterson—scandals are both integral and inescapable. These examples evidence a fixation on Pulitzer's claim to cultural authority. These criticisms put "at stake...the very belief in the Artist as a special category of person, and hence in Art as a special domain of existence...the scandalous currency that prizes put into circulation functions not to deflate this belief, but, on the contrary, to keep it aloft." ${ }^{36}$ That scandals contest the winners of the Pulitzer Prize endorse the assumption that there could or should be winners.

When the field questions the Pulitzer's efficacy as a representative of American music they are essentially evaluating its legitimacy. They conduct these evaluations on a number of fronts: is the prize relevant to the field, as it stands? Does the prize respect the composer's individual artistic autonomy over its marketability? Ultimately, these questions are rooted in a disenfranchisement with the idea of a prizes as a whole:

By presuming to rationalize the qualities of moral character and culture social goods, philanthropic institutions must of necessity reify these qualities of social life into discrete quantities subject to rational management. By the same logic that capitalist industry transforms use value into exchange value, rationalizing institutions such as...the Pulitzer transform unquantifiables such as 'moral integrity and...'quality' into countable journalism degrees and [prize awards]. ${ }^{37}$

The Pulitzer's mission to promote "distinguished" works of American music is inherently at odds with its basis in the bureaucratic principles of philanthrocapitalism. Pulitzer Prizes avoid moral corruption and threat to its use of "bureaucratic machinery" by describing its awards as the

\footnotetext{
${ }^{35}$ See Midgette, "Dissonant Thoughts on the Music Pulitzers."

${ }^{36}$ English, The Economy of Prestige, 196.

${ }^{37}$ Wensink, "Literary Philanthropy," 26-27.
} 
"inspiration for concrete social action, rather than the social action itself," thus situating its winners as the ones who do this work, deflecting attention from institutional agendas (and failures, in this regard) to the autonomous individuals. ${ }^{38}$ Indeed, many have already recognized the Pulitzer's fundamental oxymoron. In 2018, composer Alex Shapiro wrote, "When the internet allows everyone to publish and distribute their own music, and discover and build their own audiences, and subsequently reap the financial benefits of these relationships, the concept of waiting to be approved of by a panel of "experts" seems quaint at best, and professionally debilitating, at worst." ${ }^{39}$ Yet, the Pulitzer's use as a positive credential persists.

The Pulitzer typically receives top billing in composers' biographies, press releases, their C.V.s, and even in obituaries. Composers use the Pulitzer as an introduction-not to their music, for biographies rarely mention the particularly works which won them the prize — but as a mark of status. The Pulitzer Prizes frame their winners "within a specific history of 'award winners." ${ }^{40}$ Without any reference to specific elements of a composer's work, the use of a Pulitzer simply implies excellence, forging connections between composers for whom those specific elements may be radical opposites. Especially for recent winners, the lifetime achievement status of this single-work prize is a valuable aid to their career in the future.

Prestige brings Pulitzer winners a whole host of related benefits, initiating the interconversion of cultural capital into political and financial capital. Following his Pulitzer Prize win, David Lang received commission offers to further develop the little match girl passion, the winning work. The prize allowed Lang to expand the piece and reorchestrate it, from four solo singers doubling on hand percussion instruments to full choir with additional personnel solely

\footnotetext{
38 Ibid. 36.

${ }^{39}$ Alex Shapiro, "Dissing the Competition," New Music Box, September 12, 2018, https://nmbx.newmusicusa.org/dissing-the-competition/.

40 Schueth, "Willa Cather and Celebrity," 161.
} 
devoted to percussion. Similarly, Zhou Long's Pulitzer for his opera Madame White Snake attracted the attention of Beth Morrison Projects. With their intervention, the single work became one part of a trilogy. ${ }^{41}$ Other composers have followed their Pulitzer wins with commercial recordings of their winning works. Julia Wolfe, John Luther Adams, Jennifer Higdon, Steve Reich, and many others released professional recordings of their pieces the year after winning the prize. Their choice to record their winning pieces, to the exclusion of other important works in their ouvre, indicates the value of Pulitzer on commercial sales.

Though the Pulitzer is sometimes known as a prize to be given past its due to a latecareer composer, Caroline Shaw exemplifies the Pulitzer's ability to thrust less well-known composers into the national spotlight. She was only two years into formal composition study at Princeton when her prize was announced. Her Partita for 8 Voices came to be known as her "breakthrough piece," and in fact, is counted as one of her most well known. ${ }^{42}$ Both for the piece and for Caroline Shaw herself, the Pulitzer turned the nation's attention to one who might under ordinary circumstances have not gained notoriety until much later in her compositional career. ${ }^{43}$ Jennifer Higdon, for example, was 47 when she won. Despite the more established nature of her career, the Pulitzer had a profound impact on the level of her recognition. Because of her win, Higdon exclaimed "People return my calls now!" ${ }^{4}$ Paul Moravec summed it up in an interview with the New York Times: "When we got the news, I told my wife: 'This is the beginning. Now it

\footnotetext{
${ }^{41}$ It is important to note that the trilogy was not further affiliated with Zhou Long as a composer, but with librettist Cerise Lim Jacobs, who chose different composers for each of the operas.

${ }^{42}$ Frank J. Oteri begins an interview with Caroline Shaw by noting that most interviews "invariably" begin with a question about the Partita for 8 Voices. Frank J. Oteri, "Caroline Shaw: Yes, a Composer, but Perhaps Not a Baker," New Music Box, March 1, 2015, https://nmbx.newmusicusa.org/caroline-shaw-yes-a-composer-but-perhaps-not-abaker/.

${ }^{43}$ Zachary Woolfe, "Caroline Shaw: Award-Winning Composer," New York Times, April 17, 2013, https://www.nytimes.com/2013/04/18/arts/music/caroline-shaw-award-winningcomposer.html?_r $=0 \&$ module $=$ inline.

${ }^{44}$ Robert Raines, Composition in the Digital World: Conversations with 21st Century American Composers (New York: Oxford University Press, 2015), 115.
} 
begins.' The Pulitzer changes everything, and nothing. It doesn't make me a better composer, but it creates opportunities." 45

The above examples are the tangible realization of the Pulitzer's conversion of symbolic cultural capital into political and financial capital. The effects of its prestige are far from mere fringe benefits. From Lang's newfound academic career to the uptick in commissions for even Pulitzer finalists, the public's recognition of the winner's seem to indicate that despite its naysayers, any composer's Pulitzer prize is well received, even if the idea of a composition prize is less so. The decoupling of a specific winning work or composer with hated idea of a prize allows the Pulitzer to remain both valuable and coveted; people still apply, and since the throwing open of the windows in the wake of Lamar's win, greater numbers are anticipated.

\section{How the Field Shapes the Pulitzer}

Unlike awards and fellowships from the MacArthur or Guggenheim Foundations, the Rome Prize, or the Fromm Foundation, the Pulitzer has no direct influence over the kinds of music that will be written in the future. Where money given by the Guggenheim Foundation or Chamber Music America are almost always given to fund specific and premeditated artistic ventures, there are no such strings attached to the Pulitzer's award money. If it can be said to fund the production of a specific work, it does so only indirectly and retroactively. As the previous section explored, the Pulitzer can, however, manufacture celebrity, and an important result of that it catalyzes the enactment of the public's value judgements on the Pulitzer.

This phenomenon is known as artistic reflexivity. As musical works can be "valuable sources of insight into their own conditions of production," we can contextualize them by

\footnotetext{
${ }^{45}$ Julia Mead, "Living Out the Pulitzer Fantasy," The New York Times, May 30, 2004, https://www.nytimes.com/2004/05/30/nyregion/music-living-out-the-pulitzer-fantasy.html .
} 
"reading them as aesthetic objects that register their own failures to achieve formal autonomy, tracing the embedded conditions against which they struggle." ${ }^{46}$ Here, literary scholar Joseph Wensink refers to an autonomy from subversive market interests. In acknowledging that a piece of music does record details related to its economic circumstances (for instance, the instrumentation of pieces written for Eighth Blackbird or Zooid) we can better understand the potential for the constraint inherent to commissioned music. These concessions need not be nefarious: Wensink continues, describing art's capability to possess a "relative autonomy capable of providing critical distance to the market despite their inevitable complicity-a distance which in some cases might even offer a vision of literary agency in which novels might inspire genuinely transformative change." 47

In this scheme of reflexivity between the field and the artist, an idea which is again indebted to Bourdieu, there is indeed room for social change. Especially for music, social change is created by a failure of reproduction - in other words, musical change is driven by a rejection of conventions. ${ }^{48}$ However, Bourdieu's particular views on the subject have been criticized as overly deterministic and pessimistic: he posits that social transformation is rarely the motivation of an individual, and is usually a secondary result of the clashing agendas of multiple fields, rather than an informed goal in itself. ${ }^{49}$ Nonetheless, his ideas are still of some benefit to the situation at hand: the Pulitzer represents the motivations individuals and institution together. In the musical field's apparent search for certain varieties of musical innovation (as explored in Chapter Four) do Pulitzer winners of the past decade represent a maintenance or failure of reproduction? For each winner, the answer could be different. Kendrick Lamar is an

\footnotetext{
${ }^{46}$ Wensink, "Literary Philanthropy," 9.

${ }^{47}$ Ibid.

${ }^{48}$ Guillory, "Bourdieu's Refusal,” 370.

${ }^{49}$ Ibid.
} 
example of the failure of reproduction: seeing the lack of representation of African-American voices, the Pulitzer chose to award an artist and a genre who do not conform to their previous trajectory. ${ }^{50}$ Conversely, John Luther Adams's Pulitzer for Become Ocean (2014 winner) could be read as a maintenance of reproduction. Become Ocean reinforces the field's value of musical elements such as tonal centers or orchestral settings, which Luther Adams shares with many other notable composers (including Julia Wolfe, David Lang, John Adams, or Jennifer Higdon).

Throughout this thesis, attention has been drawn indirectly to several significant moments in which the will of the field caused the Pulitzer Prize to shift in direction, effecting a failure of reproduction. Of these, two of the most impactful were the 1996 and 2004 rule revisions, changing the Plan of Award to remove reference to particular performing forces, allowing submission by recording, and removing the requirement for a notated score. Most Pulitzer protocol changes have gone unnoticed, delineated only to applicants in the guidelines for submission. The 1996 and 2004 changes, however, were announced to the public via press release, and the resultant responses were so numerous that they have received their own box in the Pulitzer's archives.

Precipitating these changes was the controversy surrounding the 1992 Pulitzer Prize, awarded to Wayne T. Peterson for The Face of the Night, The Heart of the Dark. Sometime following the award announcement, it came to light that Peterson had never been in serious contention for the jury's nomination-instead, they preferred Ralph Shapey's Concerto Fantastique. The submissions were so scant that year that the jury forwarded only one piece to the Board, knowingly defiant of a 1985 protocol requiring that jurors send their nominations as a unranked list. Upon listening to Shapey's piece, the Board rejected the selection out of hand,

\footnotetext{
${ }^{50}$ For more on specific examples of the changing trajectory of Pulitzer winners, see Chapter 4.
} 
demanding another piece for consideration. The jury complied and forwarded Peterson's work.

In the weeks following, two jurors collaborated to produce a statement:

The Pulitzer Prize board's action in modifying the music jury's decision this year is especially alarming because it occurred without consultation and without knowledge of either our standards or rationale. Such alterations by a committee without professional musical expertise guarantees, if continued, a lamentable devaluation of this uniquely important award. ${ }^{51}$

While New York Times critic Alan Kozinn contends that it was not an aesthetic judgement that led to Shapey's rejection, but the seizure of power from the music jury. So, while it was not an aesthetically motivated decision, they used the opportunity to shift the power back into their own hands to solve another problem.

After years of the Board's discussions and negotiations, they reached an official agreement in 1996 to expand the range of styles of work considered; from simply large-genre works, they moved to embrace jazz, film scores, and musical theater. The jury for the following year's prize, which included Howard Reich, John Harbison, John Lewis, Joseph Schwantner, and Robert E. Ward, helped to solidify their commitment. Among the three finalists was Blood on the Fields by Wynton Marsalis, which was chosen as the 1997 winner. $^{52}$

In the following years, however, the jurors' finalist selections reverted to classical compositions, though removal of the specification of large performing forces and broader inclusion did have an impact. With the selection of a piece for solo piano by William Bolcom and compositions by Aaron Jay Kernis, John Corigliano, and John Adams, it was a clear change in direction for the Pulitzer. Despite some advances, many critics did not feel that these changes, along with additional special citations for Duke Ellington, George Gershwin, and John Coltrane,

\footnotetext{
${ }^{51}$ Alan Kozinn, “A Pulitzer Dispute: Should Music Prize Be Left to Experts?” New York Times, April 9, 1992, https://www.nytimes.com/1992/04/09/arts/a-pulitzer-dispute-should-music-prize-be-left-to-experts.html.

${ }^{52}$ For more on the 1997 Prize selection, see Chapter 5.
} 
amounted to enough. A June 1, 2004 press release announced changes to the wording of the Plan of Award yet again — the requirement for only three composers on the jury was formalized, leaving room for other musical subdisciplines to participate in the selection. ${ }^{53}$

Taken together, these rule changes show the Pulitzer's attempts to be sensitive to the criticism that it was overly-academic. With these concerted attempts to made amends, the Pulitzer was beginning to recreate its institutional identity according to the standards of a new generation of composers, whose social capital was rapidly gaining. Indeed, many interviews during the period discuss the Pulitzer's shifting identity in candid terms. Frank J. Oteri's 2005 interview with John Corigliano finds the two acknowledging the negative perception of the Pulitzer, and some of the ways it was changing at the time. ${ }^{54}$ Regardless of their motivation, that the Board realigned its rules (and its jury selections) to match the ideals of its constituents shows their beholdenness to the field.

\section{How the Pulitzer Shapes Discourse and the Field}

Long before the Pulitzer's halting acceptance of jazz, dissenting voices were already growing muffled. The Pulitzer was clearly not responsible for the change in public opinion that musical works in the jazz idiom should be eligible to win the award. Yet, the Pulitzer's official consecration was among the first yearly-awarded prizes for music composition to allow it to win, without inventing a new category. By incorporating different idioms into a single category of awards, the Pulitzer was able to insinuate that jazz deserved a place among, and could even surpass, other kinds of music making.

\footnotetext{
${ }^{53}$ Although they dropped the requirement for a score, the description for entrants in the Music category still says that a score is "strongly encouraged."

54 Frank J. Oteri, "The Gospel According to John Corigliano," New Music Box, February 1, 2005, https://nmbx.newmusicusa.org/the-gospel-according-to-john-at-home-with-john-corigliano-john-corigliano/.
} 
Reactions both negative and positive figure into the Pulitzer's reception. When one particular work is the subject of focused attention by members of various conflicting musical subgroups, its specificities can be discussed and evaluated, and eventually consensus regarding its relevance is reached. In the process of collective evaluation, Bourdieu's process of "reproduction" is enacted — either the field determines that the winning work is good, and thus they perform, circulate, and emulate it, or instead they choose to ignore it and seek out different works to endorse. In 1997, the Pulitzer intentionally and undeniably attempted to induce a failure of reproduction. Over the span of nearly a decade bridging the twentieth and twenty-first centuries, they changed their eligibility requirements with the desire to produce a specific outcome: the inclusion of jazz, or broadly, the inclusion of a more diverse range of musical voices.

The changes to the rules to allow for more diversity are, however, different from the level of complicity of its jurors and the subsequently limited range of finalists. The real value that the Pulitzer has to the field is the potential to create a failure of reproduction, not necessarily that it actually succeeds in achieving one. Many acknowledge the lack of efficacy that these pieces alone have to change the field. ${ }^{55}$ Other prizes also face this challenge. Even the Nobel Prize for economics has not resulted in so impactful a change on the eminence of winners' theories and policies. Nobel Economics Prize winner James Buchanan described its value in terms of the awareness it brings to the existence of the field. He insinuates that the Nobel Prize for Economics is not valuable for crystallizing "directions or styles of work," but for the newfound "attention paid to what economists say." 56 The political motivation which spurred the Pulitzer's

55 Frank J. Oteri, "Justin Timberlake Loses Pulitzer," New Music Box, April 11, 2005, https://nmbx.newmusicusa.org/justin-timberlake-loses-pulitzer/.

${ }^{56}$ Dean Christakis, "Prestige and Recognition in Education: Stratification, Key Informant, Historical, and Prize Design Methods" (Ph.D. diss., University of Illinois at Chicago), 225. 
consecration of John Adams in 2004 was not intended to make more people write more postminimalist music. Instead, they hoped to bring attention to a population they felt was underserved, much in the same way they hoped to elevate hip hop with Lamar's prize in 2018. A significant barrier to the Pulitzer's ability to elevate these voices is the fact that the narrative it promotes is one of exceptionalism - how can a piece effect a social change in musical culture if its relatedness to and embeddedness in the field is removed? The reception of the Pulitzer is built around the notion of winners and losers. When winners win, critics can isolate them from their contemporaries, separating their musical idiom from that of their peers. By creating undue separation between what are then cast as different factions in the musical world, a Pulitzer can create a false sense of divisiveness.

Ultimately, Shaw's branding as one of the youngest ever Pulitzer winners creates the expectation of quality that non-winning composers do not face quite so concretely. Pulitzer winners are conflated with the institution itself. With the permanent attachment of the Pulitzer name to Shaw's work and her biography, there is an open invitation for comparison to other winning works and composers which ordinarily would not be present. This creation of false and unfair standards that only some composers are forced to be evaluated against is severely detrimental.

In the midst of this critique, we are left to reflect on the Pulitzer's value to the field. Individual winning works enjoy an extended life of performances and re-stagings. The Prize serves an important credential marking past success. And yet the Pulitzer's greatest value may be its interconversion of capital, marking a more influential composer, even beyond the scope of their winning piece. The Pulitzer Prize enriches the social, cultural, political, and financial capital of its winners, placing a composer within a lineage of other composers, no matter how far 
displaced. The works by that lineage have become a canon of its own, and the most recent additions to that line of winning composers represent the newest generation of musical elites who may contribute in newly influential ways to the field of music. 


\section{Conclusion}

\section{Winning, Prizes, and Identity, or Winning Prizes and}

\section{Identity?}

In a 2018 New Music Box article, composer Alex Shapiro advocated for a turn away from composition prizes, writing that a different mantra would help young composers to make more meaningful strides toward professionalism: "Create opportunity. Do not wait for it to be

created for you." ${ }^{1}$ Composition prizes, she argues are infrastructural opportunities given only to those who have already been given enough infrastructural opportunities to cater to their particular requirements. Without specialized instruction, access to funds for entry fees, performers, recording equipment, or often times, even citizenship, composers are unable to offer a product that prize juries will consider. Even beyond simply having access to these items at all, having access to high-quality ones will often result in scores and recordings that are more professional, and more attractive as winners. Prizes are thus instruments of gatekeeping: only those with a certain degree of privilege and access are able to apply, let alone win.

Winners rosters everywhere prove Shapiro's observation correct. Take, for example, the inaugural winners of even a young composers' competition such as the Luna Lab Fellowship: five composers aged 13-17 were chosen, and even the two youngest fellows are affiliated with prestigious youth programs, such as MATA Jr. and the Julliard School Music Advancement

\footnotetext{
1 Alex Temple, "Dissing the Competition," New Music Box, September 12, 2018, https://nmbx.newmusicusa.org/dissing-the-competition/.
} 
Program. The C.V.s of the eldest fellows are already well on their way with numerous accolades from the Tanglewood Festival, Los Angeles Philharmonic, Curtis Institute of Music, and ASCAP. This might imply simply that it was their credentials that earned them their Luna Lab Fellowship, but Shapiro goes on to refute this narrative:

I have served as Chairperson and panelist for countless composer competitions and residencies over the course of the past twenty years. I have yet to witness any winner be selected because of a resumé stuffed with Important Sounding Awards. Not one. When the panelists and I looked at someone's attached C.V., it was often just a passing glance. The composers who received these juried opportunities were selected because of one marvelous thing: the excellence and creativity of their music.

Shapiro is again totally correct—prizes do not help composers to win more prizes. What she implies, though, is that this is the sole value of composition prizes. What I hope to have offered in this thesis is a cautionary counterpoint: the prize itself (and its award money) pale in comparison to the opportunities for commissions, employment, and political power it can provide. The young composers featured as Luna Lab Fellows received access to first-class composition instruction, professional performers, and a name brand endorsement that removed many barriers to success that other young composers struggle to overcome. A composition prize's value is its prestige.

The unfairness of such a system is obvious, and very present in the discourse surrounding the field of composition. Unfortunately, though, there is very little that even larger organizations such as the Pulitzer Prize can do about it. The field of music is suffocated in a neoliberal rhetoric which deals with the fundamental mismatch between the number of composers and opportunities for full-time employment by distributing those opportunities unevenly. If one hundred composers apply for a MacDowell residency, where living expenses and meals are paid for to allow the composer the time and space to work, the residency is not divided into 100 equal parts and each 
small slot given to each composer. In fact, the idea seems ludicrous - precisely because of the meritocratic biases of capitalism. Instead, the MacDowell residencies are divided into the most optimal, useful segments, and each of these is awarded to one composer.

Philanthropic organizations that support art, including the Pulitzer Prize, the Guggenheim Foundation or the Grawemeyer Award, operate according to these capitalist precepts: though the organization has funds to reward all competitors, and all competitors may be deserving, only one receives the benefit. However, as long the rest of the system of cultural production continues similarly, these reorganizers of the field are crucial for their efforts to, at least theoretically, democratize the opportunities. The Pulitzer fits neatly into this schema: in periodically injecting new life into elite circles (e.g. Caroline Shaw) or expanding their prestige to new aesthetics (e.g. John Adams or Kendrick Lamar) the prize has demonstrated its potential for usefulness. However, in the Pulitzer's implicit support of the uneven distribution of opportunities, these choices should be constantly interrogated to ensure that it remains within the nexus of its founders' goals and its constituents'.

The 2018 Pulitzer Prize for Kendrick Lamar's album DAMN. will exponentially increase the number of eligible applicants. Their inclusion presents a significant challenge to the Pulitzer; with such an enormous influx of new competitors, major structural changes could be necessary. Is a jury of five musical specialists still the optimal number of voices to winnow the selections to three finalists? Who should these jurors be? What disciplinary representations are still the most valuable in choosing what is still referred to as a "distinguished" example of American music? Although these changes need not be immediate, the application fee for the 2019 prize has already increased by $50 \%$, from $\$ 50$ in 2018 to $\$ 75$. If the number of applicants is reflective of the Pulitzer's newfound breadth of aesthetic possibility, a mere $\$ 25$ increase may prove insufficient 
to stem the rising tide of the prize's administrative costs. New applicants present new

opportunities for the Pulitzer's growth; but how rooted the Pulitzer should remain to its past is an open question.

Yet another pressing question of representation also rises from this discussion-who among these newly-embraced applicants will receive the Pulitzer Prizes for Music in the future? In a popular genre like hip-hop, the intensely collaborative process of creating an album is not mirrored in the prize's winners. The prize is always awarded to a single person for their work, regardless of significant contributions from other collaborators. This problem is of special significance because the Pulitzer Prizes treat this disparity unevenly across categories. In the Pulitzer Prize for Drama, recent musicals such as In the Heights (2009 winner) and Next to Normal (2010 winner) have awarded both composer and librettist. The Music category's operatic works, however, only recognize the composer. Although the comparison across similar categories may give pause — of course the prize in music ought only to award to music — what it proves is that the Pulitzer has already recognized the value of collaboration. Thus, in purely musical collaborations (e.g., DAMN. or In for a Penny, In for a Pound) which rely significantly on multiple contributors, it is somewhat startling that multiple award winners have not yet occurred.

Kendrick Lamar's challenges to music include notions of genre and aesthetic, representation, and authorship. In the coming decade, only time will tell how the Pulitzer will reconcile the problems he has_-thankfully_posed to its canonic model. In these issues, however, the Pulitzer is only one among hundreds or thousands of relevant culture prizes, whose unique institutional profiles seek to shape and redefine their fields. Even this study of the Pulitzer is limited in scope, and delves little into the organization's rich history. More detailed and 
nuanced treatments of the Pulitzer Prize for Music, especially with regard to its complicated relationship with genre, its impact on finalists, and its economic effects upon its winners. Additionally, studies on comparable prizes such as the Grawemeyer Award and MacArthur Fellowships are needed to contextualize how composition prizes can have concrete and even tangible effects on the kinds of music that are distributed, programmed, and prized in the United States.

Looking back over the Pulitzer's three-quarters century of existence, its ever-growing list of winners could threaten to mire the Pulitzer Prize for Music's artistic identity in its own fixity and stagnation. Especially as our canonic frame would cast the Pulitzer's pieces as members of the same lineage, it is difficult to avoid painting all the winners with the same "distinguished" brush. For present-day onlookers, the Pulitzer Prize is used by the field as an indicator of the winning piece and winning composer's superlative prestige— but it is essential that such characterizations not be confused with their identity. Identities are more complex than one piece or one composer, or even one decade of pieces or composers can show. As the long history of the Pulitzer shows, many pieces that aptly exemplify the state of American music at the time have since fallen out of fashion. Therein is the prize's beauty: listeners far removed can learn more about American music's priorities of the moment through the lens of its honored pieces, composers and juries. With careful attention to the people and process that drive its expansion, the canon of the Pulitzer Prize presents one vision of the essence of American music. 


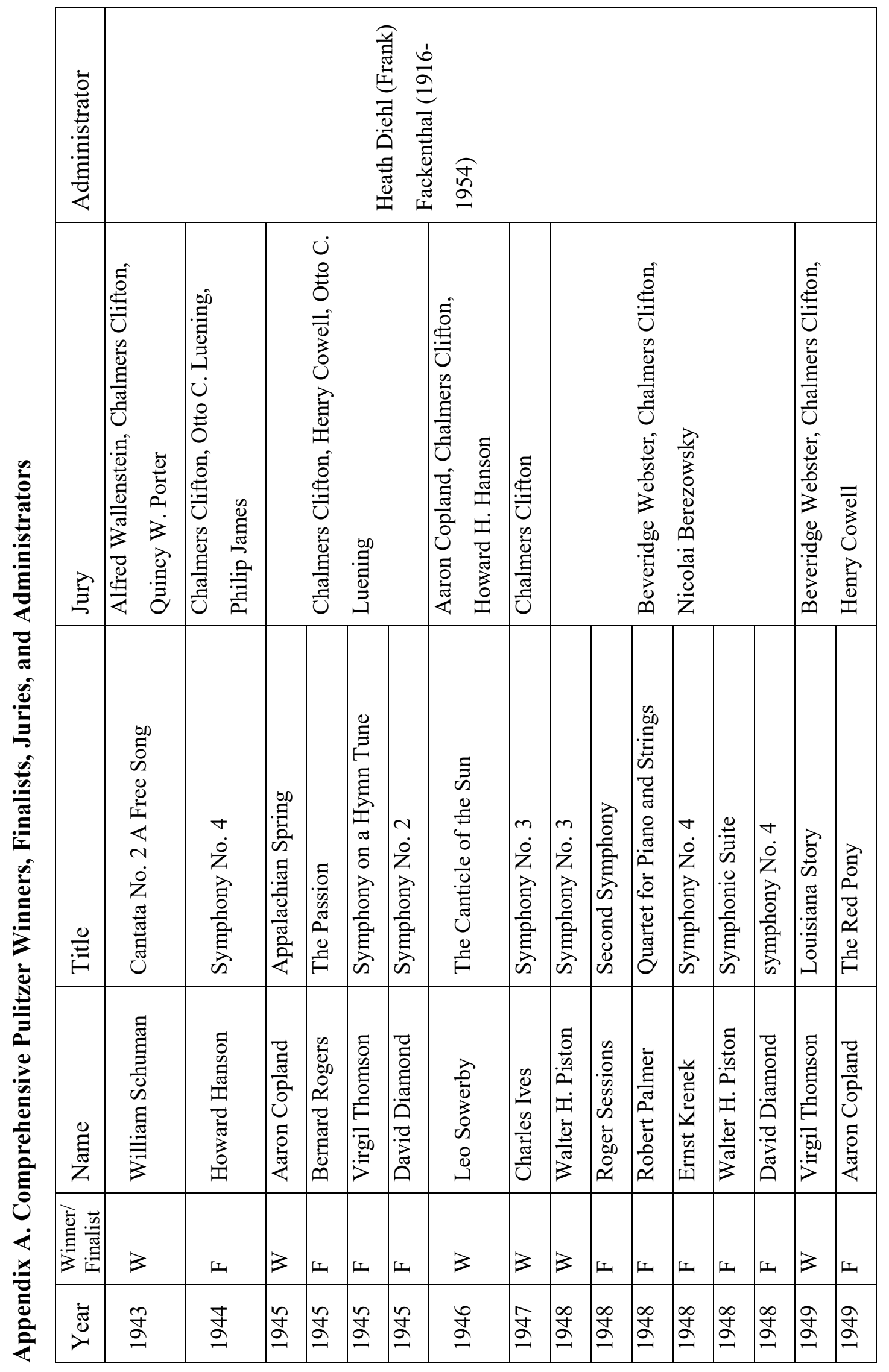









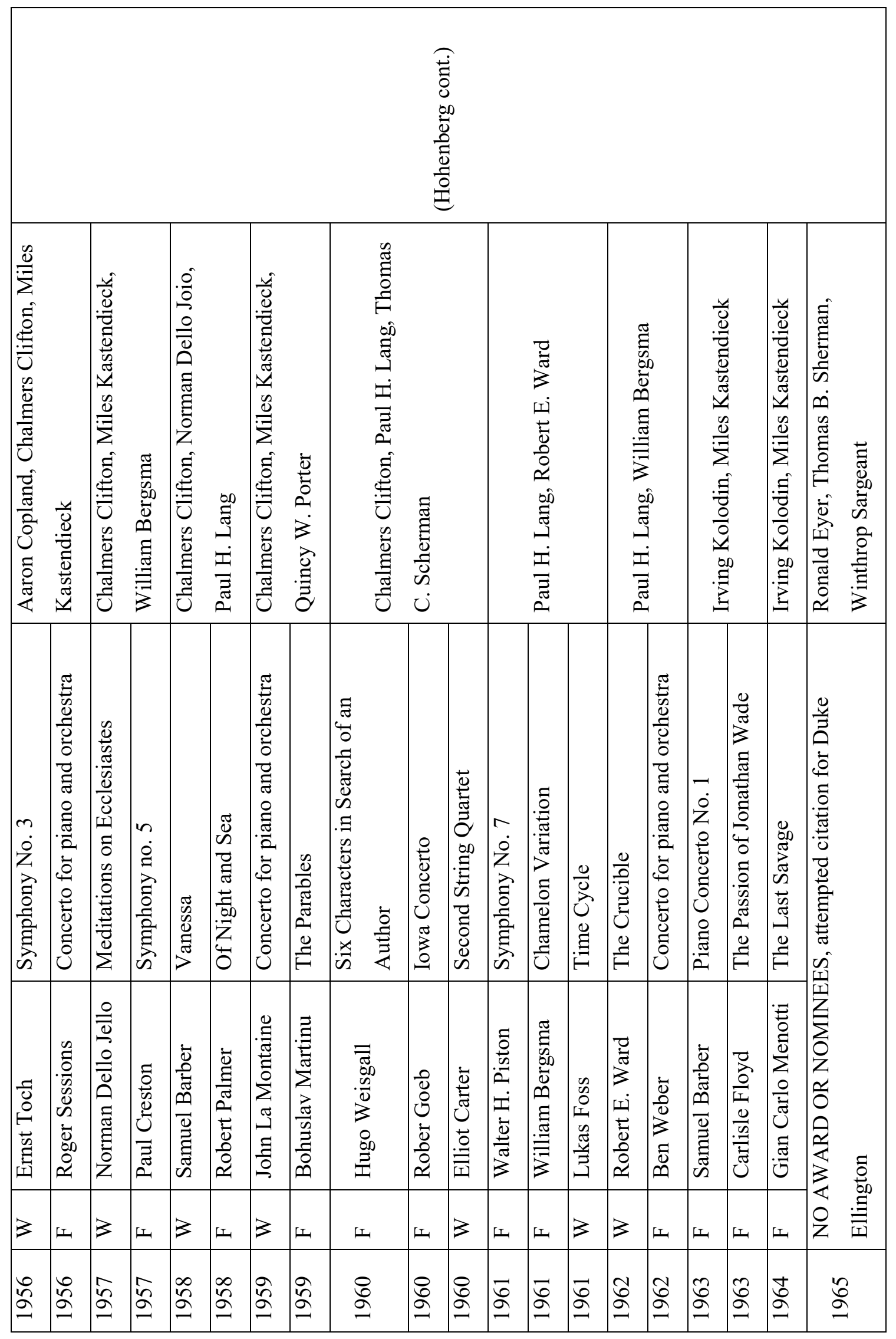




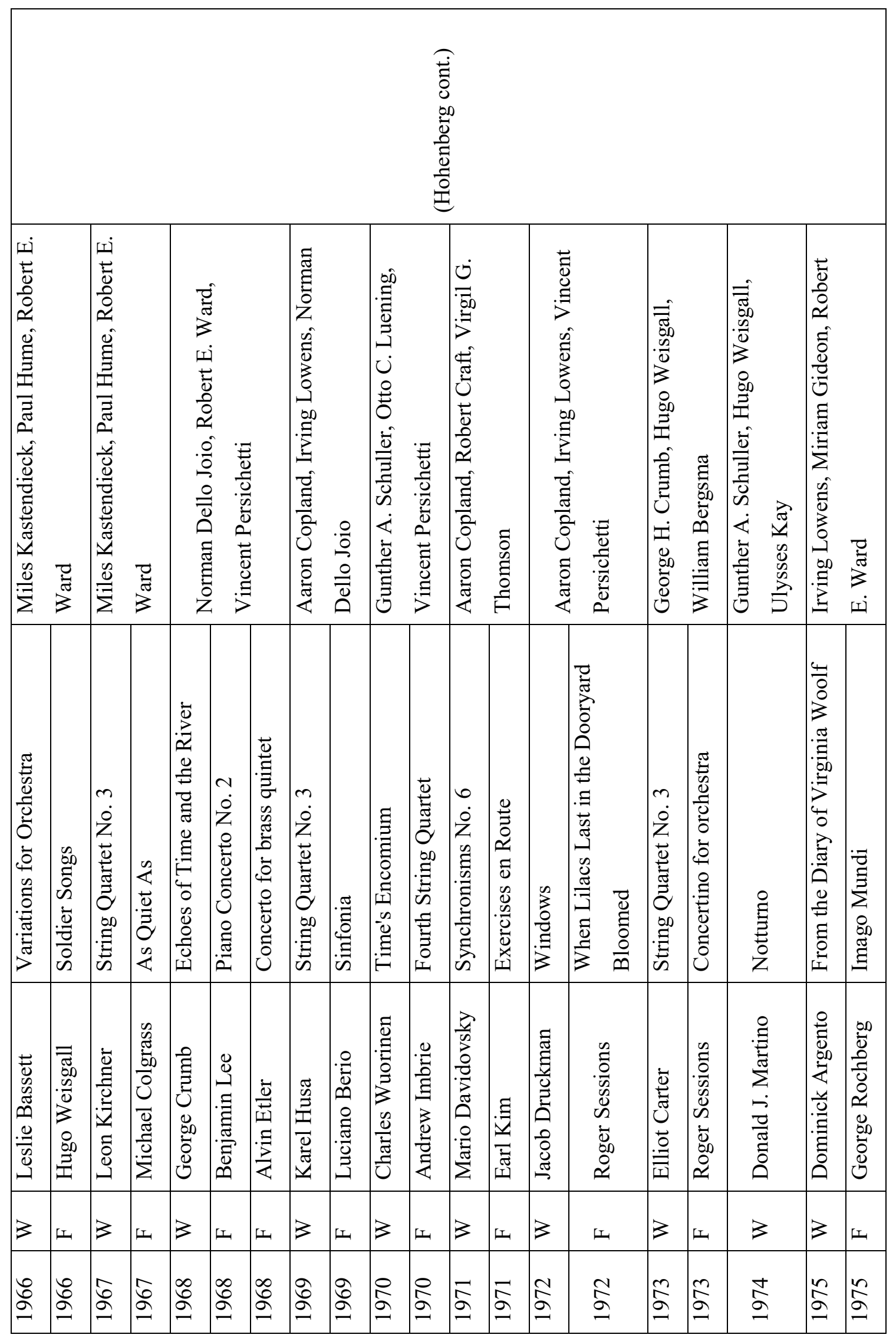









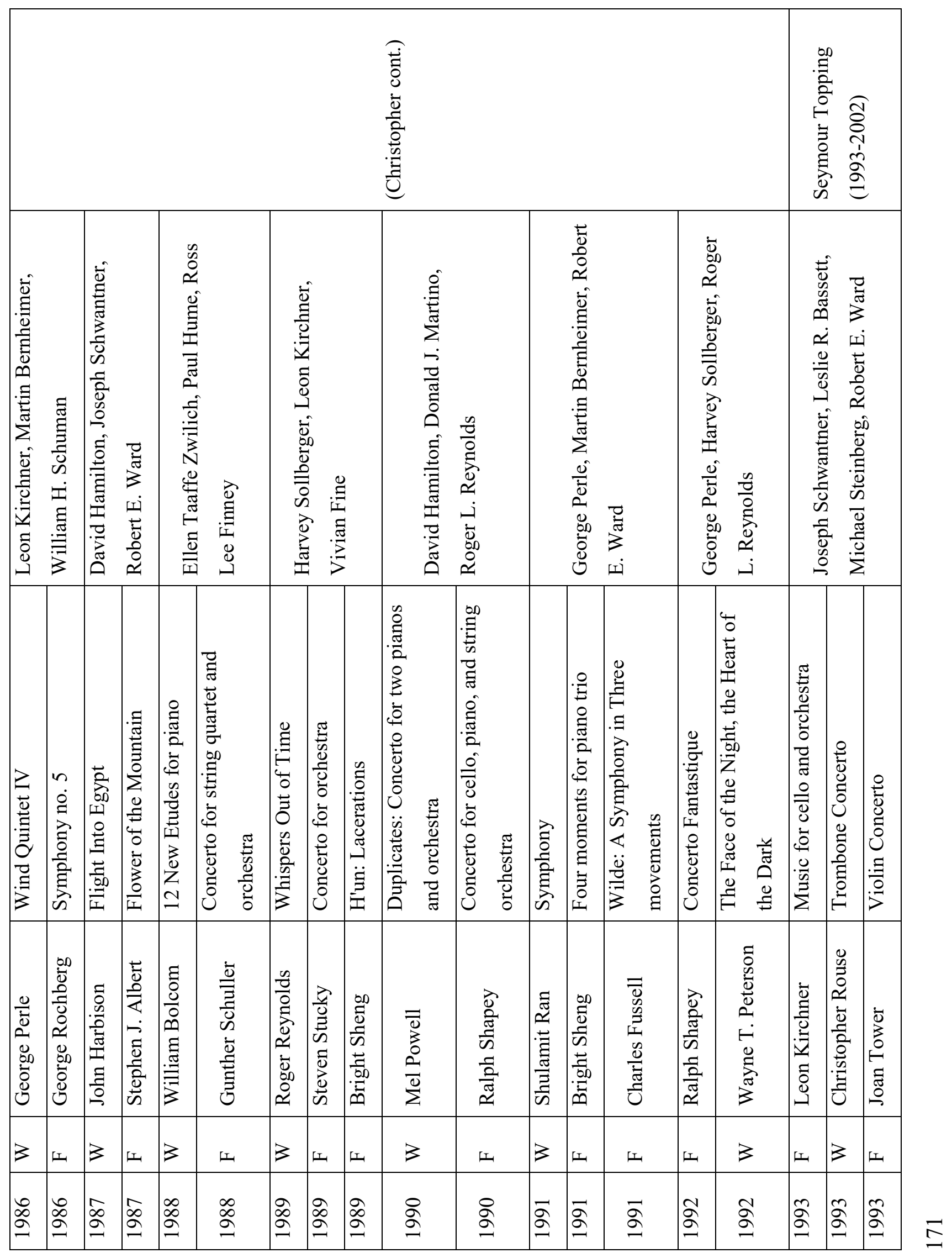




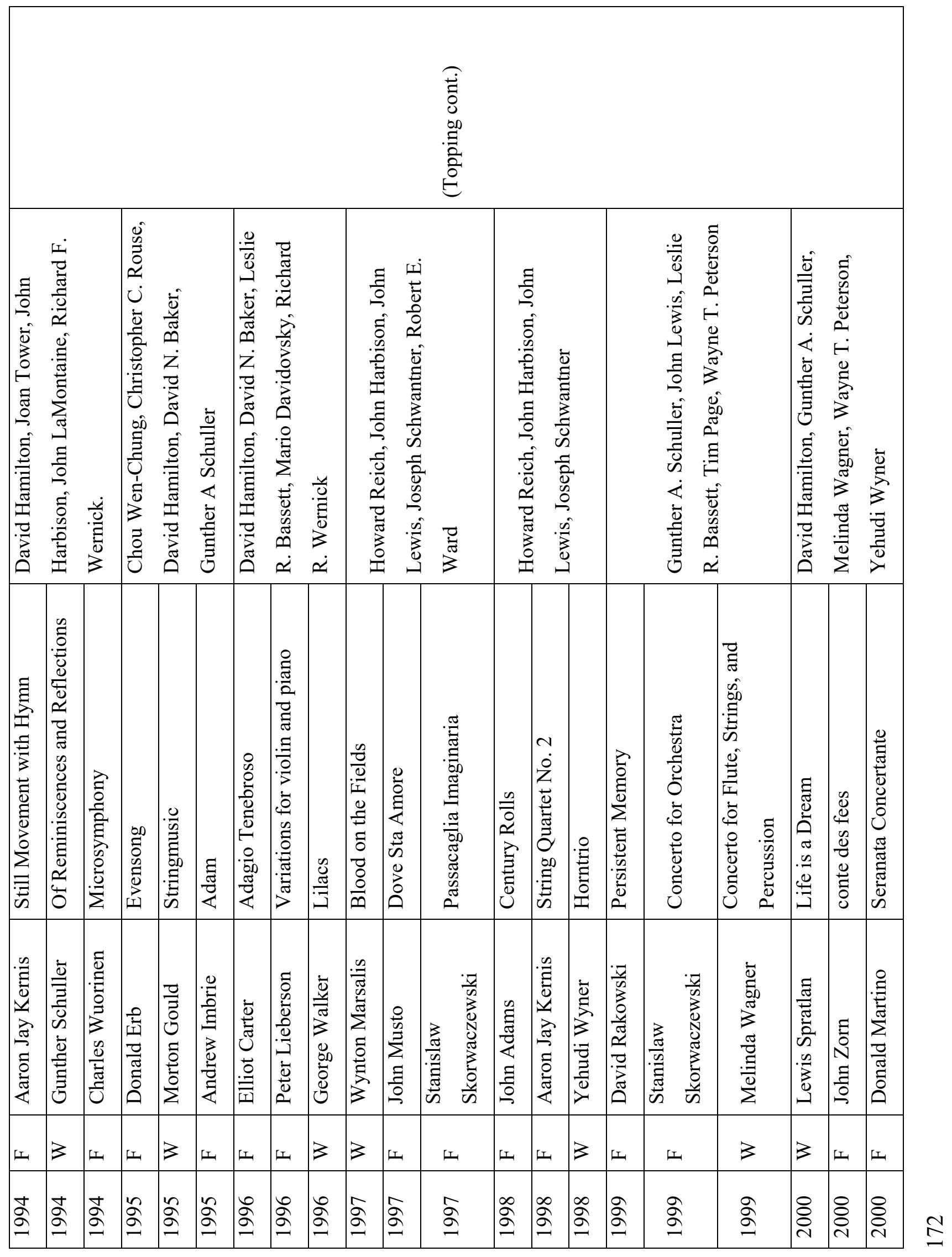




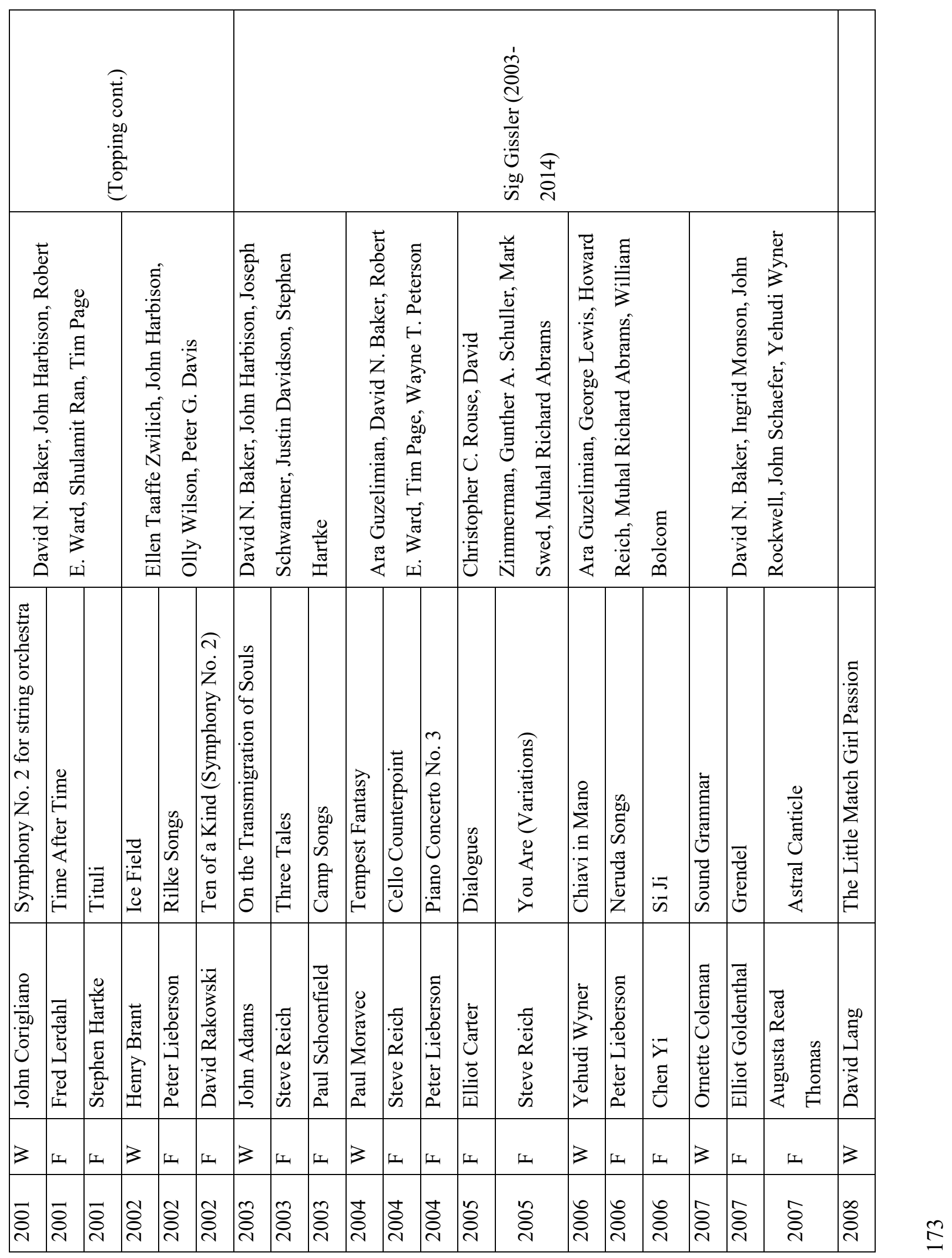














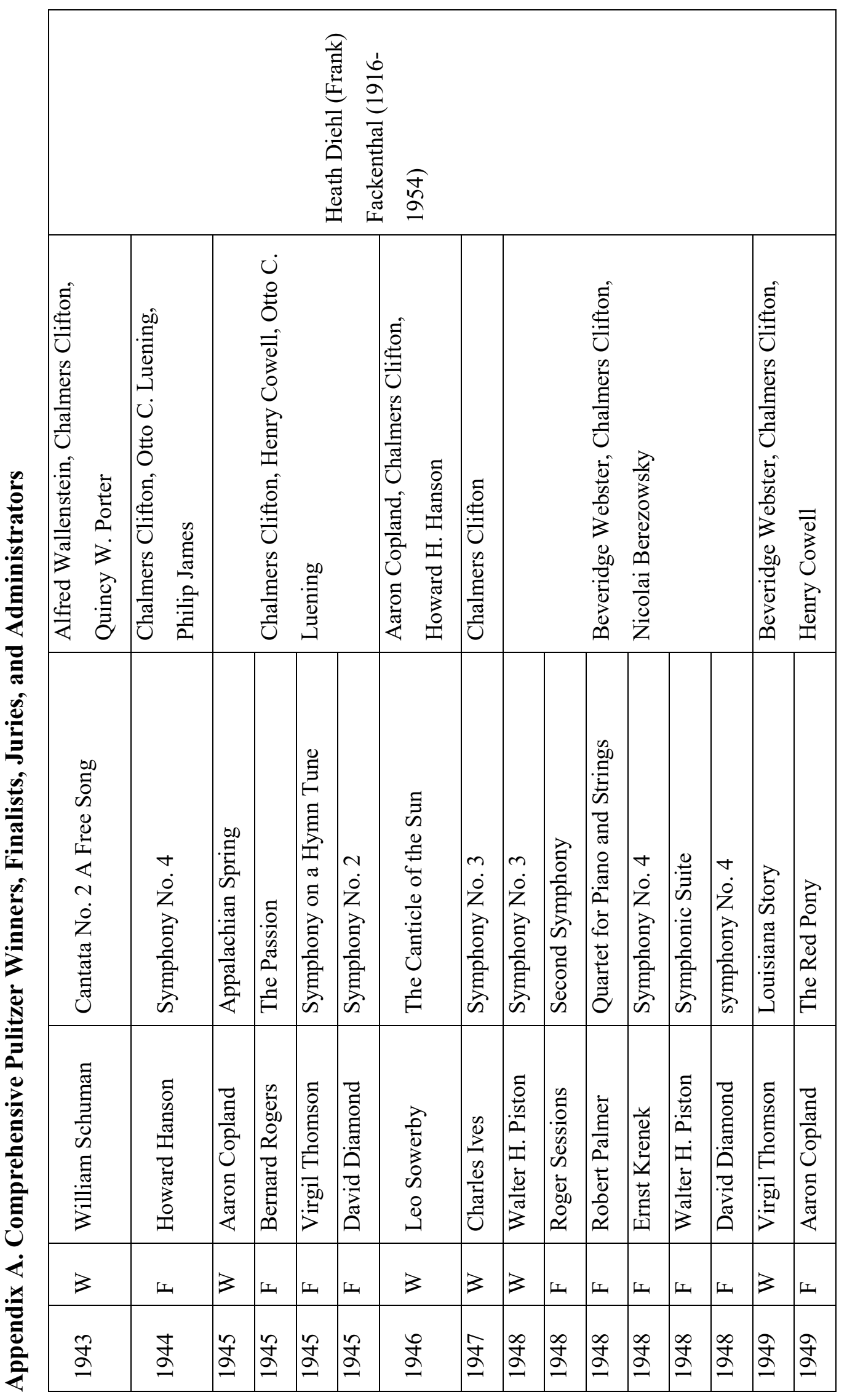




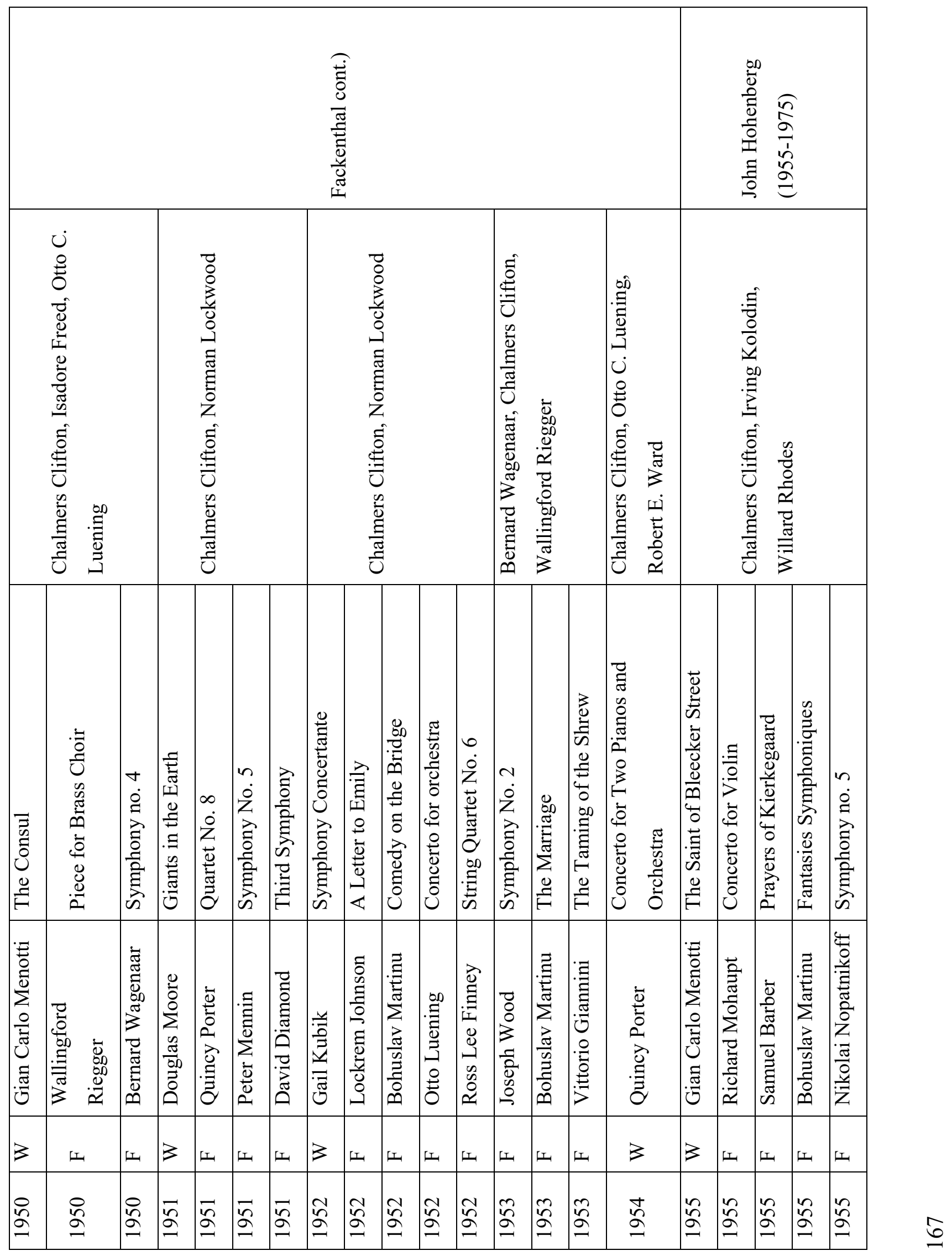




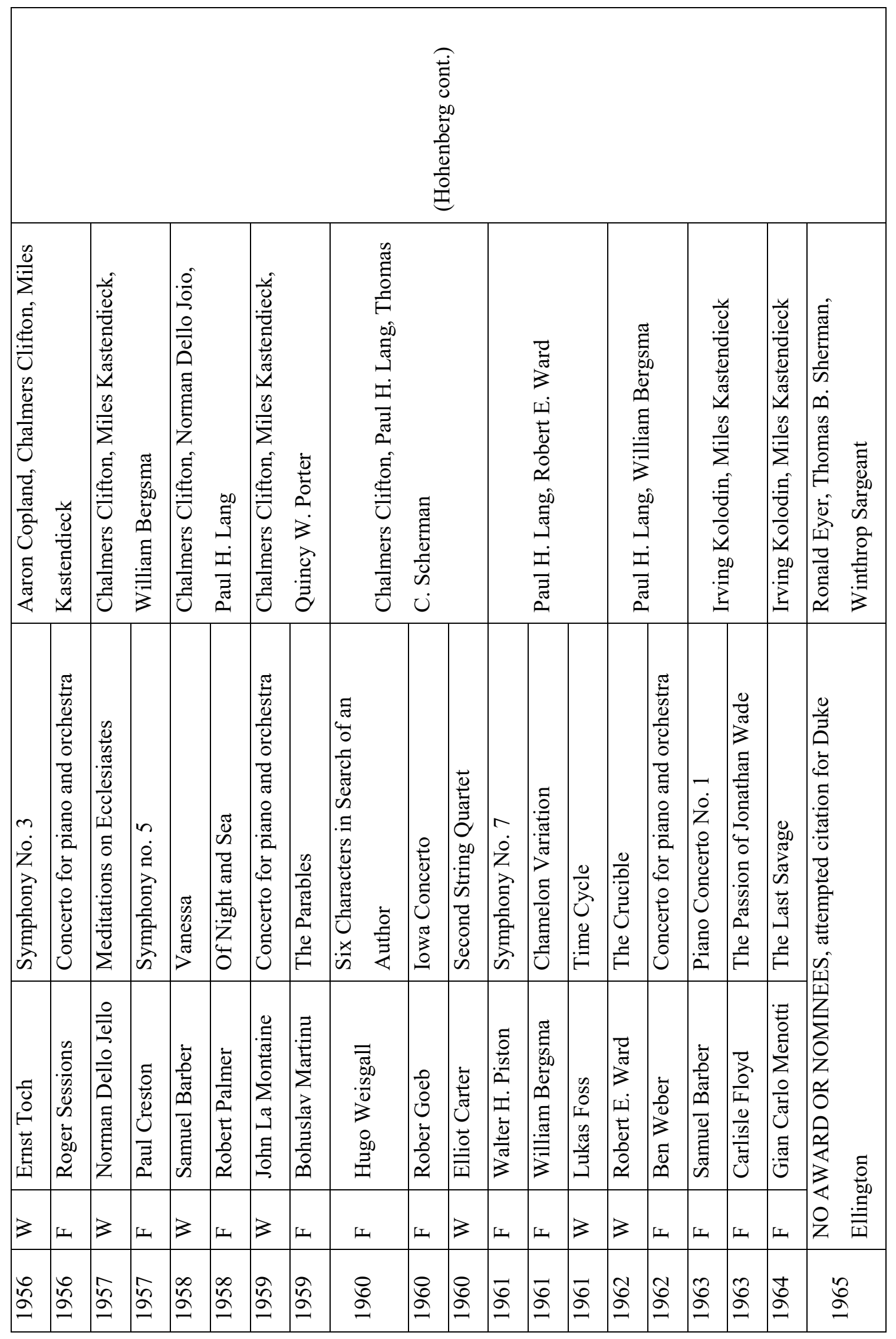




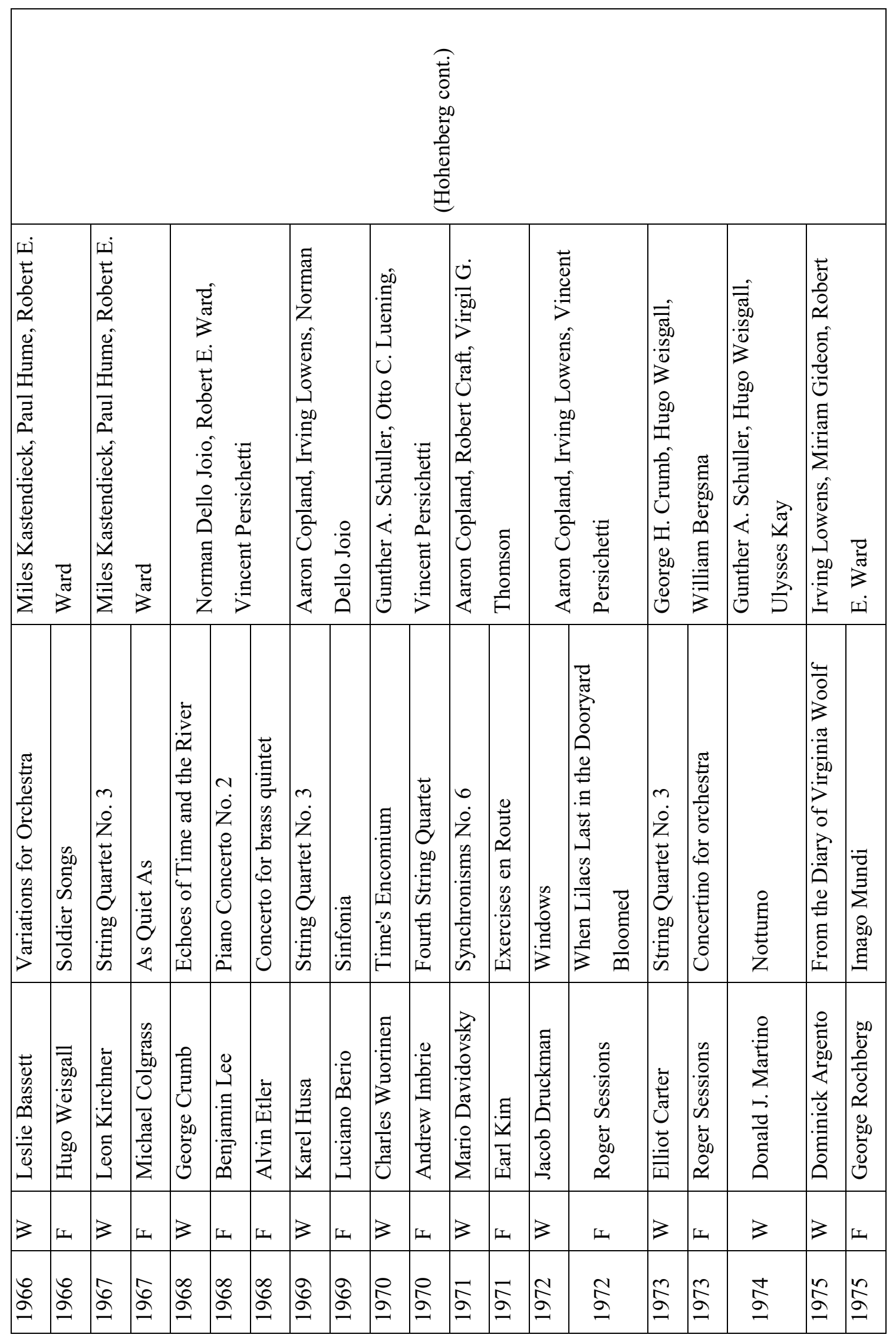




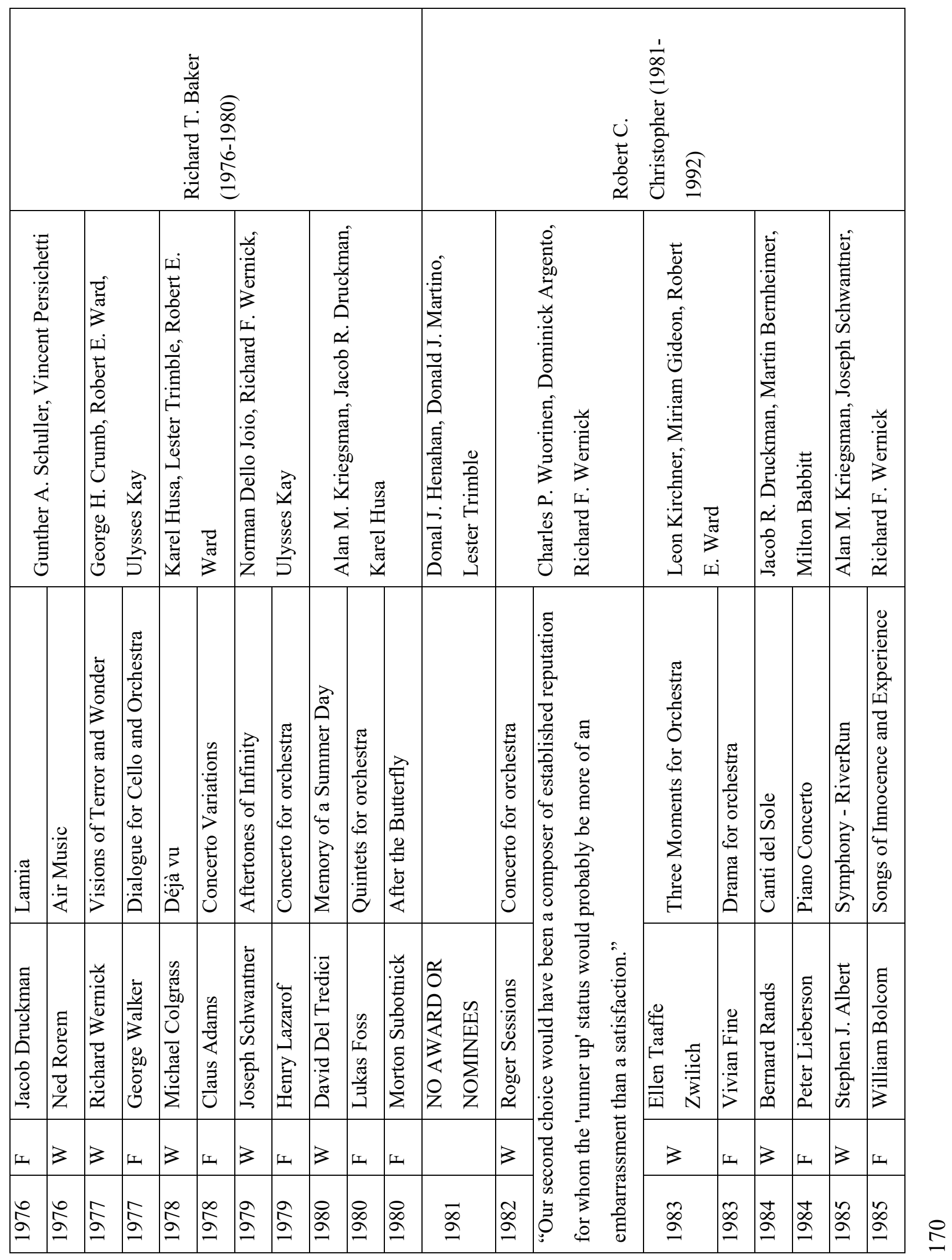




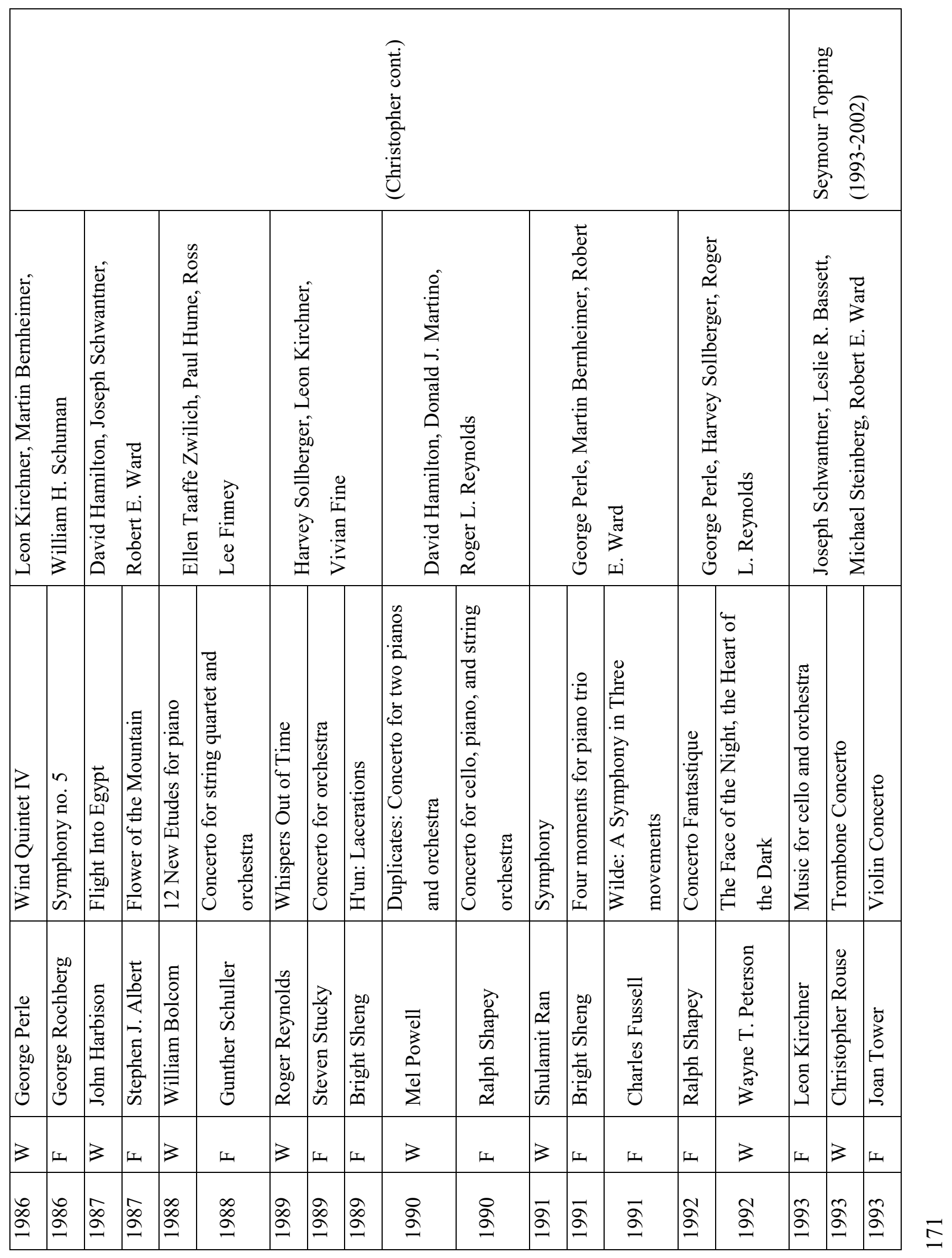




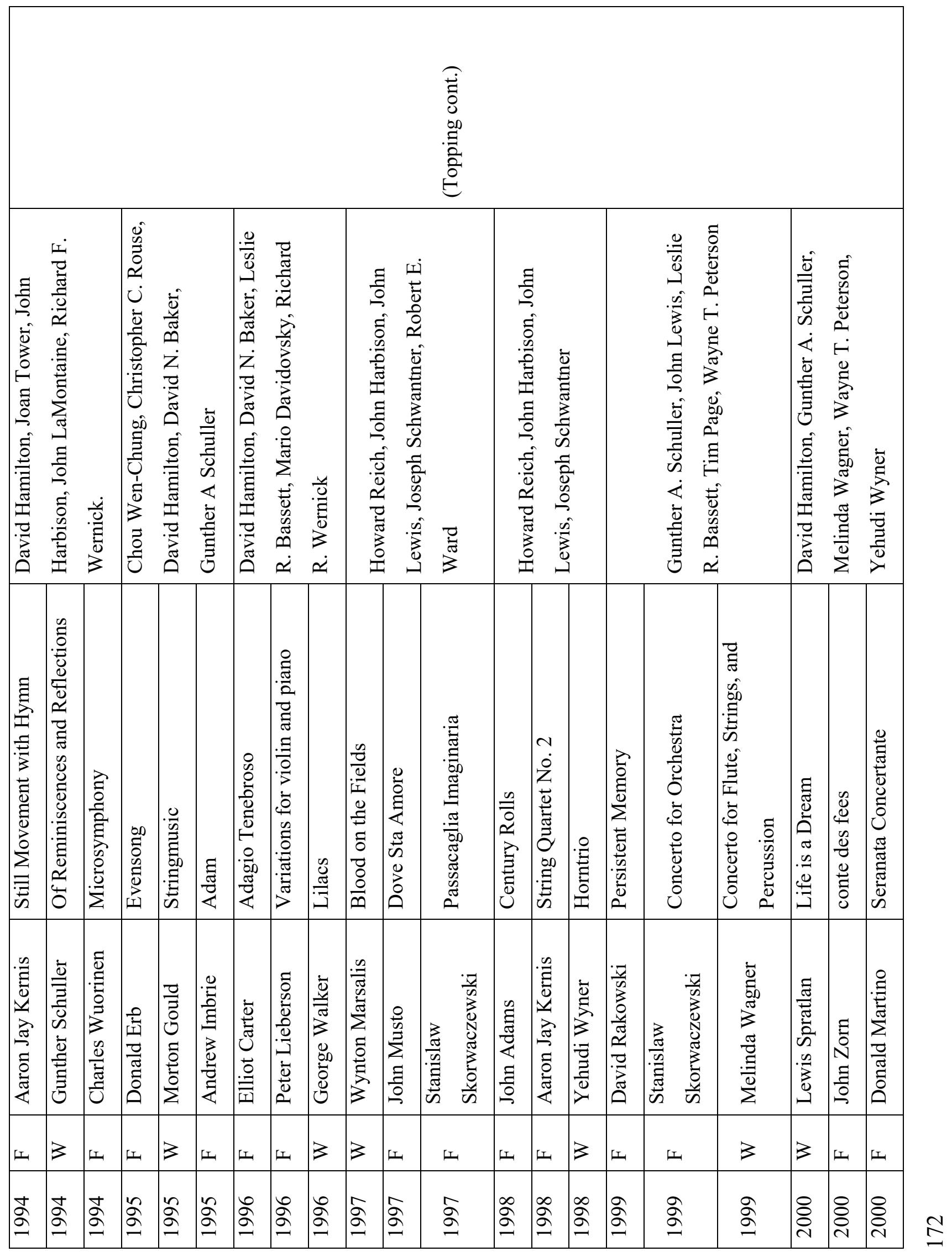




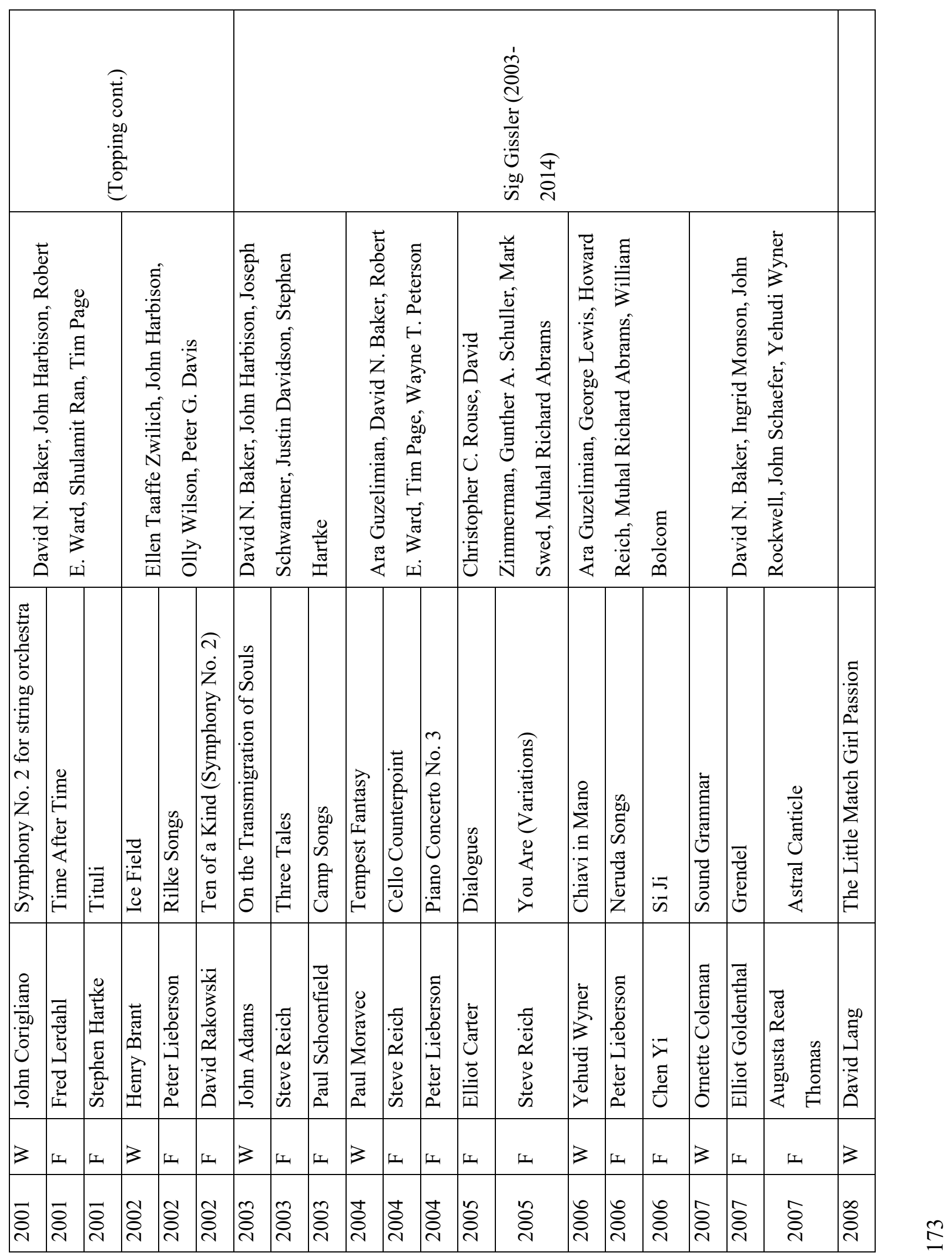




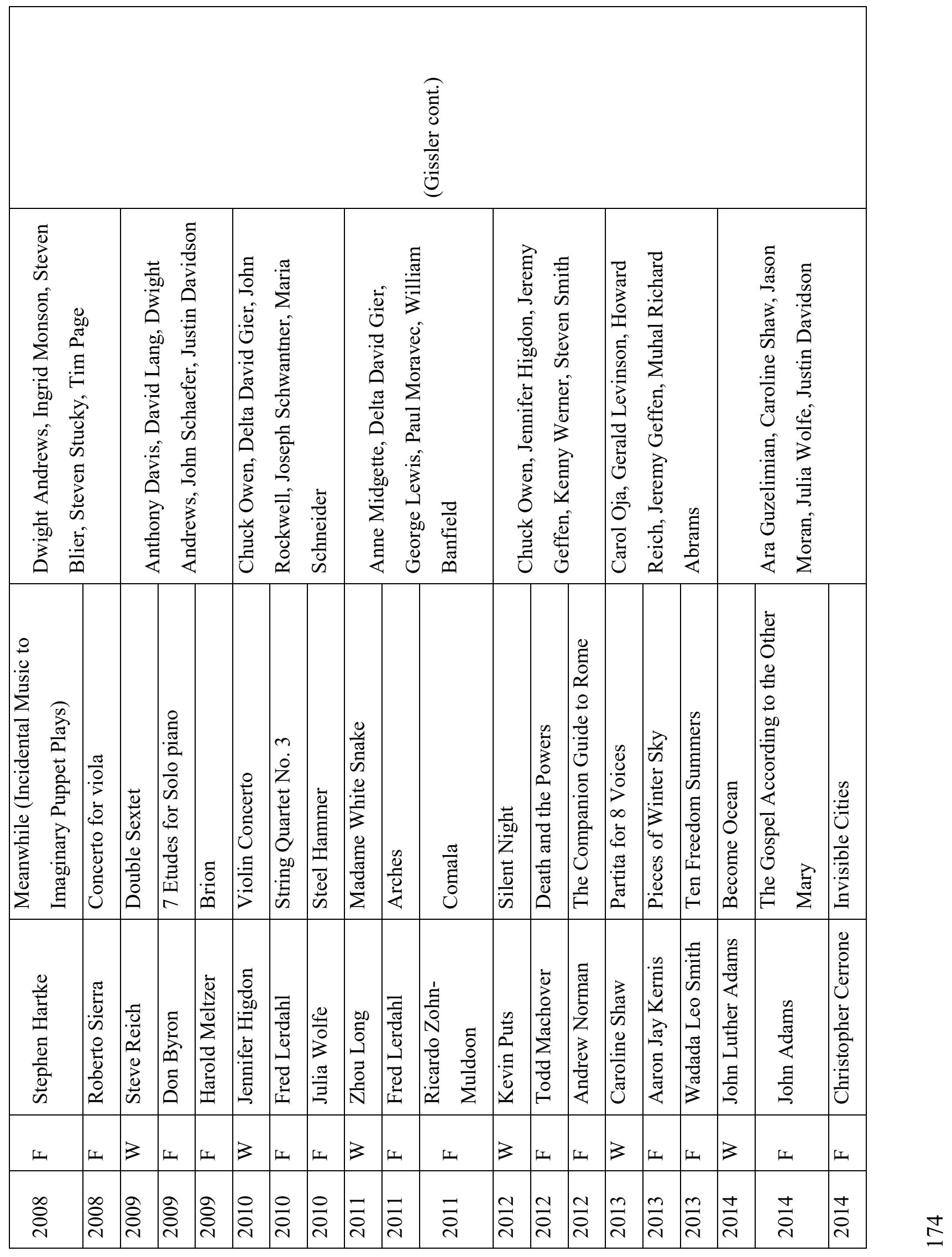




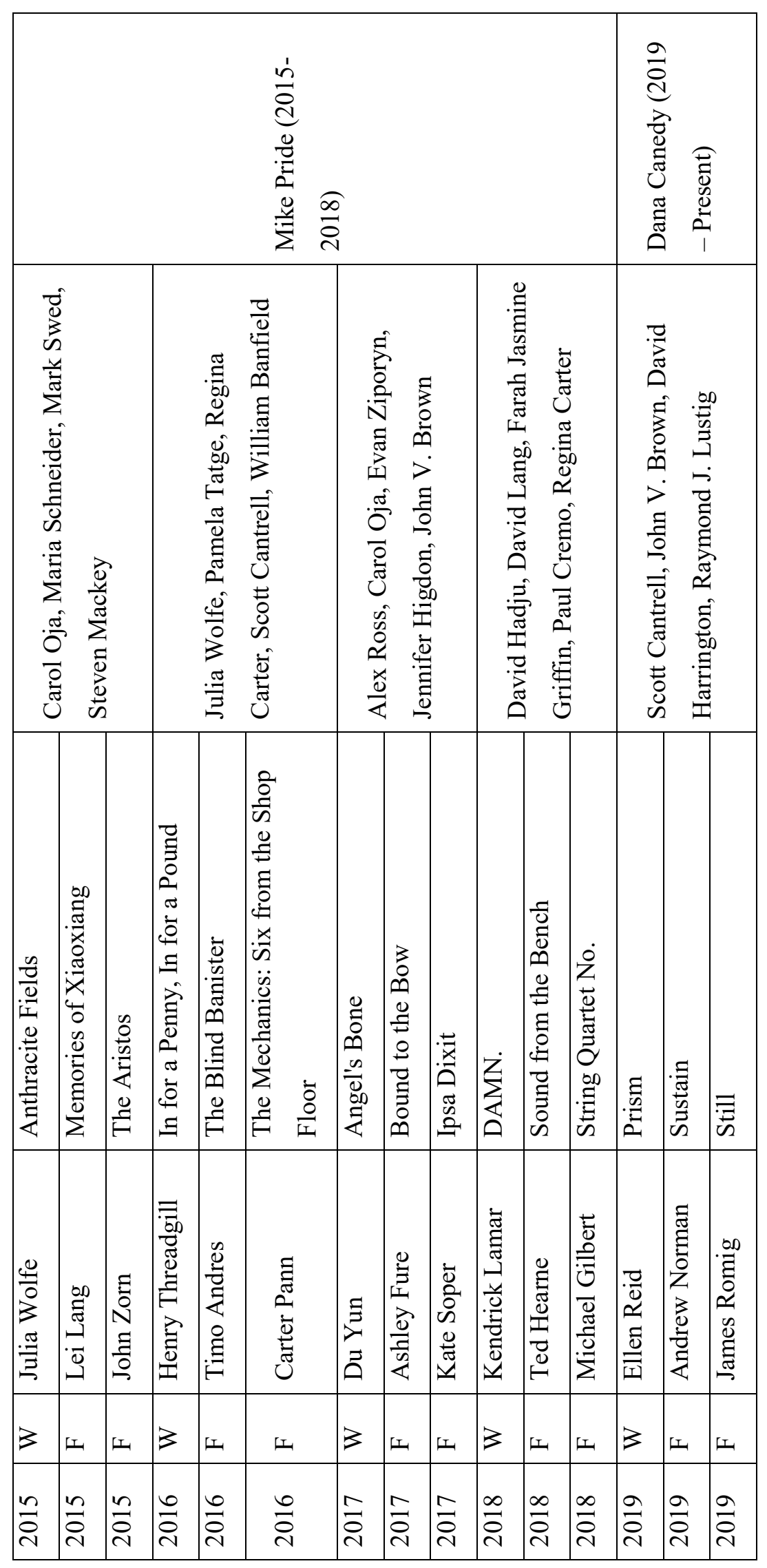




\section{Appendix B. Pulitzer Jurors by Number of Services}

\begin{tabular}{|l|l|r|c|}
\hline Range & Name & $\begin{array}{l}\text { \# } \\
\text { Services }\end{array}$ & $\begin{array}{c}\text { Pulitzer } \\
\text { Affiliate }\end{array}$ \\
\hline $1943-1960$ & Chalmers Clifton & 17 & Y \\
\hline $1954-2004$ & Robert E. Ward & 15 & Y \\
\hline $1956-1967$ & Miles Kastendieck & 7 & \\
\hline $1970-2005$ & Gunther A. Schuller & 7 & Y \\
\hline $1985-2010$ & Joseph Schwantner & 7 & Y \\
\hline $1987-2000$ & David Hamilton & 6 & \\
\hline $1994-2003$ & John Harbison & 6 & Y \\
\hline $1995-2007$ & David N. Baker & 6 & \\
\hline $1944-1970$ & Otto C. Luening & 5 & Y \\
\hline $1965-1972$ & Aaron Copland & 5 & Y \\
\hline $1979-1996$ & Richard F. Wernick & 5 & Y \\
\hline $1958-1962$ & Paul H. Lang & 4 & \\
\hline $1968-1976$ & Vincent Persichetti & 4 & \\
\hline $1968-1979$ & Norman Dello Joio & 4 & Y \\
\hline $1999-2008$ & Tim Page & 4 & Y \\
\hline $1997-2013$ & Howard Reich & 4 & \\
\hline $1955-1964$ & Irving Kolodin & 3 & \\
\hline $1957-1973$ & William Bergsma & 3 & Y \\
\hline $1969-1975$ & Irving Lowens & 3 & \\
\hline $1974-1979$ & Ulysses Kay & 3 & \\
\hline $1966-1988$ & Paul Hume & 3 & \\
\hline $1983-1989$ & Leon Kirchner & 3 & Y \\
\hline $1984-1991$ & Martin Bernheimer & 3 & \\
\hline $1993-1999$ & Leslie R. Bassett & 3 & Y \\
\hline $1999-2004$ & Wayne T. Peterson & 3 & Y \\
\hline $2005-2013$ & Muhal Richard Abrams & 3 & \\
\hline $2004-2014$ & Ara Guzelimian & 3 & \\
\hline $2009-2014$ & Justin Davidson & 3 & Y \\
\hline $2013-2017$ & Carol Oja & 2 & \\
\hline $1948-1949$ & Beveridge Webster & 2 & Y \\
\hline $1945-1949$ & Henry Cowell & 2 & Y \\
\hline $1951-1952$ & Norman Lockwood & 2 & \\
\hline $1943-1959$ & Quincy W. Porter & & \\
\hline $1973-1974$ & Hugo Weisgall & 2 & \\
\hline $1973-1977$ & George H. Crumb & Karel Husa & \\
\hline $1978-1980$ & Lester Trimble & & \\
\hline $1978-1981$ & & 3 & \\
\hline & & & \\
\hline
\end{tabular}




\begin{tabular}{|c|c|c|c|}
\hline 1975-1983 & Miriam Gideon & 2 & \\
\hline 1980-1984 & Jacob R. Druckman & 2 & $\mathrm{Y}$ \\
\hline $1980-1985$ & Alan M. Kriegsman & 2 & $\mathrm{Y}$ \\
\hline $1981-1990$ & Donald J. Martino & 2 & $\mathrm{Y}$ \\
\hline 1991-1992 & George Perle & 2 & $\mathrm{Y}$ \\
\hline 1989-1992 & Harvey Sollberger & 2 & \\
\hline 1990-1992 & Roger L. Reynolds & 2 & $\mathrm{Y}$ \\
\hline $1997-1998$ & John Lewis & 2 & \\
\hline $1988-2002$ & Ellen Taaffe Zwilich & 2 & $\mathrm{Y}$ \\
\hline 1995-2005 & Christopher C. Rouse & 2 & $\mathrm{Y}$ \\
\hline $2000-2007$ & Yehudi Wyner & 2 & $\mathrm{Y}$ \\
\hline $2007-2008$ & Ingrid Monson & 2 & \\
\hline $2008-2009$ & Dwight Andrews & 2 & \\
\hline $2007-2009$ & John Schaefer & 2 & \\
\hline $2007-2010$ & John Rockwell & 2 & \\
\hline $2010-2011$ & Delta David Gier & 2 & \\
\hline $2006-2011$ & George Lewis & 2 & \\
\hline $2010-2012$ & Chuck Owen & 2 & \\
\hline $2012-2013$ & Jeremy Geffen & 2 & \\
\hline $2010-2015$ & Maria Schneider & 2 & \\
\hline $2005-2015$ & Mark Swed & 2 & $\mathrm{Y}$ \\
\hline 2014-2016 & Julia Wolfe & 2 & $\mathrm{Y}$ \\
\hline 2011-2016 & William Banfield & 2 & \\
\hline 2012-2017 & Jennifer Higdon & 2 & $\mathrm{Y}$ \\
\hline $2009-2018$ & David Lang & 2 & $\mathrm{Y}$ \\
\hline 2016-2018 & Regina Carter & 2 & \\
\hline 1943 & Alfred Wallenstein & 1 & \\
\hline 1944 & Philip James & 1 & \\
\hline 1946 & Howard H. Hanson & 1 & \\
\hline 1948 & Nicolai Berezowsky & 1 & \\
\hline 1950 & Isadore Freed & 1 & \\
\hline 1953 & Bernard Wagenaar & 1 & $\mathrm{Y}$ \\
\hline 1953 & Wallingford Riegger & 1 & $\mathrm{Y}$ \\
\hline 1955 & Willard Rhodes & 1 & \\
\hline 1960 & Thomas C. Scherman & 1 & \\
\hline 1965 & Ronald Eyer & 1 & \\
\hline 1965 & Thomas B. Sherman & 1 & \\
\hline 1965 & Winthrop Sargeant & 1 & \\
\hline 1971 & Robert Craft & 1 & \\
\hline 1971 & Virgil G. Thomson & 1 & $\mathrm{Y}$ \\
\hline 1981 & Donal J. Henahan & 1 & $\mathrm{Y}$ \\
\hline 1982 & Charles P. Wuorinen & 1 & $\mathrm{Y}$ \\
\hline 1982 & Dominick Argento & 1 & $\mathrm{Y}$ \\
\hline 1984 & Milton Babbitt & 1 & \\
\hline 1986 & William H. Schuman & 1 & $\mathrm{Y}$ \\
\hline
\end{tabular}




\begin{tabular}{|c|c|c|c|}
\hline 1988 & Ross L. Finney & 1 & $\mathrm{Y}$ \\
\hline 1989 & Vivian Fine & 1 & $\mathrm{Y}$ \\
\hline 1993 & Michael Steinberg & 1 & $\mathrm{Y}$ \\
\hline 1994 & Joan Tower & 1 & $\mathrm{Y}$ \\
\hline 1994 & John LaMontaine & 1 & $\mathrm{Y}$ \\
\hline 1995 & Chou Wen-Chung & 1 & $\mathrm{Y}$ \\
\hline 1996 & Mario Davidovsky & 1 & $\mathrm{Y}$ \\
\hline 2000 & Melinda Wagner & 2 & $\mathrm{Y}$ \\
\hline 2001 & Shulamit Ran & 1 & \\
\hline 2002 & Olly Wilson & 1 & \\
\hline 2002 & Peter G. Davis & 1 & $\mathrm{Y}$ \\
\hline 2003 & Stephen Hartke & 1 & \\
\hline 2005 & David Zimmerman & 1 & $\mathrm{Y}$ \\
\hline 2006 & William Bolcom & 1 & \\
\hline 2008 & Steven Blier & 1 & \\
\hline 2008 & Steven Stucky & 1 & \\
\hline 2009 & Anthony Davis & 1 & \\
\hline 2011 & Anne Midgette & 1 & $\mathrm{Y}$ \\
\hline 2011 & Paul Moravec & 1 & \\
\hline 2012 & Kenny Werner & 1 & \\
\hline 2012 & Steven Smith & 1 & \\
\hline 2013 & Gerald Levinson & 1 & $\mathrm{Y}$ \\
\hline 2014 & Caroline Shaw & 1 & \\
\hline 2014 & Jason Moran & 1 & \\
\hline 2015 & Steven Mackey & 1 & \\
\hline 2016 & Pamela Tatge & 1 & \\
\hline 2016 & Scott Cantrell & 2 & \\
\hline 2017 & Alex Ross & 1 & \\
\hline 2017 & Evan Ziporyn & 1 & \\
\hline 2017 & John V. Brown & 2 & \\
\hline 2018 & David Hadju & 1 & \\
\hline 2018 & Farah Jasmine Griffin & 1 & \\
\hline 2018 & Paul Cremo & 1 & \\
\hline 2019 & David Harrington & 1 & \\
\hline 2019 & Raymond J. Lustig & 1 & \\
\hline
\end{tabular}




\section{Appendix C. Pulitzer Prize Board Members 2008-2018}

\begin{tabular}{|c|c|c|}
\hline 2016-present & Elizabeth Alexander & President, Andrew W. Mellon Foundation \\
\hline 2017-present & Nancy Barnes & $\begin{array}{l}\text { Senior Vice President of News and Editorial } \\
\text { Director, National Public Radio }\end{array}$ \\
\hline 2011-present & Robert Blau & $\begin{array}{l}\text { Executive Editor of Projects and Investigations, } \\
\text { Bloomberg News }\end{array}$ \\
\hline 2002-present & Lee C. Bollinger & President, Columbia University \\
\hline 2014-present & Katherine Boo & Author and Journalist \\
\hline 2015-present & Neil Brown & President, Poynter Institute for Media Studies \\
\hline 2018-present & Dana Canedy & Pulitzer Prize Administrator \\
\hline 2018-present & Nicole Carroll & Editor in Chief, USA Today \\
\hline 2012-present & Steve Coll & $\begin{array}{l}\text { Dean, Graduate School of Journalism, Columbia } \\
\text { University }\end{array}$ \\
\hline 2014-present & Gail Collins & Op-Ed Columnist, The New York Times \\
\hline 2014-present & John Dniszewski & \\
\hline 2010-present & Junot Díaz & Author, Massachusetts Institute of Technology \\
\hline 2012-present & Stephen Engelberg & Editor in Chief, Pro Publica \\
\hline 2011-present & Steven Hahn & Professor of History, New York University \\
\hline 2012-present & $\begin{array}{l}\text { Aminda Marqués } \\
\text { Gonzalez }\end{array}$ & $\begin{array}{l}\text { Vice President and Executive Editor, Miami } \\
\text { Herald }\end{array}$ \\
\hline 2016-present & Emily Ramshaw & Editor in Chief, The Texas Tribune \\
\hline 2010-present & Eugene Robinson & $\begin{array}{l}\text { Columnist and Associate Editor, The } \\
\text { Washington Post }\end{array}$ \\
\hline 2015-present & Tommi Shelby & $\begin{array}{l}\text { Professor of African American Studies and } \\
\text { Philosophy, Harvard University }\end{array}$ \\
\hline $2008-2017$ & Randall Bleck & $\begin{array}{l}\text { Retired President and Publisher, Argus Leader } \\
\text { Media }\end{array}$ \\
\hline $2008-2017$ & Joyce Dehli & $\begin{array}{l}\text { Edmond J. Safra Fellow in Residence for 2016- } \\
\text { 2017, Harvard University }\end{array}$ \\
\hline $2008-2017$ & Keven Ann Willey & $\begin{array}{l}\text { Vice President and Editorial Page Editor, The } \\
\text { Dallas Morning News }\end{array}$ \\
\hline $2007-2016$ & Paul Gigot & $\begin{array}{l}\text { Editorial Page Editor and Vice President, The } \\
\text { Wall Street Journal }\end{array}$ \\
\hline $2006-2015$ & Danielle Allen & $\begin{array}{l}\text { UPS Foundation Professor, Institute for } \\
\text { Advanced Studies, Princeton, NJ }\end{array}$ \\
\hline 2013-2015 & Quiara Alegría Hudes & Playwright \\
\hline 2006-2014 & Paul Tash & Chairman and CEO Tampa Bay Times \\
\hline
\end{tabular}




\begin{tabular}{|l|l|l|}
\hline $2004-2013$ & Thomas L. Friedman & Columnist, The New York Times \\
\hline $2003-2013$ & Nicholas Lemann & $\begin{array}{l}\text { Dean, Graduate School of Journalism, Columbia } \\
\text { University }\end{array}$ \\
\hline $2004-2013$ & Gregory L. Moore & Editor, The Denver Post \\
\hline $2003-2012$ & Jim Amoss & Editor, The Times-Picayune \\
\hline $2003-2012$ & Kathleen Carroll & $\begin{array}{l}\text { Executive Editor and Senior Vice President, } \\
\text { Associated Press }\end{array}$ \\
\hline $2003-2012$ & Ann Marie Lipinski & $\begin{array}{l}\text { Curator, The Nieman Foundation, Harvard } \\
\text { University }\end{array}$ \\
\hline $2011-2012$ & Margaret Sullivan & Editor, The Buffalo News \\
\hline $2010-2012$ & Jim VandeHei & Executive Editor and Co-Founder, Politico \\
\hline $2002-2011$ & David M. Kennedy & $\begin{array}{l}\text { Professor of History Emertius, Stanford } \\
\text { University }\end{array}$ \\
\hline $2002-2010$ & Amanda Bennett & $\begin{array}{l}\text { Executive Editor/Projects and Investigations, } \\
\text { Bloomberg News }\end{array}$ \\
\hline $2001-2010$ & Anders Gyllenhaal & Executive Editor, The Miami Herald \\
\hline $2000-2009$ & Jay T. Harris & $\begin{array}{l}\text { Director of the Center for the Study of } \\
\text { Journalism, UCLA }\end{array}$ \\
\hline $2000-2009$ & Richard Oppel & former Editor, Austin American-Statesman \\
\hline $1999-2008$ & Joann Byrd & $\begin{array}{l}\text { former Editor, editorial page, Seattle Post- } \\
\text { Intelligencer }\end{array}$ \\
\hline $1999-2008$ & Mike Pride & Editor, Concord Monitor \\
\hline $1999-2008$ & Donald Graham & Chairman, The Washington Post \\
\hline $2002-2008$ & Sig Gissler & Pulitzer Prize Administrator \\
\hline
\end{tabular}




\section{Bibliography}

Allen, David. "Review: The Resonant Bodies Festival Completes Its Third Year." The New York Times, September 11, 2015. https:/www.nytimes.com/2015/09/12/arts/music/review-the-resonantbodies-festival-completes-its-third-year.html.

Anderson, Stacey. "Is Caroline Shaw really the future of music?" The Guardian, June 9, 2016. https://www.theguardian.com/music/2016/jun/09/caroline-shaw-classical-music-kanye-west.

Applewhite, Ashton. "You're How Old? We'll Be in Touch." The New York Times, September 3, 2016. https://www.nytimes.com/2016/09/04/opinion/sunday/youre-how-old-well-be-in-touch.html.

Bates, Douglas. The Pulitzer Prize: The Inside Story of America's Most Prestigious Award. New York: Birch Lane Press, 1991.

"BBC Arts Night What Has the Turner Prize Ever Done for Us?" https://www.youtube.com/watch?v=I1tL581WM2c

Becker, Howard. Art Worlds. Berkeley: University of California Press, 1982.

Belcher, David. “What Dreams May Come.” Opera News 75, no. 1 (2010): 40-41.

Beljean, Stefan, Phillipa Chong, and Michele Lamont. "A Post-Bourdieusian Sociology of Valuation and Evaluation for the Field of Cultural Production." In Routledge International Handbook of the Sociology of Art and Culture, ed. Laurie Hanquinet, 38-48. New York: Routledge, 2015.

“About,” Beth Morrison Projects, Accessed March 25, 2019, https://www.bethmorrisonprojects.org/about.

Bloom, Peter. "Berlioz and the 'Prix de Rome' of 1830." Journal of the American Musicological Society 34, no. 2 (1981): 279-304.

Blumenthal, Ralph. “A Pulitzer Winner's Overnight Success of 60 Years.” The New York Times, April 11, 1996. https://www.nytimes.com/1996/04/11/arts/a-pulitzer-winner-s-overnight-success-of60-years.html

—. "Pulitzer Prize Winner - No Electronics, All He Needs is a Piano: American Composer George Walker is the First Black Recipient of the Prestigious, Annual Award for Music." Vancouver Sun April 12, 1996.

Born, Georgina. Rationalizing Culture: IRCAM, Boulez, and the Institutionalization of the Musical Avant-Garde. Berkeley: University of California Press, 1985.

Botstein, Leon. "On the Uses of the Concept of the Cosmopolitan." The Musical Quarterly 99, no. 2 (2016): 135-138. 
Bourdieu, Pierre. Distinction:A Social Critique of the Judgement of Taste. Trans. Richard Nice. Cambridge: Harvard University Press, 1987.

Brodsky, Seth. From 1989, Or European Music and the Modernist Unconscious. Berkeley: University of California Press, 2017.

Brookes, Stephen. "Zhou Long Transcends Cultural Boundaries." The Washington Post, September 9, 2016. https://www.washingtonpost.com/entertainment/music/composer-zhou-long-transcendscultural-boundaries/2016/12/09/37b0ab6c-be4f-11e6-94ac3d324840106c_story.html?utm_term=.ad07aa592c15.

Carmichael, Rodney. "How The Pulitzer Jury Opened Its Doors To Hip-Hop." National Public Radio, April 18, 2018. https://www.npr.org/sections/therecord/2018/04/19/603884855/how-the-pulitzerjury-opened-its-doors-to-hip-hop.

Christakis, Dean. "Prestige and Recognition in Education: Stratification, Key Informant, Historical, and Prize Design Methods." Ph.D. diss., University of Illinois at Chicago, 1995.

Collins, Harry and Robert Evans. Rethinking Expertise. Chicago: University of Chicago Press, 2007.

Collins, Sarah and Dana Gooley. "Music and the New Cosmopolitanism: Problems and Possibilities." The Musical Quarterly 99, no. 2 (2017): 139-165.

Colloredo-Mansfield, Rudi. “An Ethnography of Neoliberalism.” Current Anthropology 43, no. 1 (2002): 113-137.

Cook, Amanda. "Video Premiere: Angel's Bone Music Video Featuring Du Yun." I Care If You Listen, January 9, 2018. https://www.icareifyoulisten.com/2018/01/video-premiere-angels-bone-musicvideo-featuring-du-yun/.

Coscarelli, Joe. "Kendrick Lamar Wins Pulitzer in 'Big Moment for Hip-Hop."” The New York Times, April 16, 2018. https://www.nytimes.com/2018/04/16/arts/music/kendrick-lamar-pulitzer-prizedamn.html.

Covey, Paul. "The Ford Foundation-MENC Contemporary Music Project (1959-1973): A View of Contemporary Music in America." Ph.D. diss., University of Maryland, 2013.

Cunningham, Michael. "Letter from the Pulitzer Fiction Jury: What Really Happened This Year." The New Yorker, July 9, 2012. https://www.newyorker.com/books/page-turner/letter-from-thepulitzer-fiction-jury-what-really-happened-this-year.

Derks, Thea. "5 Questions to Annie Gosfield (Composer), Jury Member for the Gaudeamus Competition." I Care If You Listen, September 7, 2012. https://www.icareifyoulisten.com/2012/09/five-questions-to-annie-gosfield-jury-membergaudeamus-competition/. 
Doerrfield, Bill. “Ageism in Composer Opportunities.” New Music Box, June 5, 2013. https://nmbx.newmusicusa.org/ageism-in-composer-opportunities/.

Du Yun, “About,” Channel Du Yun. Accessed March 24, 2019, http://channelduyun.com/about/.

Ebright, Ryan. "Echoes of the Avant Garde in American Minimalist Opera." Ph.D. diss., University of North Carolina at Chapel, 2014.

Eidsheim, Nina. Sensing Sound: Singing and Listening as Vibrational Practice. Durham: Duke University Press, 2015.

English, James. "Winning the Culture Game: Prizes, Awards, and the Rules of Art." New Literary History 33, no 1 (2002): 109-135.

- The Economy of Prestige: Prizes, Awards, and the Circulation of Cultural Value. Cambridge: Harvard University Press, 2009.

- "The Economics of Cultural Awards." In The Handbook of the Economics of Cultural Awards Vol. 2, eds. Victor A. Ginsberg and David Throsby, 119-144. Oxford: North Holland, 2014.

Epstein, Louis K. “Toward a Theory of Patronage: Funding for Music Composition in France, 19181939." Ph.D. diss., Harvard University, 2013.

Fauser, Annegret. "La Guerre en Dentelles: Women and the "Prix de Rome" in French Cultural Politics." Journal of the American Musicological Society 51 no. 1, (1998): 83-129.

—. The Sounds of War: Music in the United States During World War II. New York: Oxford University Press, 2013.

Fink, Robert. Repeating Ourselves: American Minimal Music as Cultural Practice. Berkeley: University of California Press, 2005.

Fischer, Heinz-Dietrich and Erika Fischer. Musical Composition Awards, 1943-1999: From Aaron Copland and Samuel Barber to Gian-Carlo Menotti and Melinda Wagner. Munich: De Gruyter Saur, 2011.

—. Chronicle of the Pulitzer Prizes in Fiction: Discussions, Decisions, and Documents. Munich: De Gruyter Saur, 2011.

da Fonseca-Wollheim, Corinna. "For Ensembles and Singers, a Night of Backbreaking Labor." New York Times, June 1, 2014. https://www.nytimes.com/2014/06/02/arts/music/ny-phil-biennialoffers-themes-of-mining-and-building.html.

—. 'Review: In 'Angel's Bone,' Terrified Seraphim at the Mercy of Mortals." New York Times, January 7, 2016. https:/www.nytimes.com/2016/01/08/arts/music/review-in-angels-boneterrified-seraphim-at-the-mercy-of-mortals.html. 
Forman, Murray. "Ice/age: Experience, achievement, and transformations of an OG.” In Rapper, writer, pop-cultural player: Ice-T and the politics of black cultural production, ed. Josephine Metcalf \& Will Turner, 19-42. New York: Routledge, 2014.

Gann, Kyle. "Pulitzer Hacks: Amateur Composers Versus the Professionals." in Music from Downtown: Writings from the Village Voice, 120-123. Berkeley: University of California, 2006.

Hiroshi-Garrett, Charles. Struggling to Define a Nation: American Music and the Twentieth Century. Berkeley: University of California Press, 2008.

Hubbs, Nadine. Rednecks, Queers, and Country Music. Berkeley: University of California Press, 2014.

Giovetti, Olivia. “Kevin Puts's Opera Silent Night Evokes Grim Reality of War.” WQXR, November 15, 2011. https://www.wqxr.org/story/170472-kevin-puts-silent-night/.

Goehr, Lydia. "Political Music and the Politics of Music." Journal of Aesthetics and Art Criticism 51, no. 1 (1994): 99-112.

—. "Amerikamüde/Europamüde: The Very Idea of American Opera." Opera Quarterly 22, no. 3-4 (2006): 398-432.

Goffen, Rona. Renaissance Rivals: Michelangelo, Raphael, Leonardo, Titian. New Haven: Yale University Press, 2002.

Gorak, Jan. The Making of the Modern Canon: Genesis and Crisis of a Literary Idea. London: Bloomsbury, 2013.

Gordon, Bonnie. "The Courtesan's Singing Body as Cultural Capital in Seventeenth-Century Italy," in Courtesan's Arts: Cross-Cultural Perspectives, eds. Martha Feldman and Bonnie Gordon, 182198. New York: Oxford University Press, 2006.

Grady, Constance. "Kendrick Lamar Just Became the First Rapper to Win a Pulitzer,." Vox, April 16, 2018. https://www.vox.com/2018/4/16/17244186/kendrick-lamar-pulitzer-prize-damn-firstrapper.

"The History of the Grawemeyer Awards," Grawemeyer Awards, Accessed April 24, 2019. http://grawemeyer.org/award-categories-recipients/.

Guillory, John. “Bourdieu's Refusal.” Modern Language Quarterly 58, no. 4 (1997): 367-398.

Herrera, Luis Eduardo. "The CLAEM and the Construction of Elite Art Worlds: Philanthropy, Latin Americanism, and Avant Garde Music." Ph.D. diss., University of Illinois at Urbana-Champaign, 2013. 
Hoffman, Jarrett. “Oberlin to Present Winter Term Opera Angel's Bone.” Cleveland Classical, January 29, 2018. https://clevelandclassical.com/oberlin-presents-winter-term-opera-angels-bone/.

Hohenberg, John. The Pulitzer Prizes: The History of the Award in Books, Drama, Music, and Journalism Based on the Private Files Over Six Decades. New York: Columbia University Press, 1974.

Huizenga, Tom. “David Lang Wins Pulitzer Prize for Music.” National Public Radio, April 7, 2008. https://www.npr.org/2011/01/24/89442735/david-lang-wins-music-pulitzer

—_. "Zhou Long Wins Music Pulitzer For Fairy Tale Opera." National Public Radio, April 11, 2018. https://www.npr.org/sections/deceptivecadence/2011/04/18/135522931/zhou-long-wins-musicpulitzer-for-fairy-tale-opera.

Jenkins, Richard. Pierre Bourdieu. London: Taylor and Francis, 2014.

Katz, Mark. Capturing Sound: How Technology has Changed Music. Berkeley: University of California Press, 2010.

Kennedy, Gerrick D. "Kendrick Lamar Didn't Win the Grammy for Album of the Year, but He's Moving Rap to a Bigger Stage." Los Angeles Times, February 16, 2016.

https://www.latimes.com/entertainment/music/la-et-ms-grammys-kendrick-lamar-20160216story.html

Kerman, Joseph. “A Few Canonic Variations.” Critical Inquiry 10, no. 1 (1983): 107-125.

Kluth, Andrew. "A Study of the Los Angeles DIY Experimental Music Scene: Reflections on the Promise of the Possible." Ph.D. diss., University of California Los Angeles, 2018.

Kornhaber, Spencer. "Kendrick Lamar and the Shell Game of 'Respect."” The Atlantic, April 17, 2018. https://www.theatlantic.com/entertainment/archive/2018/04/kendrick-lamar-pulitzerprize/558197/.

Kozinn, Alan. "A Pulitzer Dispute: Should Music Prize Be Left to Experts?” The New York Times, April 9, 1992. https://www.nytimes.com/1992/04/09/arts/a-pulitzer-dispute-should-music-prize-beleft-to-experts.html.

Kreps, Daniel. "Madonna Accuses BBC Radio of 'Ageism' After Song Ban.” The Rolling Stone, March 14, 2015. https://www.rollingstone.com/music/music-news/madonna-accuses-bbc-radio-ofageism-after-song-ban-42426/.

Lang, David. "Major Figures in American Music: David Lang." Interview by Libby van Cleve, Yale Oral History of American Music, 7 April 2011. 
Laureau, Annette and Elliot Weininger. "Cultural Capital in Educational Research: A Critical Assessment.” In After Bourdieu: Influence, Critique, Elaboration, eds. David L. Swartz and Vera Zolberg, 105-144. New York: Kluwer Academic Publishers, 2005.

Lentjes, Rebecca. "Bang on a Can and New York Philharmonic Bring Enormous New Works to the Biennial.” Bachtrack, June 2, 2014. https://bachtrack.com/review-bang-can-nypo-biennial-may2014

Lindsay, Tedrin Blair. "The Coming of Age of American Opera: New York City Opera and the Ford Foundation.” Ph.D. diss, University of Kentucky, 2009.

Little, Karen R. and Julia Graepel. Grawemeyer Award for Music Composition: The First Twenty Years. Lanham, MD: Scarecrow Press, 2007.

Lowder, J. Bryan. “The Strange, Beautiful Music that Won the Pulitzer This Year.” Slate, April 17, 2013.

http://www.slate.com/blogs/browbeat/2013/04/17/partita_for_8_voices_pulitzer_prize_winning composition_by_caroline_shaw.html.

Lu, Julia and Alexandre Dratwicki, eds. Le Concours du Prix de Rome de musique (1803-1968). Lyon: Symmetrie, 2013.

Lynch, Christopher. "Opera and Broadway: The Debate Over the Essence of Opera in New York City, 1900-1960.” Ph.D. diss., State University of New York at Buffalo, 2013.

Lynsky, Dorian. "From Street Kid to Pulitzer: Why Kendrick Lamar Deserves the Prize." The Guardian, April 22, 2018. https://www.theguardian.com/music/2018/apr/22/kendrick-lamar-wins-pulitzerprize-damn-album.

Mathiesen, Thomas J. Apollo's Lyre: Greek Music and Music Theory in Antiquity and the Middle Ages. Lincoln: University of Nebraska Press, 1999.

McCormick, Lisa. Performing Civility: International Competitions in Classical Music. Cambridge: Cambridge University Press, 2015.

Mead, Julia. "Living Out the Pulitzer Fantasy." The New York Times, May 30, 2004. https://www.nytimes.com/2004/05/30/nyregion/music-living-out-the-pulitzer-fantasy.html.

Midgette, Anne. "Dissonant Thoughts on the Music Pulitzers." The New York Times, April 9, 2003. https://www.nytimes.com/2003/04/09/arts/dissonant-thoughts-on-the-music-pulitzers.html.

—. "Songs, Poems and Burps in a Theater for the Ear." The New York Times, October 27, 2007.

—. "Puts Wins Pulitzer." The Washington Post, April 12, 2012. https://www.washingtonpost.com/blogs/classical-beat/post/puts-winspulitzer/2012/04/16/gIQAywR3LT_blog.html?noredirect=on\&utm_term=.c722bd8aee4c. 
—_. "Roomful of Teeth, a Cappella." The Washington Post, March 19, 2013. https://www.washingtonpost.com/entertainment/music/roomful-of-teeth-acapella/2013/03/19/f6038c48-90cb-11e2-bdeae32ad90da239_story.html?utm_term=.597b3f164826.

Moore, Andrea. "Millennial Passions: New Music and the Ends of History 1989-2011." Ph.D. diss., University of California at Los Angeles, 2016.

_. "Neoliberalism and the Musical Entrepreneur." Journal of the Society of American Music 10, no. 1 (2016): 33-53.

Moulin, Raymonde. "The Museum and the Marketplace: The Constitution of Value in Contemporary Art.” International Journal of Political Economy 25, no. 2 (1995): 33-62.

van Niekirk, Johann Jacob. "David Lang's 'the little match girl passion': A Conductor's Guide." Choral Journal 56, no. 2 (2015): 8-20.

Ng, David. “Composer Zhou Long Wins Pulitzer Prize for 'Madame White Snake." Los Angeles Times, April 18 2011. http://latimesblogs.latimes.com/culturemonster/2011/04/composer-zhou-longwins-pulitzer-prize-for-madame-white-snake.html.

North, Michael T. and Susan Fiske. "A Prescriptive Intergenerational-Tension Ageism Scale: Succession, Identity, and Consumption (SIC).” Psychological Assessment 25, no. 3 (2013): 706713.

Oteri, Frank J. "The Gospel According to John Corigliano." New Music Box, February 1, 2005. https://nmbx.newmusicusa.org/the-gospel-according-to-john-at-home-with-john-corigliano-johncorigliano/.

—_. "Justin Timberlake Loses Pulitzer.” New Music Box, April 11, 2005. https://nmbx.newmusicusa.org/justin-timberlake-loses-pulitzer/.

—_. "Zhou Long Wins 2011 Pulitzer Prize.” New Music Box, April 18, 2011. https://nmbx.newmusicusa.org/zhou-long-wins-2011-pulitzer-prize/.

—_. "Du Yun: No Safety Net." New Music Box, September 17, 2014. https://nmbx.newmusicusa.org/du-yun-no-safety-net/.

Pareles, Jon and Zachary Woolfe. "Kendrick Lamar Shakes Up the Pulitzer Game: Let's Discuss." New York Times, April 17, 2018. https://www.nytimes.com/2018/04/17/arts/music/kendrick-lamarmusic-pulitzer-prize-damn.html.

Parkhurst, Bryan and Stephan Hammel. "On Theorizing a 'Properly Marxist' Musical Aesthetics," International Review of Aesthetics and Sociology of Music 48 (2017): 33-55.

Pasler, Jann. "State Politics and the 'French' Aesthetics of Prix-de-Rome Cantatas, 1870-1900," In Musical education in Europe (1770-1914): Compositional, Institutional, and Political 
Challenges, eds. Michael Fend and Michael Noiray, 27-51. Oxford: Oxford University Press, 1996.

—. "The Political Economy of Composition in the American University, 1965-1985," in Writing Through Music: Essays on Music, Culture, and Politics, 318-362. Oxford: Oxford University Press, 2008.

Payne, Nicholas. "The Business of Opera." in Cambridge Companion to Opera Studies, ed. Nicholas Till, 53-69. Cambridge: Cambridge University Press, 2012.

Penét, Pierre and Kangsan Lee. "Prize \& Price: The Turner Prize as a Valuation Device in the Contemporary Art Market." Poetics 43 (2014): 149-171.

Peterson, Richard A. and N. Anand. "The Production of Cultural Perspective." Annual Review of Sociology 30 (2004): 311-34.

Pickford, Susan. "The Booker Prize and the Prix Goncourt: A Case Study of Award-Winning Novels in Translation." Book History 14 (2011): 221-40.

Platt, Russell. “Big Deal.” New Yorker May 26, 2014. https://www.newyorker.com/magazine/2014/05/26/big-deal.

—. "The Prototype Festival." New Yorker, January 11, 2016, https://www.newyorker.com/magazine/2016/01/11/fully-committed.

Platton, Adele. "Kendrick Lamar Shrugs Off His 2014 Grammy Snub: It 'Would Have Been Upsetting If I'd Known That Was My Best Work."' Billboard, February 4, 2016. https:/www.billboard.com/articles/news/magazine-feature/6866119/kendrick-lamar-2014grammy-snub.

Polkow, Dennis. "Preview: The Pulitzer Project/Grant Park Orchestra \& Chorus." New City Music, June 10, 2010, Accessed March 26, 2019, https://music.newcity.com/2010/06/22/preview-thepulitzer-projectgrant-park-orchestra-chorus/.

Polosi, Joseph. American Muse: The Life and Times of William Schuman. New York: Amadeus Press, 2008.

Pop, Silvana. "World-Renowned Experimental Composer Du Yun To Headline An Indie Pop Dance Party At The Mann Center Friday, September 23." Uwishunu Philadelphia, September 22, 2011. https://www.uwishunu.com/2011/09/world-renowned-experimental-composer-du-yun-toheadline-an-indie-pop-dance-party-at-the-mann-center-friday-september-23/.

Poxon, Stephanie. "From Sketches to Stage: The Genesis of Samuel Barber's Vanessa." Ph.D. diss., Catholic University of America, 2005. 
Pret, Tobias, Eleanor Shaw, and Sarah Drakopoulou Dodd. "Painting the Full Picture: The Conversions of Economic, Cultural, Social and Symbolic Capital.” International Small Business Journal 34, no. 8 (2016): 1004-1027.

"How to Enter," The Pulitzer Prizes. Accessed May 25, 2018 http://www.pulitzer.org/page/how-enter

"Music Submission Guidelines and Requirements.” The Pulitzer Prizes. Accessed May 252018 http://www.pulitzer.org/page/music-submission-guidelines-and-requirements

“2018 Pulitzer Prize announcement," YouTube video, 10:55, posted by “The Pulitzer Prizes,” April 16, 2018, https://www.youtube.com/watch?v=ALQv-VTb0TI.

Quinn, Malcolm et al. eds., The Persistence of Taste: Art Museums, and Everyday Life After Bourdieu. Abingdon: Routledge, 2018.

Randall, Annie Janeiro. "Eyes on the Competition Prize.” Contemporary Music Review 16 (1997): 105112.

Reagan, Donald. "Douglas Moore and his Orchestral Works." Ph.D. diss, Catholic University of America, 1972.

Redmond, Shana. "Rapper Kendrick Lamar Winning the Pulitzer Prize for Music: What Does it Mean?" UCLA Newsroom, April 25, 2018, Accessed March 26, 2019, http://newsroom.ucla.edu/stories/kendrick-lamar.

Richardson, Susan. "Defining a place for composers: The early histories of the American Composers Alliance and the American Music Center, 1937-1950.” Ph.D. diss., Indiana University, 1997.

Ritchey, Marianna. ““'Amazing Together”: Mason Bates, Classical Music, and Neoliberal Values.” Music \& Politics 11, no. 3 (2017): 1-23.

Robin, William. "A Scene Without a Name: Indie Classical and American New Music in the TwentyFirst Century." Ph.D. diss., University of North Carolina at Chapel Hill, 2016.

—. "He Has Fans, Fame and an Acclaimed 'Brokeback Mountain' Opera. So Why Is Charles Wuorinen So Cranky?” New York Times, May 25, 2018.

https://www.nytimes.com/2018/05/25/arts/music/charles-wuorinen-brokeback-mountain-cityopera.html.

—. "Balance Problems: Neoliberalism and New Music in the American University and Ensemble." Journal of the American Musicological Society 71, no. 3 (2018): 749-793.

Rockwell, John. "Del Tredici - His Success Could be a Signpost." The New York Times October 26, 1980.

Roka, Les. "Making Order Out of Chaos: Music Criticism in U.S. Newspapers in the 1960s." Ph.D. diss., Ohio University, 2002. 
Ruhe, Pierre. “Interview: Composer David Lang On 'Little Match Girl Passion' And Downside Of The Pulitzer Prize.” Artsatl, Accessed March 24, 2019, https://www.artsatl.org/talking-with-davidlang-about-the-little-match-girl-passion/.

Rutherford-Johnson, Timothy. Music After the Fall: Modern Composition and Culture Since 1989. Berkeley: University of California Press, 2017.

Saxon, Jamie. 'Update: Princeton's Caroline Shaw Wins Pulitzer Prize for Music.” Columbia University, April 15, 2013. Accessed August 27, 2018.

https://www.princeton.edu/news/2013/04/15/update-princetons-caroline-shaw-wins-pulitzerprize-music.

Schueth, Michael. "Willa Cather and Celebrity: The Writer's Self-Image and the Literary Marketplace." Ph.D. diss., University of Nebraska at Lincoln.

Shadle, Douglas. Orchestrating the Nation: The Nineteenth-Century American Symphonic Enterprise. New York: Oxford University Press, 2015.

Shafer, Jack. "You Won a Pulitzer. Whoop De Do." Slate, April 8, 2008. https://slate.com/news-andpolitics/2008/04/why-no-one-but-journalists-care-about-the-pulitzer-prizes.html.

Shapiro, Alex. "Dissing the Competition.” New Music Box, September 12, 2018. https://nmbx.newmusicusa.org/dissing-the-competition/.

Shelemay, Kay Kaufman. "Musical Communities: Rethinking the Collective in Music." Journal of the American Musicological Society 64, no. 2 (2011): 349-390.

Shengold, David. "Madame White Snake Worthwhile Effort from Opera Boston.” Boston Musical Intelligencer, March 3, 2010. https://www.classical-scene.com/2010/03/03/madame-whitesnake-worthwhile-effort-from-opera-boston/.

Shreffler, Anne C. "The Myth of Empirical Historiography: A Response to Joseph N. Straus." The Musical Quarterly 84, no. 1 (2000): 30-39.

—. "Musical Canonization and Decanonization in the Twentieth Century." In Der Kanon der Musik: Theorie und Geschichte, eds. Klaus Pietschmann and Melanie Wald, 1-17. Munich: edition text + kritik, 2013.

Smith, James Allen. "Foundations as Cultural Actors." In American Foundations: Roles and Contributions, ed. Helmut K. Anheier and David C. Hammack, 262-282. Washington, D.C.: Brookings Institution Press, 2010.

Straus, Joseph N. “The Myth of Serial Tyranny.” The Musical Quarterly 83, no. 3 (1999): 301-43.

Swayne, Steven. "William Schuman, World War II, and the Pulitzer Prize." The Musical Quarterly 80, no. 2 (2006): 273-320. 
Taruskin, Richard. "A Myth of the Twentieth Century: The Rite of Spring, the Tradition of the New, and "The Music Itself."” Modernism/modernity 2, no. 1 (1995): 1-26.

Toepler, Stefan. "Roles of Foundations and Their Impact in the Arts." In American Foundations: Roles and Contributions, eds. Helmut K. Anheier \& David C. Hammack, 283-304. Washington, D.C.: Brookings Institution Press, 2010.

Tommasini, Anthony. "The Pulitzer Prize Was Nice and All, But a Work Is Finally Fully Heard.” The New York Times, November 5, 2013. https://www.nytimes.com/2013/11/06/arts/music/carolineshaws-partita-has-premiere-by-roomful-of-teeth.html.

Topping, Seymour. “The Biography of Joseph Pulitzer.” The Pulitzer Prizes. Accessed March 23, 2019. http://www.pulitzer.org/page/biography-joseph-pulitzer.

—. "The Administration of the Pulitzer Prizes." The Pulitzer Prizes. Accessed April 24, 2019. http://www.pulitzer.org/page/administration-prizes.

Tomoff, Kirill. Virtuosi Abroad: Soviet Music and Imperial Competition during the Early Cold War, 1945-1958. Ithaca, NY: Cornell University Press, 2015.

Trammell, Matthew. “Kendrick Lamar: Damn.” Pitchfork, April 18, 2018. https://pitchfork.com/reviews/albums/23147-damn/.

Tsioulcas, Anastasia. “Caroline Shaw, 30, Wins Pultizer for Music.” National Public Radio, April 15, 2013. https://www.npr.org/sections/deceptivecadence/2013/04/15/177348405/caroline-shaw-30wins-pulitzer-for-music.

—_. "Roomful Of Teeth: Experimental Singing, Smiles Guaranteed." National Public Radio, October 23, 2012. https://www.npr.org/sections/deceptivecadence/2012/10/22/163426225/roomful-ofteeth-experimental-singing-smiles-guaranteed.

—. "Composer Julia Wolfe Awarded MacArthur 'Genius Grant." National Public Radio, September 22, 2016. https://www.npr.org/sections/therecord/2016/09/22/495008084/composer-julia-wolfeawarded-macarthur-genius-grant.

“Entry Lists by Year," University of Louisville Libraries, Accessed March 26, 2019, https://library.louisville.edu/music/grawemeyer/entries

Uy, Michael. "The Big Bang of Music Patronage in the United States: The National Endowment for the Arts, the Rockefeller Foundation, and the Ford Foundation." Ph.D. diss., Harvard University, 2015.

Vandagriff, Rachel. “American Foundations for the Arts.” Oxford Handbooks Online (April 2015). http:/www.oxfordhandbooks.com/view/10.1093/oxfordhb/9780199935321.001.0001/oxfordhb9780199935321-e-112. 
—. "An Old Story in a New World: Paul Fromm, the Fromm Music Foundation, and Elliot Carter." Journal of Musicology 35, No. 4 (2018): 535-566.

Waleson, Heidi. “An Ambitious Sophomore Effort.” The Wall Street Journal, January 21, 2014. https://www.wsj.com/articles/an-ambitious-sophomore-effort1390344853 ? $\mathrm{mod}=$ searchresults $\&$ page $=1 \&$ pos $=2 \&$ tesla $=y$.

Waleson, Heidi. "Dystopia on Stage at Prototype Festival.” The Wall Street Journal, January 11, 2016. https://www.wsj.com/articles/dystopia-on-stage-at-prototype-festival-1452549439.

Walls, Seth Colter. "Review: Du Yun Conjures a Musical World of Legos and Chants." The New York Times, November 19, 2018. https://www.nytimes.com/2018/11/19/arts/music/review-du-yunmiller-theater.html.

Weissberg, Claudia Stone. "Sinclair Lewis, 'the Main Street Burglary' and a Rejection Notice." The Pulitzer Prizes. Accessed March 25, 2019. https://www.pulitzer.org/article/sinclair-lewis-mainstreet-burglary-and-rejection-notice.

Wells, Dominic. "In the Footsteps of Bach's St. Matthew Passion: The Passion Settings of David Lang and James Macmillan.” Tempo 67, no. 264 (2013): 40-51.

Wensink, Joseph. "Literary Philanthropy: The Pulitzer Prize, Oprah's Book Club, and Contemporary U.S. Fiction." Ph.D. diss., Brandeis University, 2012.

Wolfe, Julia. "Embracing the Clash.” Ph.D. diss., Princeton University, 2012.

Woloshyn, Alexa. "Welcome to the Tundra: Tanya Tagaq's Creative and Communicative Agency as Political Strategy." Journal of Popular Music Studies 29, No. 4 (2017): e12254.

Woolfe, Zachary. “Composer's New Passion Unspooled.” The New York Times, June 1, 2012. https://www.nytimes.com/2012/06/02/arts/music/the-gospel-according-to-the-other-mary-byjohn-adams.html.

Woolfe, Zachary. "She Tackled Aristotle in an Opera. Next Up: Medieval French Couplets." The New York Times 26 January, 2018. https://www.nytimes.com/2018/01/26/arts/music/kate-soper-herebe-sirens.html.

Yang, Mina, Planet Beethoven: Classical Music at the Turn of the Millenium. Middletown, CT: Wesleyan University Press, 2014. 